\title{
EFFECT OF LOW VELOCITY IMPACT ON THE VIBRATIONAL BEHAVIOR OF A COMPOSITE
}

WING

A Thesis

presented to

the Faculty of California Polytechnic State University,

San Luis Obispo

In Partial Fulfillment

of the Requirements for the Degree

Master of Science in Aerospace Engineering

by

Richard de Luna

March 2016 
(C) 2016

Richard de Luna

ALL RIGHTS RESERVED 


\section{COMMITTEE MEMBERSHIP}

TITLE:

AUTHOR:

DATE SUBMITTED:

COMMITTEE CHAIR:

COMMITTEE MEMBER:

COMMITTEE MEMBER:

COMMITTEE MEMBER:
Effect of Low Velocity Impact on the Vibrational Behavior of a Composite Wing

Richard de Luna

March 2016

Faysal Kolkailah, Ph.D., P.E.

Professor of Aerospace Engineering

Eltahry Elghandour, Ph.D.

Lecturer of Aerospace Engineering

Dianne J DeTurris, Ph.D.

Professor of Aerospace Engineering

Eric Kasper, Ph.D.

Professor of Aerospace Engineering 


\begin{abstract}
Effect of Low Velocity Impact on the Vibrational Behavior of a Composite Wing Richard de Luna
\end{abstract}

Impact strength is one of the most important structural properties for a designer to consider, but it is often the most difficult to quantify or measure. A major concern for composite structures in the field is the effect of foreign objects striking composites because the damage is often undetectable by visual inspection. The objective for this study was to determine the effectiveness of using dynamic testing to identify the existence of damage in a small scale composite wing design. Four different impact locations were tested with three specimens per location for a total of 12 wings manufactured. The different impact locations were over the skin, directly over the rib/spar intersection at the mid-span of the wing, directly over the middle rib, and directly over the leading edge spar. The results will be compared to a control group of wings that sustain no damage. The wing design was based on an existing model located in the Cal Poly Aerospace Composites/Structures lab. The airfoil selected was a NACA 2412 airfoil profile with a chord length of 3 inches and a wingspan of just over 8 inches. All parts cured for 7 hours at $148^{\circ} \mathrm{F}$ and $70 \mathrm{psi}$. The wings were each tested on a shaker-table in a cantilever position undergoing $1 \mathrm{~g}$ $\left(\mathrm{ft} / \mathrm{s}^{2}\right)$ acceleration sinusoidal frequency sweep from $10-2000 \mathrm{~Hz}$. The $1^{\text {st }}$ bending mode was excited at $190 \mathrm{~Hz}$ and the $2^{\text {nd }}$ bending mode was excited at $900 \mathrm{~Hz}$. After the pre-impact vibrational testing each wing was impacted, excluding the control group. To verify the experimental results, a finite element model of the wing was created in ABAQUS. The frequency and impact numerical results and the experimental results were in good agreement with a percent error for both the $1^{\text {st }}$ and $2^{\text {nd }}$ mode at around $10 \%$. 


\section{ACKNOWLEDGMENTS}

I would like to start by thanking my thesis advisors Dr. Faysal Kolkailah and Dr. Eltahry Elghandour for giving me the opportunity to work on a very challenging project. It was the support from both of them that motivated me throughout my time as a graduate student and will continue to aid me as I begin my career. Dr. Elghandour's advice in the lab was invaluable to being able to complete the complex design and manufacturing of the wing specimen. Thank you for everything you have done for me and enabled me to do

I want to thank my thesis committee members, Dr. Dianne DeTurris and Dr. Eric Kasper, for their time and assistance reviewing my work and providing feedback on my ideas and analysis to make this thesis the best it can be. I would also like to thank Dr. Kasper for his aid and advice on the finite element analysis section of this thesis as it was a very difficult model to create and would not have been possible without the aid of Dr. Kasper.

In addition, I want to thank the Cal Poly Aerospace Engineering Department for the funding I received for materials. Without the funding, this thesis would have been stopped in its tracks. I would also like to extend a thank you to Cody Thompson and Kyle Rosenow for their hard work and time provided for performing all of the $\mathrm{CNC}$ work for this project, which was quite a lot of work. I also thank my fellow graduate students for their help and advice during this project. I want to extend a special thank you to Kevin "Bacon "Barton for helping me with the MATLAB coding as well as constantly being a resource bounce ideas around during the design, manufacturing, and testing stages.

Finally, I would like to thank my family for all of the encouragement they have provided throughout my college career. My parents have always challenged me to improve at anything I do while my sisters have always been there to take me down a few pegs when I need it. 


\section{TABLE OF CONTENTS}

Page

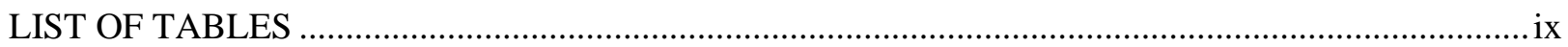

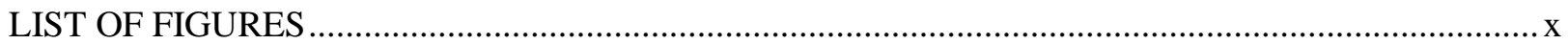

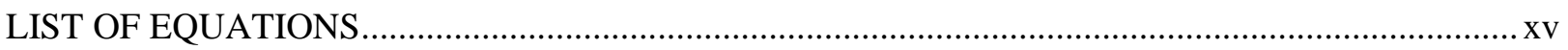

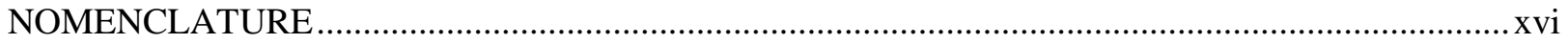

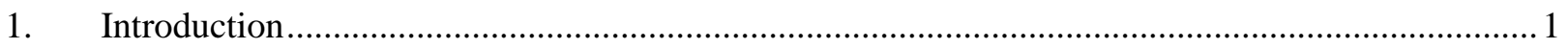

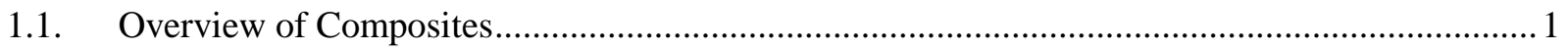

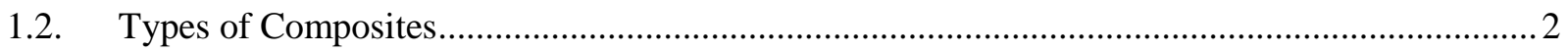

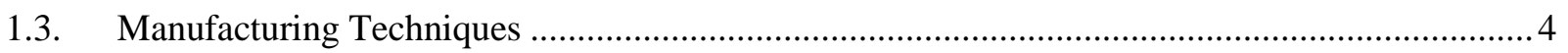

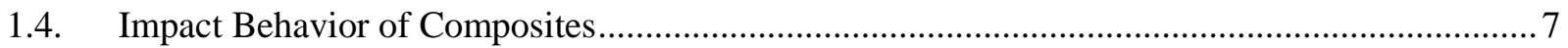

1.5. Previous Research on Impact behavior of Composites ............................................................ 9

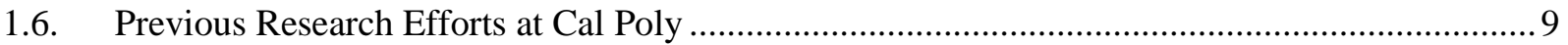

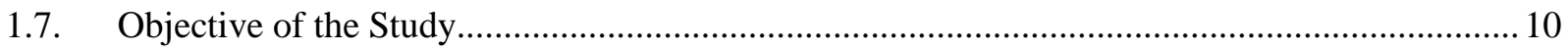

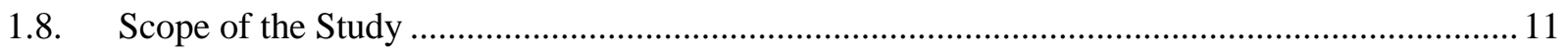

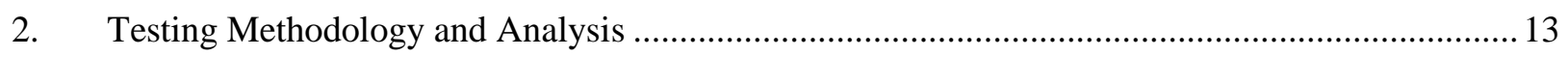

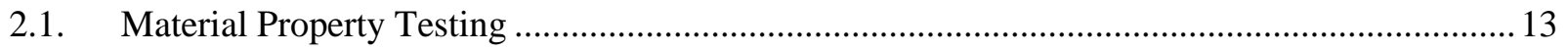

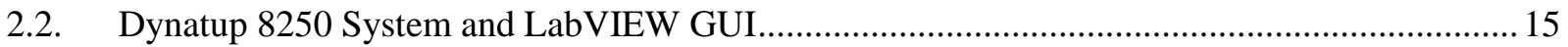

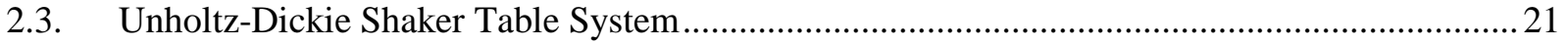

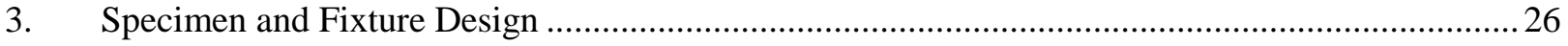

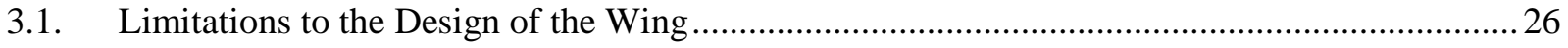




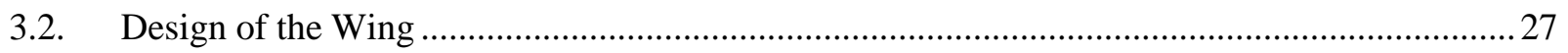

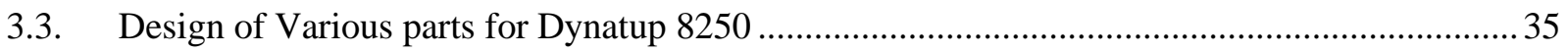

3.3.1. Dynatup 8250 Specimen Clamping Fixture ............................................................... 36

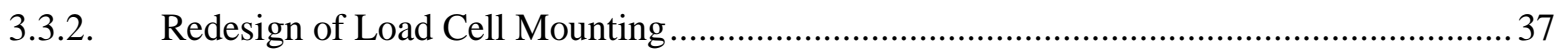

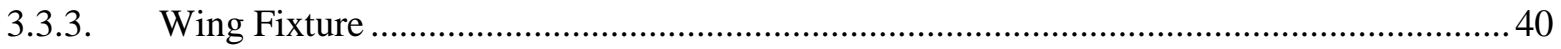

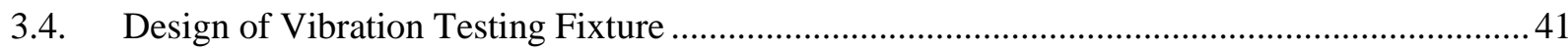

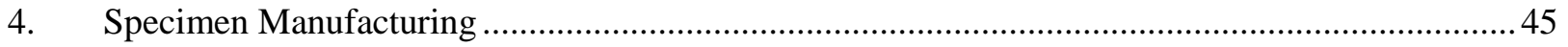

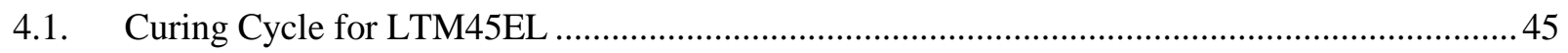

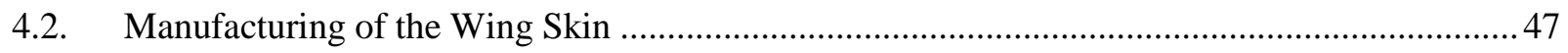

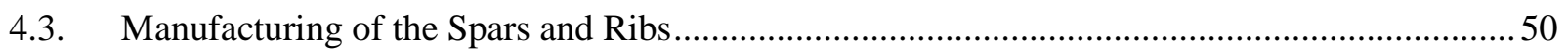

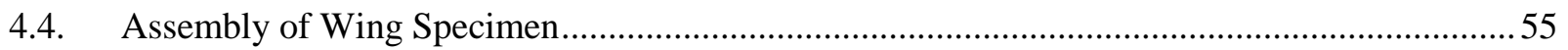

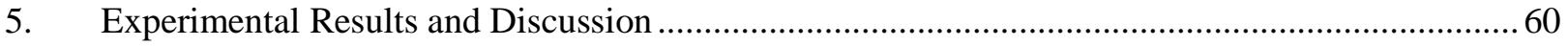

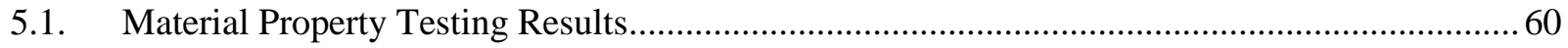

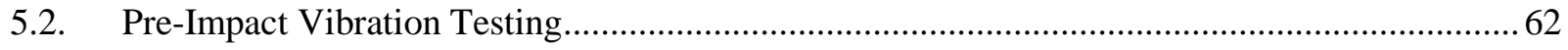

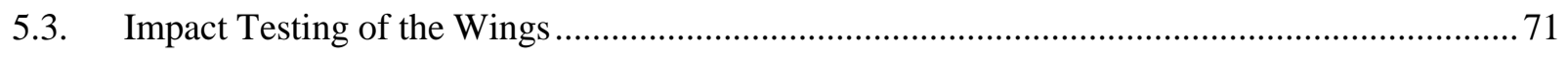

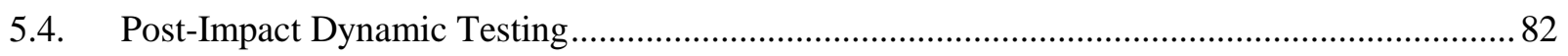

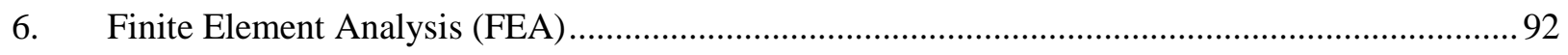

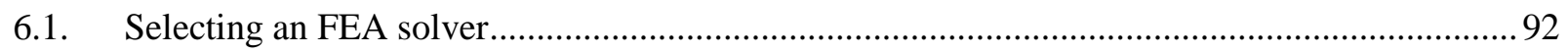

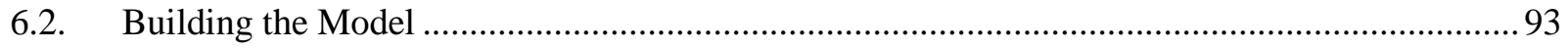

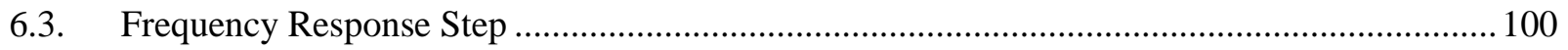

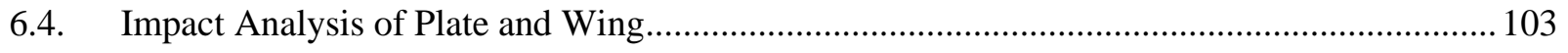




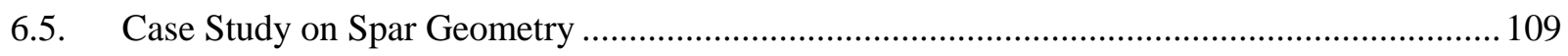

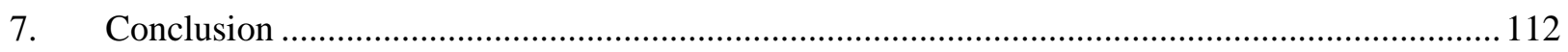

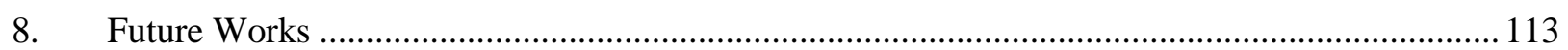

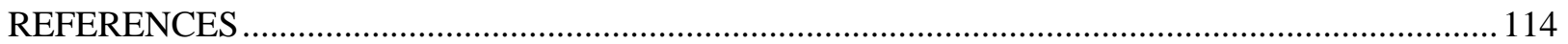

APPENDICES

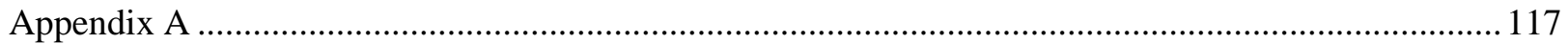




\section{LIST OF TABLES}

Table

Table 4.1-1: Various available cure cycles for LTM45EL based on material datasheet. .45

Table 4.1-2: Damping ratio results from initial cure cycle study to determine optimum cycle for study.46

Table 5.1-1: ASTM D3039 Tensile Testing Results .60

Table 5.1-2: Comparison of Experimental Values to Data Sheet Values. 62

Table 5.2-1: Averages of $2^{\text {nd }}$ mode data values and corresponding standard deviations .64

Table 5.2-2: $1^{\text {st }}$ mode dynamic data averages of Wing specimens. .68

Table 5.2-3: $2^{\text {nd }}$ mode dynamic data averages of Wing specimens . .70

Table 5.3-1: Maximum strain values for plate impact experiment. .73

Table 5.3-2: Force and velocity data from impact test of Wings 4, 5 and 6. .73

Table 5.3-3: Force and velocity data from impact test of Wings 7, 8 and 9 .75

Table 5.3-4: Force and velocity data from impact test of Wings 10, 11 and $12 .$. .77

Table 5.3-5: Force and velocity data from impact test of wings 13, 14 and 15 .78

Table 5.4-1: Comparison of pre- and post-impact data for wings 1, 2 and 3 82

Table 5.4-2: Comparison of pre- and post-impact data for wing 6 .83

Table 5.4-3: Comparison of pre- and post-impact data for Wings 7, 8 and 9 .85

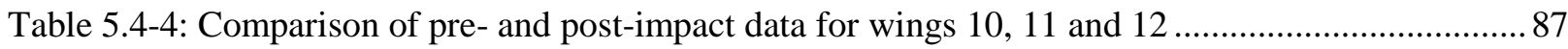

Table 5.4-5: Comparison of pre- and post-impact data for Wings 13, 14 and 15 ................................91

Table 6.2-1: Material property variables used for wing model ........................................................ 96

Table 6.3-1: Comparison of $1^{\text {st }}$ and $2^{\text {nd }}$ mode experimental and numerical results .............................. 102

Table 6.3-2: Results from convergence study of numerical wing model .......................................... 103

Table 6.4-1: Comparison of experimental and numerical results for impacted plate experiment ........... 106

Table 6.4-2: Comparison of experimental and numerical results for impacted wing results of Wing 5.107

Table 6.5-1: Frequency results for all four cases analyzed in study 110 


\section{LIST OF FIGURES}

Figure $\quad$ Page

Figure 1.2.1: Unidirectional fiber orientation of a composite laminate ............................................. 3

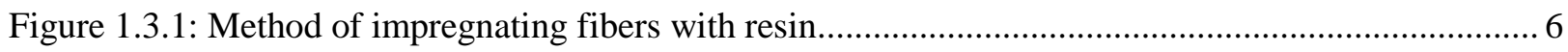

Figure 1.3.2: Heat press used to cure composite materials in the Cal Poly aerospace composites lab ....... 7

Figure 1.4.1: Aftermath of a bird strike to the nose of an aircraft ................................................... 8

Figure 1.4.2: Effect of impact damage on a composite laminate ..................................................... 8

Figure 2.1.1: ASTM D3039 Tensile Testing of Carbon Fiber Specimen............................................ 13

Figure 2.1.2: Drawing of ASTM D3039 Tensile test specimen ........................................................ 15

Figure 2.2.1: Si Detector and laser used to measure impact velocity .............................................. 16

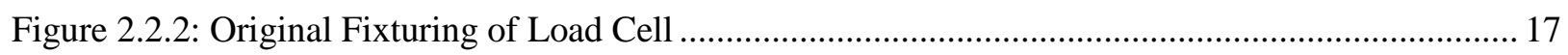

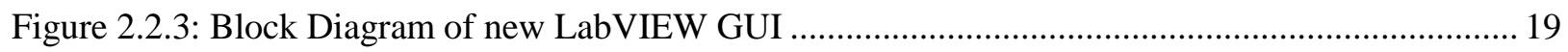

Figure 2.2.4: Block Diagram of new LabVIEW GUI with measurements of strain gages ..................... 20

Figure 2.3.1: Unholtz-Dickie Shaker Table System used for testing set to do horizontal excitation........ 22

Figure 2.3.2: Prototype wing just before initial dynamic testing ................................................... 23

Figure 2.3.3: Locations of acceleration measurements for thesis specimens ...................................... 23

Figure 2.3.4: Dimensioned locations of accelerometer measurements for wing specimen testing ........... 24

Figure 2.3.5: Half-power bandwidth method used to determine damping ratios [33]........................... 25

Figure 3.1.1: Solid model of original clamping fixture of Dynatup 8250 [31] ...................................26

Figure 3.2.1: AERO 433 wing used as basis for wing design ........................................................ 28

Figure 3.2.2: Isometric view of wing design with ribs shown in red ................................................ 29

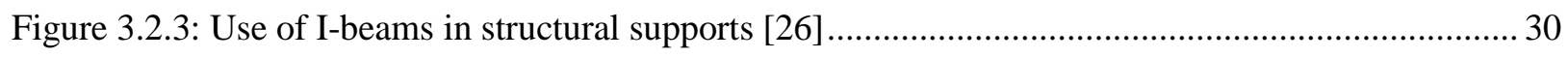

Figure 3.2.4: Example of I-beam layup for manufacturing ............................................................ 30

Figure 3.2.5: Isometric view of wing design with implementation of c-channel spars.......................... 31 
Figure 3.2.6: Example of how rib would be need to cut into three pieces to accommodate a

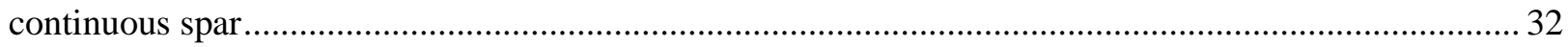

Figure 3.2.7: Misalignment of rib using interlocking method from wing prototype.............................. 32

Figure 3.2.8: Isometric view of wing design with implementation of discontinuous spars and 1-

brackets 33

Figure 3.2.9: Weld-nut used in wing design for mounting [27]......

Figure 3.2.10: Weld-nuts applied to mounting rib of prototype wing design 34

Figure 3.2.11: Wing design with implementation of mounting rib and skin overhang .......................... 35

Figure 3.3.1: Old and new plates for Dynatup 8250 specimen clamping fixture .................................. 36

Figure 3.3.2: Original constraining of load cell showing outer cylinder of load cell being unconstrained. 38

Figure 3.3.3: New load cell fixturing for Dynatup 8250 impact tester.....

Figure 3.3.4: Exploded view of new load cell mount to properly measure impact force. 40

Figure 3.3.5: CAD model of how win will be fixed in place during impact testing .41

Figure 3.4.1: Front view of 3 piece mount used to constrain wing during frequency sweep.....

Figure 3.4.2: View of how aluminum plug and screws fit onto mount

Figure 3.4.3: Heli-coil versus Thread insert [28]

Figure 3.4.4: Frequency response of wing mount to ensure there is noe modal excitations during test sweep

Figure 4.1.1: Temperature and Pressure profile for autoclave curing cycle of LTM45EL .46

Figure 4.2.1: Successful test of manufacturing method of wing skin with carbon being removed from mold with ease .48

Figure 4.2.2: Vacuum bag of experimental cure to determine validity of proposed manufacturing method of the wing skin 48

Figure 4.2.3: Wing skin in vacuum bag just before curing in autoclave .49

Figure 4.2.4: Wing skin mold after sanding and polishing 50 
Figure 4.3.1: Successful test of spar manufacturing method

Figure 4.3.2: Manufacturing of trailing edge spars using first foam mold .......................................... 51

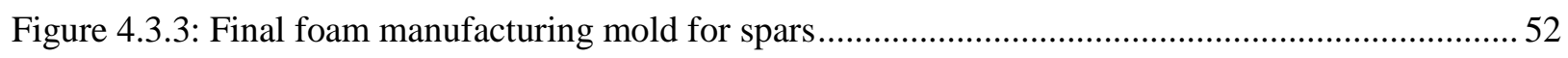

Figure 4.3.4: Cutting process used to trim spars down to size .......................................................... 53

Figure 4.3.5: Row of leading edge spars with L-brackets attached using super glue............................. 53

Figure 4.3.6: Original size of weld-nuts and trimmed base of weld-nuts for gluing to mounting rib....... 54

Figure 4.3.7: Method used to ensure that the weld-nuts aligned with the mounting rib for best

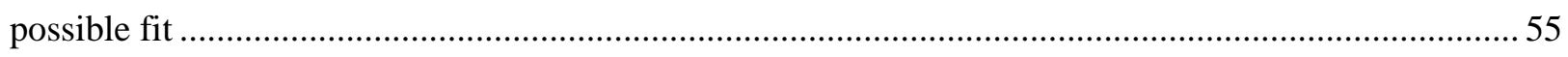

Figure 4.4.1: Layout of wing specimen sets including ribs, spars, and weld-nuts ............................... 56

Figure 4.4.2: Layout of how internal structure will be pieced together .............................................. 56

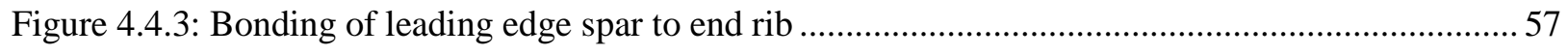

Figure 4.4.4: Mount rib with both leading and trailing edge spars glued in place .................................57

Figure 4.4.5: Top-down view of middle rib after having both sets of spars glued in place .....................58

Figure 4.4.6: All 15 completed internal structures for wing design .................................................. 58

Figure 4.4.7: Application of structural adhesive to internal structure just before being placed inside

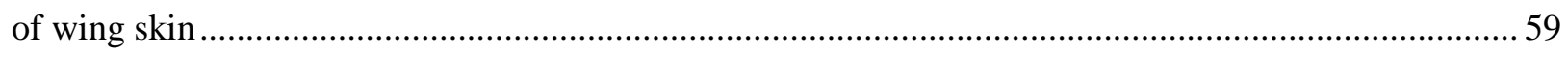

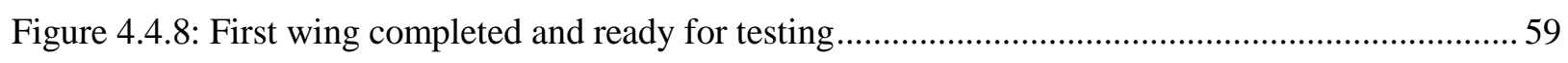

Figure 5.1.1: Stress vs strain experimental results from ASTM D3039 testing ................................... 61

Figure 5.2.1: All Frequency response results from first wing ....................................................... 63

Figure 5.2.2: Second mode response of 1 st wing along the middle of the chord .................................. 65

Figure 5.2.3: Second mode response of 1 st wing along leading edge spar .......................................... 66

Figure 5.2.4: Bar chart of response measurements showing the modal shape of the first mode .............. 67

Figure 5.2.5: Locations of response measurements of wing specimens ............................................ 67

Figure 5.2.6: Top down view of Wing 4 with accelerometers mounted over locations 3, 7 and 8 ......... 68

Figure 5.3.1: View of test plate used as strain gage verification....................................................... 72

Figure 5.3.2: Strain data from plate impact test showing permanent deformation of plate after impact .. 72 


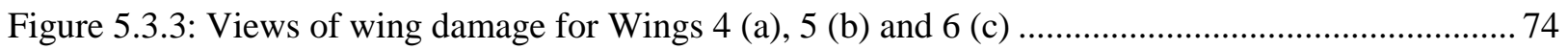

Figure 5.3.4: Close up of impact damage sustained by wing ......................................................... 75

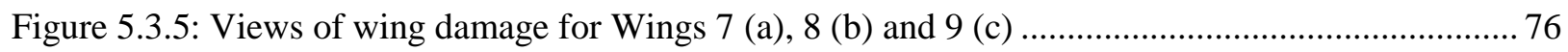

Figure 5.3.6: Views of wing damage for Wings 10 (a), 11 (b) and 12 (c) ......................................... 76

Figure 5.3.7: Force vs. Time history of Wing 10 impact test showing initial impact and the

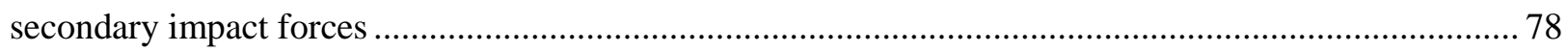

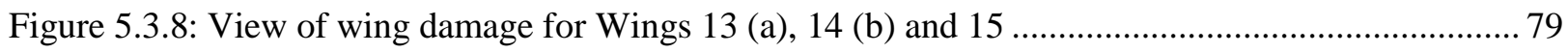

Figure 5.3.9: Force vs. time history of Wing 13 impact test ........................................................... 79

Figure 5.3.10: Force vs. time history of Wing 14 impact showing initial impact and secondary impact forces

Figure 5.3.11: Force vs. time history of Wing 15 impact showing initial impact and secondary impact forces

Figure 5.4.1: Second mode time response for Wing 6 at point 3 showing the effects of the impact damage on the time response.

Figure 5.4.2: Second mode time response of Wing 7 at point 1 showing the effect of the impact damage in the time response .86

Figure 5.4.3: Second mode time response for Wing 8 at point 1 showing the effects of the impact damage on the time response .88

Figure 5.4.4 First mode time response for Wing 12 at point 4 showing the effects of the impact

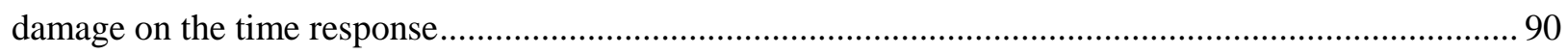

Figure 6.2.1: Creation of NACA 2412 airfoil X and Y coordinates in XFLR5 for use in Abaqus ........... 93

Figure 6.2.2: Base sketch of NACA 2412 airfoil used in creation of all model parts in Abaqus............. 94

Figure 6.2.3: Sketch of mounting rib with locations of holes labeled............................................... 95

Figure 6.2.4: Showing the side profile of leading edge spar and how it will be positioned in model assembly .95

Figure 6.2.5: View of the gaps between the middle rib and spars. .97 
Figure 6.2.6: Visualization of gap between wing skin and internal structure in Abaqus model

Figure 6.2.7: Mesh of leading edge spar

Figure 6.2.8: Results of cantilever analysis of wing model to verify all tie constraints are operating

correctly.

Figure 6.2.9: Visual confirmation that the tie constraints of the internal structure are operating

correctly .99

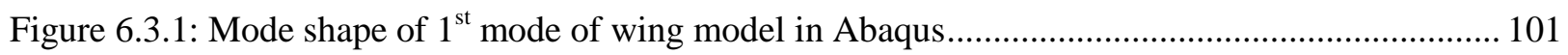

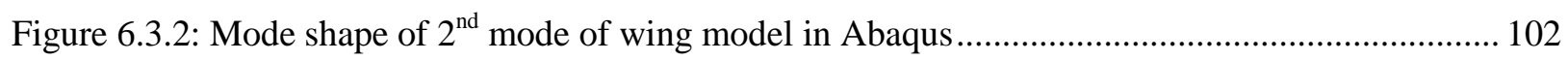

Figure 6.4.1: Isometric view of partitioned plate part to be used to verify experimental impact strain

results for plate test.

Figure 6.4.2: Isometric view of plate impact model assembly with sphere representing impact tup and showing boundary condition. 105

Figure 6.4.3: Contour view of logarithmic maximum principal strain of plate impact model...... 106

Figure 6.4.4: Isometric view of maximum mises stress for wing model impact 108

Figure 6.4.5: Isometric view of maximum mises stress for wing model impact without skin visible .... 108 Figure 6.5.1: Four different scenarios analyzed for case study on the effect of the spar geometry on the natural frequencies of the wing 109 Figure 6.5.2: Isometric view of torsional mode for Case 1 study 110 


\section{LIST OF EQUATIONS}

Equation

Page

(2.2.1) .21

(2.2.2) .21

(2.3.1) .24

(2.3.2) .24

(5.3.1) .74

(6.3.1) .100 


\section{NOMENCLATURE}

$\mathrm{E}_{1}$ - elastic modulus (psi)

$\mathrm{G}$ - shear modulus (psi)

$\mathrm{M}^{\mathrm{MN}}$ - mass matrix of size $\mathrm{MxN}$ (slug/in ${ }^{3)}$

$\mathrm{K}^{\mathrm{MN}}$ - stiffness matrix of size $\mathrm{MxN}(\mathrm{psi})$

$\mathrm{V}_{\mathrm{ex}}$ - excitation voltage of strain gages (V)

$\mathrm{V}_{\mathrm{r}}$ - remainder voltage $(\mathrm{V})$

$\mathrm{V}_{\text {min }}-$ minimum voltage measured by strain gage $(\mathrm{V})$

$\mathrm{V}_{\max }-$ maximum voltage measured by strain gage $(\mathrm{V})$

$\mathrm{V}$ - velocity (ft/s)

$\mathrm{GF}$ - gage factor

$\mathrm{m}-$ mass $\left(\mathrm{slug} / \mathrm{in}^{3}\right)$

$\zeta_{\mathrm{n}}-$ damping ratio

$\varepsilon-\operatorname{strain}(\mu \mathrm{in} / \mathrm{in})$

$\omega_{\mathrm{n}}-$ natural frequency $(\mathrm{Hz})$

$\Phi^{N}-$ vector of eigenvalues of size $N(\mathrm{~Hz})$ 


\section{Introduction}

In this chapter, the definition of composite materials and composite manufacturing methods will be explored. First, a breakdown of what makes a material composite will be evaluated and then a few different types of composite materials are introduced. Afterwards, some manufacturing techniques will be discussed. Finally, this chapter will wrap up with a look at the effect of impact damage on composite structures, previous work done in this area and the objective and scope of this study.

\subsection{Overview of Composites}

Composite materials are not a new discovery found in the last few decades, but have been around for thousands of years. Some of the earliest uses for composite materials came from the manufacturing of mud bricks by the Israelites [32]. They combined clay and straw to create bricks that were able to reinforce buildings, better than traditional clay bricks. Another example of early composite usage is the composite bow used by the Mongols in their conquest of Asia. This bow was fashioned from a lamination of bone, wood, and glue and was able to generate more power than traditional bows. Throughout history, it can be shown that composites have been implemented to give someone an advantage over substitute items or systems. More recently, this has been occurring in the aerospace industry with aircraft and spacecraft systems making the transition to designs that heavily implement composite materials.

What defines a composite for this thesis is two or more materials combined on a macro level to create a new material with improved properties. The key distinction between composites and metal is that composites vary on a macro scale while metal alloys, which are also a combination of multiple materials, vary on a micro scale. On a large scale, alloys are said to be homogenous and therefore cannot be considered a composite material. One major benefit to composites is the user's ability to tailor a composite to the type of situation it will be used in. If a very stiff, rigid structure is desired, a mixture of resin and fibers can be created to adhere to that design. If instead a flexible yet light structure is desired, 
a different combination of resin and fiber can work. Some of the different properties that can be specifically calibrated are: stiffness, strength, fatigue life, weight, corrosion resistance, thermal conductivity, and thermal insulation. It is important to note that not all of these properties can be improved at once. Each property has tradeoffs that must be made. For example, if you want a very strong material, then the fatigue life of the material will be much shorter. These types of tradeoffs are always considered when determining what material will be used in a design.

Across the board, composite materials are experiencing increased usage over traditional materials (e.g. aluminum, steel). The reason for this growth is due to the uncommon customization that can be performed with composite materials and the general overall weight savings gained from using composite materials over metals.

\subsection{Types of Composites}

There are many different ways to classify composites today varying from the type of fiber reinforcement used to the type of resin mixed with the fibers. The various types of reinforcements are particulate, fibrous, and laminated [1]. Each type of reinforcement can produce a material with very different characteristics so it is important to have an idea of how each material performs before making a selection in a design.

Particulate composites consist of one or more materials contained or suspended within a different matrix material. This type of composite can be composed of both metallic and nonmetallic particles depending in the desired use. One very common particulate composite used worldwide is concrete. Concrete is a mixture of rock and sand contained within a mixture of cement and water. When the water and cement are mixed, a chemical reaction causes the material to harden while the sand and rock is used to strengthen the final material. Concrete has exceptional compressive properties and can last an incredibly long time under appropriate conditions. However, this type of composite is very susceptible to cracks and creep causing failures. Another form of particulate composite is cermet. Cermet is a 
mixture of nonmetallic particles suspended in a metallic matrix [1]. Major uses of cermets are in resistors and capacitors. This is because a cermet can operate in high temperature environments (e.g. resistors).

Fibrous or fiber-reinforced composite materials can be classified as a combination of very thin fibers embedded into a matrix, typically resin. The purpose of the resin is to suspend the fibers in place and facilitate load transfer between them as well as protect the fibers from environmental damage and wear. Figure 1.2.1 illustrates the typical fiber-reinforced composite material [25]. There are two classifications of fibrous composites; continuous and discontinuous. Continuous fibers excel under loading conditions that involve linear forces applied along the fibers but tend to be susceptible to failures under shear loadings. These types of materials are also likely to be brittle and have little to no plasticity before failure. This type of fiber is typically made by aligning fibers in a specific direction and then embedding resin into the fibers to give some rigidity to the structure. Discontinuous fiber composites are used more in secondary low stress structures due to the lower overall strength properties. This composite is created as continuous fiber composites except the orientation of fibers is not controlled. This means that discontinuous fiber composites cost much less to manufacture. Two of the most used fiber reinforcements are glass-fiber polymers (fiberglass) and carbon-reinforced polymers.

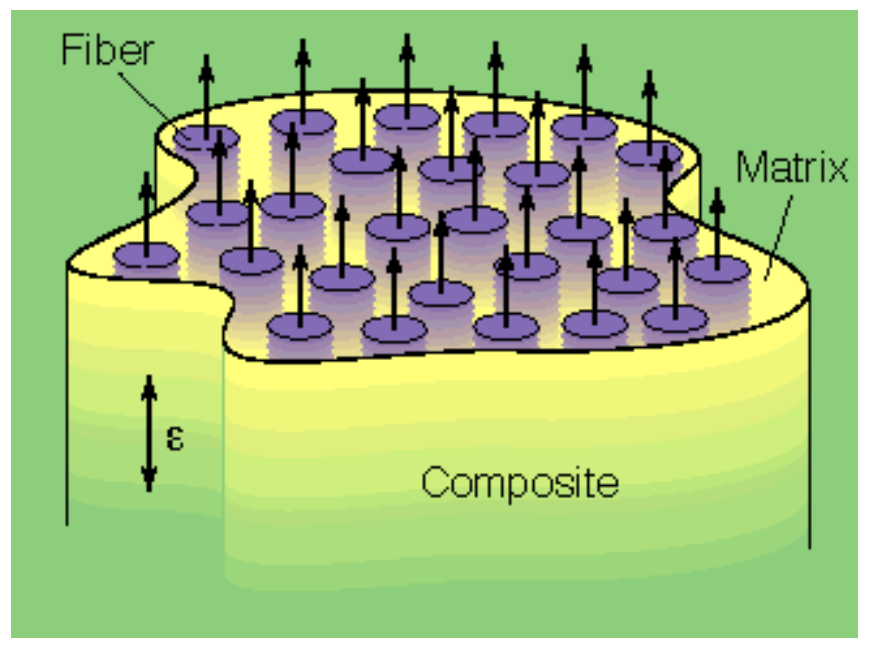

Figure 1.2.1: Unidirectional fiber orientation of a composite laminate

The final type of composite material is a laminate. A laminate is a combination of at least two different materials bonded together to form a single material. Laminates are used to combine the best aspects of multiple layers to result in a higher quality material such (e.g. low weight, high strength, or elevated attractiveness). Laminates can be made of multiple fibrous composite layers at varying angles 
to improve certain traits. For example, when building a tube out of composite materials carrying torque loads, orienting fibers at $+45^{\circ}$ and $-45^{\circ}$ allows the composite laminate to carry much higher torque loads when compared to a tube with fibers oriented at $0^{\circ}$. However, if you require a part to have very high tensile strengths, then having a laminate with a majority of fibers oriented along the tensile load will perform better than a laminate of $+45^{\circ}$ and $-45^{\circ}$. This simple customization is the reason for the widespread use of fiber-reinforced composites today.

Another form of laminate is a sandwich panel. This type of composite typically is made up of a low density core (e.g. foam, honeycomb) being "sandwiched" and bonded between two thin laminated face sheets. This process dramatically increases structural stiffness with very little weight increase due to the low density core material used. Attempting to mimic this stiffness with a laminate is not feasible because the number of layers required to produce the equivalent stiffness would be very cost inefficient. Typical face sheet materials include fiberglass, carbon fiber, and natural fibers (e.g. hemp). A practical use for sandwich panels is floor and wall panels in aircraft because large area wall and floor panels can be created with very little added weight to the structure.

\subsection{Manufacturing Techniques}

The manufacturing process for composites varies widely depending on the cost and time available. Each process has its own advantages and disadvantages and these characteristics is how manufacturers decide how to cure the composite materials used. These processes include: hand lay-up, resin infusion, press molding and autoclaving. There are common traits that each of these processes require. The first is the addition of thermal energy to cure and solidify the matrix of the composite. This can be done either by heating the part to a desired temperature or using a two-part matrix generating its own heat through a catalytic reaction. The second common trait is pressure being applied during curing. Pressure needs to be applied to the part to squeeze out excess resin and to ensure no air bubbles in between the laminates. Air bubbles between the laminates can severely degrade the structures overall strength and may cause premature failures. 
The most common method is the hand lay-up method. This method involves impregnating dry fibers with resin by hand and then layer by layer, placing sheets over a mold and then curing at room temperature while under a vacuum. This process can be sped up by artificially heating the part in an oven or on a heat table. The resin typically used in this method is a low viscosity resin that flows easily and hardens over a long time period. This is done specifically so that excess resin can be drawn from the part under vacuum. A side effect of this manufacturing process is that the laminate quality is entirely dependent upon the operator's skill and exhibits a higher variability from batch to batch. This type of process would not be suitable for large scale or high performance designs.

Resin-infusion is a method mimicing the hand lay-up method but differentiates itself when the fiber is impregnated with resin. For the hand lay-up, resin is applied by hand and then sealed in a vacuum whereas with resin-infusion, the vacuum is first pulled over the dry fibers and then the resin is drawn into the mold by the vacuum pump. This method produces a higher quality part because the resin is more evenly distributed.

There is an alternative to this method and it involves the use of pre-impregnated (pre-preg) fiber. There are two methods to manufacturing pre-preg, the first involves a two-step process by which resin is spread across one face of a sheet and spun into rolls [7]. The second step is to mix the fiber and resin into a single roll. Done by drawing fiber through a series of rollers, a heating table, a cooling table, and a light table. The purpose of the heat table is to liquefy the resin so that it flows around the fibers and creates a uniform ratio of fibers to resin. The cooling table is then used to cause the resin to become more viscous and bind to the fibers while the light table is used to inspect the roll for defects or anomalies that can occur during manufacturing. This first method is used to impregnate both unidirectional fibers as well as weaves (Figure 1.3.1)[ 7]. The second method of impregnating the fiber is to combine the first and second stages into a single step. This method is used only for woven fibers [7]. It begins with a roll of woven fiber being drawn into a resin bath. The resin bath is then cooled to solidify the resin. Using pre-preg is superior to a hand lay-up because of the consistency increase from 
part to part. It is also easier to lay-up due to the highly viscous nature of the resin used in pre-preg. Resin used for hand lay-ups tend to flow very easily while resin used in pre-pregs is very tacky and stable. These resins are designed to begin flowing after certain temperatures are achieved. However, lead to a major challenge for working with pre-laminates as they require bulky machinery to heat the resin for curing.

One method of curing pre-preg laminates is to use a heat press (Figure 1.3.2) to squeeze excess resin and air out of the laminate while adding energy into the structure to solidify the resin. This method requires a minimum of a two-piece mold that can withstand both the temperatures and compressive

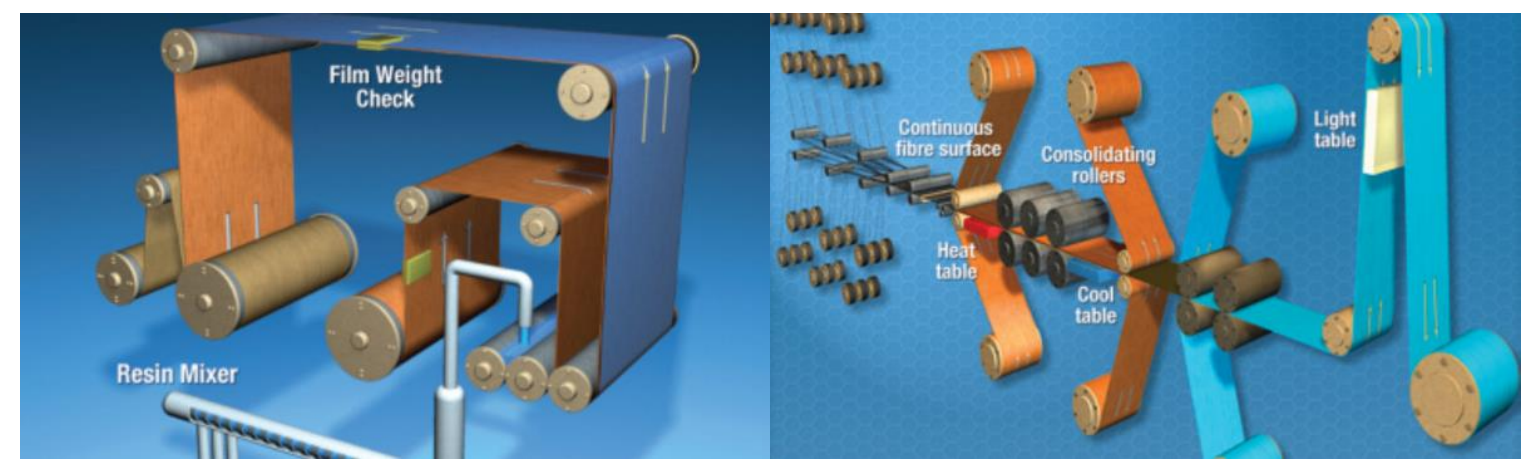

Figure 1.3.1: Method of impregnating fibers with resin

forces applied during curing. The press pictured uses a piston to drive the bottom platen upward and compressing the substance between the upper and lower platens while also adding heat to cure the part. Heat presses are not restricted to this size. Some presses produce wall sized panels for aircraft and have the capability of compressing the part under thousands of pounds of force. 
The last method of manufacturing is the use of an autoclave. This is the preferred method of curing for high quality and high consistency parts. The process involves laying up the composite over a mold and then enclosing the part in a vacuum bag and debulking the part. Debulking is the process of leaving a part under vacuum for a few minutes to draw as much air as possible out of the layers. After debulking, a part is taken to the autoclave which typically is a pressurized and heated cylinder. Autoclaves produce such high quality parts due to the high pressure achieved during

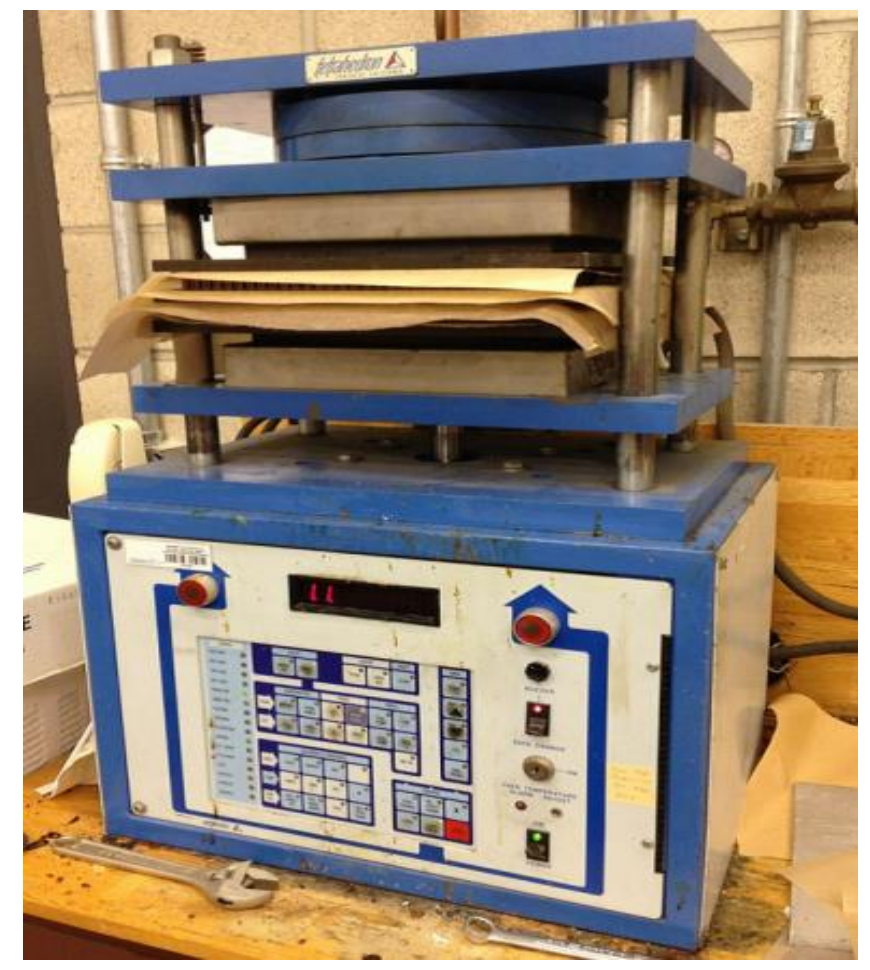

Figure 1.3.2: Heat press used to cure composite materials in the Cal Poly aerospace composites lab

the curing cycle. Autoclaves can cure parts at pressures upwards of $90 \mathrm{psi}$ and temperatures from $250^{\circ} \mathrm{F}$ and above.

\subsection{Impact Behavior of Composites}

A constant concern in composite structures is the effect of foreign object impacts on the structural integrity of any system using composite materials. Impacts can vary from common low velocity strikes like a tool drop during maintenance to high velocity impacts like debris striking the aircraft. The most dangerous and least common type of impact is a high velocity, high mass impact such as a bird strike. An example of this type of impact can be seen in Figure 1.4.1 [29]. Collisions such as these can not only severely damage the structure but also cause catastrophic events, like in flight emergencies. However, low velocity impacts are just as dangerous because of how difficult this damage can be detected.

Overall, low velocity impacts reduce the strength of composites and often cause considerable subsurface damage to a structure. The most common impacts of this type that occur are hail, debris at takeoff, or 


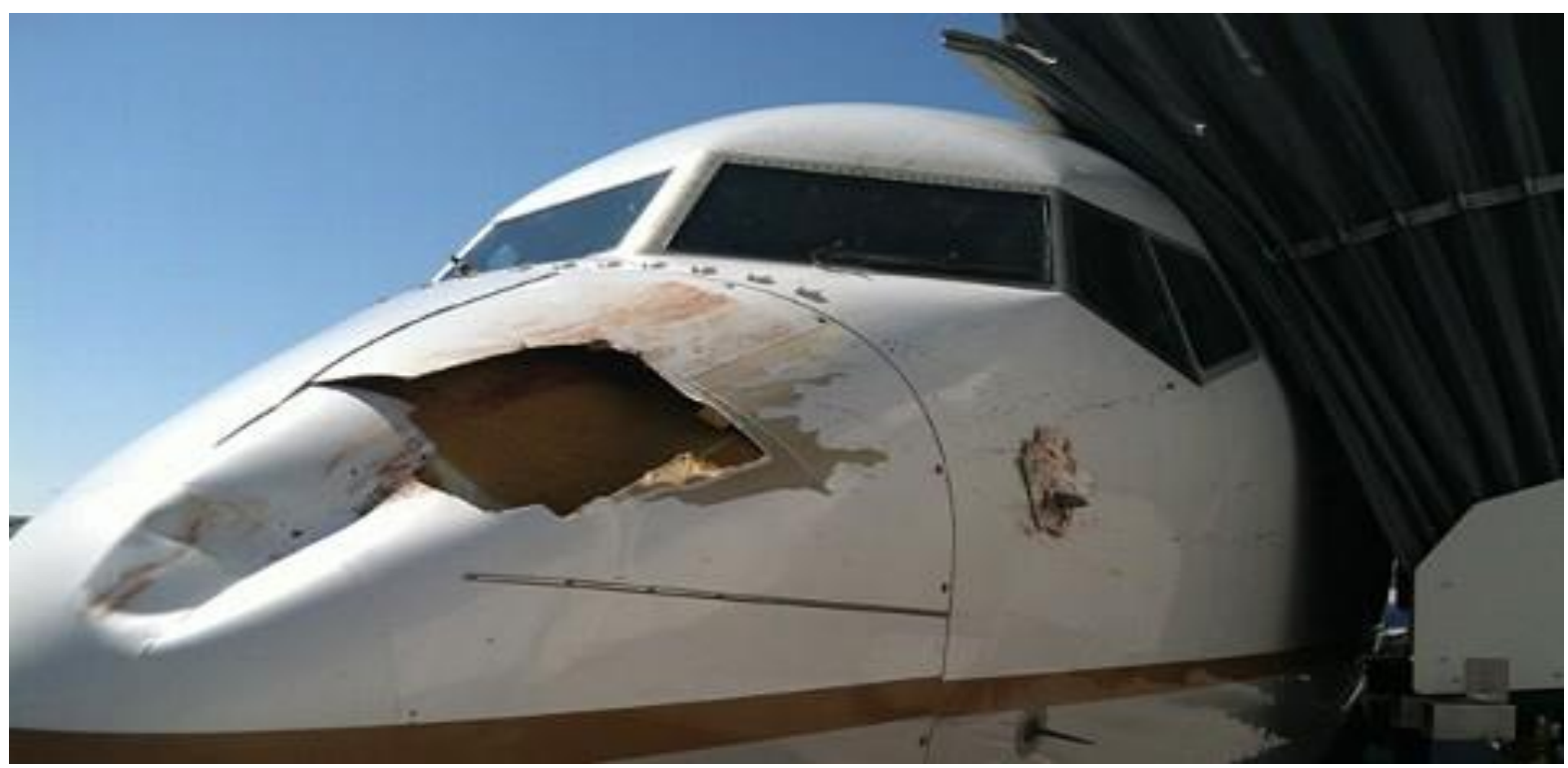

Figure 1.4.1: Aftermath of a bird strike to the nose of an aircraft

tools dropped during maintenance of the aircraft. This type of damage is typically simulated with either a drop tower or air cannon.

Impact strength is a structure's ability to resist high-rate loading. This is one of the most important structural properties for a designer to consider, but is often the most difficult to quantify or measure. A constant concern for composite structures out in the field is the effect that nonvisible damage will have on a system. An impact into a composite structure can create interlaminar damage, often resulting in a severe reduction in strength and stability of the structure (e.g. Figure 1.4.2)[30]. In the Figure 1.4.2, the danger of impact damage is not just isolated to the immediate area surrounding an impact

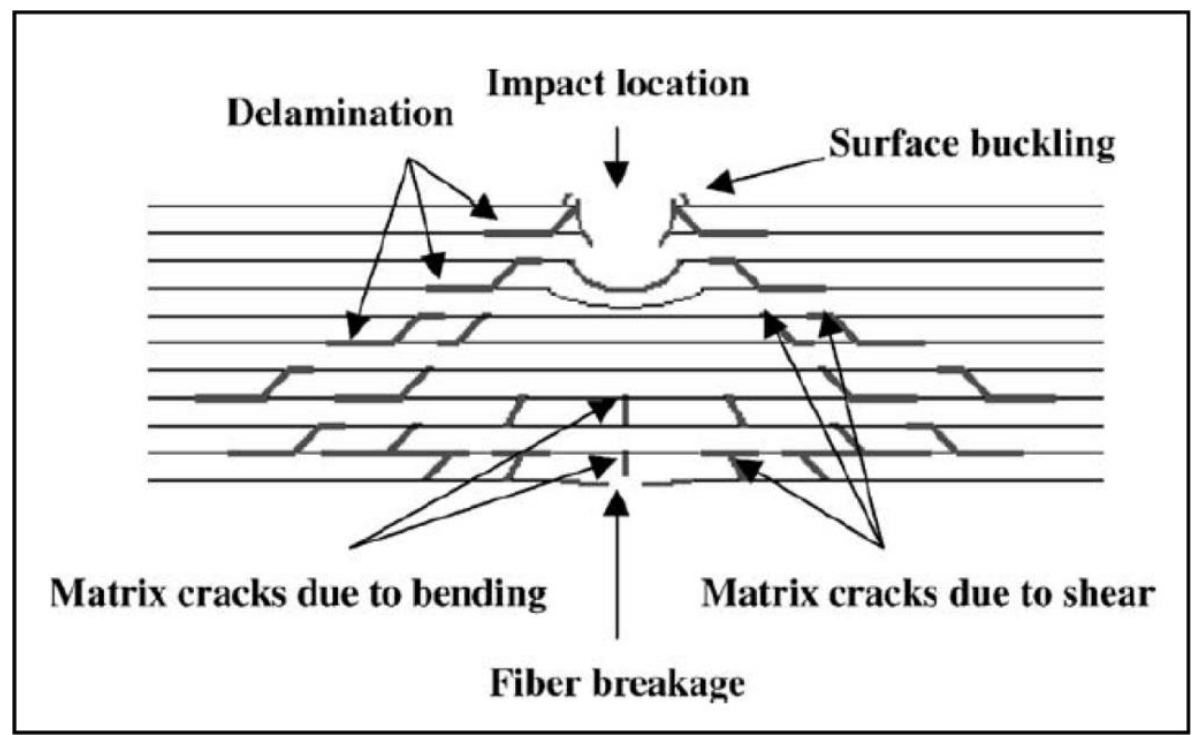

Figure 1.4.2: Effect of impact damage on a composite laminate 
location, but also spreads the damage outward between composite layers. It is the subsurface damage like the interlaminar cracks that are very difficult to detect.

\subsection{Previous Research on Impact behavior of Composites}

There have been vast amounts of papers and studies done on the impact behavior of composites with a focus on low velocity impacts. Perez et al., [9] examined detecting impact damage using vibrational testing of composite laminates. The dynamic loading condition was each laminate hanging freely and then tapped with a roving hammer to produce the modal excitations of the laminate. The testing showed that large changes to the dynamic characteristics of the laminates were key indicators a laminate had sustained impact damage. The laminates were made of unidirectional carbon fiber plies with an orientation of $\left[45^{\circ} / 0^{\circ} /-45^{\circ} / 90^{\circ}\right]_{5 \mathrm{~s}}$ for a total of 40 plies per laminate used. The impact test followed ASTM D7136 with impact energies ranging from 6.6 to $70 \mathrm{~J}$. The dynamic characteristics of each sample were characterized using a mono-axial accelerometer. The results of the testing showed impact-induced damages resulted in detectable changes in the vibration response of the test coupons. It was also determined the mode shapes tended to show the largest changes.

A second effort into assessing the delamination of composite materials was done by Garcia et al. [10], in which a method for diagnosing damage in structures was tested. The method tested was to measure the time domain structural vibration response of test specimen. Delaminations were created in

the test specimens by placing Teflon sheets to create a discontinuity between the laminate layers. It was determined that this method of detection was measure small changes in the vibrational response of the composite laminates. It was also shown that detection method was able to localize the delaminated areas based on looking at the nodal responses of each tested specimen.

\subsection{Previous Research Efforts at Cal Poly}

A previous research study that was done at Cal Poly by Kodi Rider [3] also used vibrational characteristic changes to assess how well damage arrestment devices (DADs) worked on keeping impact 
damage localized to the epicenter of the impact strike. The DADs were fiberglass beams imbedded into composite sandwiches with the DADs running along both the length and width. The sandwiches were impacted using the Dynatup 8250 in the Cal Poly Aerospace Composites/Structures Lab and then placed on the Unholtz-Dickie shaker table system and loaded under a $1 \mathrm{~g}$ sinusoidal acceleration from 10-2000 Hz. The results of this research was change in the first and second mode time response of specimen signaled an impact had occurred and damage was present in the structure. The DADs proved to aid in keeping structural damage localized to the impact site. It was also shown that varying the location of an accelerometer could effectively detect the presence of face-core delaminations, especially near impact sites. The results if this research was the DADs would improve the damping characteristics of composite sandwiches under vibrational loading. It was also shown that accelerometers can effectively detect damage of a structure.

\subsection{Objective of the Study}

Previous research has all focused on simple geometries while this study is meant to determine if this method can work on more complex structures. The geometry was a small scale wing structure composed of a skin, spars, and ribs. The objective of this study was to determine the effectiveness of using accelerometers to detect damage of a wing structure after being damaged by a low-velocity impact. The design of the wing was based off of an existing wing model that is used in the Aerospace Experimental Stress Analysis class with some slight changes to fit the constraints of the testing apparatus' used in this study. The two testing apparatus used were the Unholtz-Dickie electrodynamics shaker table system and the Dynatup 8250 vertical drop weight impact testing machine. Dynamic testing was done with a $1 \mathrm{~g}$ sinusoidal sweep from $10-2000 \mathrm{~Hz}$ with accelerometers being placed at various locations across the wing to measure dynamic characteristics. The impact testing was done so various locations of the structure were impacted. Because the wing geometry had ribs and spars, the internal geometry varied along the span. Four different impact scenarios were tested: impacts over the skin, over the leading edge spar, over the middle rib, and over the middle rib/leading edge spar intersection. There 
was also a set of control wings that were not impacted to be used as a baseline for the testing. Three wings were created for each scenario and assembled accordingly. All parts of the structure were cured in an autoclave for 7 hours at $148^{\circ} \mathrm{F}$ and $70 \mathrm{psi}$. To determine whether or not damage is detected by the accelerometers, the natural frequencies and damping ratios of each wing was analyzed and compared before and after testing to determine if a large change had occurred at specific locations or across the entire structure. The structure was also modeled in Abaqus and analyzed to determine of the dynamic characteristics of the numerical model could match the experimental results of the wing structure.

\subsection{Scope of the Study}

The remainder of this study is organized in order of setting the ground work for testing, the creation of the testing specimen, and then the experimental and numerical results. Chapter 2 introduces the method of testing for material properties as well as the impact and dynamic tests some important parameters of these tests. This section also goes over any upgrades or changes done to testing apparatus such as the rewriting of the LabVIEW software used to operate the Dynatup 8250 impact machine. The LabVIEW software was rewritten to improve the troubleshooting capabilities of the user as well as implement the used of strain gages during testing. Chapter 3 goes over the design process for the wing structure and the decisions constraints involved in the design. The design and creation of testing fixtures is also discussed in this section with various fixtures being required to effectively test the wing geometry. Chapter 4 discusses the manufacturing and assembly process of the wing structure. Topics in Chpter 4 include the manufacturing of the skin, spars, and ribs as well as the final assembly step of the structure and the specific method of vacuum bagging and machining are all explained here. Chapter 5 discusses the results of the pre- and post-impact dynamic testing and the results from the impact test itself. For the impact test, the failure modes of the structures as well as the maximum force measured were analyzed to understand how the structure absorbed the impact at the various tested locations. The vibrational testing was analyzed by first looking at the average value change of each wing to determine if major changes had occurred and then a point by point check was completed to see if any drastic changes 
had occurred near the impact sites. Chapter 6 discusses the creation of the finite element model used to model the wing design, the implementation of the frequency sweep check and the impact step, and the comparison of the experimental and numerical natural frequencies. Chapter 7 gives an overview of the research results as well as conclusions drawn from the data. Chapter 8 will provide direction for future works. 


\section{Testing Methodology and Analysis}

This chapter will go over the various testing done and the approach taken for each test. The first section evaluates the different testing methods used to determine the material properties of the LTM45EL carbon fiber weave used in the project as well as how the values are determined. Tensile and compressive testing was done. After that, anything and everything involved in the use of the Dynatup 8250 impact testing machine including new LabVIEW software created to improve the troubleshooting and testing capabilities of the machine will be evaluated. Also covered is the implementation of strain gage measurements using the LabVIEW software as well as the analysis used to determine the strain measurements. This chapter will wrap up with the testing methodology for the dynamic test as well as how the damping ratio is calculated.

\subsection{Material Property Testing}

In order to compare testing results to finite element results, the material properties of the LTM45EL needed to be determined. Due to testing limitations, only a few types of ASTM test methods can be performed because a lack of fixtures. The test method performed was ASTM D3039 [22]. This test method requires a uniaxial testing machine to apply either a tensile or compression load. The Instron 8801 Servo hydraulic Fatigue Testing System located in the Cal Poly Aerospace Structures/Composites lab was used to perform the ASTM methods above. The fixtures used were heavy-duty hydraulic wedge grips that applied a shear force to the test coupons to facilitate loading. The Instron 8801 is capable of tensile and compression loading up to $22,000 \mathrm{lb}_{\mathrm{f}}$. Due to carbon fibers low crush resistance it was important to apply tabs to every tested specimen to ensure failure of the specimen occurred in the gage section rather than the grip regions. Tabs used were made of AL 6061-T6 sheet metal that was $1 / 8^{\text {th }}$ inch thick. The tabs were bonded to the specimens

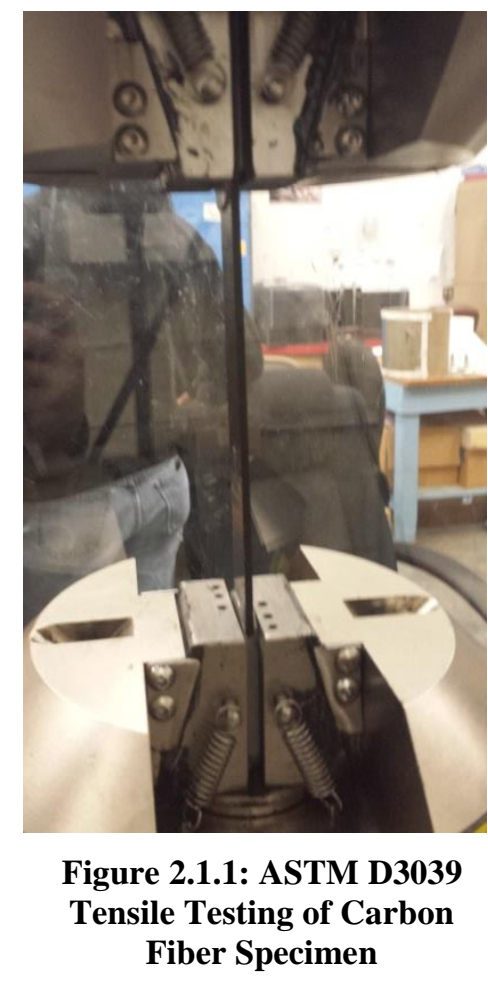


using Magnolia $56 \mathrm{~A} / \mathrm{B}$ structural adhesive. It is important that the tabs be as close to parallel as possible so no bending or torsional stress is induced during testing. To ensure this, specimens were placed in the hydraulic press located in the Cal Poly Aerospace Structures/Composites lab just after the application of structural adhesive and placement of the tabs and compressed between two plates for 6 hours under $100 \mathrm{lb}_{\mathrm{f}}$. The hydraulic press was used because the two plates used on the press were designed and maintained as close to parallel as possible. To prevent dis-bonding of the tab and specimen, the tab face was scratched up to increase adhesion.

ASTM D3039 which describes the process used to determine tensile properties for polymer matrix composite materials. This method requires long, thin strips to be pulled along the long axis of the coupon until failure while measuring load and extension for the material. The test uses an extension rate to move the lower head down, stressing the coupon until failure. The lower head moves at a rate of 0.05 inches/minute as stated ASTM D3039. Load, extension, stress, and strain are all recorded every 0.1 seconds until failure. The failure criterion for this test was a $40 \%$ drop in applied load occurred. In order for the values to be considered correct, a set of 5 specimens needed to show similar failure strengths. Test specimens were considered to be balanced and symmetric due to the symmetry of the LTM45EL weave. Based on this assumption, the suggested dimensions were for each strip was 10 inches long, 1 inch wide and 0.1 inches thick. In order to achieve this thickness, 6 layers of LTM45EL weave were laminated together and cured in the autoclave for 7 hours at $158^{\circ} \mathrm{F}$ and $70 \mathrm{psi}$. The laminate was cured at a dimension of 12 inches by 12 inches. The oversizing of the laminate was to minimize edge effects to the laminate's performance. The test strips were cut to size using a water-cooled tile-saw and tabbed using the structural adhesive named above. After tabbing was completed, the test strips were numbered and then tested in the Instron 8801. Test specimen were individually loaded and tested, noting failure modes for each tested specimen. All five tested specimen failed in the gage section which is desired, as well as having ultimate loads very close to each other. Results for this experiment can be found in chapter 5. A drawing of the tensile specimen can be seen in Figure 2.1.2. 


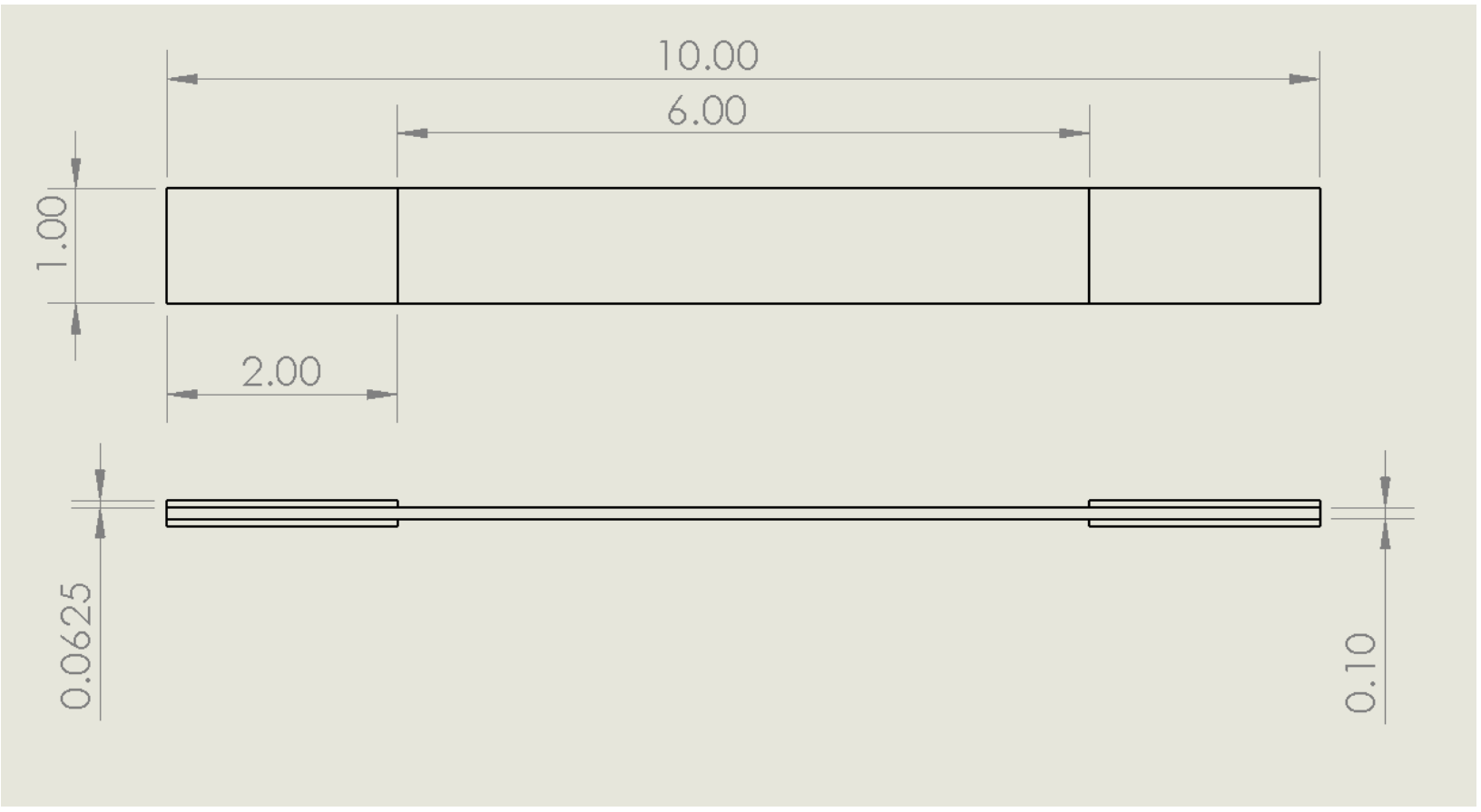

Figure 2.1.2: Drawing of ASTM D3039 Tensile test specimen

The only analysis required for this data is to determine the modulus of each specimen. The modulus is determined by loading in the stress and strain data from the raw data files into MATLAB and then fitting a linear polynomial to that data. Once the polynomial has been determined, two points are then manually selected from a plot using MATLAB's ginput function and the slope between the two points is calculated. Since a liner polynomial is applied to the data, selecting two points anywhere in the line will produce the same modulus.

\subsection{Dynatup 8250 System and LabVIEW GUI}

The impact testing followed ASTM D71 36 [24] and was performed on the Dynatup 8250 drop weight impact machine located in the Cal Poly Aerospace Structures/Composites lab. The machine consists of a housing where test specimens are damaged by dropping a crosshead. The crosshead consists of interchangeable weight plates ranging from $5 \mathrm{lb}_{\mathrm{f}}$ to $75 \mathrm{lb}_{\mathrm{f}}$. The energy from the drop is channeled into the impact tup. The tup is a 0.625 inch diameter rod of hardened steel that drives into the test specimen to cause localized damage. Mounted to the tup was a THD-3K-W through hold load cell from Transducer Techniques and a model 1011a piezoelectric accelerometer from VIP Sensors. At the 
bottom of the testing section is a clamping fixture designed by Daniel Barath and Dr. Elghandour in 2013 [31]. The fixture is used to clamp a specimen in place during testing. To the right and just above the clamping fixture is a LED light and a Sibiased detector used to measure the instantaneous velocity at impact. The two data acquisition systems used is a NI USB9162 DAQ[18] card and a NI SC-2345 Signal Conditioning box [19]. The software used to run a test is a LabVIEW software written by Kodi Rider in 2012 and updated by Jeffery

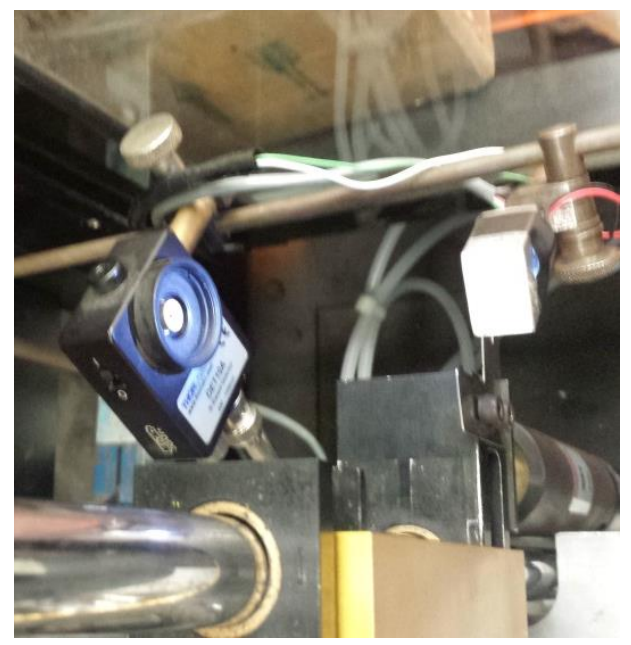

Figure 2.2.1: Si Detector and laser used to measure impact velocity Carter in 2014 [5]. After data is processed by the DAQs, the data is then saved to a LabVIEW data file and stored through LabVIEW. Over the next few paragraphs will be a more detailed description of how the Dynatup 8250 system operates.

To measure the instantaneous velocity of the crosshead, LED light is pointed directly at the Sibiased detector causing the detector to output a voltage [16]. When the LED light is obstructed, the voltage output of the detector drops close to zero. A two-pronged flag attached to the crosshead passes between the LED light and detector, obstructing the light twice and creating two distinct data points in time. By measuring the distance between the two flags as well as counting the time elapsed between the two low voltage points, the speed of the cross head can be calculated. The LED light is powered using an NI SCC-AO10 isolated voltage output carrier and provides a voltage of $3 \mathrm{~V}_{\mathrm{dc}}$ to power. The voltage output from the detector is read into LabVIEW and stored for later analysis. It is important to verify that the LED light and detector are in alignment before testing. Equally important is to verify only the prongs of the flag cross the light beam, otherwise, the velocity data can be drastically effected.

In order to obtain the force versus time history and impact force of the test, a THD-3K-W load cell was used. The load cell has a maximum loading of $3000 \mathrm{lb}_{\mathrm{f}}$ with an accuracy of $+/-1 \%$ of the measured force. It is a thru-hole style cell that was mounted between the impact tup and crosshead 
assembly. It was determined over the course of this thesis that this loading configuration was improper and did not measure the true impact force. This, along with a solution, is explained in Section 3.4.2 with the redesign of how the load cell is loaded. The load cell is connected to a NI SCC-SG24 twochannel load cell input module that supplies a $10 \mathrm{~V}_{\mathrm{dc}}$ excitation voltage to the full bridge circuit inside of the load cell. The output of the load cell ranges from 0-20 mV/V (millivolts per volt) which corresponds to a force range of $0-3000 \mathrm{lb}_{\mathrm{f}}$.

The accelerometer is attached to the load cell using tacky wax and is used to measure the acceleration time history of the impact event. The accelerometer is a single axis accelerometer that outputs a pC/g (picocoulombs per $\mathrm{g}$ ) signal which is too small for the DAQ to measure. The signal is passed through a VIP Sensors 5004-10 charge converter that converts the high impedance charge signals from the accelerometer to low impedance voltage signals. The charge converter had a gain of $10 \mathrm{mV} / \mathrm{pC}$ (millivolts per picocoulombs). After passing through the charge converter the signal is then read into a NI SCC-ACC01 single channel accelerometer input module.

The LabVIEW software created by Kodi Rider used two DAQ Assistant blocks corresponding to the two different DAQs described earlier. Raw data was outputted from these two blocks and sent to three waveform graphs, which plotted live data from the accelerometer, load cell, and detector. Raw data was also written and stored in a .lvm file to later be analyzed in MATLAB. One drawback to the LabVIEW code written by Kodi was the waveform graphs were not updated until after a test was run. This indicates if troubleshooting for the measurement devices was necessary to be completed, a new run was required to be performed anytime a change was made, which would increase the time it would take for troubleshooting to be completed. Another flaw to the software was it was difficult to change the runtime of a test or the rate at which data was

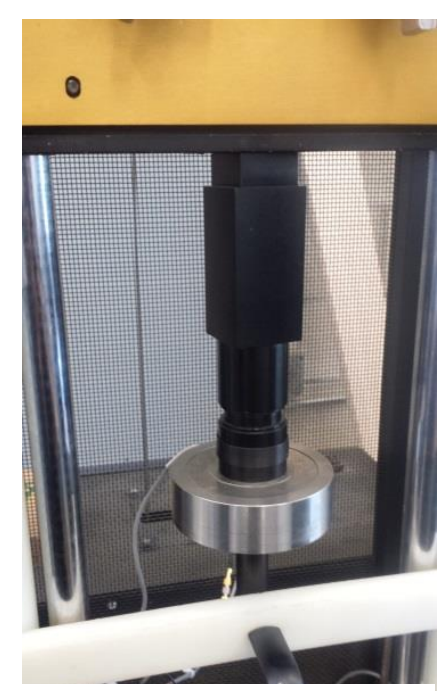

Figure 2.2.2: Original Fixturing of Load Cell 
polled. In order to do this, the DAQ Assistant boxes needed to be individually opened and altered as did the time of a run. Additionally, instances when calibrating the machine where test runs were lost or incorrectly saved because live data readings from the various pieces of equipment were not available. One instance occurred when the LED light and detector were miss-aligned after replacing a specimen in the test section causing the velocity data from run to not be saved. For these reasons, a new LabVIEW code was written with the assistance of Bradley Schab.

The new software implemented a real-time updating of the waveform graphs so that the steadystates of each signal could be verified and that the devices were working properly. Another improvement to existing GUI was the implementation of Time and Rate input boxes. The boxes worked to determine how long the waveforms would update as well as how fast the data was polled. For this thesis, the waveforms were updated every second and data was taken at a rate of $50 \mathrm{kHz}$. A toggle switch was also implemented in the GUI so that storing of the data could be turned on or off at any time. Once the toggle switch isswitched on, all data taken from that point and in the future will be stored in a temporary array until either the toggle switch is switched off or the data is saved by clicking the save button in the GUI. The save button will allow you to name and save a Microsoft Excel file to any location you would like. After saving, toggling the store data switch will remove any stored data and the GUI will be ready to perform the next test without stopping. This means the LabVIEW software can run continuously while able to save testing runs, reducing the amount of time required between each test. In the excel file, data is stored in three columns with column A being load cell data, column B accelerometer data, and column $\mathrm{C}$ detector data. The block diagram for the new LabVIEW GUI can be seen in Figure 2.2.3. 
It was also desired to upgrade the LabVIEW software to be able to record data from multiple strain gages as there are three NI SCC-SG01 two-channel modules not in use. The modules read in voltage changes from strain gages with an excitation voltage of $2.5 \mathrm{~V}_{\mathrm{dc}}$. For use with strain gages, a separate LabVIEW software file was created implementing up to 4 strain gages. The ability to use more strain gages can be done in the future by simply adding new channels to the DAQ assistant mimicking the existing architecture. Operating the GUI is the same as running the previous version with the strain

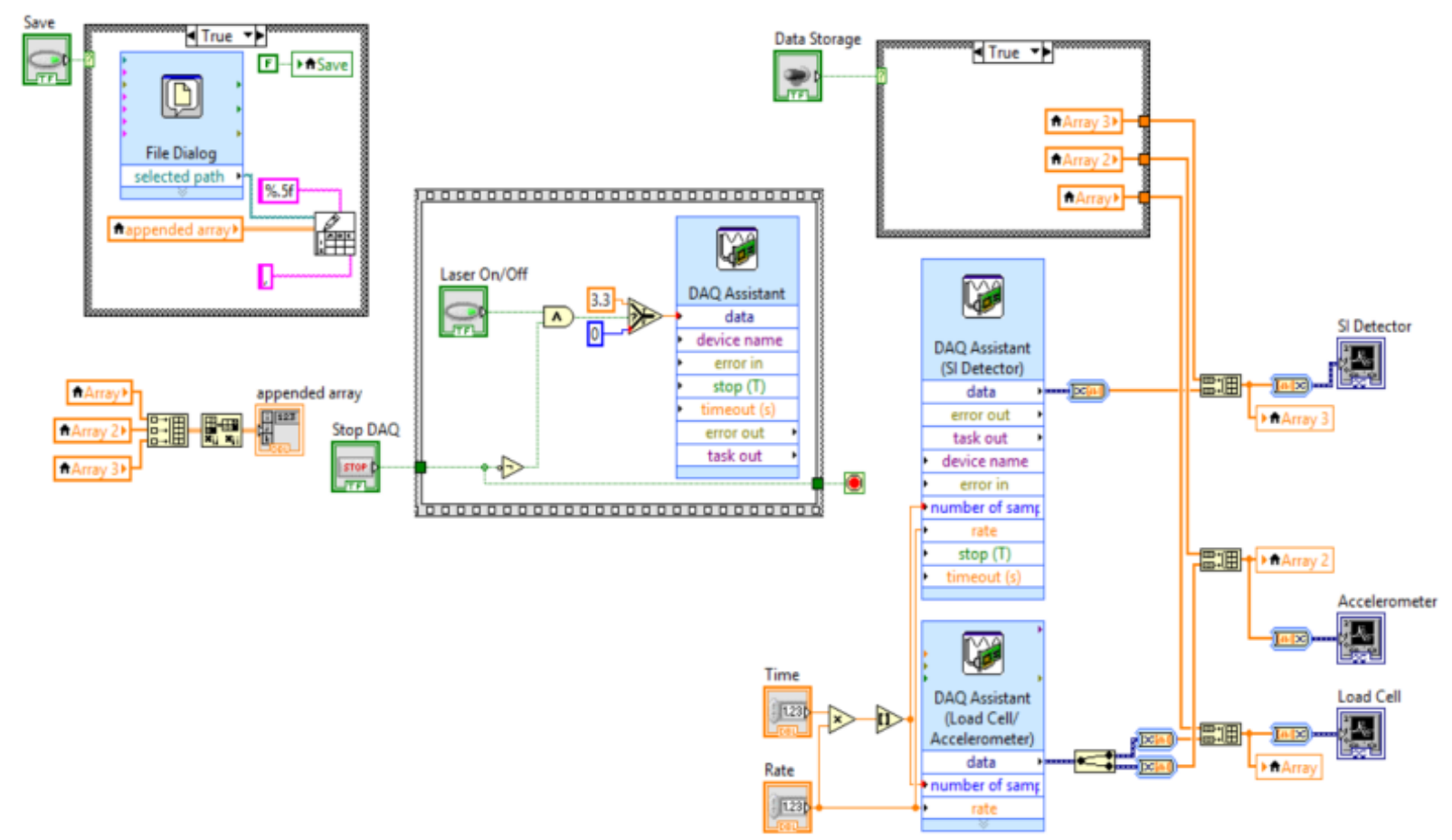

Figure 2.2.3: Block Diagram of new LabVIEW GUI

gage data being added in columns after the initial three columns reserved for the load cell, accelerometer and detector data. To verify that the strain gages were operating correctly, a metal strip was loaded into 
Instron and loaded to $5000 \mathrm{lb}_{\mathrm{f}}$ while simultaneously recording strain data through the LabVIEW software. Data was analyzed in MATLAB and the calculated modulus was compared to the ideal values

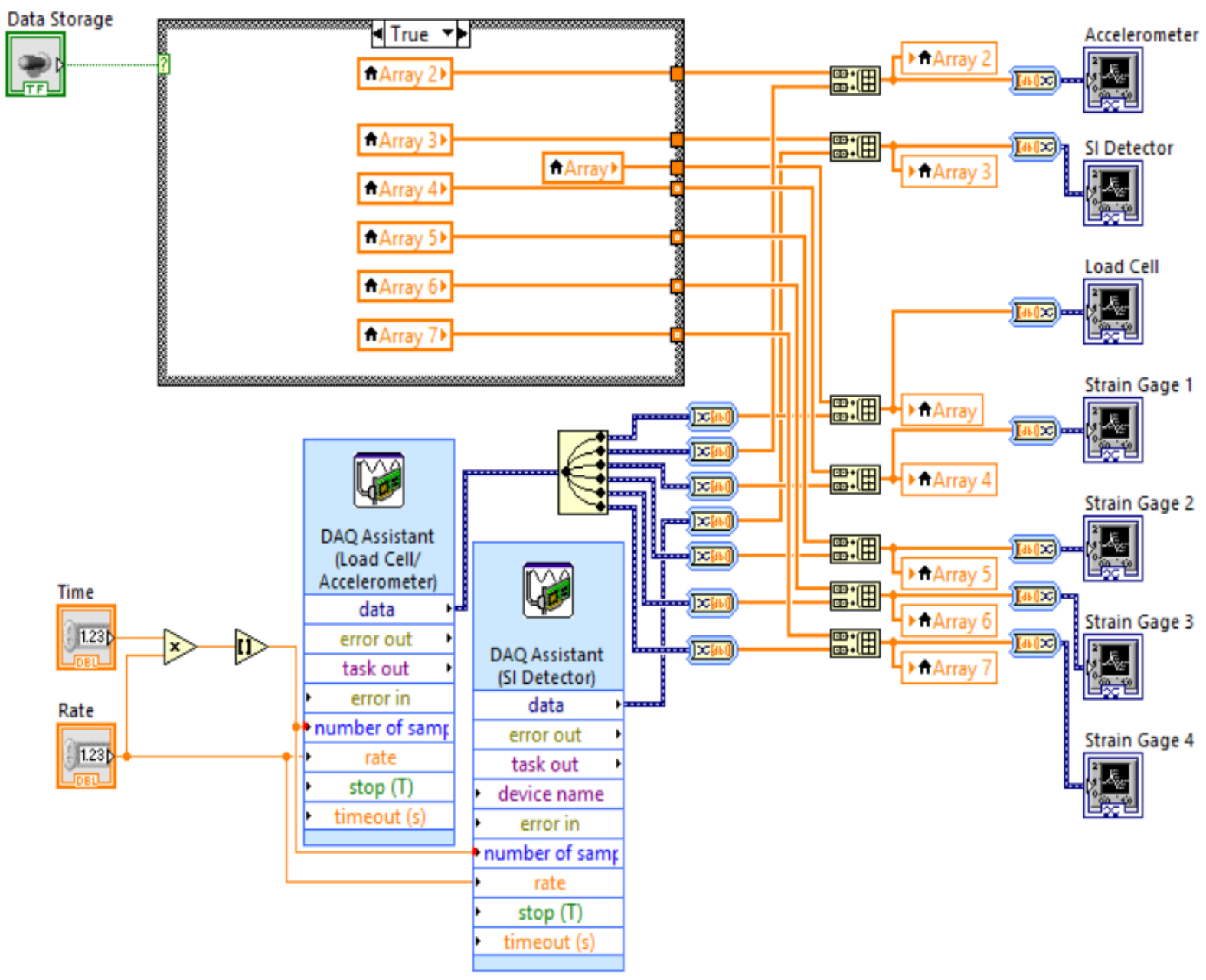

Figure 2.2.4: Block Diagram of new LabVIEW GUI with measurements of strain gages

for aluminum and was within $1 \%$. This test validated the NI SCC-SG01 modules were reading in data correctly. The LabVIEW GUI with the strain gage implementation is shown in Figure 2.2.4.

The analysis done for impacted specimen consists of a few sorting algorithms in MATLAB to find when free fall begins, when the initial contact between the tup and the test specimen occurs, when the detector voltage drops, and the max force applied during impact. Data is loaded into MATLAB 
using the csvread function and is then separated into arrays for load, acceleration, velocity, and individual strain gages. The detector and accelerometer arrays are passed through a moving average filter to smooth out the data. In order to obtain the velocity at impact, the detector data is inverted and the findpeaks function is used to locate the first two peaks in the data set. The data is inverted because a steady state voltage is higher than when the prongs of the flag intersect the light beam, so inverting the data turns the valleys into peaks. The reason the first two peaks are found is because for certain cases, the crosshead can bounce after impact and intersect the LED light again causing a new set of peaks in the data. Once the peaks are located, the code uses the data rate to determine the time elapsed between peaks and the velocity is calculated by dividing the distance between the two peaks by the time elapsed.

The maximum impact force is determined by simply searching the load cell array for the maximum value measured during testing. To determine the strain applied during impact, the voltage data is read in and calculated using an equation found in the NI SCC module catalog. The equation converts the voltage change into a strain measurement. The equation can be seen below and were taken from the National Instruments $\mathrm{SG}$ module user manual [17]. $\mathrm{V}_{\max }$ and $\mathrm{V}_{\min }$ are the maximum and minimum voltages measured during impact and $V_{e x}$ is the voltage applied to the strain gage from the module. The gage factor for all gages used is 2.14 from the products packaging. Equation 2.2.1 describes how to calculate the remainder voltage which is then fed into equation 2.2.2 to determine the strain applied.

$$
\begin{aligned}
& \boldsymbol{V}_{\boldsymbol{r}}=\frac{\boldsymbol{V}_{\text {max }}-\boldsymbol{V}_{\text {min }}}{\boldsymbol{V}_{\boldsymbol{e x}}} \\
& \varepsilon=\frac{-4 * V_{r}}{G F *\left(1+2 * V_{r}\right)}
\end{aligned}
$$

\subsection{Unholtz-Dickie Shaker Table System}

The Unholtz-Dickie Electrodynamics Shaker is located in the Cal Poly Aerospace Structures/Composites lab (Figure 2.3.1). This system will be used to measure any changes to the frequency response of the wing specimens. The system is ideally suited for testing heavy, oversized, or non-symmetrical loads on specimens where orientation with respect to gravity is necessary. The table is 
capable of oscillating a specimen either vertically or horizontally. The software used to perform test profiles is VwinII and can range from sine sweeps, random vibrations, chirping, and white noise forcing functions with a frequency range up to $5000 \mathrm{~Hz}$. Testing performed for this thesis was completed with the shaker head

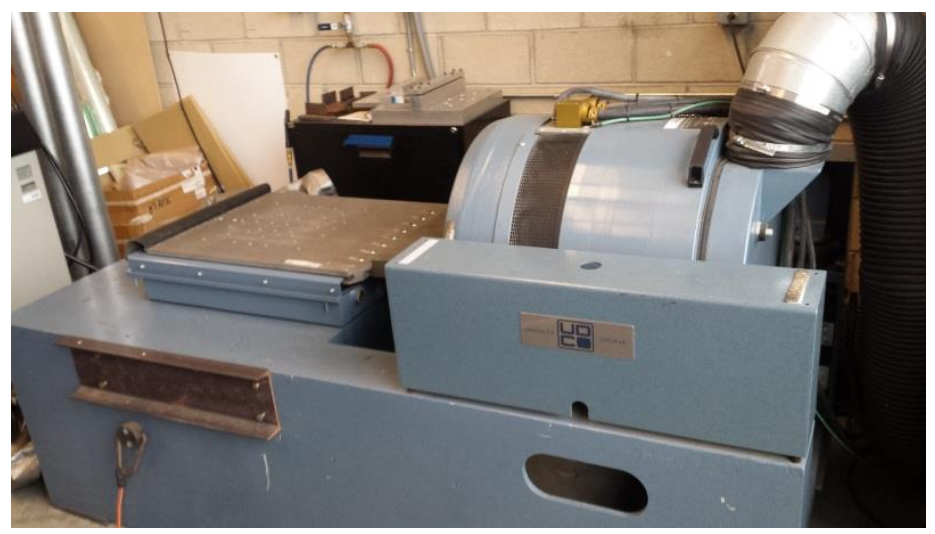

Figure 2.3.1: Unholtz-Dickie Shaker Table System used for testing set to do horizontal excitation

in the vertical position. The test profile will be a $1-\mathrm{g}_{\mathrm{pk}}$ acceleration sine sweep ranging from $10-2000 \mathrm{~Hz}$ with a run tine of 1 minute. The VwinII software has the capability of recording data from four different channels, where one channel is designated as the control channel. There needs to be a control channel because the VwinII software uses a feedback loop from the control channel to ensure the proper acceleration is being applied to the specimen. That leaves channels 2-4 to be used to record data. The accelerometer used for the control channel was a PCB piezotronics single axis accelerometer with an axial sensitivity of $9.74 \mathrm{mV} / \mathrm{g}$. This accelerometer was placed on whatever mounting fixture was used to hold the specimen in place during testing. For the other three channels, model 1011a piezoelectric accelerometers from VIP Sensors were used to measure frequency at various locations along the test specimens. Each of the VIP accelerometers required a model 5004 charge converter to amplify the output signal. These converters were identical to the converter used with the Dynatup 8250.

For the prototype wing design, measurements were taken along the leading and trailing edge spars every inch from the wing root. Once the wing design was finalized, the first wing manufactured was thoroughly tested with accelerometer measurements taken at every $1 / 2$ inch along the span of the wing and at five different locations across the chord for a total of 80 data points. Every subsequent wing test after this one needed to be completed with a much smaller sample size. The shaker system was experiencing electrical problems in the amplifier. To minimize the load placed on the system, 9 
locations were tested on each wing before and after impact testing. The locations tested centered around the impacted region of the wing with two points towards the wing tip. A diagram of the tested points below in Figure 2.3.2 and the dimensioned locations are labeled in Figure 2.3.3.

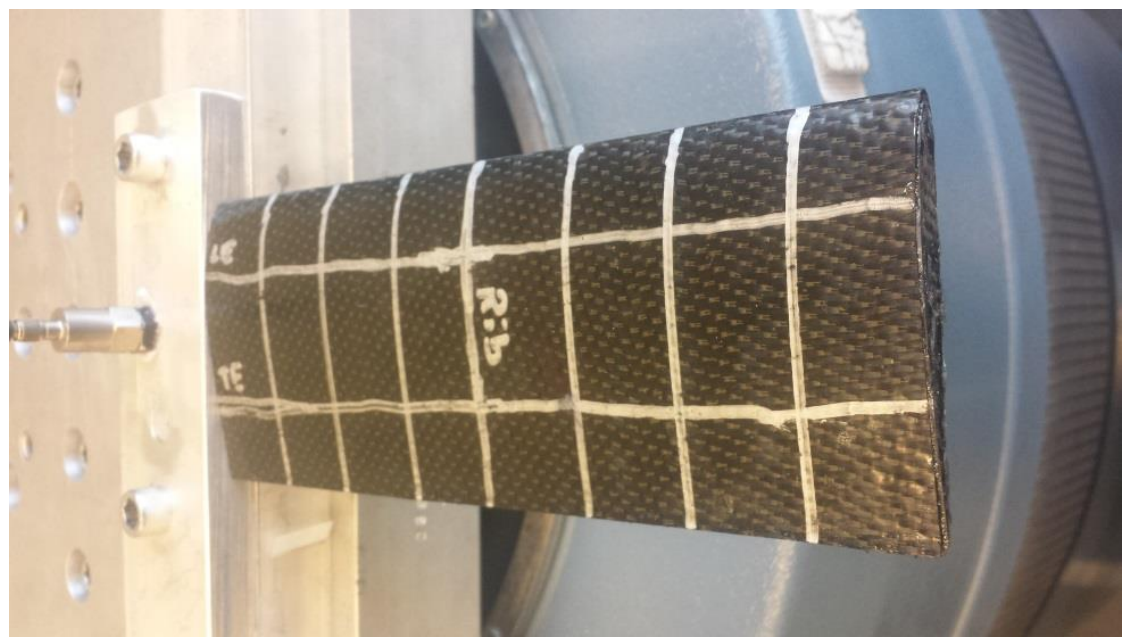

Figure 2.3.2: Prototype wing just before initial dynamic testing

After testing, the data is loaded into MATLAB for post-processing. VwinII saves each run as a Microsoft Excel file so csvread is used to load the data into MATLAB. After the data has been loaded into MATLAB, the resonant response, resonant frequency, damping ratio and time response for the first and second mode of each run is determined. The resonant response and frequency are determined by

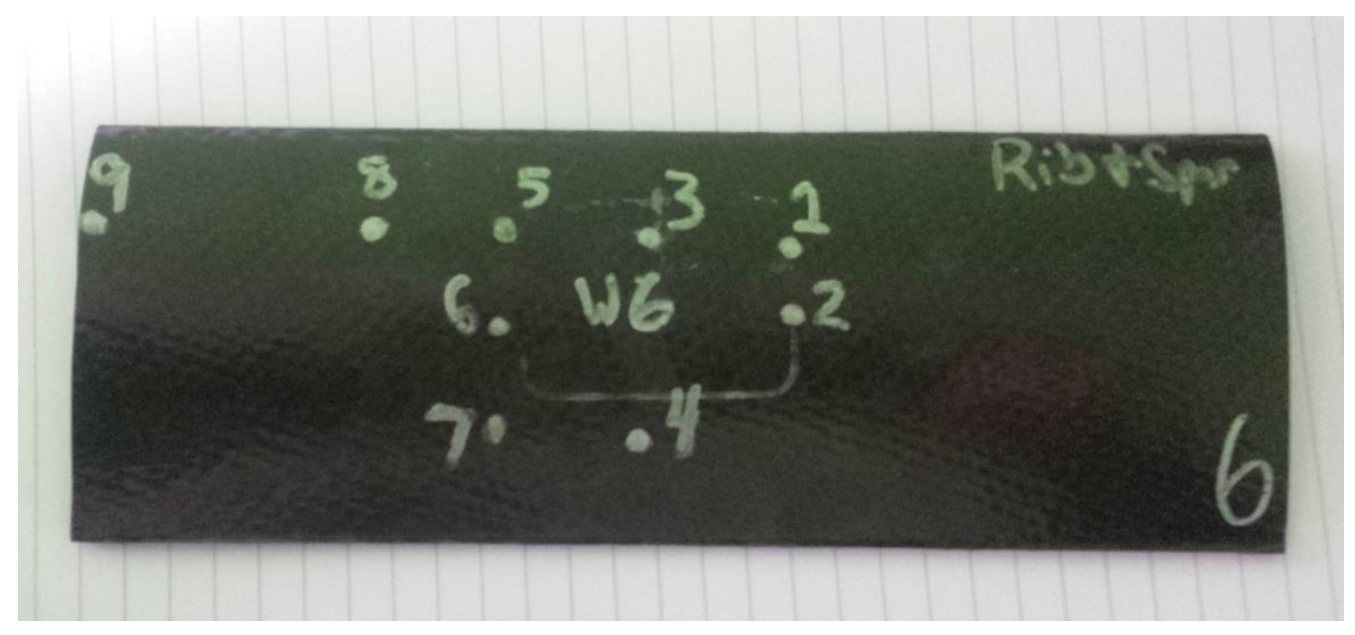

Figure 2.3.3: Locations of acceleration measurements for thesis specimens 
locating maximums of the response and the corresponding frequencies, known as natural frequencies $\left(f_{n}\right)$. Next the damping ratio is determined by using the half-power bandwidth method. This method works by using the natural frequency and the resonant amplitude to determine the natural damping the system has. First, the resonant amplitude is divided by the square root of two, and the corresponding frequencies are determined, one to the left $\left(\mathrm{f}_{\mathrm{a}}\right)$ and one to the right $\left(\mathrm{f}_{\mathrm{b}}\right)$ of the natural frequency. Now

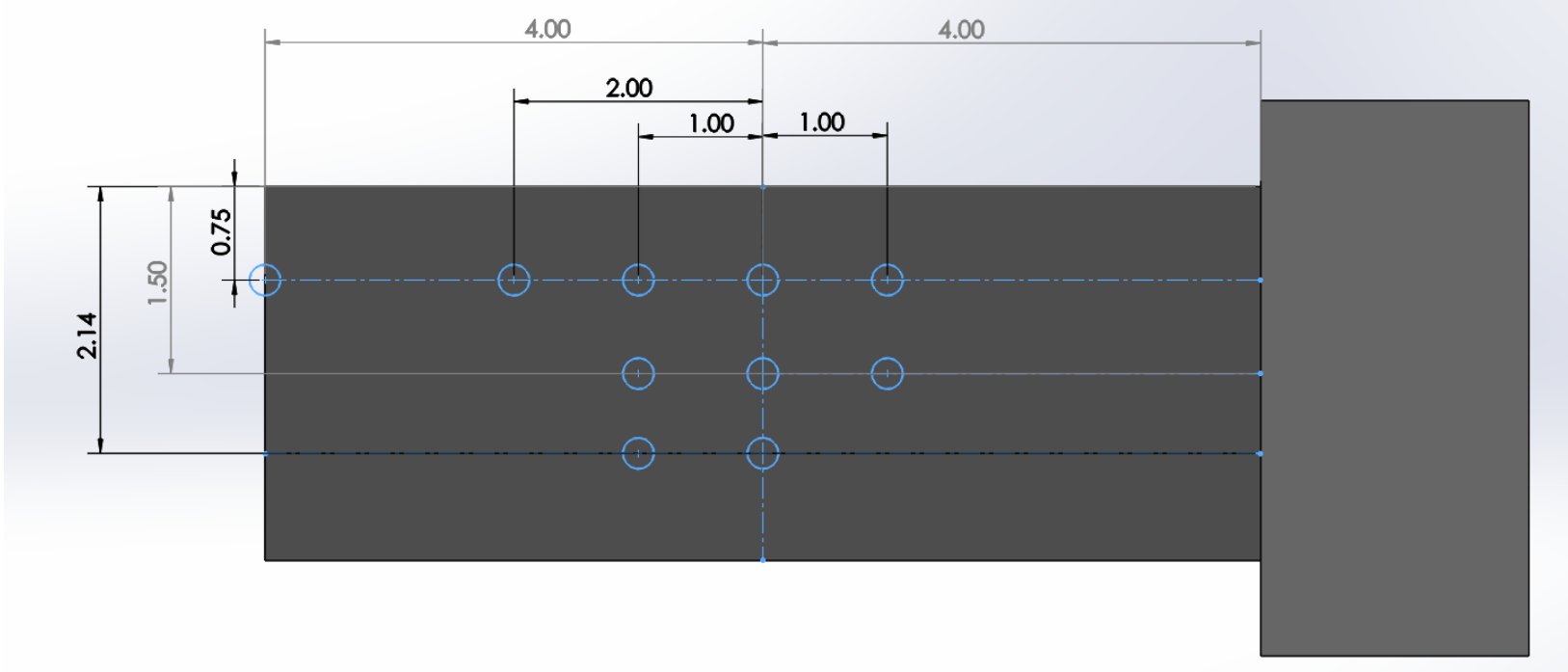

Figure 2.3.4: Dimensioned locations of accelerometer measurements for wing specimen testing

that half-power frequencies have been found, the damping ratio is determined using Equation 2.3.1, where $\mathrm{n}$ is the corresponding bending mode.

$$
\zeta_{n}=\frac{f_{b}-f_{a}}{2 * f_{n}}
$$

After determining the damping ratio is determined, the time domain response for the system can be solved. To obtain the time response solution, the transfer function for a simple mass-spring-damper system was used and a harmonic forcing function was applied. The transfer function can be seen in Equation 2.3.2:

$$
\frac{\omega_{n}^{2}}{1+2 \zeta \omega_{n}+\omega_{n}^{2}}
$$


The half-power bandwidth method, also known as the $3 \mathrm{~dB}$ method, works by obtaining the resonant response and finding the natural frequency at which the response occurs.

The code written first converts the frequency response of each run into a piecewise polynomial to be then used with fminbnd, a minimization function, to determine the location of the desired resonance frequency and response acceleration. Once the frequency of each mode is determined, the damping ratio is then calculated. The damping ratios were calculated using the half-power bandwidth method. The half-power bandwidth method is used for determining the damping ratios for transient responses of a system. The method starts with first locating the resonant frequency and its concurrent response

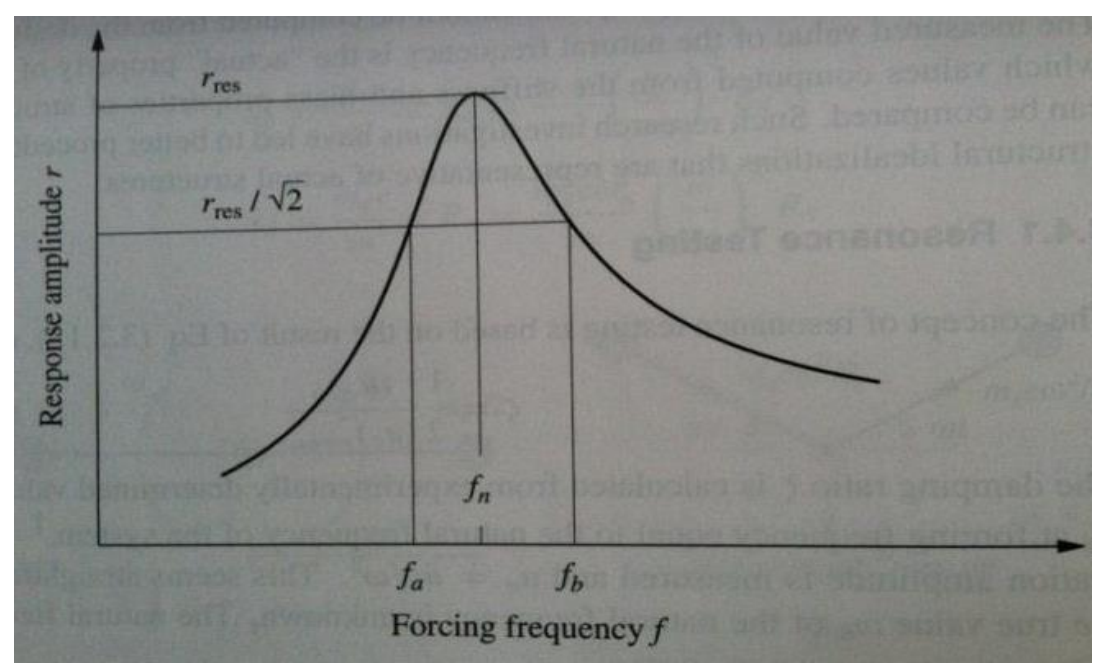

Figure 2.3.5: Half-power bandwidth method used to determine damping ratios [33]

acceleration, which was performed using the fminbnd and pchip functions. Once this has been done, the half-power frequencies are determined using the MATLAB fzero function and subtracting the resonant response divided by square root of 2 . The fzero function determines where a function equals zero and the corresponding input value so by subtracting the response value at $\mathrm{f}_{\mathrm{a}}$ and $\mathrm{f}_{\mathrm{b}}$, and outputting the frequencies at which the function now equals zero. These values are used to determine the damping ratio. Once the natural frequency and damping ratio have been calculated, they are entered into the transfer function and the time response is determined using the MATLAB impulse function. 


\section{Specimen and Fixture Design}

This chapter investigates the methodology and process used to design the wing structure as well as any fixtures required for testing of the wing. An explanation of the constraints for the wing design and then the design of the wing is fleshed out and brought to life. Next, the three different fixtures designed and manufactured for the Dynatup 8250 impact tester will be shown. These parts include a redesign of how the load cell was constrained to provide true force data, an improvement to the existing testing section to allow for larger parts to be tested, and finally a set of aluminum bars used to even distribute the compressive loading force applied to the wing during impact. At the end of the chapter the design of the testing fixture used during the dynamic testing of the wing will be discussed. This fixture is used to hold the wing in a cantilever position while the sine sweep is done.

\subsection{Limitations to the Design of the Wing}

Before a wing design could be created, the limitations to the wing needed to be set. The limitations to the geometry were the autoclave, Unholtz-Dickie shaker table and Dynatup 8250. The limitation for the autoclave was how big of a piece could be vacuum bagged and cured. The internal size of the autoclave is 48 inches by 24 inches which did not end up constraining the design or manufacturing of the wing. The next system, the Unholtz-Dickie shaker table, did not limit the final design because the weight of the specimen would not come close to weight limit of the shaker table which is close to $100 \mathrm{lb}_{\mathrm{f}}$.

Size is also not a limiting constraint to the shaker table as no enclosure exists for the

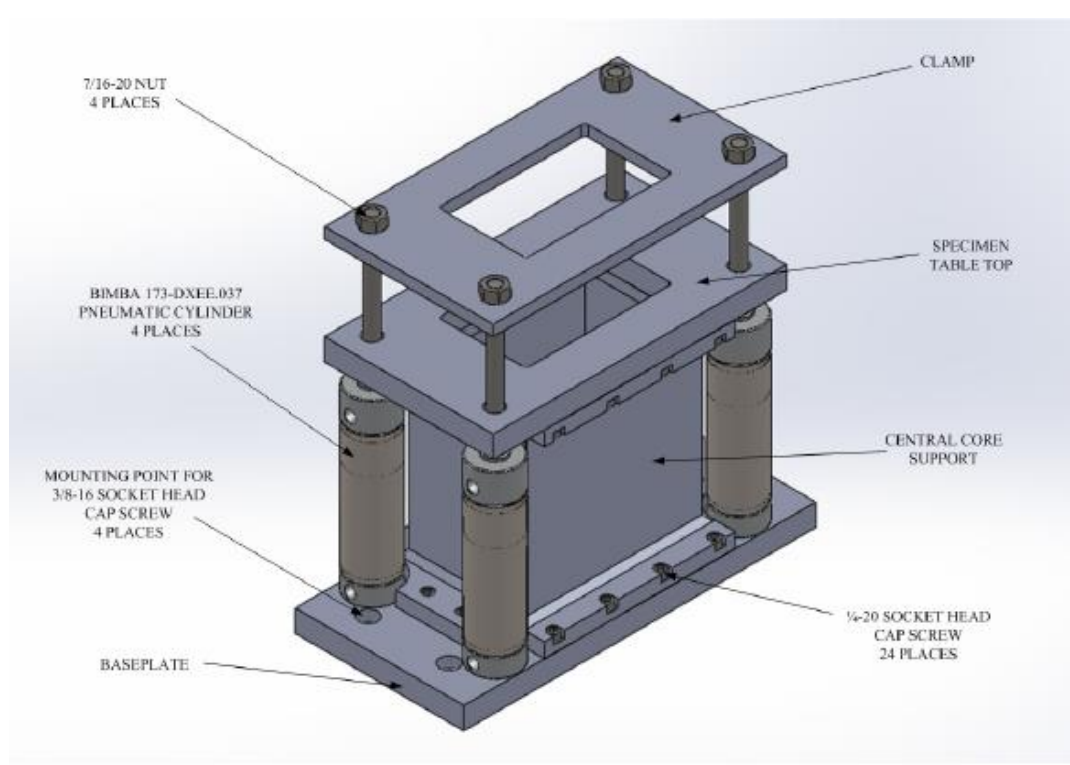

Figure 3.1.1: Solid model of original clamping fixture of Dynatup 8250 [31] 
testing section. The major constraint to this design is the Dynatup 8250 testing section. As discussed in Section 2.2, the Dynatup has a clamping fixture that is used to secure specimen in place during testing. A 3D model of the fixture is visible below in Figure 3.1.1. The fixture works by clamping an upper plate with a 3 inch by 5 inch opening, as per ASTM D7136. The plate is pulled down by 4 pneumatic pistons with a pressure of 60 psi. Because of the piston rails, specimen width is limited to just under 4 inches, and if the length is greater than 7.5 inches, up to a maximum of 10 inches. If the specimen length is less than 7.5 inches, then the width limit expands to 5.75 inches because the specimen will be located inside of the pistons. It is also important to note that whatever wing design is implemented, sufficient room is required for the wing to move laterally in the clamping fixture so that various regions of the structure can be impacted, as previously mentioned in Chapter 1.

\subsection{Design of the Wing}

The wing design was modeled after a simplified version of an aircraft wing used in AERO 433. The wing used is made out of AL 6061-T6 and is used to show how a wing structure reacts to a bending load. The structure consists of two spars, 5 internal ribs with spacing ranging from 4 inches to 4.5 inches, and an outer skin. The airfoil profile is symmetric and generic, but does not conform to a standard NACA airfoil shape and instead has a much more discrete shape (Figure 3.2.1). The 433 wing model has a span of 17 inches and a chord length of 5.8 inches which is too large for the design to mimic on a one to one scale so certain structural aspects of the wing were used in the design. The features that mimicked were the use of two spars, a rib spacing of four inches, and the using steel screws to mount the inner rib for testing. 
The first defined aspect of the wing was what airfoil would be selected. A generic and widely used airfoil, NACA 2412, was selected to be used for this design, because manufacturing of the complex shape would be simplified due to the small chamber of the airfoil. A secondary reason for selecting a simple airfoil shape was because future theses done in the Cal Poly Aerospace Structures/Composites lab would be able to use molds and testing fixtures created for this thesis. After defining what airfoil profile would be used, the chord length needed to be set. The ratio of chord width to wing span of the AERO

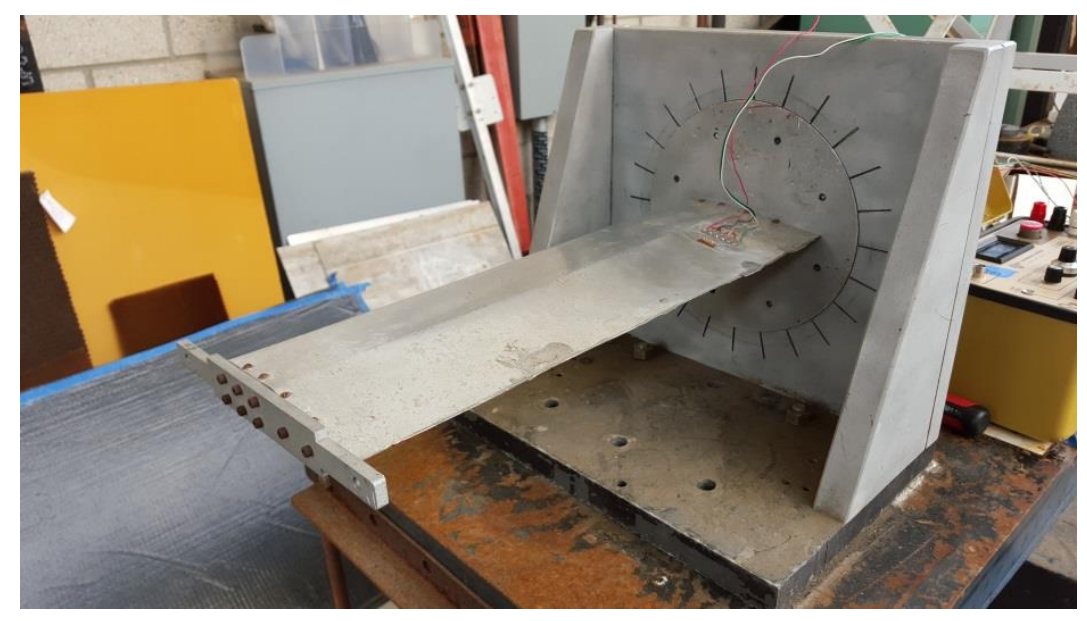

Figure 3.2.1: AERO 433 wing used as basis for wing design

433 model is 2.9 . The ratio of the wing design would to be in the range of this value. Because a rib spacing of four inches was to be used, and the length of the specimen was limited to 10 inches based upon the Dynatup testing section, the span of the wing would be approximately 8 inches. Taking a 9 inch span, and applying the same chord width to span ratio as the AERO 433 design, the chord length of the thesis specimen would be 3.6 inches; however, this width would leave no room for the wing to be moved laterally, which as provided earlier, is not viable for the design. Due to this reason, the chord length was shortened to 3 inches, which gives a span to chord ratio of 2.67 , close to the ratio derived value of 2.9 from the AERO 433 wing design. So far, the major dimensions of the wing have been defined with a chord of 3 inches, a span of eight inches, and a rib spacing of 4 inches as displayed in Figure 3.2.2. Three ribs are present, spaced every 4 inches with a total span of 8 inches. 


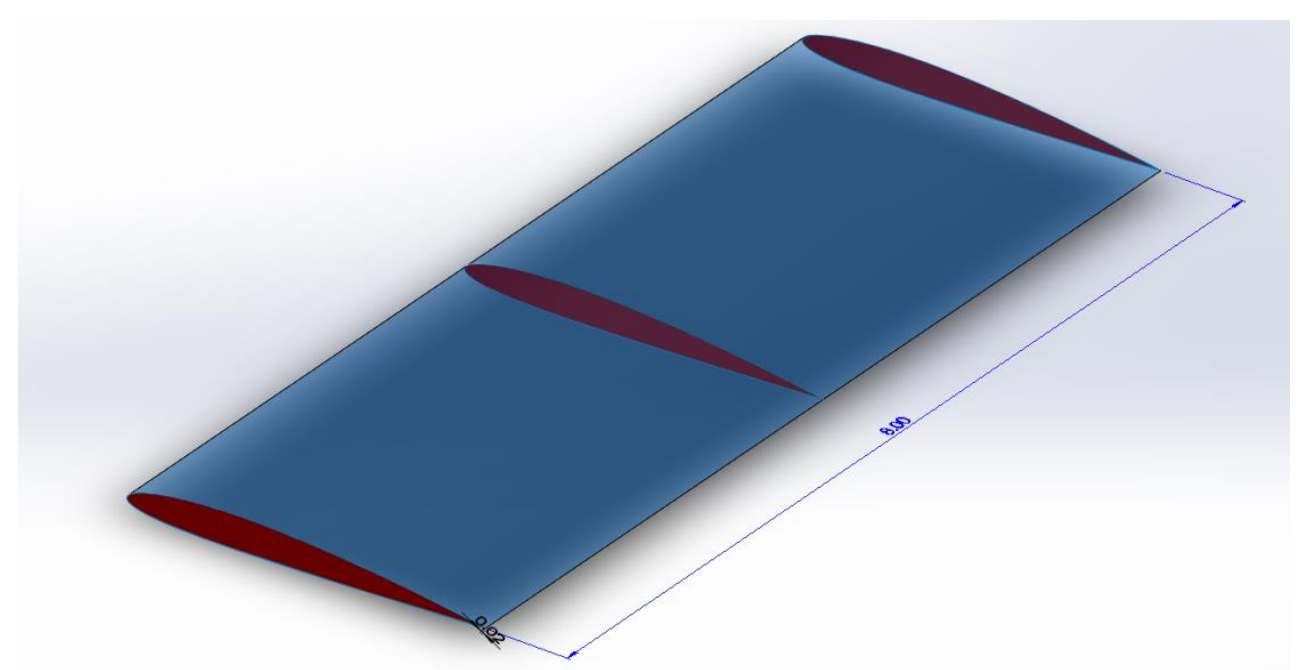

Figure 3.2.2: Isometric view of wing design with ribs shown in red

Now that wing design has a general shape, more of the detailed design work can be done. The cross-section of the spars was the next feature to be defined. There were initially three options being considered: a c-channel, I-beam, and square beam. Each cross-section had positives and negatives and all performed well under bending loads; however, due to the size of the parts that would be created, manufacturing drove the selection of this feature. The square beam cross section would prove to be the most complex manufacturing process. There are multiple ways to manufacture a composite square beam including bladder molding, post-cure adhesion of two halves, or a two-part mold that would require quite a lot of work to unstick the part from the mold. Bladder molding would be the most efficient but because of the size of the part, it was deemed not feasible and a poor investment of the limited resources. Also, the square beam would be a very stiff spar which is not ideal for this design. Due to the short length of the span, the design will need to be as flexible as possible so that the $1^{\text {st }}$ and $2^{\text {nd }}$ mode frequencies can be excited. An I-beam or c-channel as the spar cross section was the best possible design.

The I-beam is a very common cross-section used to carry bending loads and is most easily identified with use as structural supports for tall buildings. An example of I-beams being used for structural support can be seen in Figure 3.2.3. For this application, the layup would be quite complicated. As an under-graduate, I participated in a composite I-beam competition for SAMPE and 
designed a 24 inch long carbon fiber I-beam. The layup for this beam was quite complicated because it consisted of a center laminate for the web, two laminates, one for the top flange and one for the bottom flange, and two c-channels used to connect the web and flanges. Below in Figure 3.2.4 is an example of the layup scheme that would be used. The scheme requires a

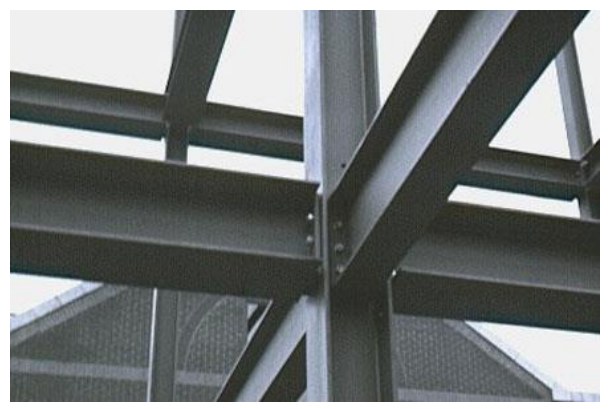

Figure 3.2.3: Use of I-beams in structural supports [26] minimum of two pieces for the mold, one for each c-channel which is not ideal. By far, the simplest cross-section option is the c-channel. It requires a single part for the mold would require a simple layup. This is the most ideal cross-section because it has the lowest number of variables involved in the layup. For the I-beam, there can be many different defects that naturally occur from batch to batch including unevenness between the c-channels causing the flanges to no be parallel and voids occurring along the seams where the c-channels, web and flanges come into contact. The single c-channel part would only require that the plies be held tightly against the male mold during vacuum bagging, which is very easy to ensure because the bag and plies can be adjusted even after a vacuum is pulled. It is much more difficult to ensure that the c-channels in the I-beam design do not shift during bagging because there is no direct access to them. A way around this problem would be to manufacture the I-beam as separate parts and then glue them together; however, this would add unnecessary weight and an additional manufacturing step, which is undesired. For these reasons, the spars used for this wing design would end up being c-channels with flanges having lengths of 0.25 inches. The length of the spars was chosen so that there would be sufficient surface area to glue the spars to the skin effectively. At this point in the design, the internal structure had a basic shape with two sets of c-channel spars, three ribs spaced every 4 inches. The wing skin envelopes the

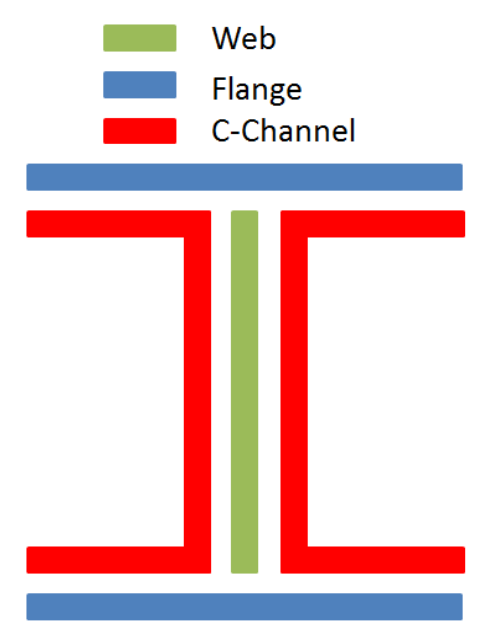

Figure 3.2.4: Example of I-beam layup for manufacturing 
internal structure. Figure 3.2.5 is an isometric view of what the design looks like at this point.

From this, it must be decided how the internal structure will be assembled. One major question is how the rib and spar intersection is handled. One idea was separating the middle rib into three sections with the spar remaining continuous along the span. This requires some form of L-bracket to be used to attach the rib pieces in place during manufacturing. However, this would greatly complicate the assembly of the specimens. Trying to keep the various pieces of the ribs in-line can prove difficult and could introduce a high amount of variation across the specimens. It would also be very difficult to

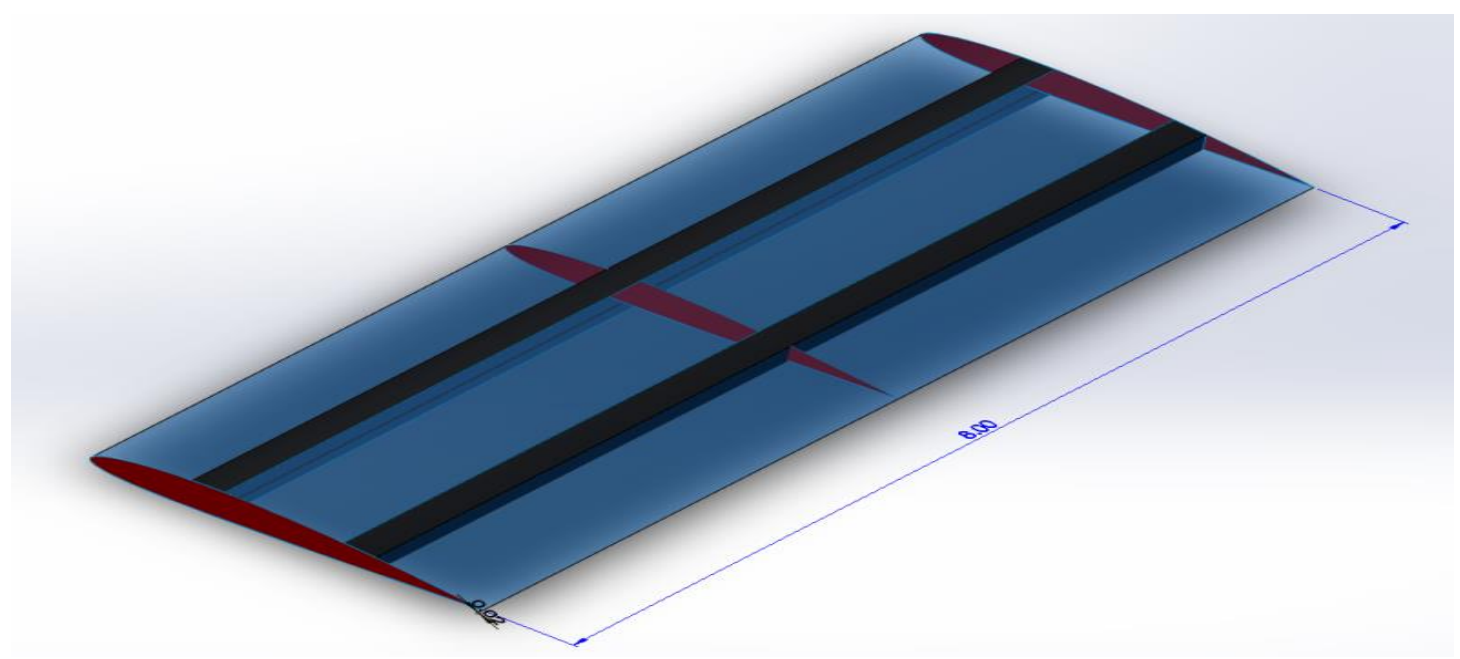

Figure 3.2.5: Isometric view of wing design with implementation of c-channel spars

precisely cut the ribs so the c-channel spars and the middle piece of the rib would fit flush with each other because of how thin the spars would end up. An example of this structure is visible in Figure 3.2.6. The next idea was to use interlocking slits in both the rib and spar. It would make assembly of the internal structure of the wing very simple and quick. However, when testing out this method, it was discovered how difficult it is to line up the slits on the leading and trailing edge spars. If the slits were not lined up, the rib would be skewed, causing variation from wing to wing. This was shown in a prototype build of the wing where the spars had the slits cut and the rib was glued into place. An example of how the rib and spar would interlock and the misalignment of the prototype is displayed in Figure 3.2.7. The third configuration which was used in the final design was to keep the rib intact while 

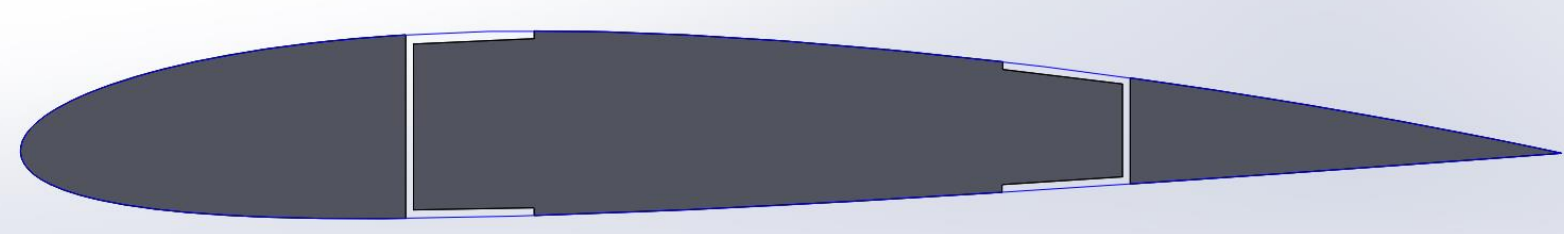

Figure 3.2.6: Example of how rib would be need to cut into three pieces to accommodate a continuous spar

splitting the spar into two 4 inch pieces and using L-brackets to adhere the spar to the rib. This design was used because it is easier to control the parallelism between the two halves of the leading and trailing edge spar. This method did not suffer the same drawback as the first configuration with the ribs being separated into three pieces. No super precise cutting would need to be done so the rib and spars fit together. The 8 inch spars would be simply cut into 4 inch segments and then assembled afterwards, using straight edges and right triangles to maintain alignment. The final internal configuration implemented into the 3D model is displayed in Figure 3.2.8. As exhibited in Figure 3.2.8, L-brackets are shown to be used to connect the spars to ribs internally. The next step in the design was to determine the thicknesses of each part of the design.

In order to determine the appropriate thickness for each a few laminates were manufactured using varying thicknesses ranging from a single ply to six layers. In order to provide as much flexibility to the structure as possible, the spars and skin need to be as thin as possible. The ribs in contrast would need to be thicker because the inter-laminar thickness of the parts would become a factor when gluing the ribs to the skin. After curing each plate and measuring the pliability of each sheet by feel, it was decided that a single layer of LTM45EL would be sufficient for the skin and spars while two layers would be used for the middle and wing tip rib. The root rib would be used to mount the

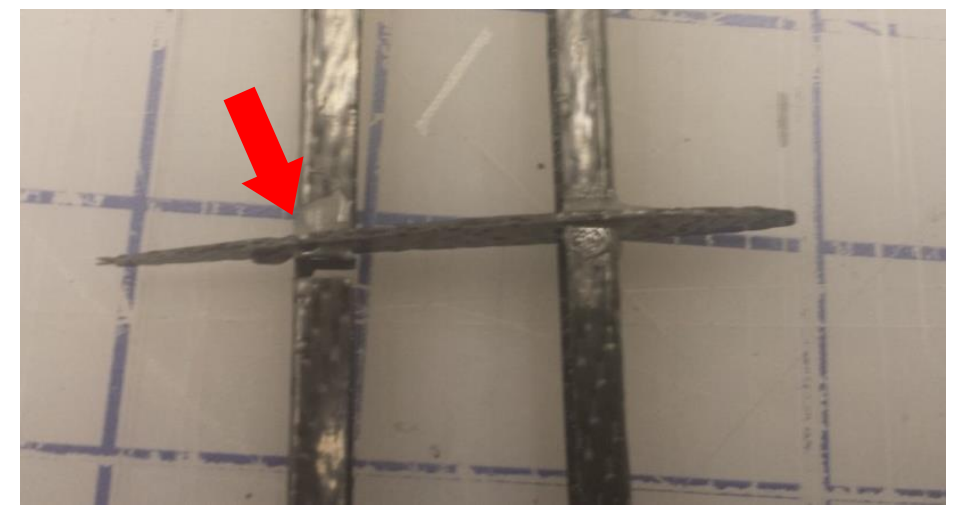

Figure 3.2.7: Misalignment of rib using interlocking method from wing prototype 


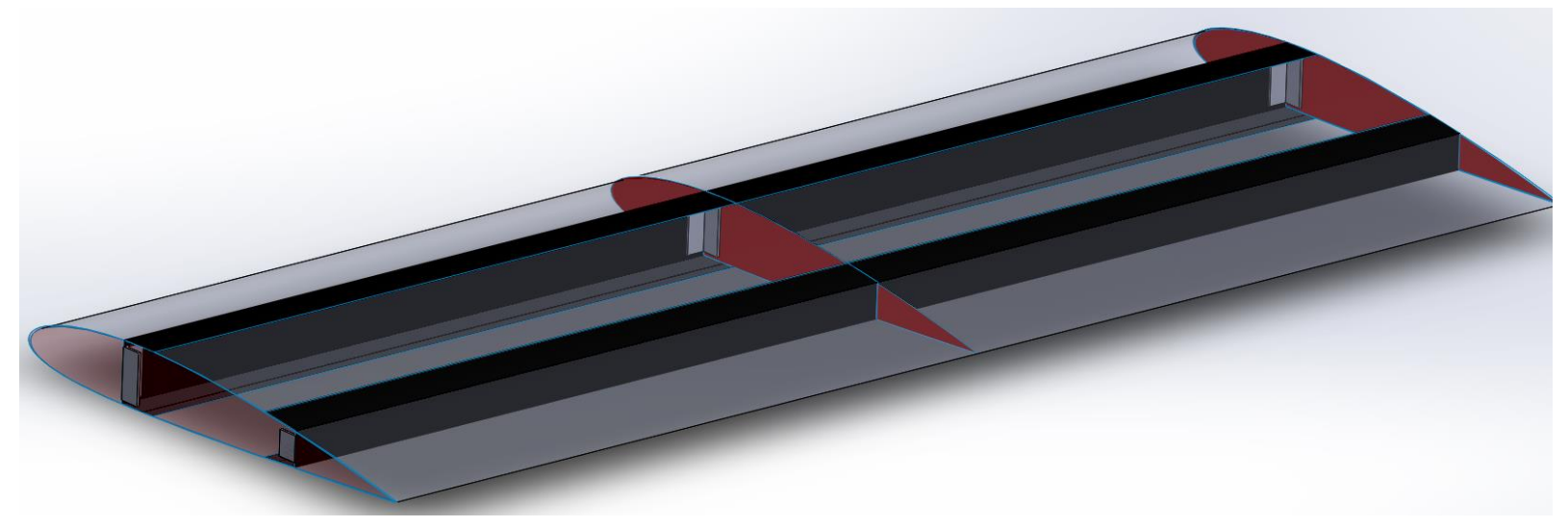

Figure 3.2.8: Isometric view of wing design with implementation of discontinuous spars and l-brackets wing during dynamic testing. It was decided that it needed to be the thickest piece and four layers of LTM45EL were used for the root rib. The reason a single layer of LTM45EL was sufficient was because the LTM45EL roll used for this thesis was thicker than most other weaves in the lab. Typical pre-preg weaves available in the structures lab have a pre-cured thickness of around 0.008 inches such as the MTM49 weave used by Cuauhtemoc Cuna for his thesis. However, the LTM45EL roll had a precured thickness of 0.016 inches. This meant a single layer of LTM45EL would have equal thickness compared to two layers of an MTM49 weave. A drawback was that the overall length of the wing would increase because of the thickness of the ribs would be retained. This decision was made because it would be easier to cut the spars into even 4 inch sections instead of attempting to cut 4 inches minus the thickness of the rib. For this reason, the wing span grew from 8 inches to 8.128 inches. The skin and spars would all have a post cured thickness of 0.016 inches, the middle and outer ribs would be 0.032 inches thick, and the root rib would be 0.064 inches thick.

The next step in the design was to determine how the wing would be mounted for the vibrational testing. Previous cantilever vibration testing done in the structures lab used two metal plates to sandwich one end of the beam and left the

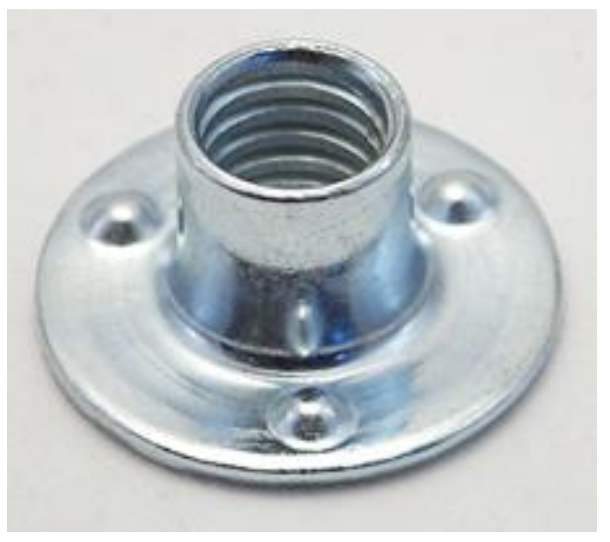

Figure 3.2.9: Weld-nut used in wing design for mounting [27] 
opposite end free. This method cannot be replicated for this experiment due to the hollow internal structure of the wing. There is not enough surface area to effectively fix the root end of the wing with a clamp. So instead of clamping the wing, it was decided that the wing would be held in place using screws and nuts. The best nut to use would be weld nuts because of the large flange at the base of the nut. The flange would serve as a large surface area for gluing the nut to the inner face of the root rib. The screws used were 3 inch \#6-32 machine screws. For a prototype build of the wing design, two weld nuts were glued to the internal face the root rib and two holes were drilled into the root rib to allow machine screws to thread into the weld nuts. Figure 3.2.10 displays the weld nuts glued to the mounting rib and the spars glued to the mounting rib using carbon L-brackets for the prototype build of the wing design. Visible in Figure 3.2.10, the weld nut flanges had to be trimmed to match the airfoil profile of the rib. Performing this does not reduce the effectiveness of the weld nuts. During testing of the prototype wing, it was found that only using screws to hold the wing in place was not sufficient as the screws needed to be retightened after a few runs. It was determined during vibrational testing; the machine screws were slowly loosening due the torsional load applied to the fixed end. A wing does not have a symmetric cross-section, there is some torsional loading on the machine screws and over time this caused the screws to loosen. To fix this, the wing skin was extended past the root rib by 0.25 inches, extending the skin length to 8.378 inches. This change coincided with a change to the mount used to fix the wing during vibrational testing. The design of the testing fixture will be elaborated on in Section 3.4. The overhang of the wing skin is used to clamp the skin and reduce the torsional load applied to the mounting screws.

In summary, the design of this wing was driven by space requirements from the Dynatup 8250 impact testing machine as well as an emphasis on the

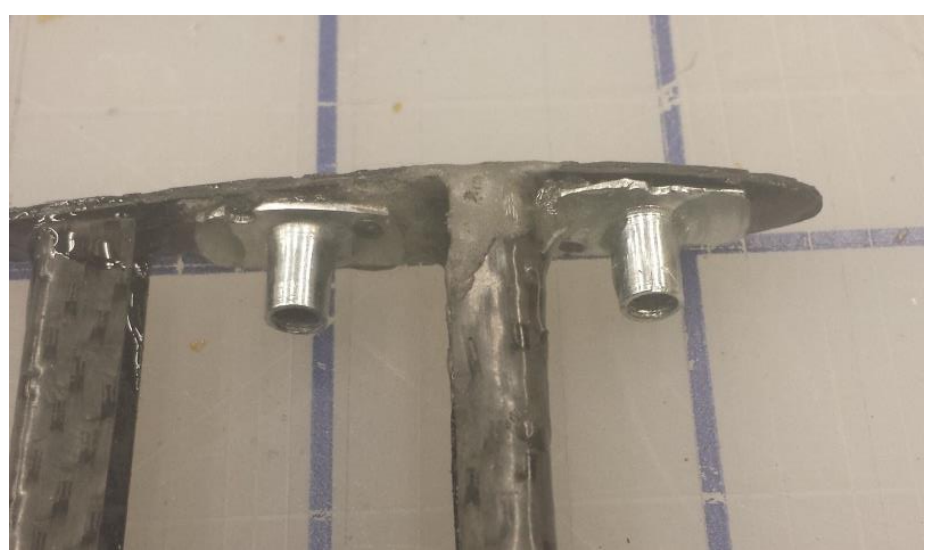

Figure 3.2.10: Weld-nuts applied to mounting rib of prototype wing design 
ability to manufacture and assemble the design. For real world applications, designing to manufacturing is ideal to adhere to when designing a system and it extended to this design. The final design features a NACA 2412 airfoil profile, an 8.128 inch wingspan, a 3 inch chord length, three ribs spaced four inches apart from each other with the innermost rib being twice as thick to support mounting of the specimen during testing, as well as two sets of 4 inch spars resting between each two ribs and being held in placed using carbon fiber L-brackets and Magnolia 56 A/B structural adhesive. A 3D model of the final design can be seen in Figure 3.2.11. Detailed drawings for each part and the assembly drawing are also in the Appendix.

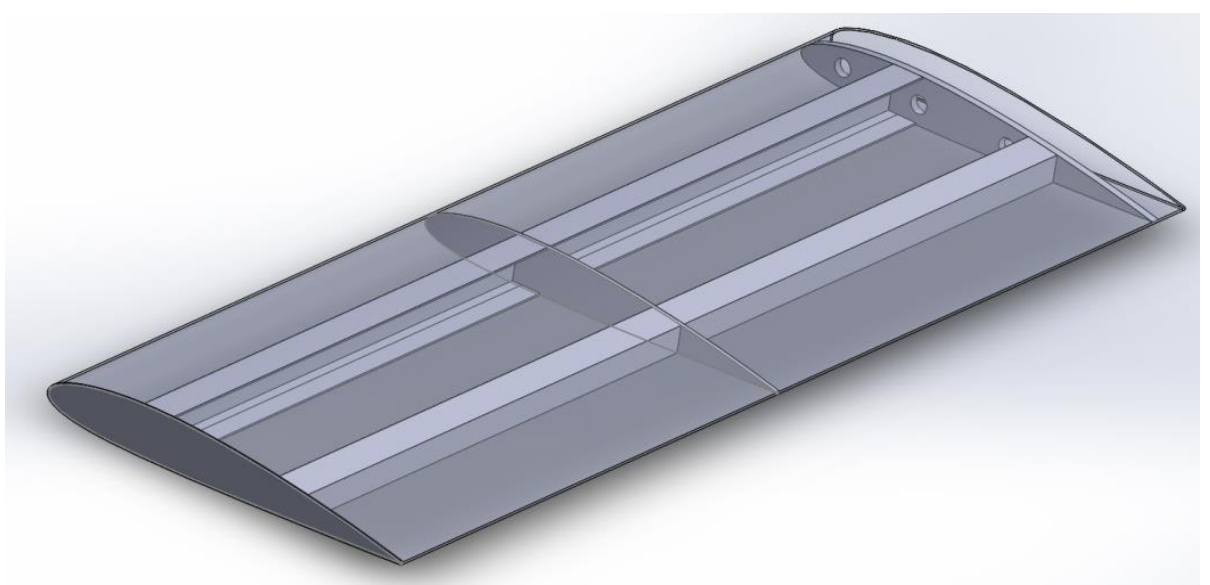

Figure 3.2.11: Wing design with implementation of mounting rib and skin overhang

\subsection{Design of Various parts for Dynatup 8250}

Three different parts were designed and manufactured for the impact tester, the first was a new clamp fixture designed to increase the allowable specimen width for testing, the second was a fixture designed to correctly constrain the current load cell, and finally, a fixture was designed to hold the wing specimen and evenly distribute the clamping force across the wing skin. All fixtures were created from 6061-T6 aluminum. 


\subsubsection{Dynatup 8250 Specimen Clamping Fixture}

As stated in Chapter 2, Daniel Barath designed and created a fixture for his senior project. The fixture was designed to mount into the Dynatup 8250 's existing mounting holes and incorporate a pneumatic clamping system to hold the specimen in place. ASTM D7136 specifies the use of toe-clamps to hold specimen in place for testing, however, the switch to pneumatic clamping was desired by Dr.

Elghandour, the advisor to this senior project. The fixture was designed to withstand the largest possible impact force the Dynatup 8250 could generate $\left(\sim 31000 \mathrm{lb}_{\mathrm{f}}\right)$. The fixture featured a base plate which mounted to the base of the Dynatup 8250. Above this was the core support that provided a raised the platform where the specimen was placed and created a hole for debris to fall into. Next was a table top where the specimen was placed. Finally, a plate that was used to clamp the specimen into place was connected to the four pneumatic pistons. The pistons apply a clamping pressure of $60 \mathrm{psi}$. There was a 3 inch by 5 inch opening cut into both upper plates and the core support which was completed to match the opening used in ASTM D7136.

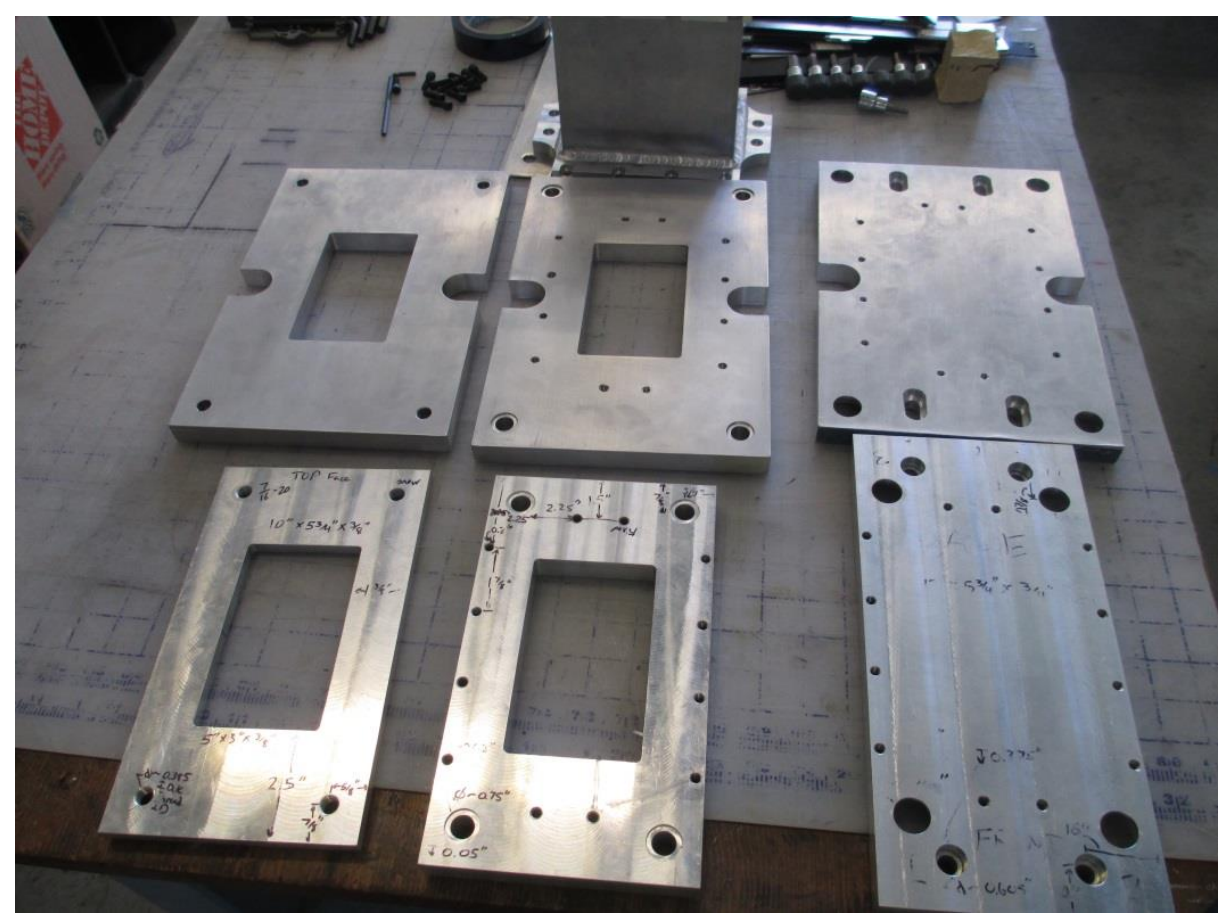

Figure 3.3.1: Old and new plates for Dynatup 8250 specimen clamping fixture 
The major reason this fixture was redesigned was to allow proper clearance for the wing to move so that the impact tup could be aligned over the appropriate strike point. The previous fixture only allowed a specimen width of 4 inches which matches ASTM D7136. In order to accommodate the testing parameters, the width needed to be opened up past 4.5 inches so the wing could properly align. The new fixture design closely resembles the older fixture and even reuses the core support part. The clamp plate, table top plate, and mounting plate were all enlarged. The width was increased from 5.75 inches to 8 inches. This change allowed the pneumatic cylinders to be moved outward by an inch each, increasing the allowable specimen width to 6 inches. The larger width was determine based upon available room in the Dynatup 8250, as well as allowing future theses and projects to increase specimen sizes. The three plates were machined by Kyle Rosenow using the aerospace departments CNC Endmill and were installed into the Dynatup 8250 upon completion. Drawings for the machined plates are located in the Appendix. The original plates and new plates can be seen in Figure 3.3.1

\subsection{2. $\quad$ Redesign of Load Cell Mounting}

The load cell that is currently used with the Dynatup 8250 is a THD-3K-W load cell. The load cell is used to obtain a force versus time plot of the impact. The load cell has a maximum force rating of $3000 \mathrm{lbs}$ with an accuracy of $+/-1 \%$ of the measured force. The load cell is a thru-hole donut load cell consisting of a connected inner and outer cylinder and incorporates a full bridge circuit and uses strain gages in the region connecting the inner and outer cylinders to measure the force applied. This means that a load is measured by the differential displacement of the inner cylinder to the outer cylinder. However, previously, the load cell was loaded only using the thru-hole, leaving the outer cylinder unconstrained (Figure 3.3.2). From Figure 3.2.2, the inner outer cylinder has no bracing and so cannot effectively measure any impact force. Because the load cell was not constrained properly, any force measurement was inaccurate and did not represent the true impact force. What was measured was the inertial force of the out cylinder slowing down upon impact. In order to obtain true force values, the load cell needed to be re-constrained so the inner and outer cylinders were independently constrained. It 
is unclear why the load cell was previously constrained improperly or why it was never examined or tested.

In order to correctly capture the load cell, a capsule was designed where the outer cylinder would be held in place, while the impact tup would apply a load to the internal cylinder. Some limitations to the design were weight minimization to add as little weight as possible to the apparatus, the ability to mount to the existing rail, and limiting overall size so the fixture is not hard to install and does not affect the overall performance of the testing apparatus. The design process for the fixture began with defining what was necessary to be constrained and how the impact tup, load cell, and rail would all fit together. The tup would need to be loaded against the inner cylinder and held in place with a nut while the load cell would be only

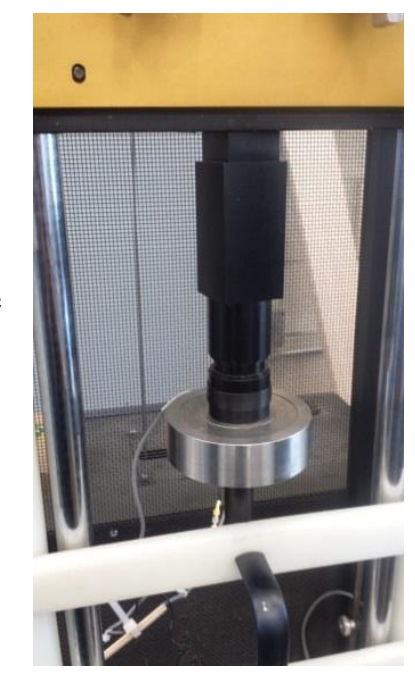

Figure 3.3.2: Original constraining of load cell showing outer cylinder of load cell being unconstrained have the outer cylinder fixed. This was performed by creating a two piece fixture, with a base mounting to the existing rail system, and a lid clamping the load cell into place. The base would end up being the heaviest addition to the rig because of the need to carry the impact force. The outer cylinder is fully fixed meaning that load of the impact is transferred completely from the inner cylinder to the outer cylinder, thus causing the actual force to be measured.

The final design is visible in Figure 3.3.3. The fixture has an outer diameter of 4.5 inches and is designed to lock into the existing rail via a $1 \frac{1}{2}-13$ threaded-hole and a rectangular extrusion for clocking purposes. The base of the fixture is 1.1 inches tall and features $8 \frac{1}{4}-20$ threaded holes spaced evenly around the circumference at 4 inches from the center. Also, a $1 / 4$ inch channel was milled out to allow passage of the load cell cabling. In order to save weight, there were 8 pockets milled out along the outer edge of the fixture. These pockets lead to a weight savings of approximately $0.2 \mathrm{lbs}$. The clamping portion of the load cell features 8 thru-holes indexed to mirror the threaded holes of the base. There is also a large round applied to the outer edge to also reduce weight. The hole in the clamping portion of the fixture was designed to only interact with the outer cylinder. Size was a limiting factor to the design, 
the impact tup needed to be blocked so that the threaded portion could be secured inside the base, but not restrict the deflection of the load cell. A gap of approximately 0.1 inches was left between the end of the threads for the tup, and the bottom face of the seat. A specially made nut was used to secure the tup in placed. Any store bought nut with the appropriate thread size would be too tall to fit into this combined space so Kyle Rosenow used some spare aluminum to turn a 0.25 inch nut that would be used to secure the tup in place. There was no consideration given to proper thread engagement for the nut and tup because the nut would only need to support the impact tup and washers used to step the tup outboard from the load cell. An

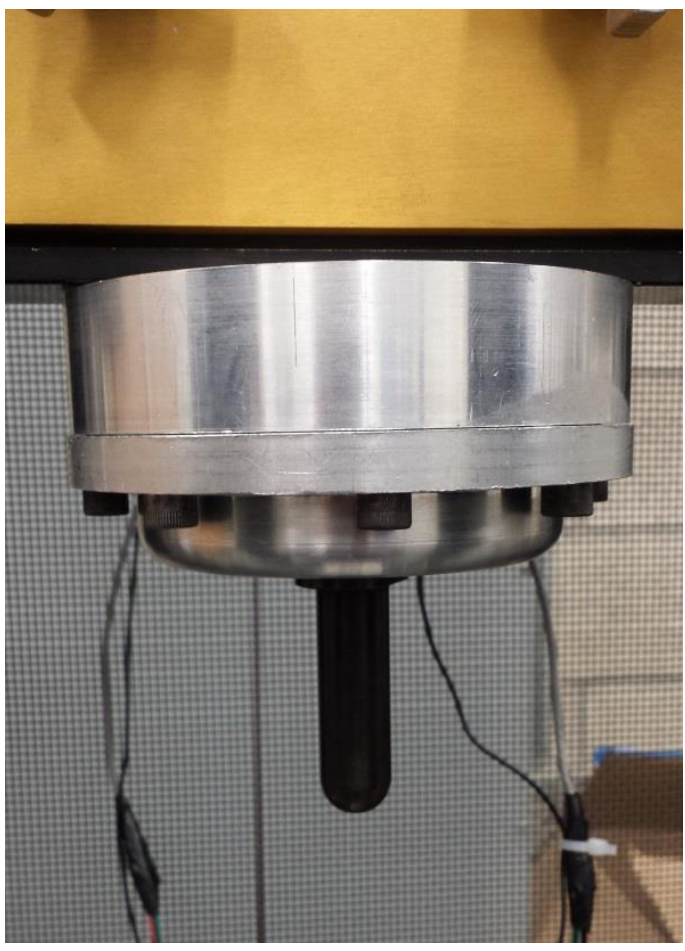

Figure 3.3.3: New load cell fixturing for Dynatup 8250 impact tester exploded view of the new load cell mount can be seen in Figure 3.3.4.

Instead of creating a new fixture, additional options were explored such as replacing the current load. The available options for replacement included a new strain gage based load cell that would have the impact tup thread into one face while being mounted to the rail using the opposite face. A second and more preferable option would have been the purchase of a piezoelectric based load cell. When calling Transducer Techniques, the company that manufactured the current load cell, the representative said when a load cell is used for dynamic load cases such as impact, piezoelectric load cells perform much better. A piezoelectric load cell has a higher overload threshold when compared to a strain gage based load cell. However, piezoelectric load cells are quite expensive and do required the additional use of an amplifier. The new fixture was created for just under $\$ 60$ for the raw materials. 


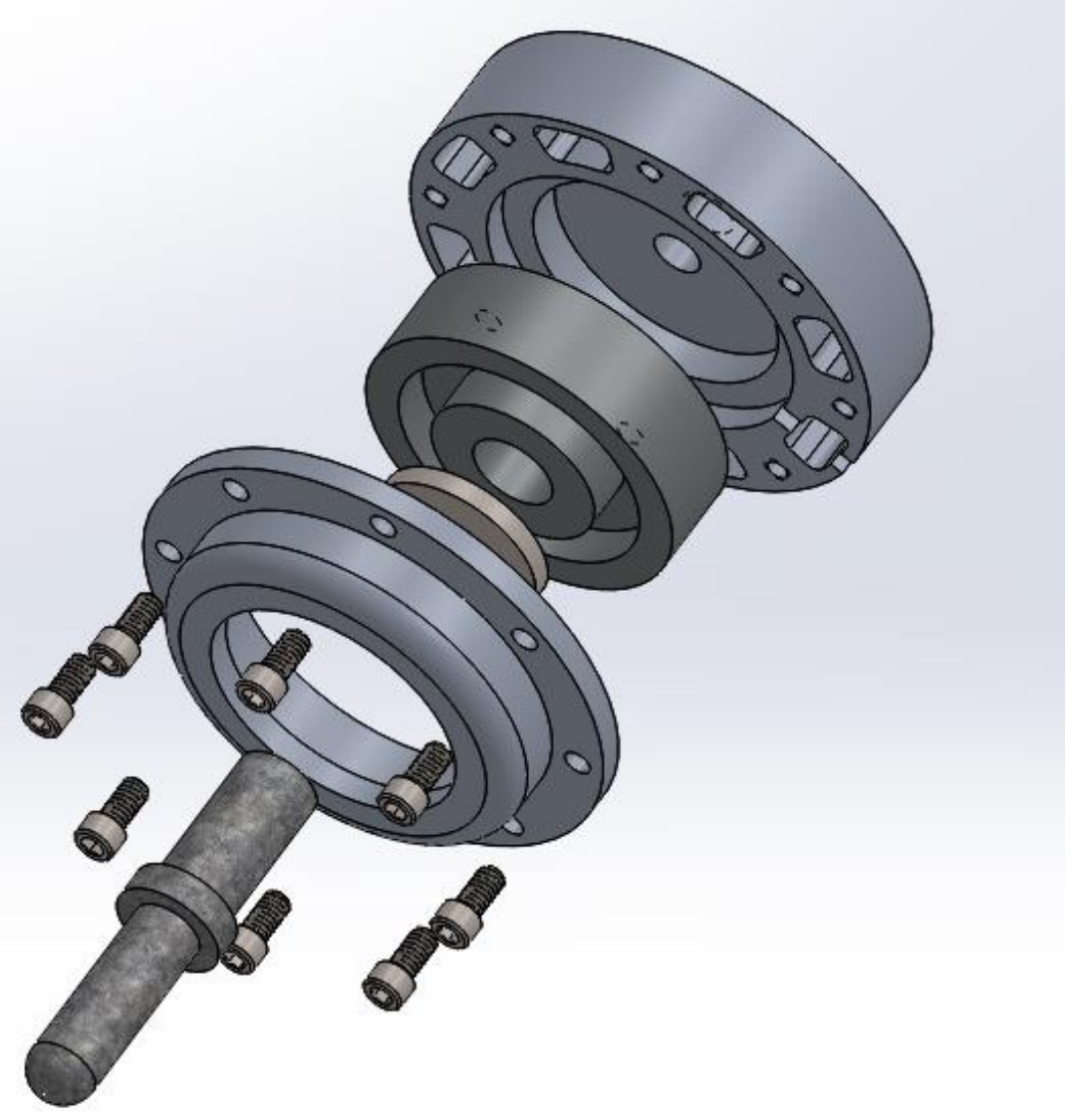

Figure 3.3.4: Exploded view of new load cell mount to properly measure impact force

\subsubsection{Wing Fixture}

The wing was constrained during the impact tests using two 6061 aluminum bars with the upper and lower profiles of the wing milled out. The purpose of this fixture is to firmly secure the wing for testing without creating stress concentrations. If the wing was clamped without the use of the fixture, the wing would be crushed because the pressure force would be concentrated on the thickest portion of the airfoil ruining the specimen before any testing was even done. The fixture was designed to secure the upper and lower portions of the airfoil while also using a flat face on the outer edges of the fixture as 
stops so the wing was not compressed beyond its static shape. The fixture was machined on a CNC end mill by Allen Captina. The CAD model is visible in Figure 3.3.5.

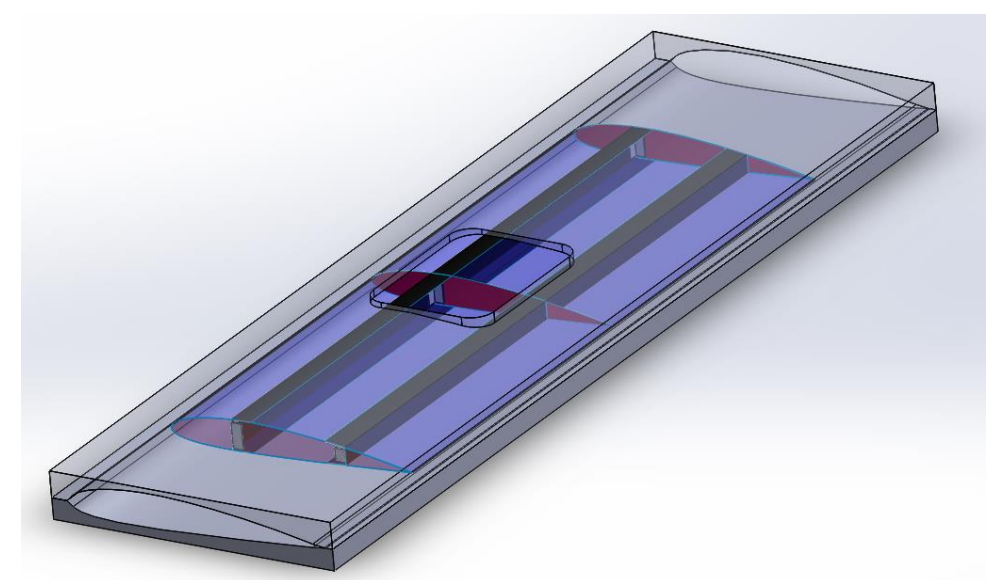

Figure 3.3.5: CAD model of how win will be fixed in place during impact testing

\subsection{Design of Vibration Testing Fixture}

Testing the wing design on the shaker table presented a challenge because the structure is hollow and applying a clamping force to the hollow wing would create stress concentrations in the region where the skin and rib come into contact, possibly causing damage. The innermost rib was designed thicker than the other two ribs; so this rib could be used as an anchor when holding the wing to the fixture. The first fixture created was a simple bar of aluminum 6061 with two holes drilled into the side to bolt the wing and two holes drilled through the top to mount the fixture to the shaker table. As mentioned earlier in Section 3.2, the first attempt at the mount showed many different problems that needed to be fixed before the final testing could be completed. The plan to reduce the torsional stress on the bolts as mentioned earlier was to extend the skin beyond the innermost rib by $1 / 4 \mathrm{inch}$. The fixture used to mount the wing during testing is displayed in Figure 3.4.1. The purpose of the design is to bolt the face of the inner rib to the middle plug and then use the upper and lower halves of the mold to clamp down onto the overhanging skin and reduce the torsional loading on the bolts. A third bolt hole was added at the suggestion of Dr. Elghandour to distribute the load more evenly across the rib. The bolt holes were placed so that they would not interfere with the mounting of the spars with the hole closest to the leading 
edge being in front of the leading edge spar and the other two holes being placed between the leading and trailing edge spars.

To mount the wing, the middle plug is placed face to face against the inner rib and then the wing and plug are placed into the bottom half of the fixture and three screws are threaded through the bottom half, plug, and into the weld nuts glued to the inner rib. The screws are then hand tightened being careful not to over-tighten and cause damage to the

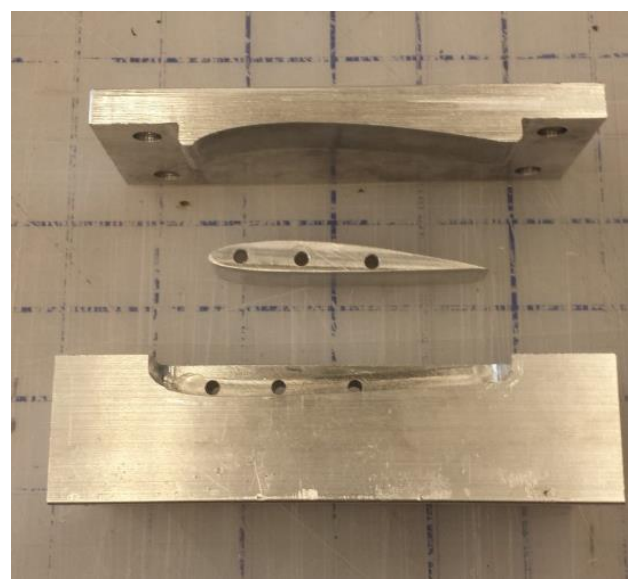

Figure 3.4.1: Front view of 3 piece mount used to constrain wing during frequency sweep inner rib. In Figure 3.4.2, the plug is seen resting in place on the bottom half with the screws in place. The four outer holes are steel threaded key-inserts. The inserts are used along with bolts to clamp the upper half of the mold down over the plug and skin overhang, locking the skin and preventing any rotational displacement. The inserts were used over just threading the aluminum of the bottom half due to concerns that over time the wear and tear from repeated testing would cause the aluminum threads to be ineffective. Threaded inserts are used to directly stop this from occurring. They are put into place by machining a large thread that matched the outer thread of the insert and then threading the insert into the hole. The reason for selecting threaded inserts is because this is currently used on the shaker table mounting surface. The only different between what was used on the mount and what is used on the table mounting surfaces is that key-inserts instead of HeliCoils were used. HeliCoils are coiled steel inserts that are threaded and locked into place using any available thread lock glue. What were used for the mount were ACME key-inserts. These inserts operate the same way as HeliCoils except they are a little bit more robust and use pins that are driven into the material after installation to lock the insert in place. Figure 3.4.3 displays a comparison of HeliCoils and key-inserts. The two counter sunk holes in Figure 3.4.2 were used to bolt the entire fixture to the testing table. 


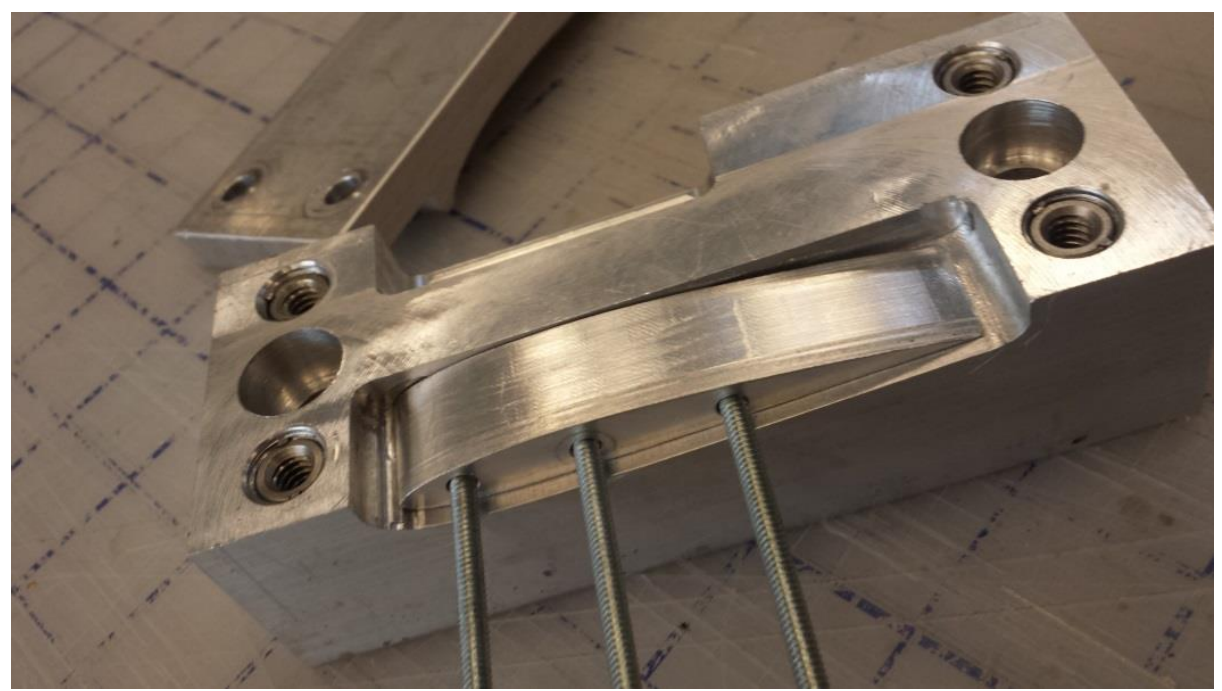

Figure 3.4.2: View of how aluminum plug and screws fit onto mount

Once the fixture was designed and manufactured, it needed to be tested to determine any of its natural frequencies were excited during the sinusoidal sweep the wings would be tested under. The reason this was done was to verify that the fixture did not interfere or skew the testing results. To mount the fixture, the base is first bolted to the shaker table with two black phosphate coated bolts found in the drawer behind the table and tightened to $25 \mathrm{ft}-\mathrm{lbs}$. The plug is placed in the carrier of the bottom half and the screws are pushed through to restrict movement of the plug. For testing the mount, three individual weld nuts were used to hold the plug in place. The final step is to bolt down the upper portion of the mount. The mount testing went quickly and no signs of resonance were seen. Testing was done by placing accelerometers over various places of the mount and measuring the frequency response. No natural frequencies were detected during any of the test runs for the mount (Figure 3.4.4). For the entire sweep, from 10-2000 Hz, the accelerometers measured the same response acceleration as was being generated by the VwinII software. In the figure, the various lines represent accelerometer measurements around the mount.

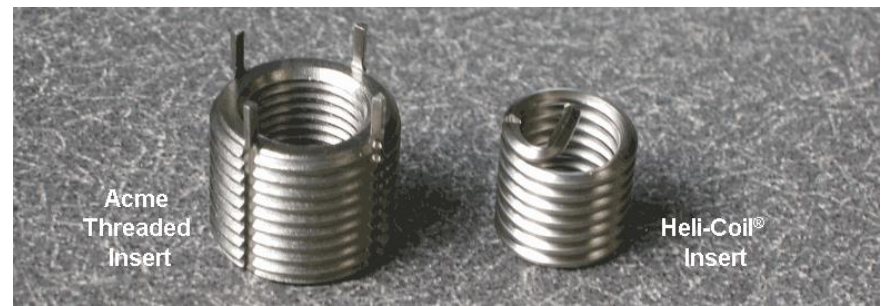

Figure 3.4.3: Heli-coil versus Thread insert [28] 


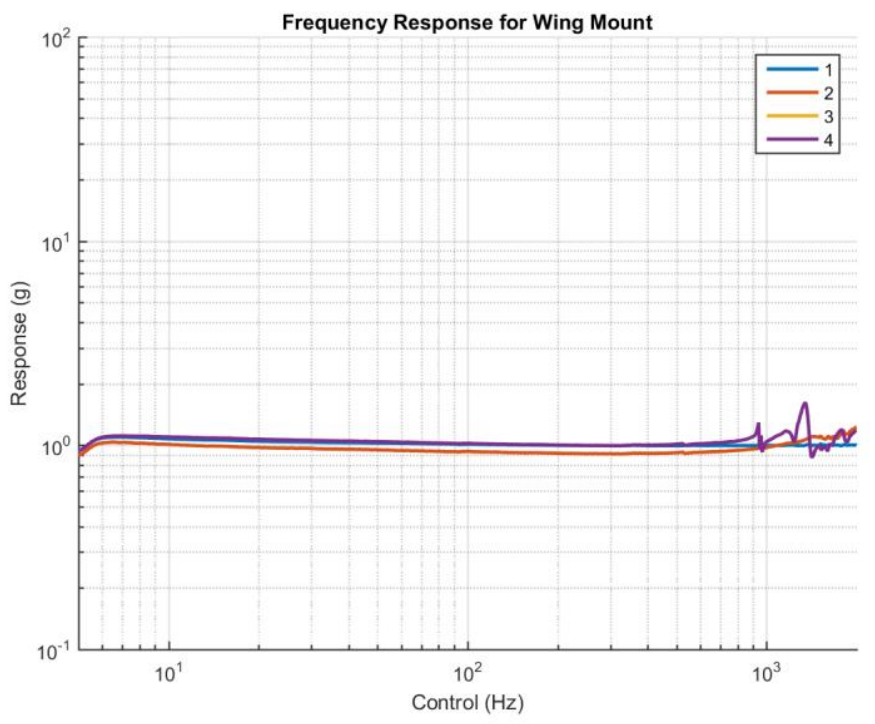

Figure 3.4.4: Frequency response of wing mount to ensure there is noe modal excitations during test sweep 


\section{Specimen Manufacturing}

This chapter covers the manufacturing process for the wing design. First, a test was done to determine the best cure cycle to be used for part manufacturing throughout this thesis project. Afterwards, the manufacturing method for the skin and the testing done will be presented. The third topic goes over the manufacturing of the internal structure parts (i.e. ribs and spars). And finally, this chapter will end with a look at the assembly process for the wing design.

\subsection{Curing Cycle for LTM45EL}

The cure cycle used for this thesis was selected by first curing various plates of LTM45EL using the heat press located in the lab to cure each plate.

The material data sheet (MDS) for LTM45EL listed various different cure cycles with varying soak temperatures and times [8]. Table 4.1-1 displays the various cure cycles that were available. Due to the resources required to run the autoclave (e.g. water, air, energy) as well as the having to be in the lab while the autoclave is running, a cure time of 24 hours was rejected.

Table 4.1-1: Various available cure cycles for LTM45EL based on material datasheet

\begin{tabular}{|c|c|}
\hline Temperature $\left({ }^{\circ} \mathrm{F}\right)$ & Cure Time $(\mathrm{hrs})$ \\
\hline 122 & 24 \\
\hline 140 & 9 \\
\hline 158 & 7 \\
\hline 176 & 4 \\
\hline 194 & 2 \\
\hline 248 & 1.5 \\
\hline
\end{tabular}

Ideally, a cure time of less than a few hours would

be selected as it would equate to a very fast turnaround time for curing. It would also mean a quick manufacturing for all of the required assembly pieces. After curing a single plate for 1.5 hours at $248^{\circ} \mathrm{F}$ using the heat press in the aerospace composites lab, the quality of the laminate was so poor that this cure cycle was rejected. Next, 4 different plates were created using the remaining four cure cycles. Each plate was cut into thin strips and then tested dynamically on the shake table, impacted from 12 inches, and then tested dynamically again to see if the damping ratios for the first and second mode of the strips had changed. The results are listed in Table 4.1-2. From testing, it was shown that for the first 
mode, there is a small change for the damping ratio. For the second mode damping ratio, the change is much more drastic. The damping ratios for the pre- and post-impact tests are showcased in Table 4.1.2. Based on this data, and on a visual inspection of the laminates, a 7 hour, $158^{\circ} \mathrm{F}$ cycle was chosen. The 7 hour cycle was chosen because it showed the largest variation for the first and second mode damping ratios. Figure 4.1.1 is a plot of the cure cycle selected.

Table 4.1-2: Damping ratio results from initial cure cycle study to determine optimum cycle for study

\begin{tabular}{|l|l|l|l|l|l|l|}
\hline Damping & $1^{\text {st }}$ mode & $1^{\text {st }}$ mode & $\%$ & $2^{\text {nd }}$ mode & $2^{\text {nd }}$ mode & $\%$ \\
Ratios & pre impact & post impact & Difference & pre impact & post impact & Difference \\
\hline $2 \mathrm{hrs}$ at & 0.0225 & 0.0222 & 1.33 & 0.0215 & 0.0220 & 2.36 \\
\hline $4 \mathrm{hrs}$ at & 0.0225 & 0.0219 & 2.67 & 0.0222 & 0.0252 & 13.51 \\
$176^{\circ} \mathrm{F}$ & & & & & & \\
\hline $7 \mathrm{hrs}$ at & 0.0228 & 0.0221 & 3.07 & 0.0204 & 0.0223 & 9.31 \\
$158^{\circ} \mathrm{F}$ & & & & & & \\
\hline $9 \mathrm{hrs}$ at & 0.0225 & 0.0219 & 2.67 & 0.0205 & 0.0223 & 11.71 \\
$140^{\circ} \mathrm{F}$ & & & & & & \\
\hline
\end{tabular}
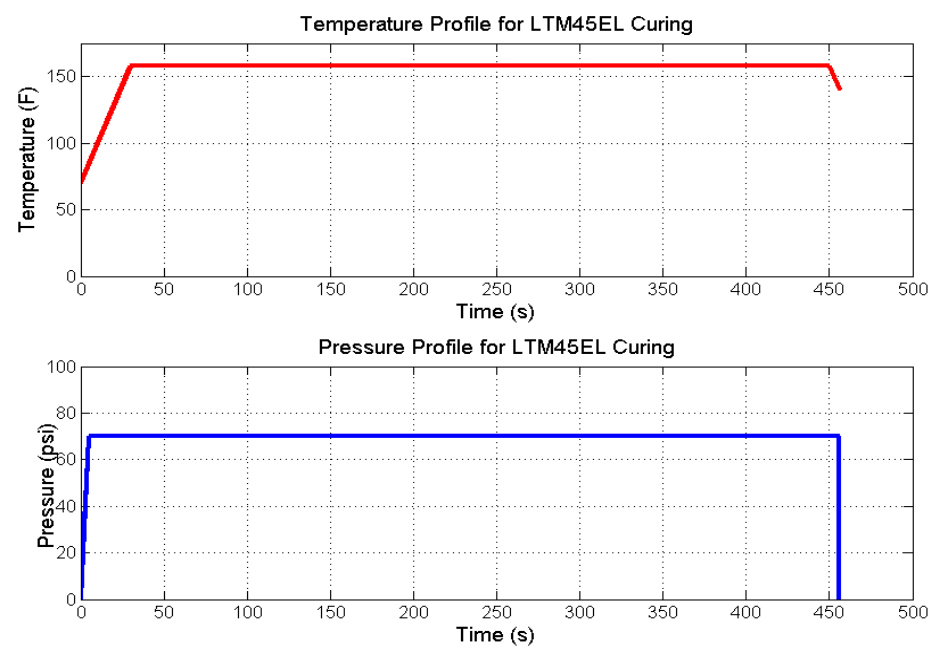

Figure 4.1.1: Temperature and Pressure profile for autoclave curing cycle of LTM45EL 


\subsection{Manufacturing of the Wing Skin}

There were multiple ideas as to how the wing skin could be manufactured. The various ideas included: creating a top and bottom half of the skin and then gluing together post-cure, a three-part construction, and using a single sheet and wrapping around a male plug. The idea used to manufacture all of the wings skins for this thesis was a single ply of material wrapped around a male plug. This concept was chosen because it had the lowest manufacturing complexity out of the three various options. The way this technique would work would be to wrap the carbon around a male plug that was machined to match the NACA 2412 airfoil profile starting at the trailing edge and wrapping the material across the bottom face, around the leading edge, and then connecting again at the trailing edge after enclosing the upper surface of the mold. The circumference of the airfoil is over 6 inches and the wingspan over 8 inches; sheets of carbon were cut into 8 inch by 10 inch squares. Having excess material in a layup is standard practice for any composite manufacturing process because it is important to drive edge effects away from the desired part. As stated in Chapter 3.2, a single sheet of material would be used for each wing skin manufactured. One problem with manufacturing the skin this way was any excess material on one end of the sheet would come into contact with the other end of the sheet after wrapping around the mold. If the two sheets were allowed to come into contact, they would cure together in the autoclave. The solution to this problem was to place a single sheet of non-porous teflon coated film around the aluminum mold. The size of the sheet was one inch longer than the composite ply in both the length and width and separated the carbon from both the aluminum mold as and itself. This had the added bonus of not requiring constant application of mold lubricant to the aluminum every few cures. Also, the Teflon film was able to last multiple cures before degrading to a point insufficient for use, making it the most functional. The lifespan typically lasted three to four cure cycles. Though it became the most favorable option, this concept needed to first be proven before it would be used to manufacture all of the wing skins. 
To prove this was the

desired option, a single sheet of

LTM45EL was wrapped around a

scrap piece of wood following the

same method described above.

Displayed in Figure 4.2.1 is the

carbon wrapped around the wood

block with the vacuum bag sealed

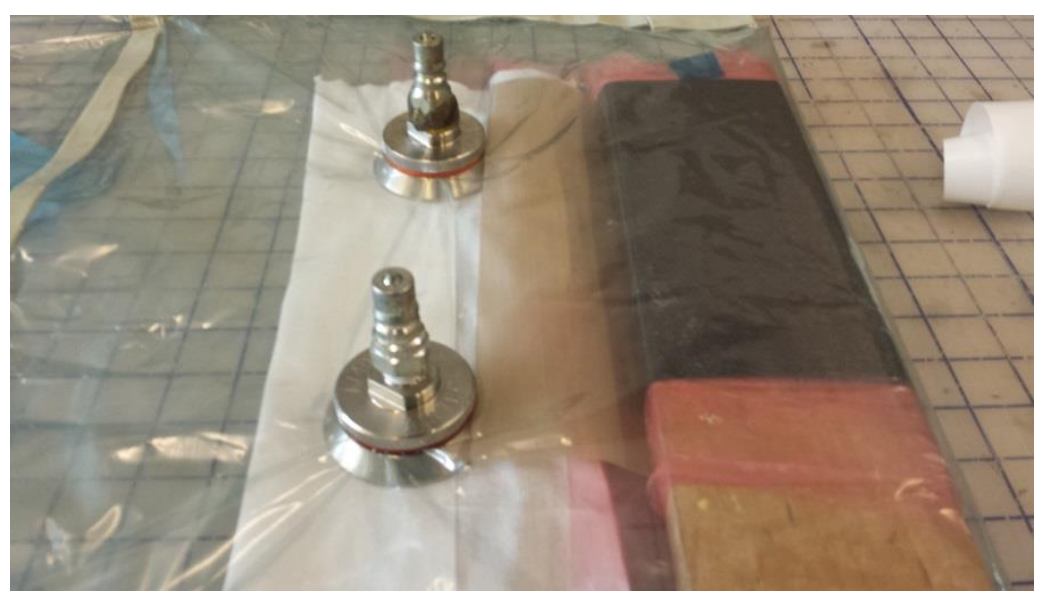

Figure 4.2.2: Vacuum bag of experimental cure to determine validity of proposed manufacturing method of the wing skin and ready to be de-bulked. The

brownish sheet between the block and nozzles is the Teflon sheet used to prevent the carbon from coming into contact after wrapping. The result of this test is shown in Figure 4.2.2. A very important lesson learned from this test run was that corners where carbon has to turn require a large amount of attention during the de-bulking step before being placed in the autoclave. If care is not taken during the layup and de-bulking, the carbon can begin to slide and create unwanted crease in the part. The reason this crease occurs is because during de-bulking, the last areas becoming pressurized are corners and areas with abrupt slope changes, such as the corners of the wood block or the leading and trailing edge of the wing. To prevent this from occurring, de-bulking is broken down into multiple quick steps with small amounts of air being pulled from the bag, adjusting the bag and carbon so that the sheet is wrapped very tightly around the mold, and then pulling more air out. This process is repeated multiple times until the bag has all air removed. Once the air is entirely removed, the sheet would be worked to ensure the sheet is wrapped around the mold as tightly as possible. This was done by beginning at the leading edge of the mold, and massaging the material, pushing and excess material towards the trailing edge of the wing. Figure 4.2.3 displays a wing skin bagged and about

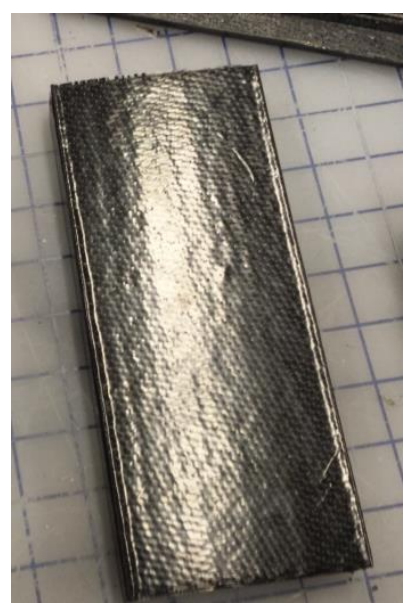

Figure 4.2.1: Successful test of manufacturing method of wing skin with carbon being removed from mold with ease 
to be cured in the autoclave. The pink film is used to facilitate airflow from the carbon to the white cotton sheet on the right side of the figure. This film is a form of breather material dotted with holes. If this film was not used, then air could get trapped under the carbon or teflon film below meaning the part would need to be scrapped. All wing skins were manufactured this way.

The wing skin mold, as seen in Figure 4.2.4, was machined from AL 6061-T6 by Kyle Rosenow in the Aerospace Departments CNC end mill. The wing was machined by first cutting a rough profile of the upper surface of the wing and then using a smaller bit to cut a finer profile. The reason for starting

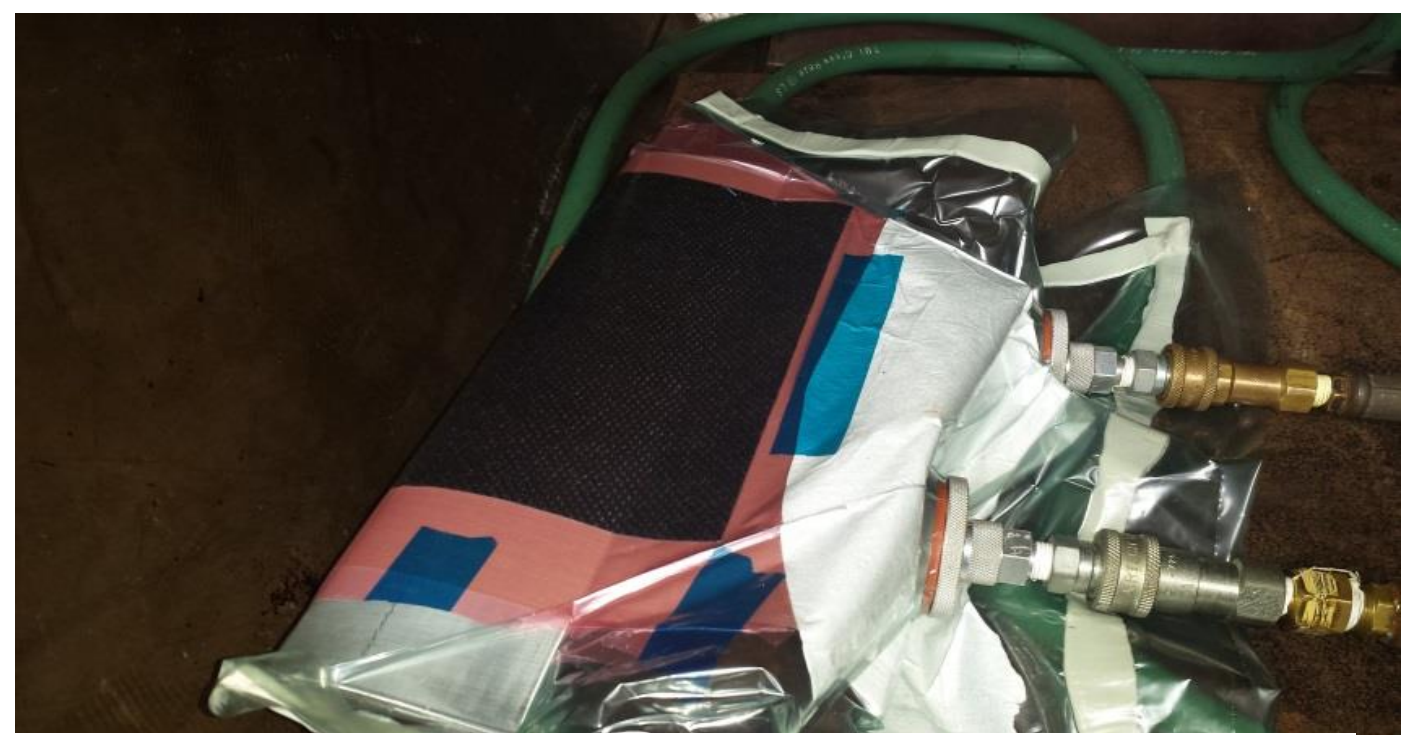

Figure 4.2.3: Wing skin in vacuum bag just before curing in autoclave

with a more rough profile is to decrease the total machining time of the part. Once the top profile was cut, the part was flipped over and the bottom profile was cut in the same fashion. Once the profile was finished, the clamped ends of the mold were cut off using a band saw. At this point the mold had the general shape of the NACA 2412 profile, but had small ridges across the wing. However, due to aluminum being very soft, all that was needed was a fine grit sand paper to sand the mold down to the finished part as seen in Figure 4.2.4. To provide some variability to the mold, the length of the mold was 
designed to be 13 inches so future theses could use this same mold for wing spans up to 12 inches.

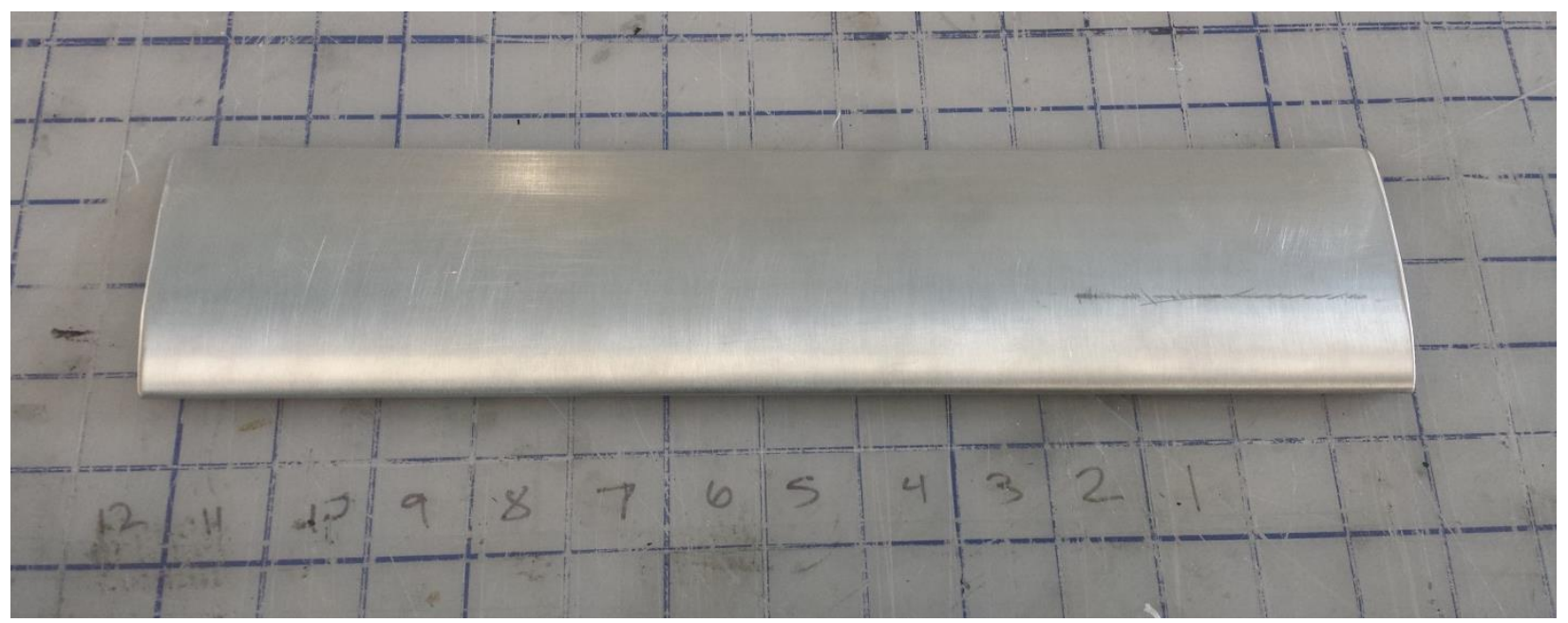

Figure 4.2.4: Wing skin mold after sanding and polishing

\subsection{Manufacturing of the Spars and Ribs}

Manufacturing of the ribs and spars was much simpler compared to the skin. One major reason was that the size and complexity of the parts was very low. In order to get the spars to have the correct shape, a mold was created by cutting channels of the proper thickness out of dense foam. This mold could survive an autoclave curing cycle. The channels were cut out using a table saw because it was the most efficient and accurate cutting method available. Foam was used over metal because the geometry of the spars was very simple and did not require a robust mold. Before having this mold made however, a test was performed to ensure the foam could both withstand a cure cycle in the autoclave and create a part matching the design. The prototype mold can be seen in Figure 4.3.1. Preparation for the mold included applying scotch tape over any surface that would come into contact with carbon fiber as well as a generous application of release wax to make removal of the carbon easier. As shown in

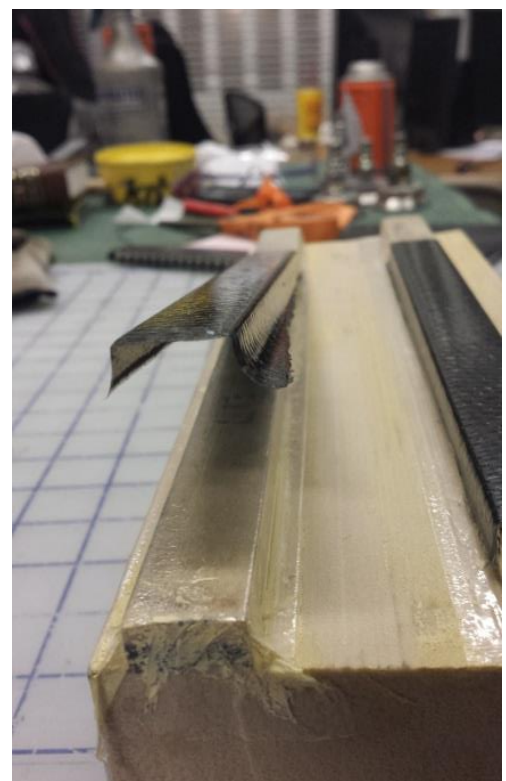

Figure 4.3.1: Successful test of spar manufacturing method 
Figure 4.3.1, the test was a success with the mold withstanding the autoclave cure as well as proving a viable method for manufacturing.

Once the prototype mold proved this was a viable manufacturing method, it was time to create a full-scale mold. This new mold was also cut using a table saw with the 4 ridges the spars were wrapped around to be cured. The channels were each 10 inches long and would produce 4 sets of spars for every cycle the mold was put through. However, during manufacturing of the mold, an errant cut was made causing one of the channels to become very weak and deform during the cure cycle. The deformed channel and the mold after running through an autoclave cycle is displayed at the bottom of Figure 4.3.2. Also showcased is the waviness in the other sets of spars. This was due to the channels the carbon was draped over becoming flimsy during the cure cycle. The mold would not be able to produce reliable parts, a new one needed to be made.

The next and final mold made to cure the spars was made out of much denser foam than the previous molds.

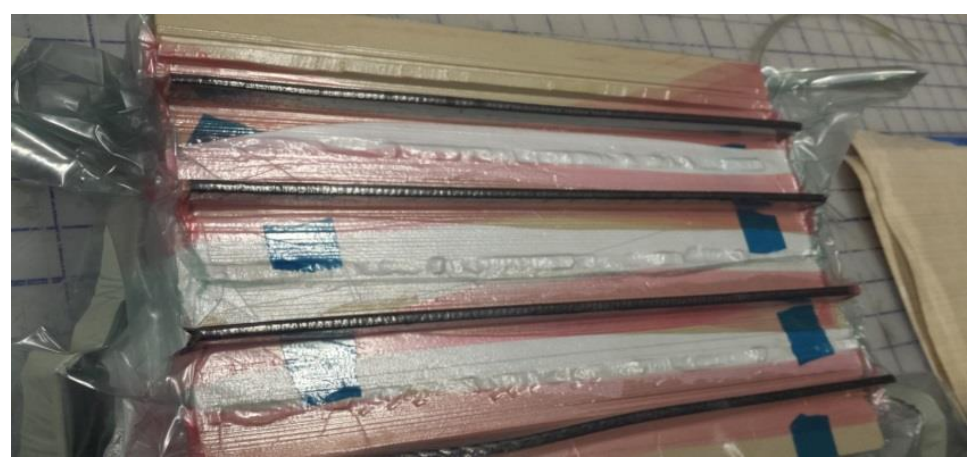

Figure 4.3.2: Manufacturing of trailing edge spars using first foam mold

This foam did not have a designation or marker identifying the foam itself but showed no sign of degradation from cycle to cycle such that this foam would not succumb to the same problems. The final mold consisted of a 10 inch by 15 inch foam block with 8 different channels (as seen in Figure 4.3.3).

The channels spanned the full length of the block and each individual channel created 24 inch spar sections. So for every cycle the mold went through, 8 sets of spars were created, drastically reducing the total time required to manufacture all of the necessary spar sets. This mold was also covered with adhesive tape however instead of using the mold release wax, a liquid mold release donated by Quatro Composites was used because it was easier to apply and left no residue on the mold. 
The layup process for the spars was very time consuming because of the necessary care taken to

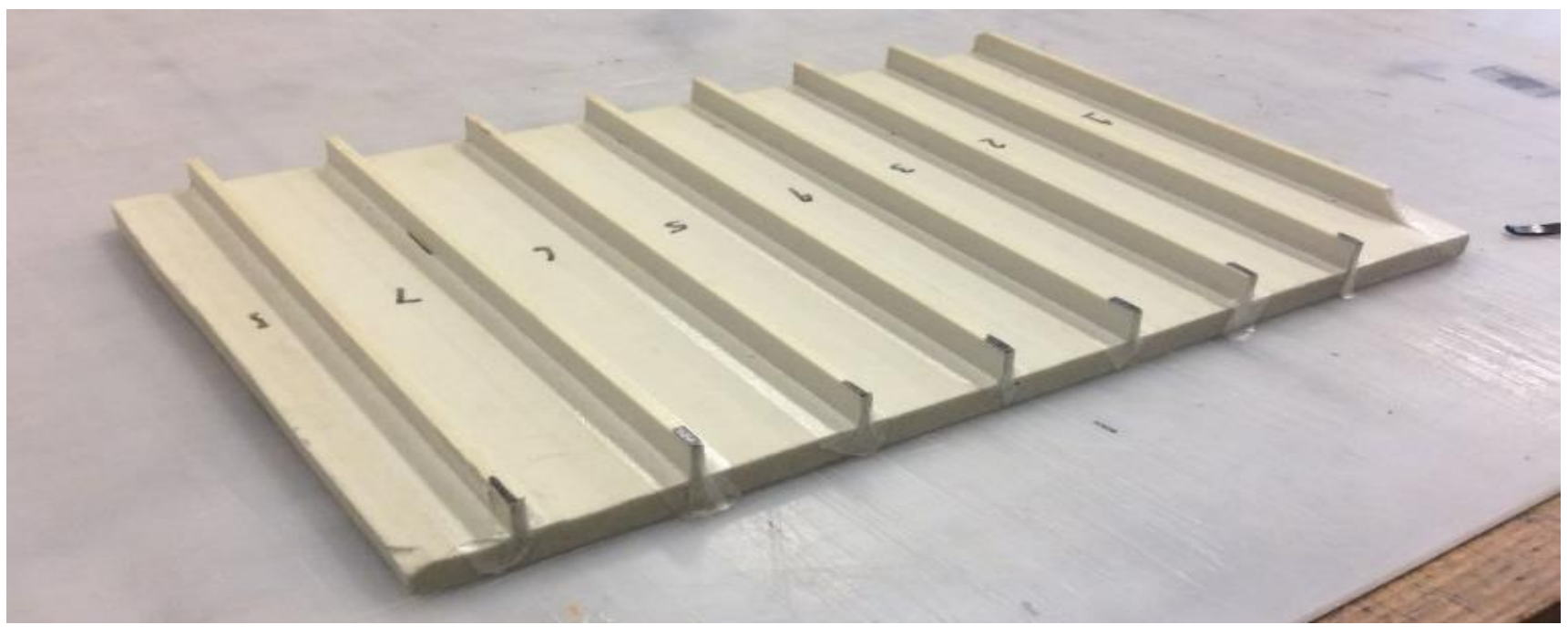

Figure 4.3.3: Final foam manufacturing mold for spars

ensure each piece did not slip when the air was pulled from the vacuum bag. To begin, carbon fiber was cut into 10 inch by 1 inch strips and then had some plastic breather film applied to both sides of the material. After all of the strips and mold were prepared, each strip was placed over a ridge and folded over. Due to how stiff the uncured composite was, the fiber needed to be massaged for around a minute that left a slight bend in each strip. The purpose of this was to preset the bend of the carbon so that when the vacuum bag was drained of air, the carbon would naturally fall into place instead of sliding and becoming misaligned. In between each channel, cotton breather was placed so that air could travel from the carbon through the breather film into the cotton and then out of the bag through the vacuum nozzles. One important part to the bagging process of the spars was getting the bag to properly fill in the tight corners at the bottom of each ridge. If the bag did not fill in all the way down to the corners than the carbon would not cure to the proper shape but instead flex outward away from the ridge. To do this, the bag was cut much larger than would be traditionally used and air was pulled from the bag in short segments. After each pull of air, the bag was readjusted to fill in any tight corners to pull the carbon against the mold as tightly as possible. Once the mold was bagged and drained of air, it was placed in the autoclave and cured. Removing the spars was very simple due to the two pieces of film placed onto the strips. The film extended longer than the strips and with the application of the mold release, just a 
slight pull on the film lifted the spars off of the mold. Once the spars were cured, they needed to be cut into 4 inch segments and then have their flanges cut to down to 0.25 inches. This was done using a water cooling tile saw as seen in Figure 4.3.4. The final step required to get the spars ready for assembly was to get the L-brackets glued into place. This was done using super glue. The L-brackets were created using the scrap ends from the spars and then super glued into the appropriate place. Figure 4.3.5 shows a row of spars with the L-brackets attached waiting to be assembled.

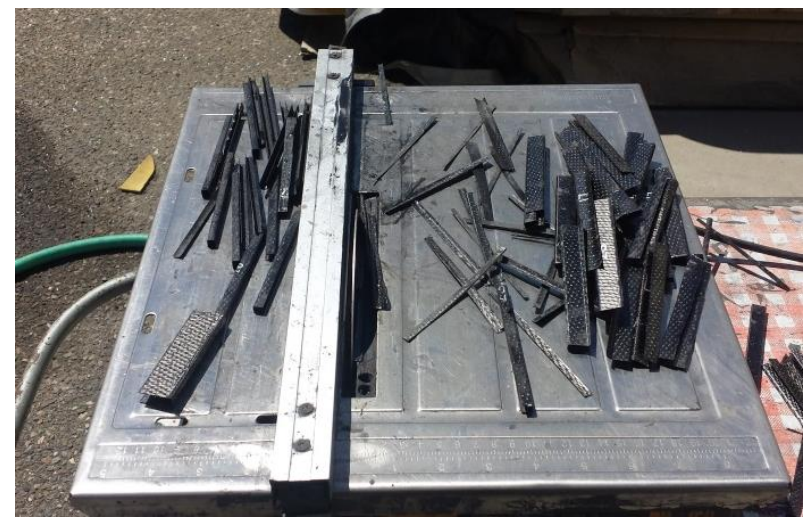

Figure 4.3.4: Cutting process used to trim spars down to size

Before assembly however, the L-brackets for each spar

were trimmed down to be in-line with the ends of the spar flanges. This was done to keep the L-brackets from overlapping the weld nut flanges that were glued to the inner rib and keep each wing as uniform as possible.

The ribs were manufactured by first creating 2 laminates 0.032 inches ( 2 layers) thick and a

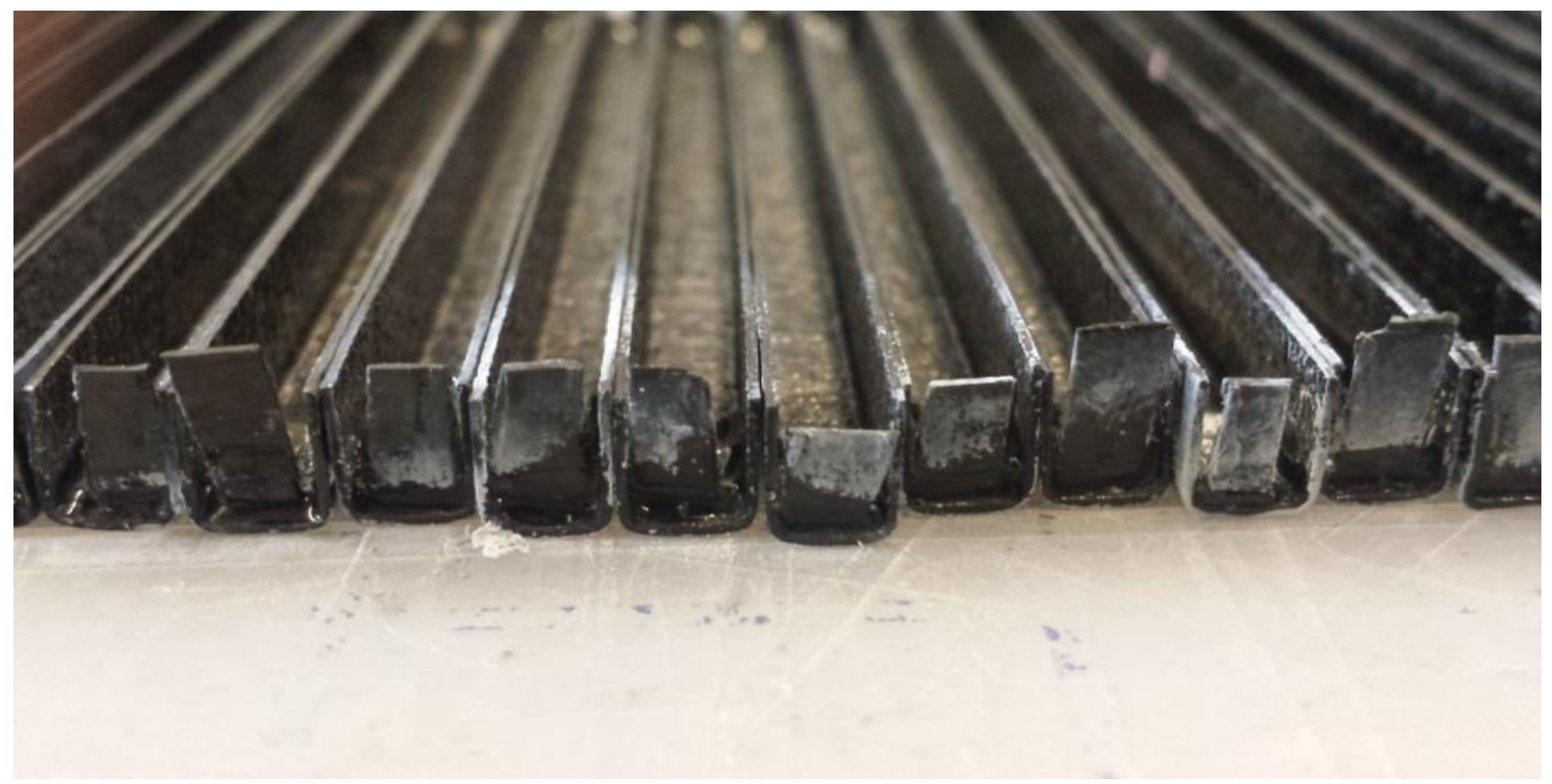

Figure 4.3.5: Row of leading edge spars with L-brackets attached using super glue 
laminates 0.064 inches (4 layers) thick. All of the laminates had dimensions of 12 inches by 12 inches. In order to accurately match the NACA 2412 airfoil, the ribs were cut out using the Aerospace departments CNC end mill by Kyle Rosenow. To prevent the thin laminates from bowing when placed in the vice grips of the mill, the laminates were glued to a wooden block. While the plates were being cut, the holes for the mounting ribs were also drilled to ensure no misalignment occurred between the weld-nuts and the dynamic testing fixture. After cutting, each of the individual ribs had the edges filed to remove excess fibers not fully cut through by the end mill. At this point all, the thinner ribs were complete and ready for assembly. However, the mounting ribs required another process before being ready for assembly.

The next step done for the mounting ribs was to glue the weld-nuts in place. As a reminder, the weld-nuts were used to restrict lateral movement of the wing specimens during dynamic testing. To begin, three weld-nuts were set aside for each wing specimen and were cut to specifically match the NACA 2412 profile of the airfoil. One nut was placed in front of the leading edge spar location while the other two nuts were located between the leading and trailing edge spars. Figure 4.3.6 displays before and after shot for the weld nuts. The nuts were then glued to the rib in the appropriate locations. To verify the weld nuts matched up with the holes drilled into the mounting rib a screw was inserted through the mounting rib hole and then threaded into the weld nut. Glue was then applied to the nut flange face that would come into contact with the rib, pulled firmly against the rib face and held securely place while the glue solidified as shown in Figure 4.3.7. In the figure, a clear gap exists between the left and middle weld nut where the spar will be glued. The trailing edge spar will be glued just to the right of the rightmost weld-nut.

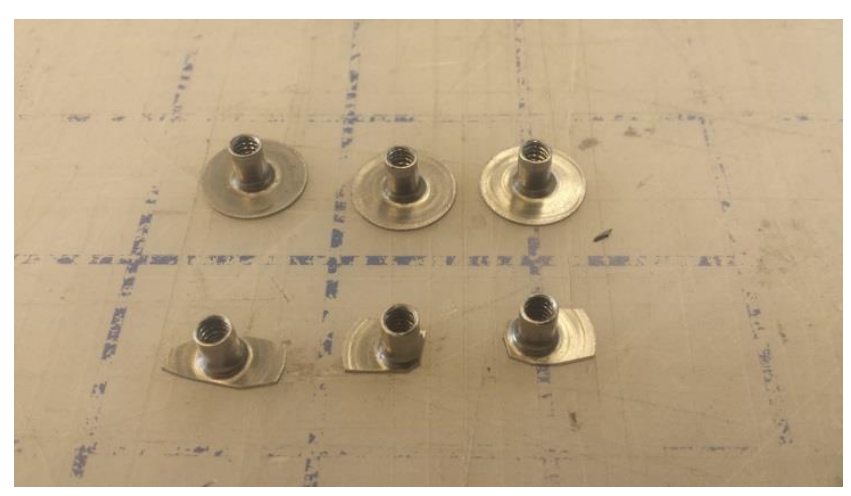

Figure 4.3.6: Original size of weld-nuts and trimmed base of weld-nuts for gluing to mounting rib 


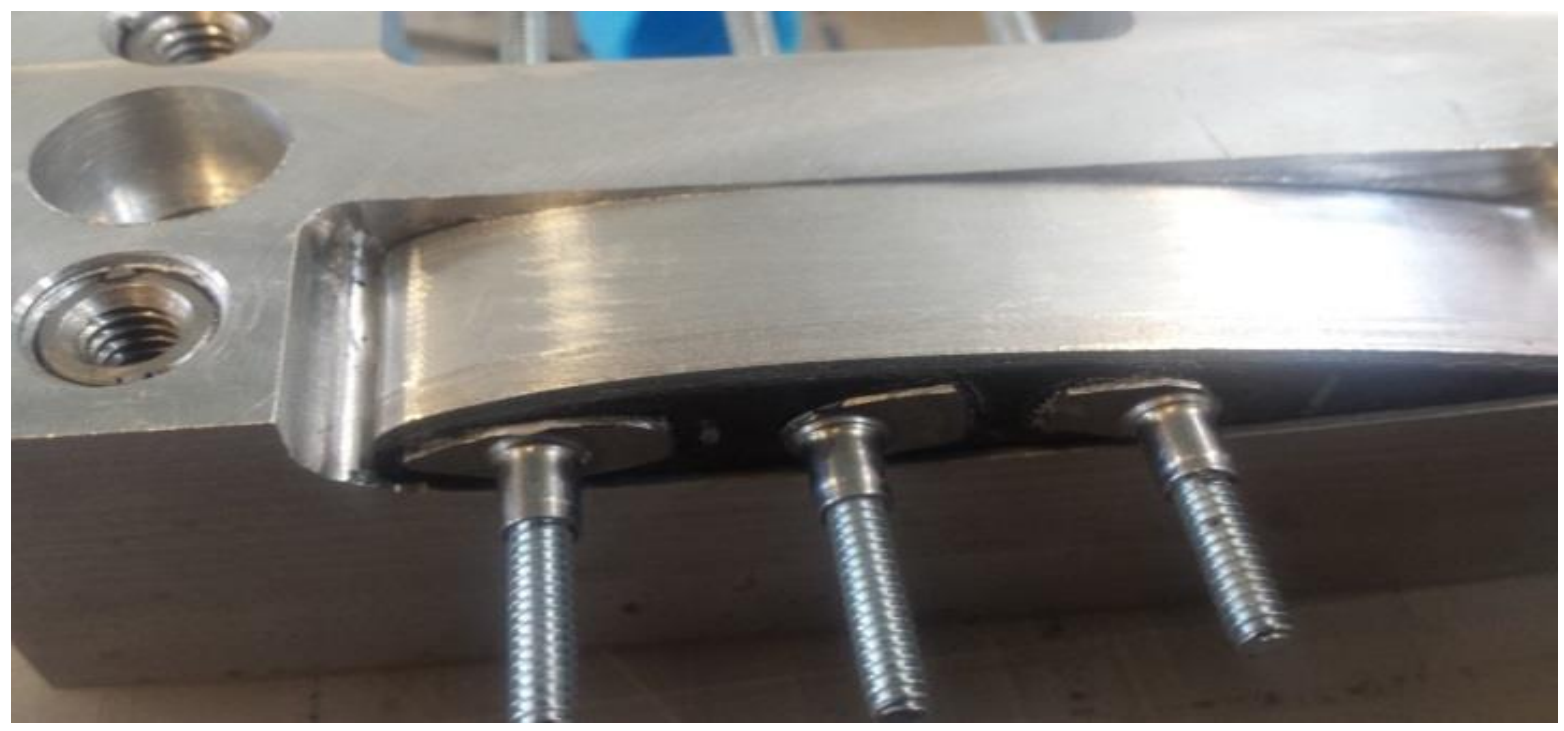

Figure 4.3.7: Method used to ensure that the weld-nuts aligned with the mounting rib for best possible fit

\subsection{Assembly of Wing Specimen}

The wing assemble was finished in two stages, assembly of the ribs and spars to create the internal structure of the wing and the addition of the skin and final trimming of excess material. Before assembling each internal structure, the parts for each wing were separated to ensure that there were enough parts to construct all 15 specimens. There were enough parts to make 21 wings for emergencies (i.e. an error occurred during assembly, rendering the set unusable). Figure 4.4.1 displays each set of internal parts. One reason it was important to group the parts was so that the lengths of all of the spars could be matched as closely as possible. This was necessary because the length of the spar tended to vary from 4 inches to 4.025 inches. The variation of the lengths occurred during cutting of the spar segments on the tile saw. Any spar that was manufactured outside of this size window was discarded as displayed by the stack of spars in the lower right corner of Figure 4.4.1.

The internal assembly was first put together using super glue and then checked for alignment before applying the structural adhesive to strengthen the bonds. To begin, the internals of a wing were laid out as shown in Figure 4.4.2. The gray lines in the figure are used to aid in lining up the spars with the appropriate locations on the ribs. The first step was to glue the spars to the outer ribs. Gluing took 


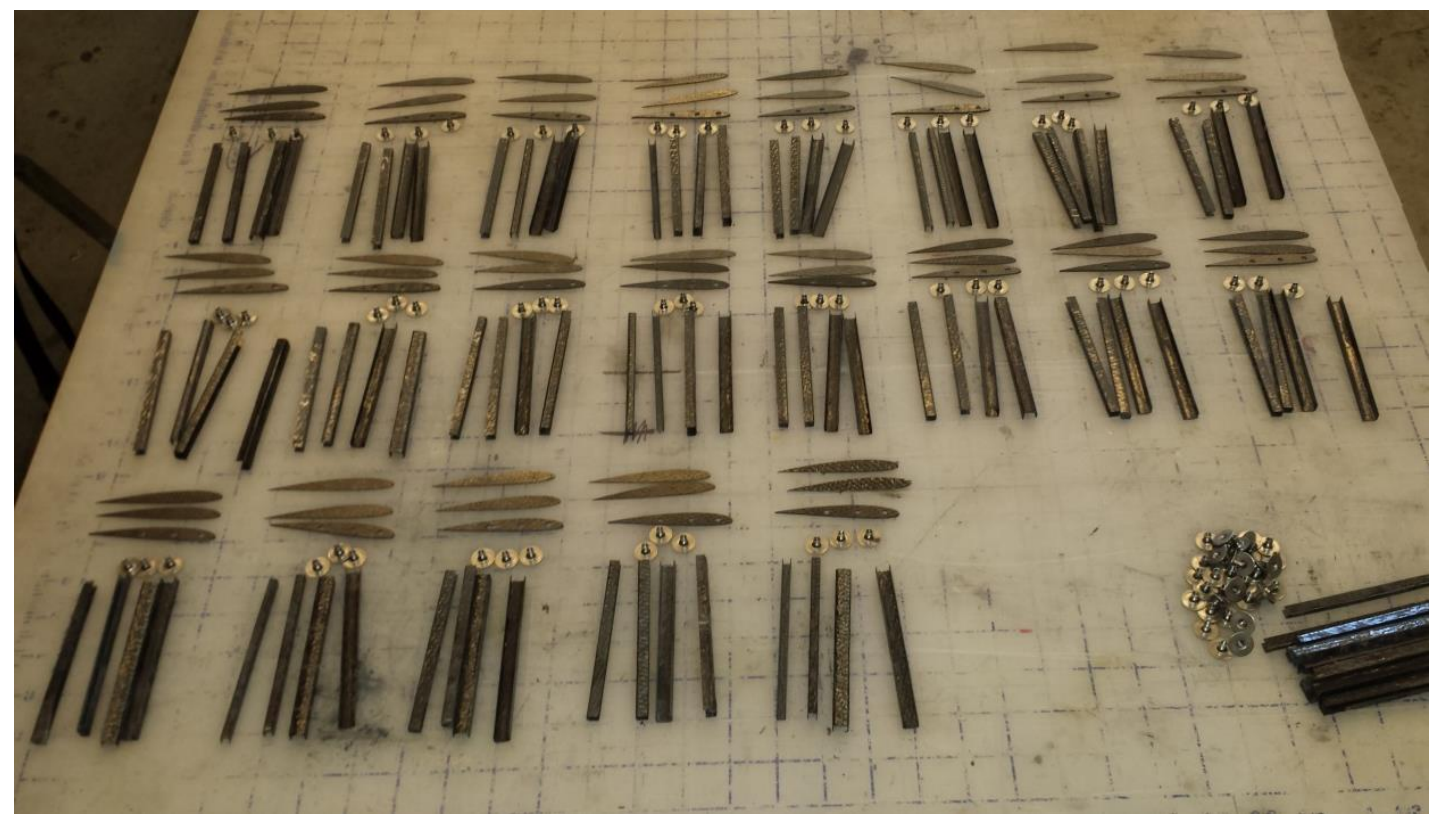

Figure 4.4.1: Layout of wing specimen sets including ribs, spars, and weld-nuts

place on cutting mats that had boxed lines on them so that the angle between the ribs and spars could be controlled as accurately as possible. To bond the spar to the rib, a small dab of super glue was placed onto the L-bracket of the spar. Next, the spar was pressed firmly into place against the rib and held in place for up to 30 seconds for the glue to solidify. While the glue solidified, care was taken to keep the spar in alignment. A finished bond of the spar to the rib is shown in Figure 4.4.3. In the figure, the leading edge spar, outer rib and the L-bracket used to connect the two pieces is showcased. The process was done with first applying the leading edge spar and then repeating the process for the trailing edge spar. This same process was repeated with the mounting rib while taking care to keep place the spars so that they do not interfere with the weld-nuts already glued to the rib. The finished mounting rib half is

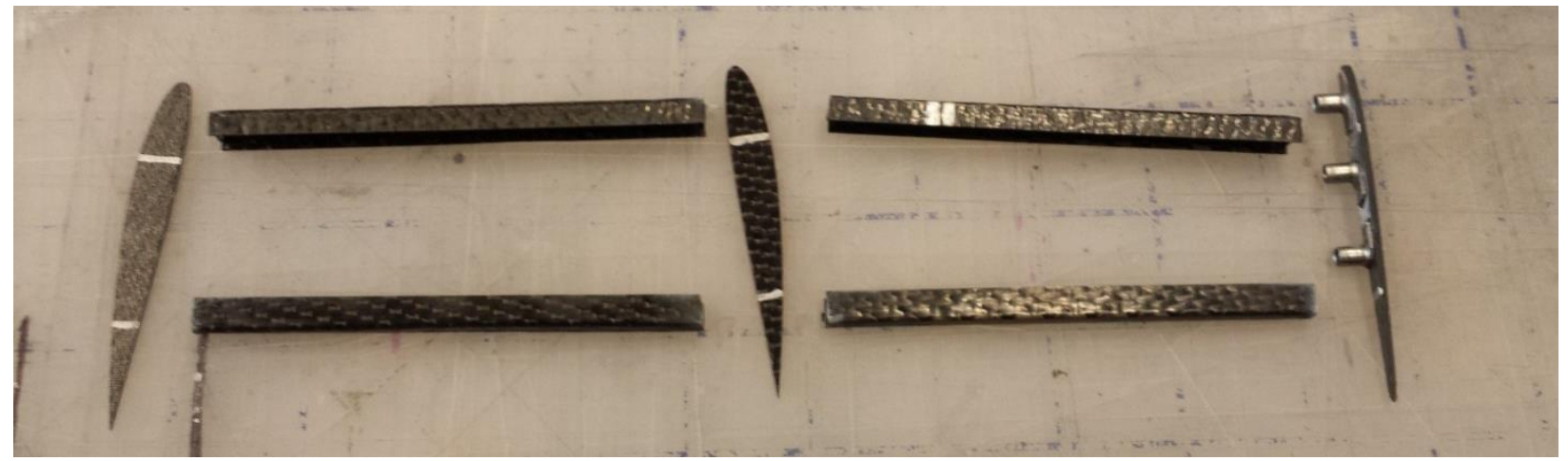

Figure 4.4.2: Layout of how internal structure will be pieced together 
displayed in Figure 4.4.4. After gluing the both sets of spars to a rib, it was time to glue the middle rib into plate.

The middle rib was first adhered to the spars connected to the mounting rib. This was done by placing glue onto both of the spar L-brackets and then firmly pressing the middle rib against them. It was necessary to glue both spars at the same time because gluing them one by one could possibly cause the first bond to break when

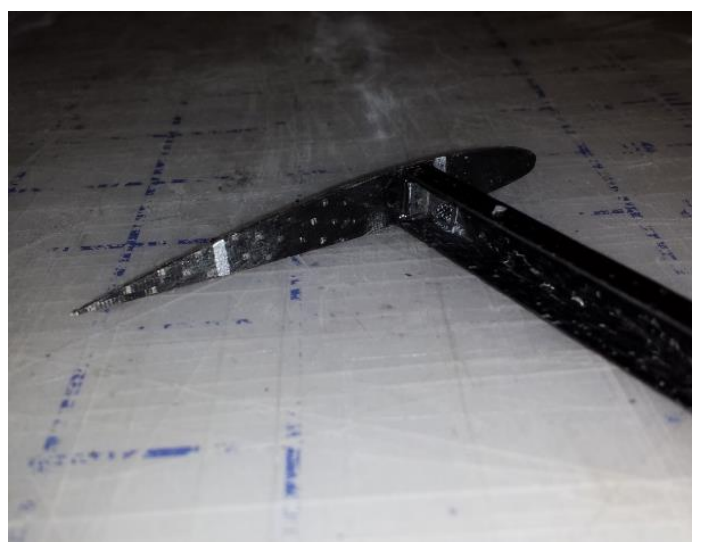

Figure 4.4.3: Bonding of leading edge spar to end rib applying glue to the second area. The reason the spars were grouped this way was so each set was as close to the same length as possible. If the spar pairs were of different lengths, then the ribs at either of the spar pairs would never be parallel which is not desired in the design. Figure 4.4.5 shows an up-close view of the middle rib after it has been glued into place. As seen in the Figure, the edge for the spars does not fully come into contact with the rib faces. This will be corrected when the structural adhesive will be added to fill in these gaps. This process was done for all 15 wing structures and all 15 finished internal structures is presented in Figure 4.4.6.

Once all of the internal structures were completed, each internal section was test fit with the wing skin it would be paired with to determine how well the parts would fit together. After each test fit was complete, it was time to begin the final assembly step of attaching the skin to the internal structure. To complete this, structural adhesive was applied to the top and bottom of the flanges of the spars and edges of the ribs of the internal structure while also adding a strip of adhesive to the trailing edge of the skin to aid in closing out the trailing edge. Once the adhesive was applied, the internal structure was carefully placed into position inside of the skin. All of the surfaces of the internal structure were covered with adhesive, screws that

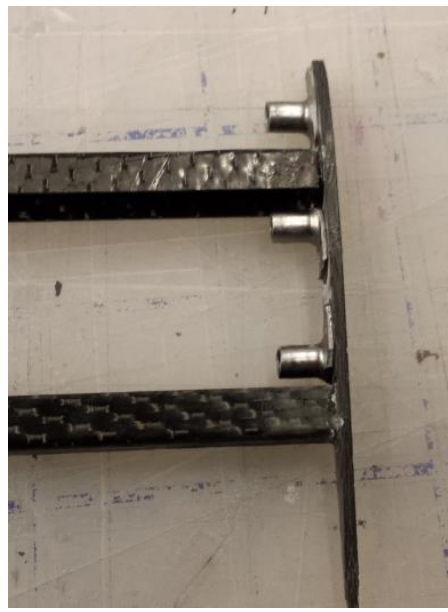

Figure 4.4.4: Mount rib with both leading and trailing edge spars glued in place 
were inserted into the weld nuts were used to position the internal assembly into place. Once the internal structure was set, it was then placed into the impact mount designed to hold the specimen in place during impact testing. This was used to would allow the application of uniform pressure across the skin surface while the adhesive cured.

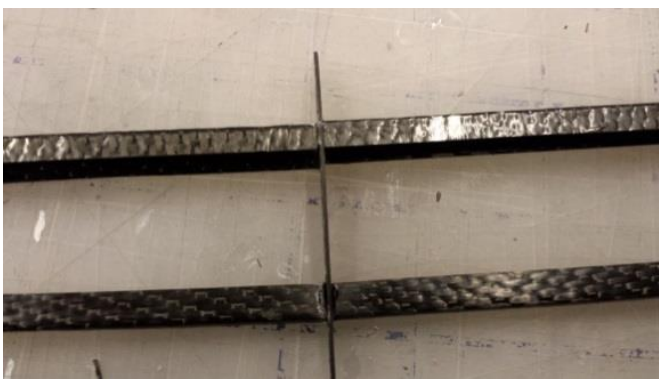

Figure 4.4.5: Top-down view of middle rib after having both sets of spars glued in place

To increase the pressure applied, some weights were placed

over the top plate for the duration of the curing. To speed up the curing process, the wing was placed on the heating table in the Cal Poly Aerospace Structures/Composites lab that was designed by Dr. Elghandour to speed up the process of curing composite parts. The table was set to $150^{\circ} \mathrm{F}$ and took approximately 2 hours for the adhesive to solidify. Once the adhesive had cured, the wing was taken from the fixture and placed off to the side to await one last machining step before the specimen was complete. This process was repeated for each wing specimen. The final phase of manufacturing for each wing was to trim off the excess skin and trailing edge flaps. The skin was manufactured at 10 inches long and was trimmed to the final dimension after assembly. The wingtip was trimmed so the end of the skin was flush with the outer rib and the inner section was trimmed to match the 0.25 inch overhang as designed for the dynamic testing fixture. A finished wing specimen is displayed in Figure 4.4.8.

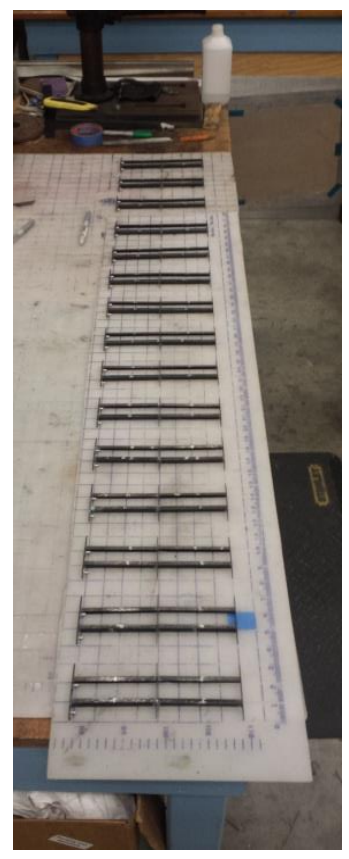

Figure 4.4.6: All 15 completed internal structures for wing design 


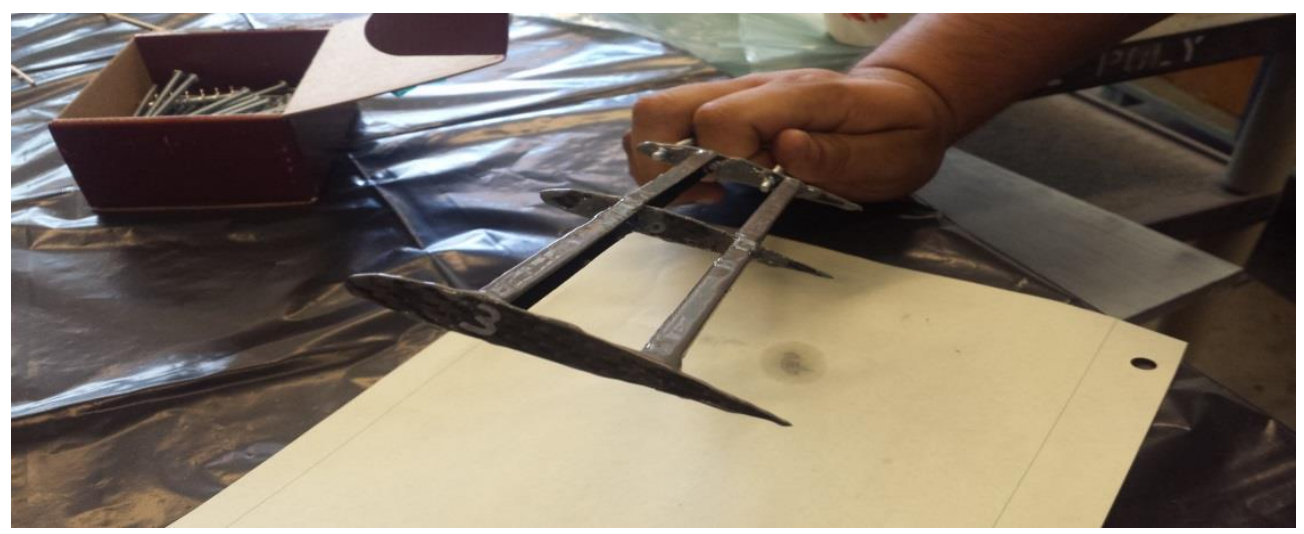

Figure 4.4.7: Application of structural adhesive to internal structure just before being placed inside of wing skin

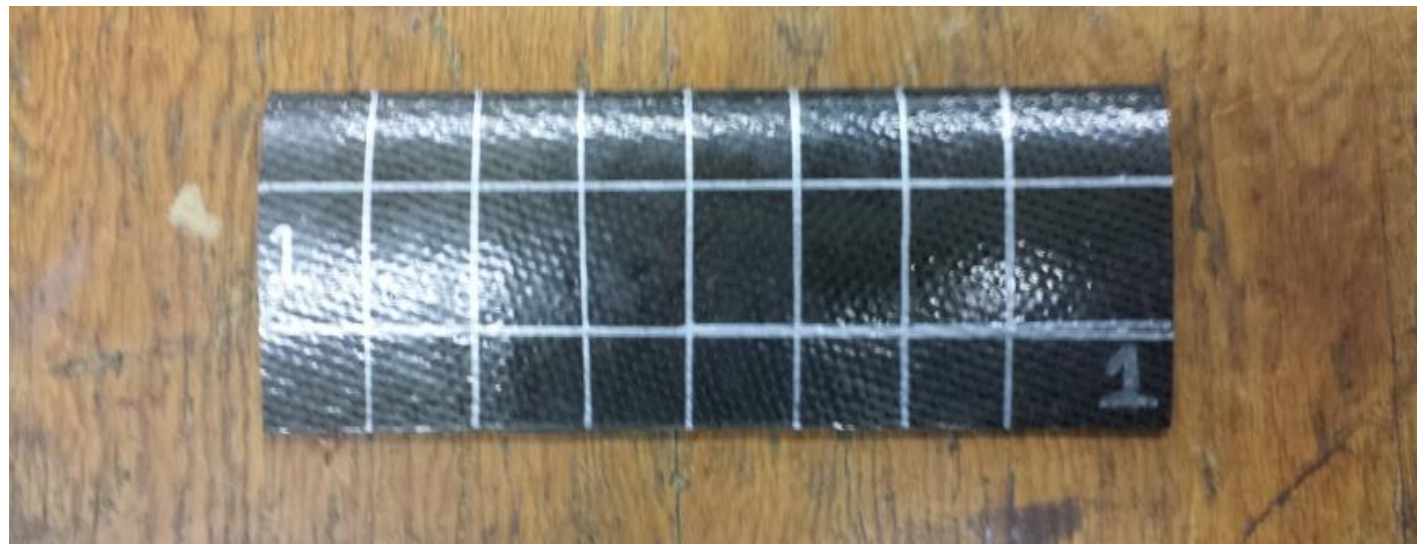

Figure 4.4.8: First wing completed and ready for testing 


\section{Experimental Results and Discussion}

Chapter 5 is the core of this project with an analysis of the experimental results for material property testing, dynamic testing, and impact testing. Results for the material property testing of the tension and compression specimens are discussed in Section 1. Section 2 presents the results of the preimpact dynamic testing of the wings meaning the dynamic results for the wings before they are damaged under impact. Section 3 is a failure analysis of each group of wing impacts including similarities and difference in each group. Section 4 compares the pre- and post- impact dynamic characteristics of each wing specimen. The post-impact data is taken from the wings after each one was damaged using the Dynatup 8250.

\subsection{Material Property Testing Results}

After testing all tensile specimens, the data was read into MATLAB and analyzed. The results of the testing are available in Table 5.1-1. The average ultimate tensile strength was $105 \mathrm{ksi}$ with a standard deviation of $3.7 \mathrm{ksi}$. This means the variation across each specimen was around $3.5 \%$ of the mean meaning that the five specimens tested can be considered similar. The average tensile modulus was 6,240 ksi with a standard deviation of $240 \mathrm{ksi}$. The variation for Young's Modulus was 3.85\%.

Figure 5.1.1 displays the experimental results from each specimen plotted over each other. The stress strain curve for this material shows that there is no plastic deformation occurring before failure which is expected. LTM45EL is a very strong and brittle material.

Table 5.1-1: ASTM D3039 Tensile Testing Results

\begin{tabular}{|c|c|c|c|c|c|}
\hline Specimen \# & 1 & 2 & 3 & 4 & 5 \\
\hline Ultimate Tensile & 107 & 102 & 100 & 107 & 109 \\
Strength (ksi) & & & & & \\
\hline \multicolumn{2}{|c|}{ Mean (ksi) } & 105 & Standard Deviation (\%) & 3.5 \\
\hline Tensile Modulus (ksi) & 6,540 & 6,110 & 5,980 & 6,120 & 6,440 \\
\hline
\end{tabular}




\begin{tabular}{|c|c|c|c|}
\hline Mean (ksi) & 6,240 & Standard Deviation (\%) & 3.8 \\
\hline
\end{tabular}

The testing results for LTM45EL were consistent across all specimens meaning the values determined from these tests are to be taken as the true material properties for this material. Now that the material strength is determined, it is important to determine the degradation the material roll has sustained.

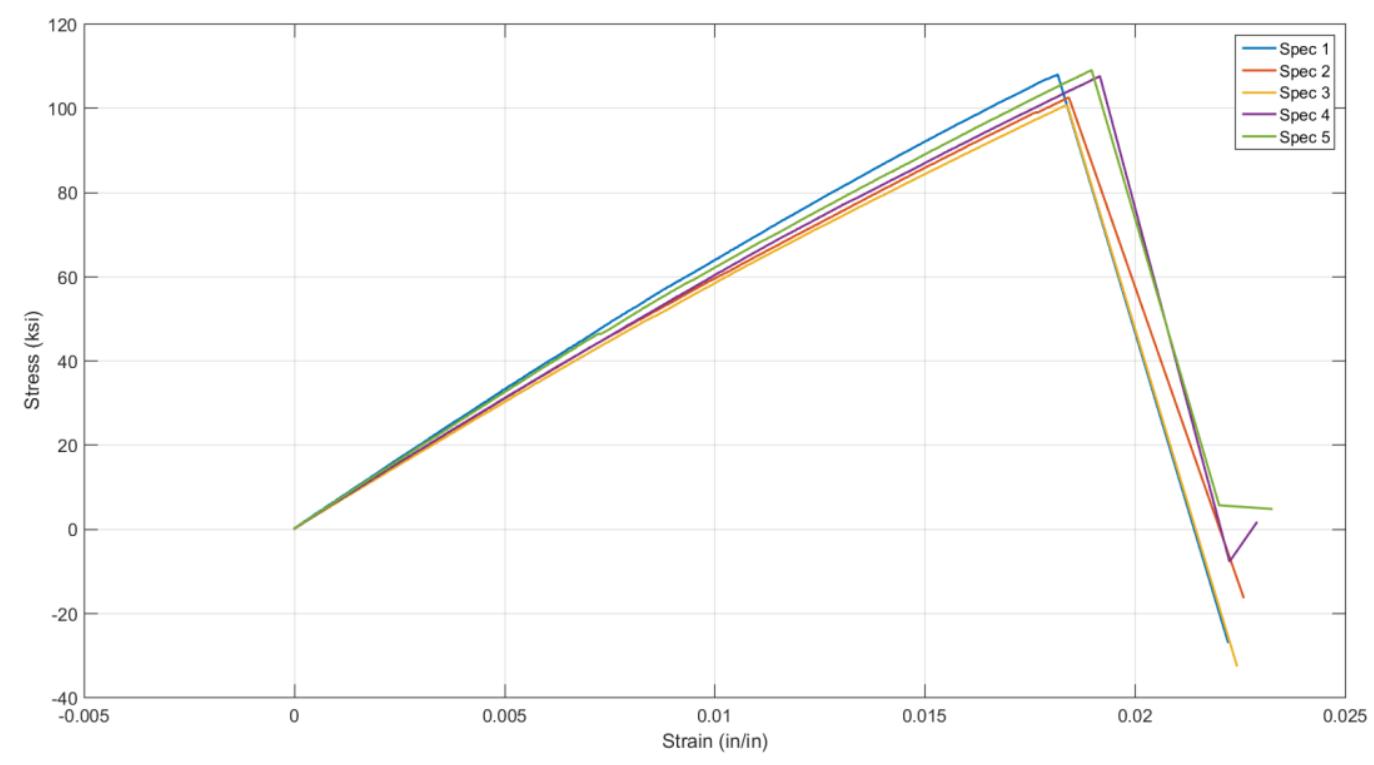

Figure 5.1.1: Stress vs strain experimental results from ASTM D3039 testing

Table 5.1-2 lists the tested material properties compared to the material properties taken from the material data sheet. From the table, it can be shown that the LTM45EL material has had major strength degradation since its manufacturing date in 2007. This is to be expected, prepreg materials typically have a shelf life of 6-12 months depending on what temperature the material is stored at. The reason prepreg expires is because while the material is stored in a freezer at a low temperature, the resin is still slowly curing. As discussed in Section 1.2, the resin system of a prepreg is partially cured during manufacturing so that the resin and matrix will stay together during layups and transportation. However, the resin never stops curing, but is slowed drastically at lower temperatures. This phenomenon is partially the reason for such drastic strength loss. The resin over the last few years has been slowly 
curing causing the material to lose strength. Another source of strength loss is that the material was cured at 70 psi instead of the recommended 90 psi however this cannot be fixed. The reason is the autoclave that was used for this thesis has a pressure cap of 70 psi and cannot be pressurized any higher. After experimental testing was completed, it was determined that the measurement of strain from the Instron was very inaccurate and so a quick test was done to determine the tensile modulus of the LTM45EL weave using a more accurate method of measuring strain. An extensometer was held firmly against a tensile specimen and tested to $4000 \mathrm{lb}_{\mathrm{f}}$. As seen in Table 5.1-2, the use of an extensometer shows that the tensile modulus of the material is much closer to the data sheet that previously thought.

Table 5.1-2: Comparison of Experimental Values to Data Sheet Values

\begin{tabular}{|c|c|c|c|c|}
\hline Value & Experimental & Data Sheet & \% Difference & Extensometer \\
\hline Ultimate Tensile & 107 & 88.6 & 20 & N/A \\
Strength (ksi) & & & & \\
\hline Tensile Modulus & 6,240 & 9,060 & 31 & \\
\hline$(\mathrm{ksi})$ & & & & \\
\hline
\end{tabular}

\subsection{Pre-Impact Vibration Testing}

Before impacting any of the wings, it was important to first characterize how the wings would responds to determine the natural variation across the sample size. Wing 1 was tested the most thoroughly as mentioned in Chapter 2.3 with 80 different locations analyzed and tested. The other 14 specimens were compared to this wing to determine the natural variation as well as establish a baseline for each wing before impact to be compared to after being damaged.

Wing 1 was the first wing to be fully assembled and tested. This wing is one of the three control wings. The wing was placed onto the vibration table and then tested multiple times. Five different locations were tested for every $1 / 2$ inch of span and the data was analyzed (as explained in Chapter 2.3). Figure 5.2.1 displays the resulting over-plotted frequency responses. In the figure, a definitive first 
mode excitation exists around $200 \mathrm{HZ}$ with a less clearly defined second mode excitation between 900 $\mathrm{Hz}$ and $1000 \mathrm{~Hz}$. When analyzing each run and determining each natural frequency, the average first mode excitation occurred at $196 \mathrm{~Hz}$ with a standard deviation of $3.5 \mathrm{~Hz}$ while the second mode average was $923 \mathrm{~Hz}$ with a standard deviation of $121 \mathrm{~Hz}$. A much higher variation for the second mode excitation is present due to the asymmetric geometry of the wing. For solid symmetric structures, the natural frequency excitation occurs uniformly across the specimen whereas the wing structure does not have evenly distributed mass. Mass for the wing structure is concentrated along the spars, which is where the majority of the material and adhesive is located and ca n cause the modal excitation frequency

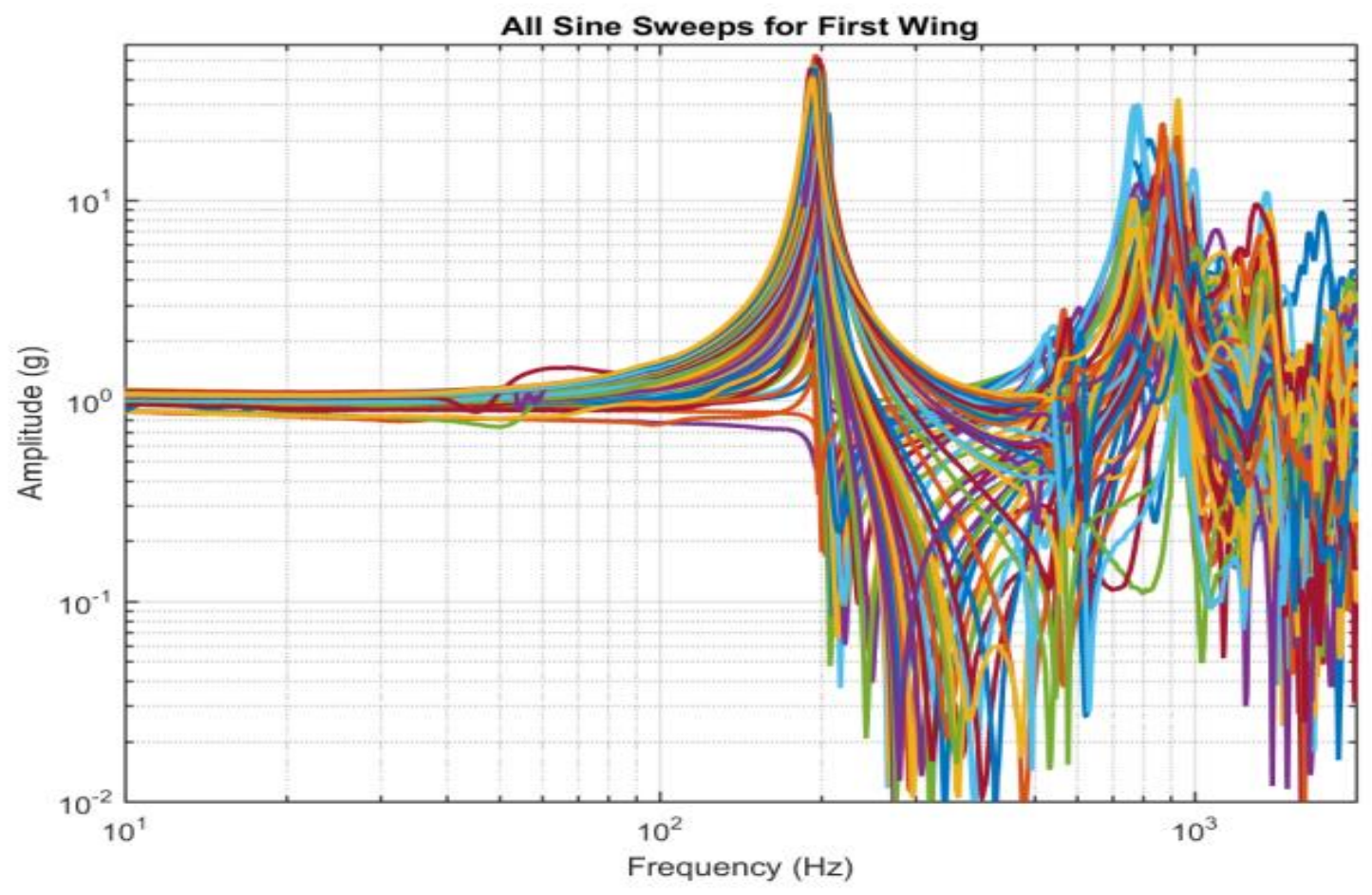

Figure 5.2.1: All Frequency response results from first wing

to fluctuate. When analyzing the data of the second mode more closely and comparing the natural frequencies along each chord location, a clear result shows the high variation of the second mode excitation stems from areas not along the spars. In Table 5.2-1, the second mode natural frequency and damping ration averages and standard deviations at each chord location. The highest variation occurs at the trailing edge of the wing due to trailing edge of the wing being discontinuous. As mentioned earlier 
in this paper, the trailing edge of the wing is glued together with structural adhesive and caused the high damping ratio variation along this section. The second region with high variation is the middle chord region. What is believed to be occurring is the skin is displacing up and down more than the surrounding regions during testing, increasing the effective damping of the region and causing a higher variation of the second mode excitation.

Table 5.2-1: Averages of $2^{\text {nd }}$ mode data values and corresponding standard deviations

\begin{tabular}{|c|c|c|c|c|}
\hline Chord Location & $\begin{array}{c}\text { Average 2 } \\
\text { Mode Frequency } \\
(\mathrm{Hz})\end{array}$ & $\begin{array}{c}\text { Standard } \\
\text { Deviation of } \\
\text { Frequency (\%) }\end{array}$ & $\begin{array}{c}\text { Average 2 } \\
\text { Mode Damping } \\
\text { Ratio }\end{array}$ & $\begin{array}{c}\text { Standard } \\
\text { Deviation of } \\
\text { Damping Ratio } \\
(\%)\end{array}$ \\
\hline Leading Edge & 952 & 5.56 & 0.042 & 54.24 \\
\hline $\begin{array}{c}\text { Leading Edge } \\
\text { Spar }\end{array}$ & 930 & 1.82 & 0.030 & 10.33 \\
\hline Half Chord & 922 & 16.70 & 0.062 & 66.12 \\
\hline $\begin{array}{c}\text { Trailing Edge } \\
\text { Spar }\end{array}$ & 921 & 2.28 & 0.027 & 7.41 \\
\hline Trailing Edge & 950 & 21.26 & 0.078 & 69.23 \\
\hline
\end{tabular}

A clear visual representation of this is shown when comparing the frequency responses along the leading edge spar and along the wing at $50 \%$ of the chord focusing between $500 \mathrm{~Hz}$ and $1100 \mathrm{~Hz}$. This is displayed in Figures 5.2.3 and 5.2.2 respectively. In Figure 5.2.2, a clearly defined region around 900 $\mathrm{Hz}$ is where the natural frequency is being excited. When examining Figure 5.2.3, the region of the natural frequency excitation is much larger and varies from $800 \mathrm{~Hz}$ to $1000 \mathrm{~Hz}$. This also corroborates that it is the displacement of the skin in this region that is causing the high variation seen. 
Another interesting finding came when looking at the first mode response amplitudes across the

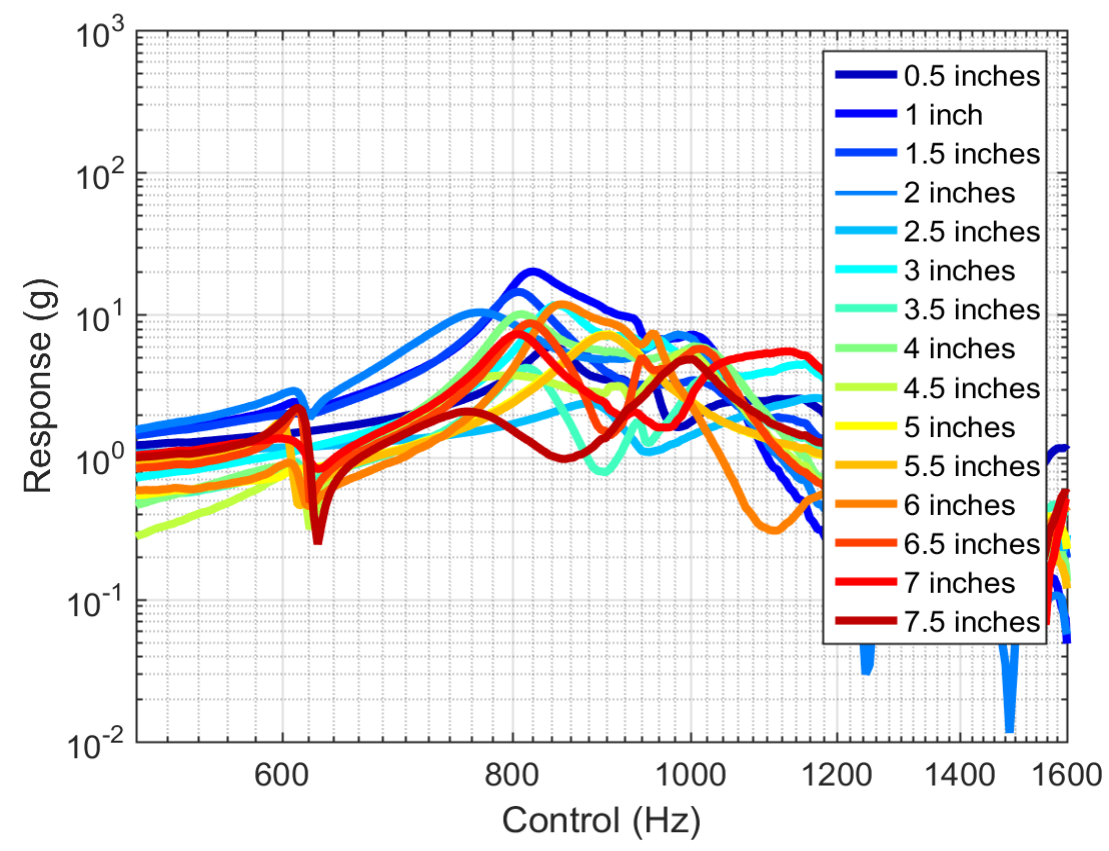

Figure 5.2.2: Second mode response of 1 st wing along the middle of the chord

wing. Figure 5.2.4 is a 3D bar chart with the long axis representing various locations along the span, the depth axis representing different chord locations, and the vertical axis showing the response amplitude at each point. From this chart, the modal shape of the wing in the first natural frequency region mimics the shape that would be seen for a beam under the same condition. From Figure 5.2.4, it is clearly visible that as the accelerometer is moved out along the wing span, the response amplitude increases. As mentioned in Chapter 2, the response amplitude is directly proportional to the displacement. This means the mode shape of the wing matches what would be expected for a first bending mode of a cantilever beam with the lowest displacement occurring near the fixed end and the highest at the tip. Now because this structure is in no way continuous, it will not perfectly mimic a simple cantilever beam, but the trend can still be seen. The same trend can be seen for the second mode response, the Figure can be found in the appendix section. 


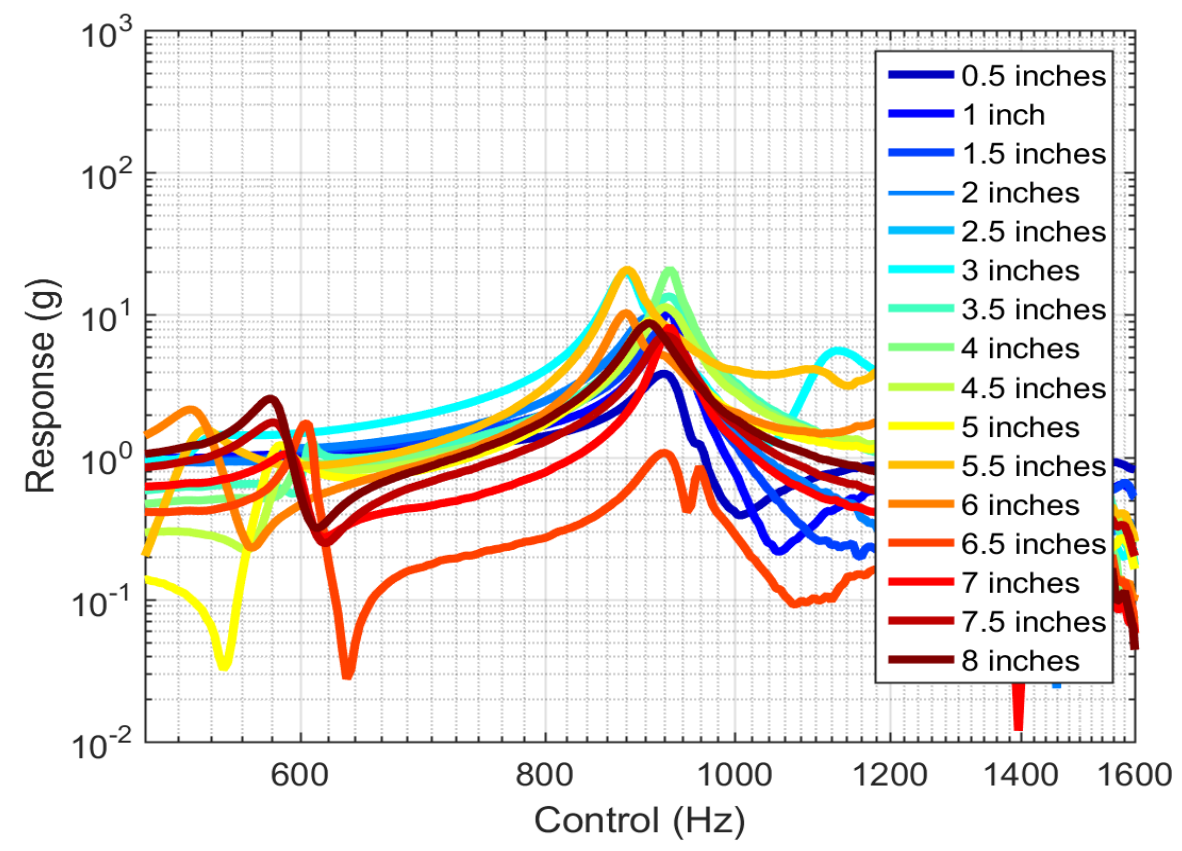

Figure 5.2.3: Second mode response of 1st wing along leading edge spar

Every wing after Wing 1 experienced fewer total test runs due to problems the shaker table was experiencing. The testing of the wings pre-impact went smoothly with no trouble experienced on the shaker table. Each individual wing was placed onto the shaker table and had measurements made that the locations specified in Chapter 2.3. The locations tested are displayed in Figure 5.2.5. Points 1, 3, 5, 8 , and 9 are all located along the leading edge of the wing with points 3 and 4 also lying directly over the middle rib. Points 4 and 7 lie along the trailing edge spar and points 2 and 6 are located over hollow regions of the wing.

After testing all of the wings, the data was again analyzed using MATLAB. All of the wings had very similar first mode excitations with the exception of Wings 4 and 5. Wings 4 and 5 had strain gages placed on them for strain measurements during impact and also had lead wires attached during the pre-impact testing. Figure 5.2.6 shows the $4^{\text {th }}$ Wing mounted in on the shaker table with the leading wires attached and wrapped around the wing. The wires being attached altered the mass distribution of the wing and lowered the natural frequency for the first mode excitation to $168 \mathrm{~Hz}$. For this reason, the 


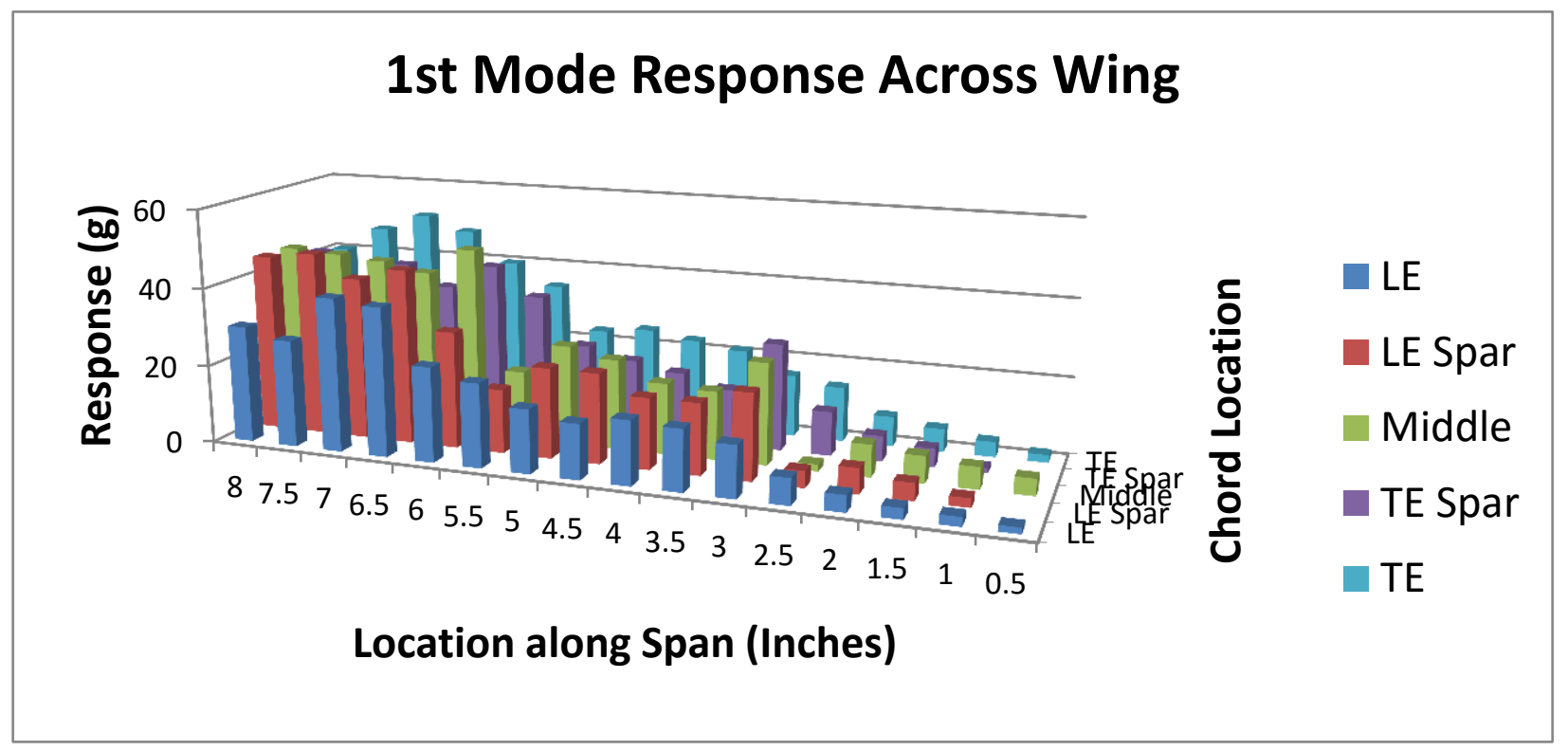

Figure 5.2.4: Bar chart of response measurements showing the modal shape of the first mode dynamic data from Wings 4 and 5 cannot be used when analyzing the before and after effects of the impact. For the other 12 Wings, their dynamic results will be analyzed independently and then compared at the end of this section.

To analyze the rest of the wings, the results will be grouped into first and second mode data.

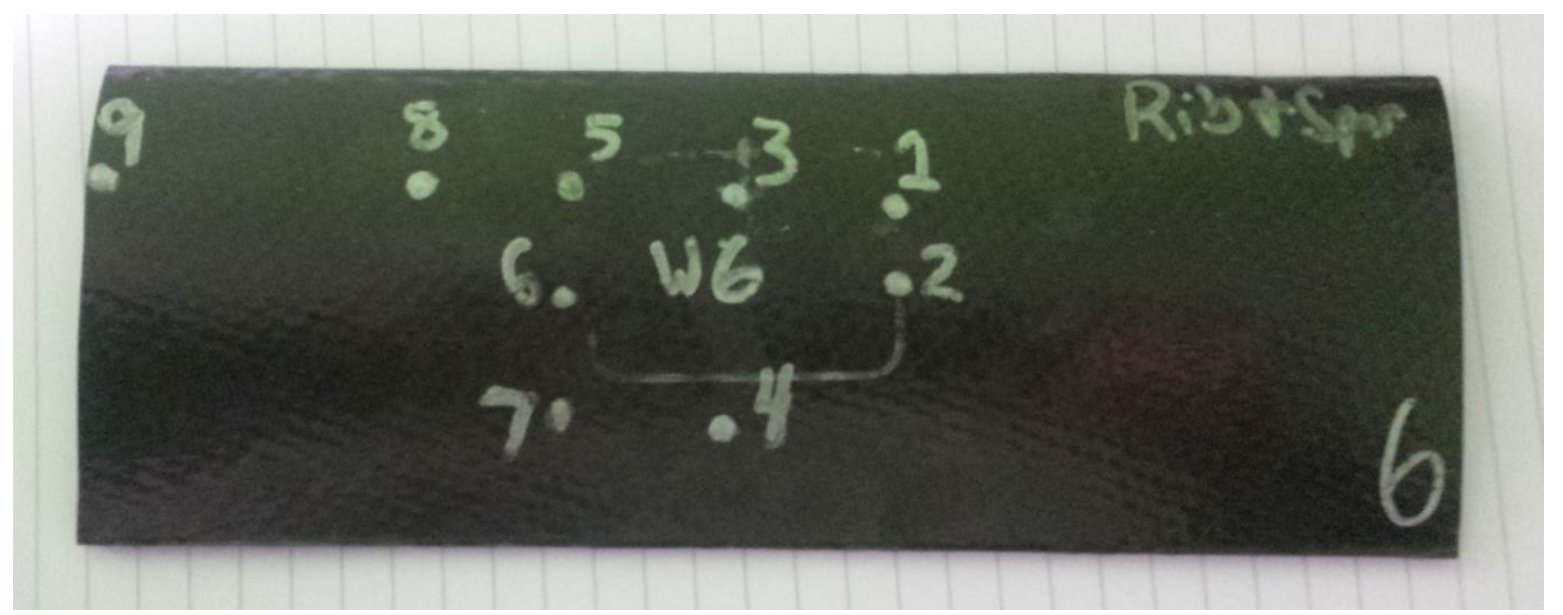

Figure 5.2.5: Locations of response measurements of wing specimens

Table 5.2.2 lists the first mode natural frequency and damping ratio along with the standard deviation for each wing and the weights of each wing. From here on, Wing 1 data will represent only the 9 common points tested across all of the wings. The table shows most of the wings have their first mode natural 
frequency excited between $190 \mathrm{~Hz}$ and $200 \mathrm{~Hz}$ with the exceptions being Wings 4 and 5. The variation for each wing was also very small, ranging from $4 \mathrm{~Hz}$ to $5 \mathrm{~Hz}$. This suggests that all of the wings manufactured are very similar and that the manufacturing process was well controlled. There is however, a high variation in the damping ratio from wing to wing with the lower end being 0.0139 and the upper end 0.0198 . This can be explained by an inability to accurately control the thickness of the adhesive applied during assembly and the natural variation of the carbon fiber. There standard deviations for the damping ratios are also small relative ranging from 0.0007 to 0.0044 . Based off of this

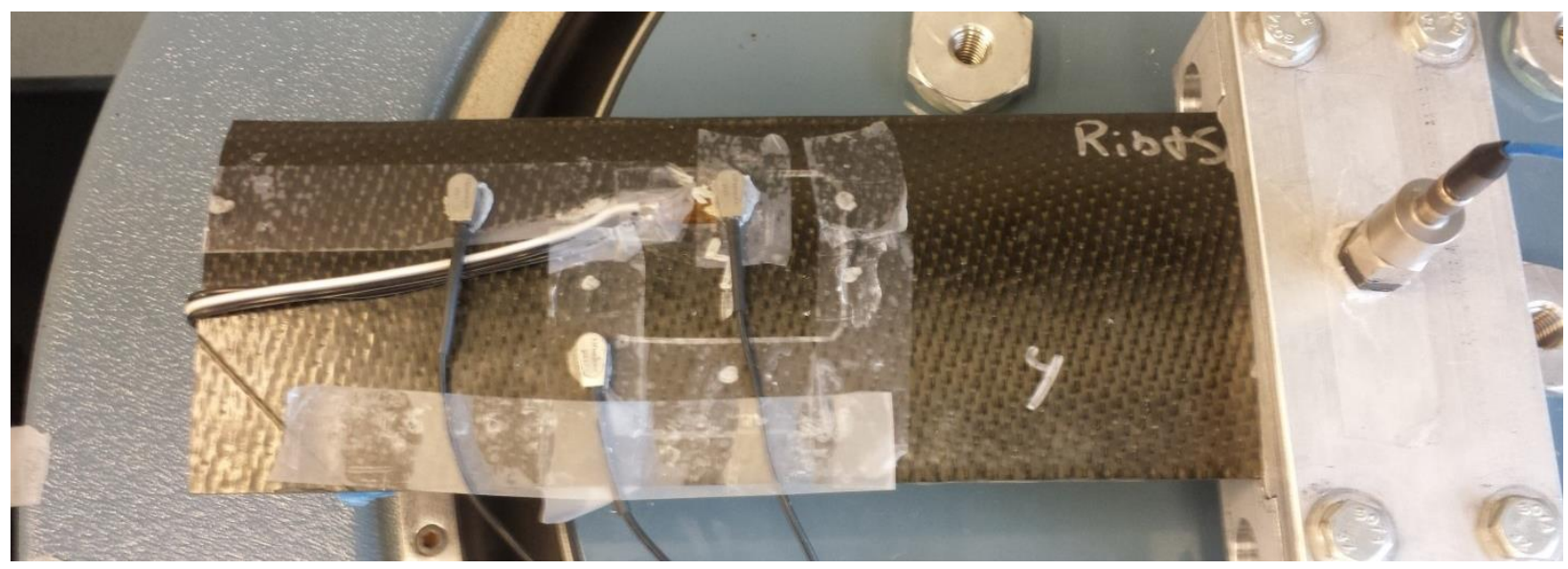

Figure 5.2.6: Top down view of Wing 4 with accelerometers mounted over locations 3, 7 and 8

data, it's accurate to state first mode characteristics of all of the wings are similar.

Table 5.2-2: $1^{\text {st }}$ mode dynamic data averages of Wing specimens

\begin{tabular}{|c|c|c|c|c|}
\hline & $1^{\text {st }}$ Mode Natural & Standard & $1^{\text {st }}$ Mode & Standard \\
& Frequency (Hz) & Deviation (\%) & Damping Ratio & Deviation (\%) \\
\hline Wing 1 & 198 & 2.83 & 0.0160 & 18.75 \\
\hline Wing 2 & 193 & 2.38 & 0.0149 & 11.41 \\
\hline Wing 3 & 189 & 2.59 & 0.0164 & 4.26 \\
\hline Wing 4 & 168 & 2.92 & 0.0434 & 20.05 \\
\hline Wing 5 & 168 & 1.91 & 0.0315 & 13.99 \\
\hline
\end{tabular}




\begin{tabular}{|c|c|c|c|c|}
\hline Wing 6 & 195 & 2.15 & 0.0168 & 10.71 \\
\hline Wing 7 & 195 & 2.31 & 0.0198 & 2.02 \\
\hline Wing 8 & 189 & 2.22 & 0.0158 & 5.69 \\
\hline Wing 9 & 188 & 2.66 & 0.0162 & 11.11 \\
\hline Wing 10 & 194 & 2.32 & 0.0153 & 4.57 \\
\hline Wing 11 & 196 & 2.50 & 0.0160 & 7.50 \\
\hline Wing 12 & 189 & 2.65 & 0.0155 & 10.32 \\
\hline Wing 13 & 196 & 2.45 & 0.0139 & 5.75 \\
\hline Wing 14 & 189 & 2.43 & 0.0155 & 4.52 \\
\hline Wing 15 & 195 & 2.87 & 0.0148 & 18.24 \\
\hline
\end{tabular}

The same results for the second mode are displayed in Table 5.2-3. For the second mode, the natural frequencies ranged from $850 \mathrm{~Hz}$ to $900 \mathrm{~Hz}$ and the standard deviation varied from $40 \mathrm{~Hz}$ to 60 Hz. So as expected, the second mode of each wing tended to have a higher variation. This is also true for the damping ratio of the wings. The range for the second mode damping ratios was from 0.0146 to 0.0299 with the standard deviations spanning from 0.0026 to 0.0222 . The two wings with the highest average damping ratios were Wings 7 and 8 , while also having the highest variation of the damping ratios. Wing 7 and Wing 8 both produced incredibly high damping ratios at Location 2, which is directly over a hollow region of the wing closest to the wing root. The values at location 2 were 0.0763 and 0.0655 respectively. No commonality was seen across all of the wings. All other wings except for Wings 7 and 8 had damping ratios at Location 2 within the standard deviation. One reason for the skewed data of Wings 7 and 8 could be that not enough adhesive exists over the spar and rib near this location, allowing more energy to be dissipated. When examining the damping ratio at Location 1 for Wing 8 , the damping ratio is higher than the average of Wing 8 alleging that Wing 8 does not have enough adhesive along the spar. However, for Wing 7, the damping ratio at location 1 is very close to 
the average. If the damping ratio for location 2 is removed then the average damping ratio falls to 0.0190 and the standard deviation falls to 0.0052 which closely mimics the data from the other wings. It is difficult to determine what the difference with Location 2 of Wing 7 is because all of the data for Wing 7 is similar to the other wings in the group.

Table 5.2-3: $2^{\text {nd }}$ mode dynamic data averages of Wing specimens

\begin{tabular}{|c|c|c|c|c|}
\hline & $\begin{array}{c}2^{\text {nd }} \text { Mode } \\
\text { Natural } \\
\text { Frequency }(\mathrm{Hz})\end{array}$ & $\begin{array}{l}\text { Standard } \\
\text { Deviation }\end{array}$ & $\begin{array}{c}2^{\text {nd }} \text { Mode } \\
\text { Damping Ratio }\end{array}$ & $\begin{array}{l}\text { Standard } \\
\text { Deviation }\end{array}$ \\
\hline Wing 1 & 864 & 5.90 & 0.0215 & 36.84 \\
\hline Wing 2 & 839 & 6.67 & 0.0223 & 63.23 \\
\hline Wing 3 & 864 & 6.02 & 0.0146 & 26.71 \\
\hline Wing 4 & 825 & 5.69 & 0.0495 & 54.74 \\
\hline Wing 5 & 808 & 4.08 & 0.0392 & 15.81 \\
\hline Wing 6 & 884 & 4.64 & 0.0207 & 20.29 \\
\hline Wing 7 & 874 & 5.03 & 0.0272 & 81.61 \\
\hline Wing 8 & 868 & 5.81 & 0.0299 & 64.88 \\
\hline Wing 9 & 795 & 4.40 & 0.0232 & 21.12 \\
\hline Wing 10 & 870 & 7.12 & 0.0151 & 45.69 \\
\hline Wing 11 & 905 & 5.19 & 0.0205 & 31.22 \\
\hline Wing 12 & 861 & 5.11 & 0.0170 & 24.11 \\
\hline Wing 13 & 887 & 4.85 & 0.0148 & 18.92 \\
\hline Wing 14 & 858 & 6.06 & 0.0185 & 37.29 \\
\hline Wing 15 & 871 & 5.97 & 0.0167 & 15.57 \\
\hline
\end{tabular}




\subsection{Impact Testing of the Wings}

As mentioned earlier in Chapter 2.3, there were various locations impacted. The first three wings act as control specimens. Wings 4-6 sustaining damage over the middle rib/leading edge spar intersection. Wings 7-9 sustaining damage a half inch inward from the mid-span of the wing over the leading edge spar. Wings 10-12 sustained damage over the over the middle rib at $50 \%$ of the chord. Finally wings 13-15 sustained damage over only skin located a half inch to the right of the middle rib at $50 \%$ of the chord. No damage was sustained by the first 3 wings, the wings are not analyzed in this section.

Wings 4-6 were impacted directly over where the middle rib and leading edge spar intersect. This is the most robust section of the wing due to the large amount of adhesive concentrated there so little visible damage is expected from the impact force. Each wing was placed in the Dynatup 8250 testing clamp, clamped in place by the pistons, and then damaged by the impact tup set to 8 inches above the wing. As mentioned previously in Chapter 5.2, Wings 4 and 5 were equipped with strain gages to have strain data taken during the impact testing. The reason strain gages were implemented so late into the process was because it was uncertain whether or not the shaker table would be available for use. After testing Wing 1, the shaker table was unavailable for a few weeks due to electrical problems in the amplifier and shaker head. Because the system would be repaired in a timely manner, an alternative idea was done to apply strain gages to the wing to determine the amount of damage sustained. Before testing the wings though, it needed to be determined how well the DAQ for the Dynatup 8250 worked with strain gages.

To test how well the DAQ would work, an experiment was performed using the Instron 8801 system by pulling an aluminum bar with a strain gage attached and reading the data into the LabVIEW DAQ created to read in strain data that was discussed in Chapter 2.2. The test pulled the bar under uniaxial tension up to $1000 \mathrm{lb}_{\mathrm{f}}$ and measure strain data as the bar was elongated. The data was then used to determine the Young's Modulus of the bar. The Young's Modulus calculated was 10.21 msi while the 
documented Young's Modulus is 10 msi. So using the strain data and load cell data, the Young's modulus of aluminum was determined within 2 percent of the actual value which is considered very accurate. This proves that the strain data taken using the new LabVIEW DAQ is accurate.

To also confirm the strain gages were working correctly, a 4 inch by 6 inch by 0.125 inch plate of aluminum was impacted from a height of twelve inches. The strain data from the impact test would then be compared to an FEA model of the same scenario. The strain gages were placed at various locations near the impact site with two gages lying on the long axis of the plate and two gages perpendicular to the long axis. Figure 5.3.1 is a top view of the impacted plate. The impact force on the plate was $909 \mathrm{lb}_{\mathrm{f}}$ and the impact velocity was $8 \mathrm{fps}$. The strain gages all operated perfectly during the test. The strain data is available in Figure 5.3.2. The figure displays some permanent deformation on the gages after impact, which is

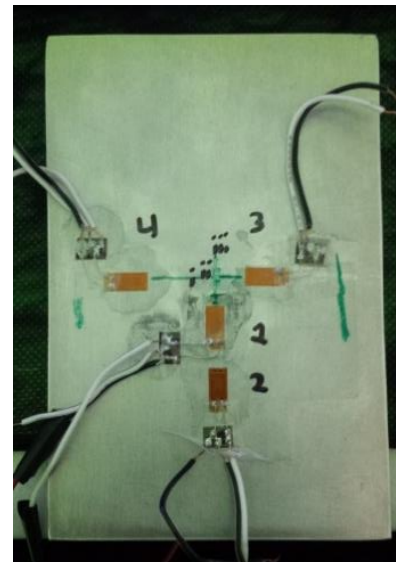

Figure 5.3.1: View of test plate used as strain gage verification expected when impacting the aluminum. The maximum strain measured from each gage can be found in Table 5.3-1. This strain data will be compared to an FEA model in the next chapter.

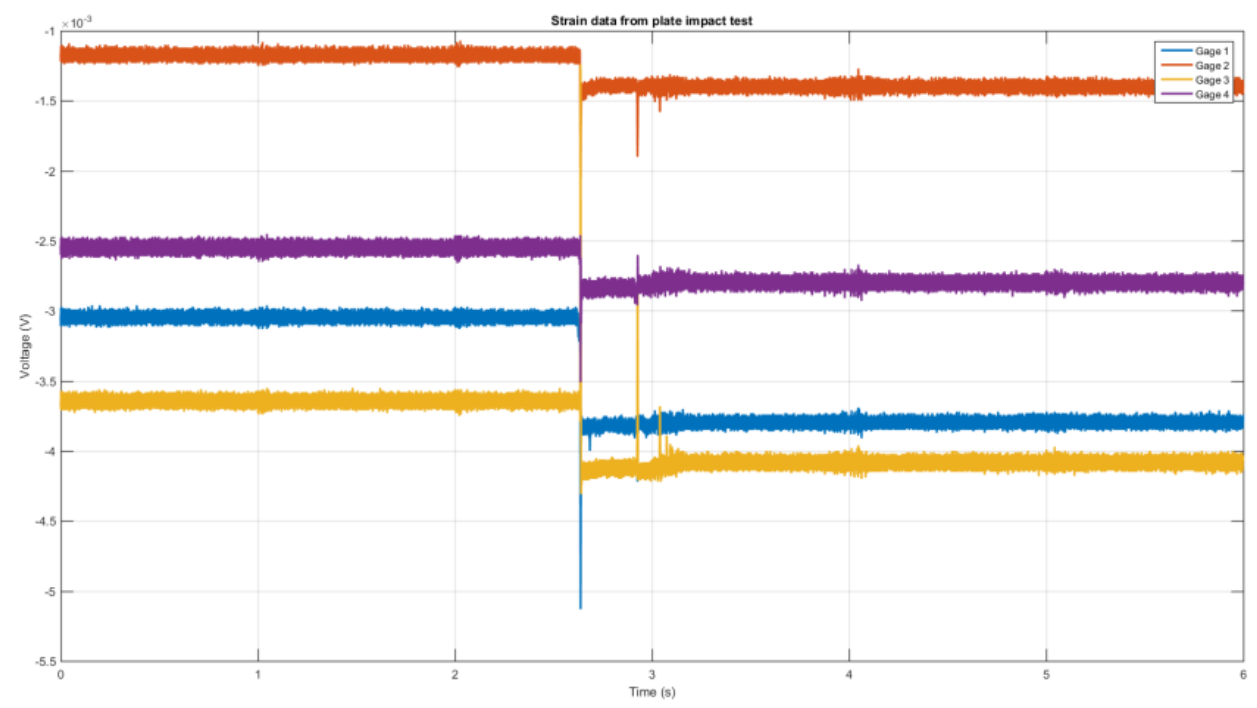

Figure 5.3.2: Strain data from plate impact test showing permanent deformation of plate after impact 
Table 5.3-1: Maximum strain values for plate impact experiment

\begin{tabular}{|l|l|}
\hline Gage Number & Maximum Strain $(\mu \mathrm{in} / \mathrm{in})$ \\
\hline Gage 1 & 1,600 \\
\hline Gage 2 & 1,000 \\
\hline Gage 3 & 2,300 \\
\hline Gage 4 & 700 \\
\hline
\end{tabular}

Only Wing 5 was able to provide strain data as during the impact test. Testing of Wing 4 yielded no usable data as the connection between the solder points and the strain gage became disconnected during the impact. However, force data was still able to be taken during the impact. In Table 5.3-2, the maximum impact force measured and the impact velocity for Wings 4, 5, and 6. Images of each impact can also be seen in Figure 5.3.3. When analyzing the impact forces, Wing 5 seemed to have felt a lower impact force even though the impact velocity was nearly identical to the other two tests. However, when looking at the visible damage of Wing 5 compared to Wings 4 and 6, it was clearly visible that Wing 5 had sustained much more noticeable damage and deformation of the wing skin. The deformation of Wings 4 and 6 seemed to be just slight cracks of the wing skin around the impact sight while wing 5 showed a significant deformation of the skin. A better look at the damage sustained by Wing 5 can be seen in Figure 5.3.4. In the figure, a depression of the skin to the right of the strain gage as well as a crack running from the leading edge to the trailing edge of the wing.

Table 5.3-2: Force and velocity data from impact test of Wings 4, 5 and 6

\begin{tabular}{|c|c|c|}
\hline & Maximum Impact Force $\left(\mathrm{lb}_{\mathrm{f}}\right)$ & Impact Velocity $(\mathrm{ft} / \mathrm{s})$ \\
\hline Wing 4 & 860 & 6.42 \\
\hline Wing 5 & 570 & 6.34 \\
\hline Wing 6 & 939 & 6.55 \\
\hline
\end{tabular}


The reason the impact force of wing 5 was lower when compared to Wings 4 and 6 was because there was more work done deforming the skin with Wing 5, meaning more energy was absorbed during the impact resulting in a lower impact fore.

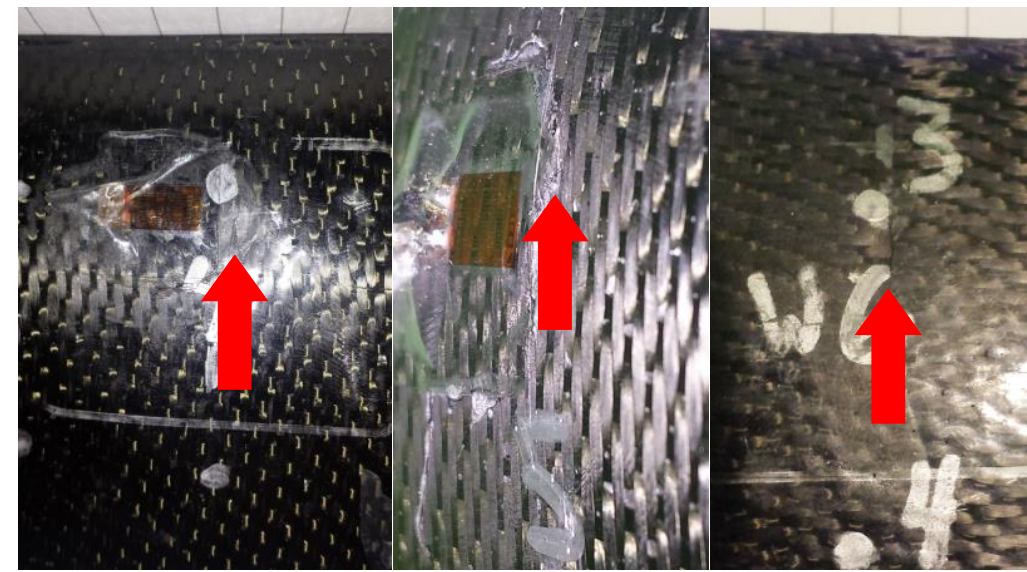

(a) (b) (c)

Figure 5.3.3: Views of wing damage for Wings 4 (a), 5 (b) and 6 (c)

Work-Energy principle and is explained with Equation 5.3.1 where $\mathrm{m}$ is the mass of the object, $\mathrm{V}$ is the impact velocity of the impact, $\mathrm{F}$ is the impact force, and $\mathrm{d}$ is how deep the impact penetrated.

$$
\frac{1}{2} m V^{2}=F * d
$$

In the equation, all of the kinetic energy of the fall is converted into deforming the wing skin and by rearranging Equation 5.3.1; it can be shown the impact force is inversely proportional to the depth of the impact. This principle is the reason why bumpers of cars are designed to deform; the force of a crash is lowered due to the energy dissipation of the bumper. So because Wing 5 has much more skin deformation than the other two wings, the impact force should be lower as the data states. As for the failure mode of the impact over the rib/spar intersection, it seems to just be slight cracking of the wing skin with no visible damage to the internal structure of the wing. As for the strain data measured during the impact, the strain gage for Wing 5 measure a maximum strain of 780 ( $\mu \mathrm{in} / \mathrm{in})$. 


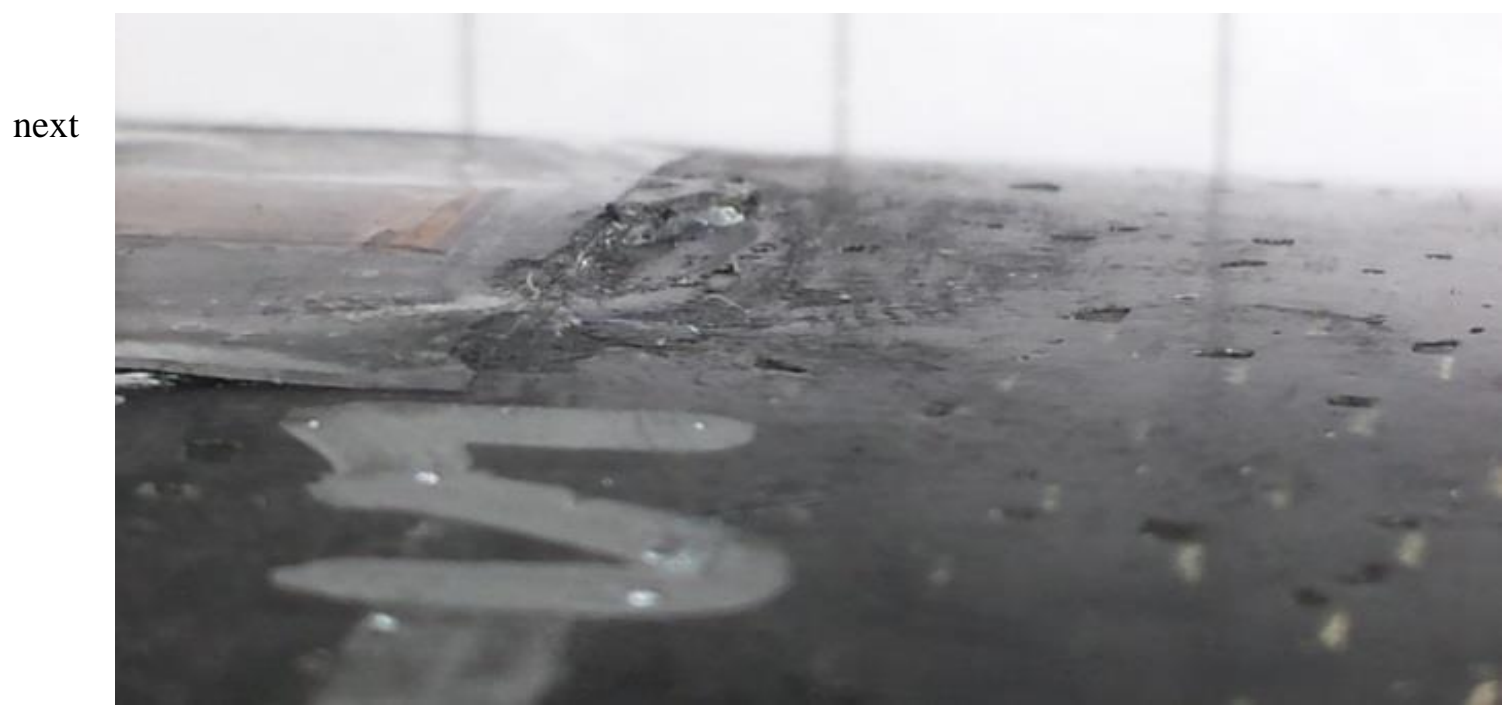

The

Figure 5.3.4: Close up of impact damage sustained by wing

impact location looked at was an impact directly of the leading edge spar, a half inch inward from the middle rib and consisted of Wings 7, 8, and 9. The images of each impact are displayed in Figure 5.3.5. In the figure there is clear cracking of the skin for Wings 7 and 8. As for Wing 9, there is evidence of fibers splitting and cracking in the photo. The impact forces and velocities can be found in Table 5.3-3.

Table 5.3-3: Force and velocity data from impact test of Wings 7, 8 and 9

\begin{tabular}{|c|c|c|}
\hline & Maximum Impact Force $\left(\mathrm{lb}_{\mathrm{f}}\right)$ & Impact Velocity $(\mathrm{ft} / \mathrm{s})$ \\
\hline Wing 7 & 187 & 6.52 \\
\hline Wing 8 & 242 & 6.54 \\
\hline Wing 9 & 285 & 6.44 \\
\hline
\end{tabular}

From this group of impacts, Wing 7 sustained the lowest impact force of $187 \mathrm{lb}_{\mathrm{f}}$ while Wing 9 sustained the highest impact force with $285 \mathrm{lb}_{\mathrm{f}}$. When visually inspecting the damage to each wing, it was clear the most visual damage was seen in Wing 7. There was a clear crack 1.1 inches long running from the leading edge towards the trailing edge. After pressing down onto the impact location, it was evident that the leading edge spar had sustained some heavy damage to the right of the impact site. When pressing down, it was felt that the spar underneath the skin give way as if the vertical portion of the c-channel had 
buckled during the impact.

This same phenomenon

was felt when examining

wing 8 however wing 8

deformed much less when

compared to Wing 7. The

damage of Wing 8 was

also visually smaller than

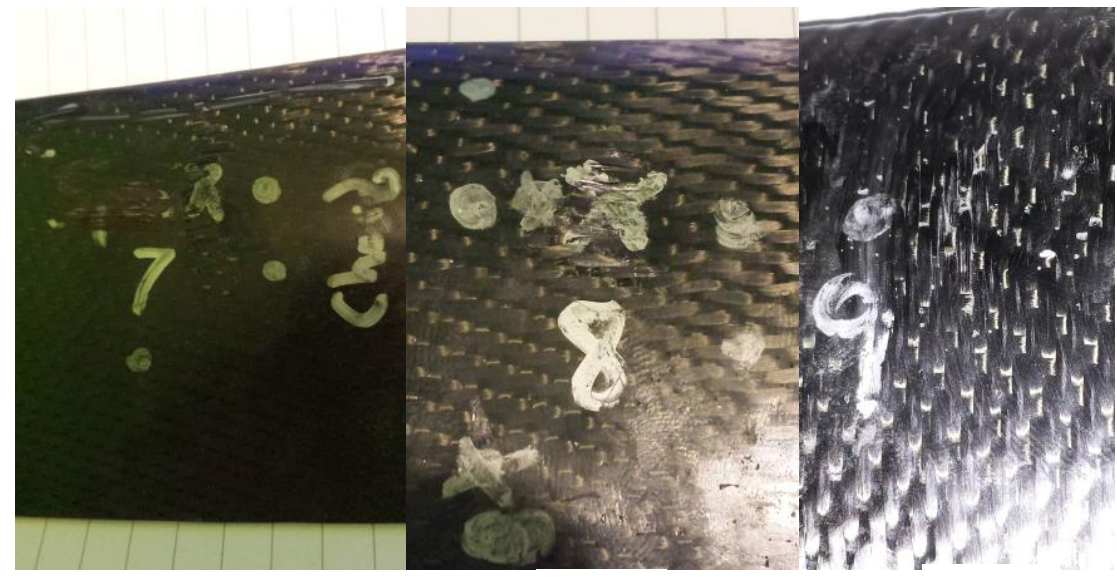

(a) (b) (c)

Wing 7 with the crack

Figure 5.3.5: Views of wing damage for Wings $7(a), 8(b)$ and $9(c)$

length being just under 0.6 inches. A lower amount of damage can also be inferred by again looking at the load cell data from the test runs. So following this trend, Wing 9 should, and does, have the least visible damage among the three wings due to the very minimal amount of surface damage that can be seen. The only visible damage to Wing 9 is a few frayed and broken fibers at the impact site. Also, when firmly pressing down over the impact location of Wing 9, no perceptible deformation occurs like the other two wings suggesting the leading edge spar in this section did not buckle from the impact.

The third impact location tested was the directly over the middle rib at $50 \%$ of the chord. The impact forces and speeds are listed in Table 5.3-4 below and the pictures of the damage sustained are available in Figure 5.3.6. The failure modes for these impacts are more varied than the previous sets. Wing 10 impacted just to the right if the rib and glanced deep into the skin in Figure 5.3.6. There is a nice round hole at the impact site

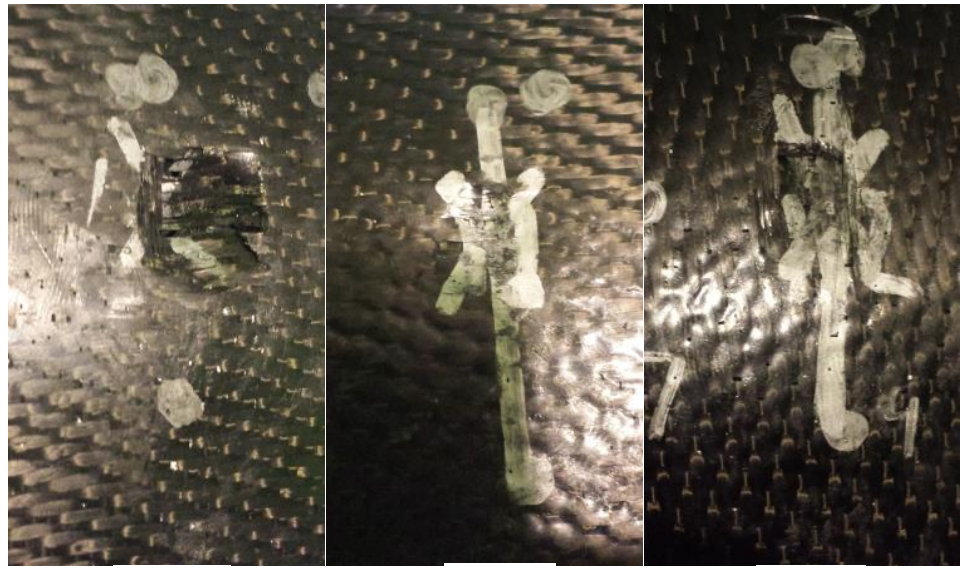

(a) (b)

Figure 5.3.6: Views of wing damage for Wings 10 (a), 11 (b) and 12 (c) where the tup penetrated into the wing. The impact for Wing 11 was directly over the rib and left a small 
dimple in the skin. Wings 12 had the tup glance off of the middle rib and penetrate the wing skin to the right of the wing skin. The impact of Wing 12 was interesting because instead of the skin deforming as Wing 10 had, the skin seemed to crack along the rib and create a sort of flap seeming to slow the tup.

An interesting note is the impact force of Wing 10. When analyzing data it was seen from the force data, two different impacts occurred during this test, the first being the penetration of the skin and glancing off the middle rib and the second is the tup bottoming out against the bottom skin section. The penetration of the skin is low due to how the skin actually is. Figure 5.3.7 shows the force versus time plot of the impact data for Wing 10. In the figure, an initial impact is present and then about 0.005 seconds later there is a second, much stronger impact, which is the top bottoming out against the bottom wing skin and mounting fixture. The reason the impact tup does not penetrate through the next layer of skin is because the fixture that holds the wing in place is pressed directly against the wing skin.

Table 5.3-4: Force and velocity data from impact test of Wings 10, 11 and 12

\begin{tabular}{|c|c|c|}
\hline & Maximum Impact Force $\left(\mathrm{lb}_{\mathrm{f}}\right)$ & Impact Velocity $(\mathrm{ft} / \mathrm{s})$ \\
\hline Wing 10 & $175^{*}$ & 6.50 \\
\hline Wing 11 & 404 & 6.39 \\
\hline Wing 12 & 235 & 6.52 \\
\hline
\end{tabular}

The final impact location was just inward of the middle rib and behind the leading edge spar so only the skin was struck by the impact tup. The impact forces and velocities are listed below in Table 5.3-5 and the images of the impacts can be seen in Figure 5.3.8. The impacting of only the wing skin saw the highest variation between impact forces. Wing 13 was the lowest of the three impact forces. The maximum force measured during impact was only $170 \mathrm{lb}_{\mathrm{f}}$. However, Wing 13 was also the only wing requiring the impact tup to be separated from the wing by force. 


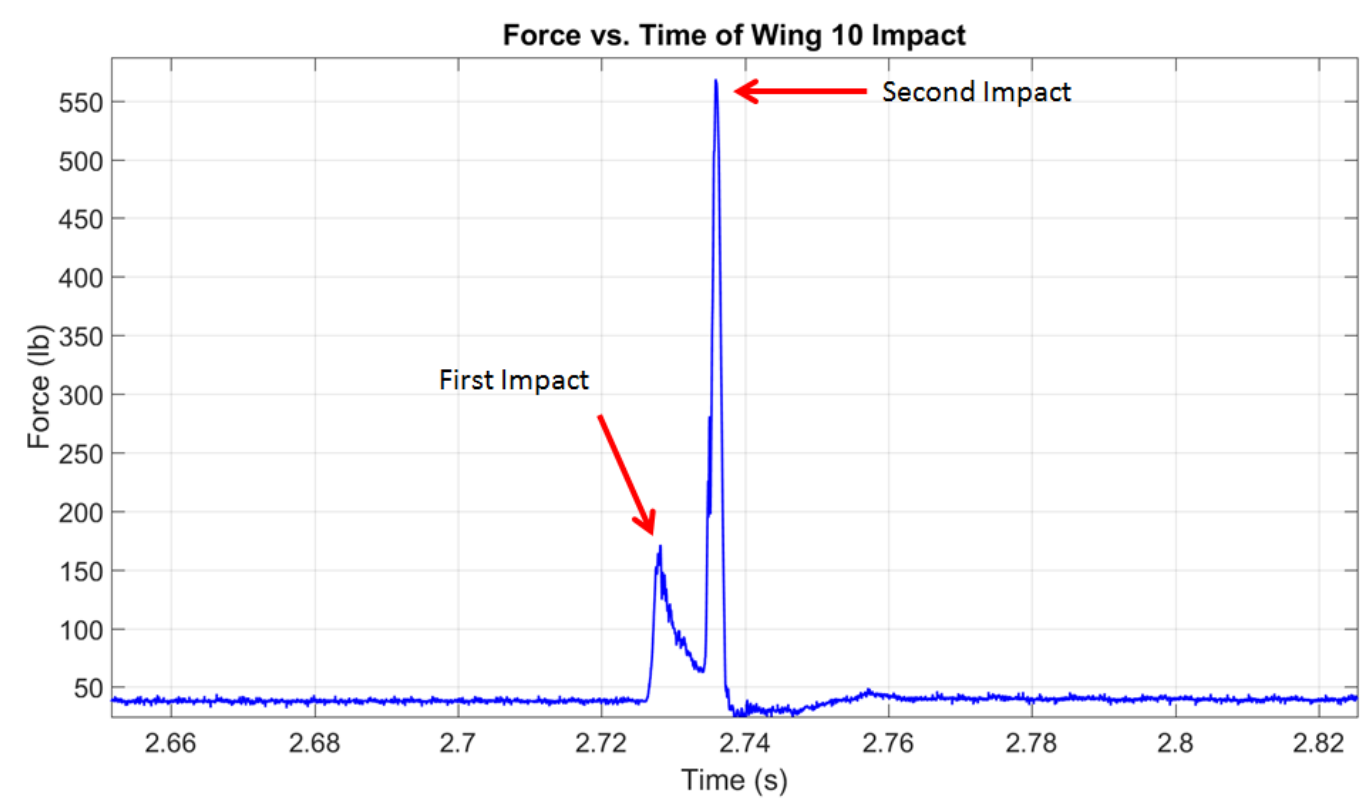

Figure 5.3.7: Force vs. Time history of Wing 10 impact test showing initial impact and the secondary impact forces

Table 5.3-5: Force and velocity data from impact test of wings 13, 14 and 15

\begin{tabular}{|c|c|c|}
\hline & Maximum Impact Force $\left(\mathrm{lb}_{\mathrm{f}}\right)$ & Impact Velocity $(\mathrm{ft} / \mathrm{s})$ \\
\hline Wing 13 & 170 & 6.41 \\
\hline Wing 14 & $205^{*}$ & 6.54 \\
\hline Wing 15 & $195^{*}$ & 6.39 \\
\hline
\end{tabular}

Based upon the visual evaluation of the impact damage for Wing 13, it is likely that instead of tup penetrating the wing all the way to the bottom skin, the carbon deformed in such a way it created a cushion absorbing the energy of the impact force. This is displayed in the force versus time response of Wing 13 shown in Figure 5.3.9. Displayed in Figure 5.3.6, it is clear after the maximum impact force is reached, the energy slowly dissipates. The impact tup and rail seemed to bounce up after impact, because of the slope change in the data. An upward slope means the load cell is being unloaded and since the data moves up and then back down again it means that the tup bounced. 
Wing 14 was also a very interesting impact to analyze. As displayed in Figure 5.3.8, a very long and distinct crack formed parallel to the middle rib and a sort of flap was formed. This flap would have done very little to slow the speed of the impact and this is

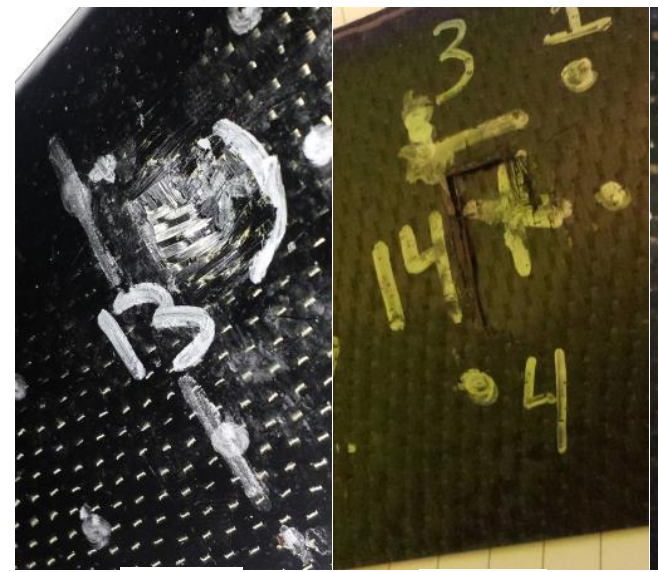

(a)

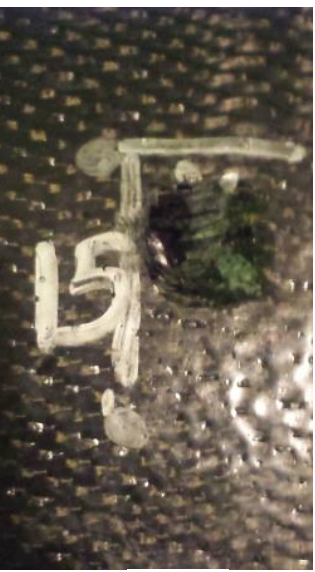

(c)

Figure 5.3.8: View of wing damage for Wings 13 (a), 14 (b) and 15 why the second impact force

measure during the Wing 14 test is so much higher than the other tests. The impact tup hit the bottom of the wing skin at almost full velocity. The force versus time data from Wing 14 is displayed in Figure 5.3.10. When comparing the data shown in Figure 5.3.7 and Figure 5.3.10, the change in force of Figure 5.3.10 is much more abrupt than in Figure5.3.7. What this suggests is the upper layer of skin immediately gave way to the impact force and provided little to no resistance to the impact tup whereas with Figure 5.3.7, the rate of change for force is smoother suggesting the upper portion of wing skin is

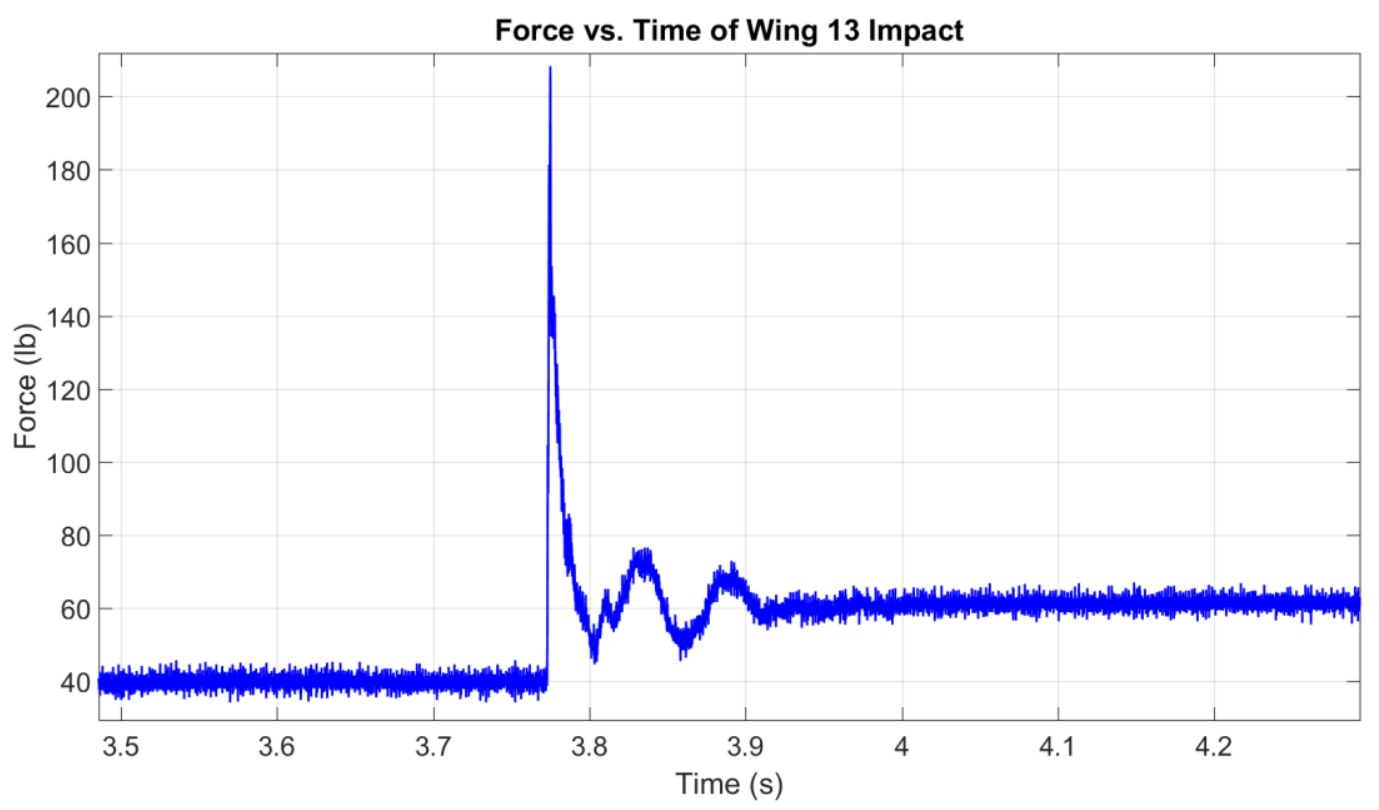

Figure 5.3.9: Force vs. time history of Wing 13 impact test 
resisting the movement of the impact tup, resulting in a lower impact force. Based on the data shown in Figure 5.3.10, the upper portion of wing skin crushing during the test did very little to absorb the kinetic energy of the impact tup. The reason the secondary impact of Wing 14 was so high because it collided with the bottom portion of the wing skin at almost full speed.

As with Wing 14, Wing 15 also had a two-stage impact, but showed a much lower secondary impact. Visually, the impact damage is similar to that of Wing 13 however, when looking closer the damage to the skin is more substantial. For Wing 15, the skin seems to have just been moved away from the point of impact tup during the impact, causing slowing due to friction. However, it was considerably less compared to Wing 13's data. The force versus time data for Wing 15 can be seen in Figure 5.3.11. From the figure, it is shown that at the initial impact there seems to be some resistance by the skin as the force peaks multiple times around $140 \mathrm{lb}_{\mathrm{f}}$ and then slowly decreases until the tup bottoms out and the impact force maxes out at $475 \mathrm{lb}_{\mathrm{f}}$.

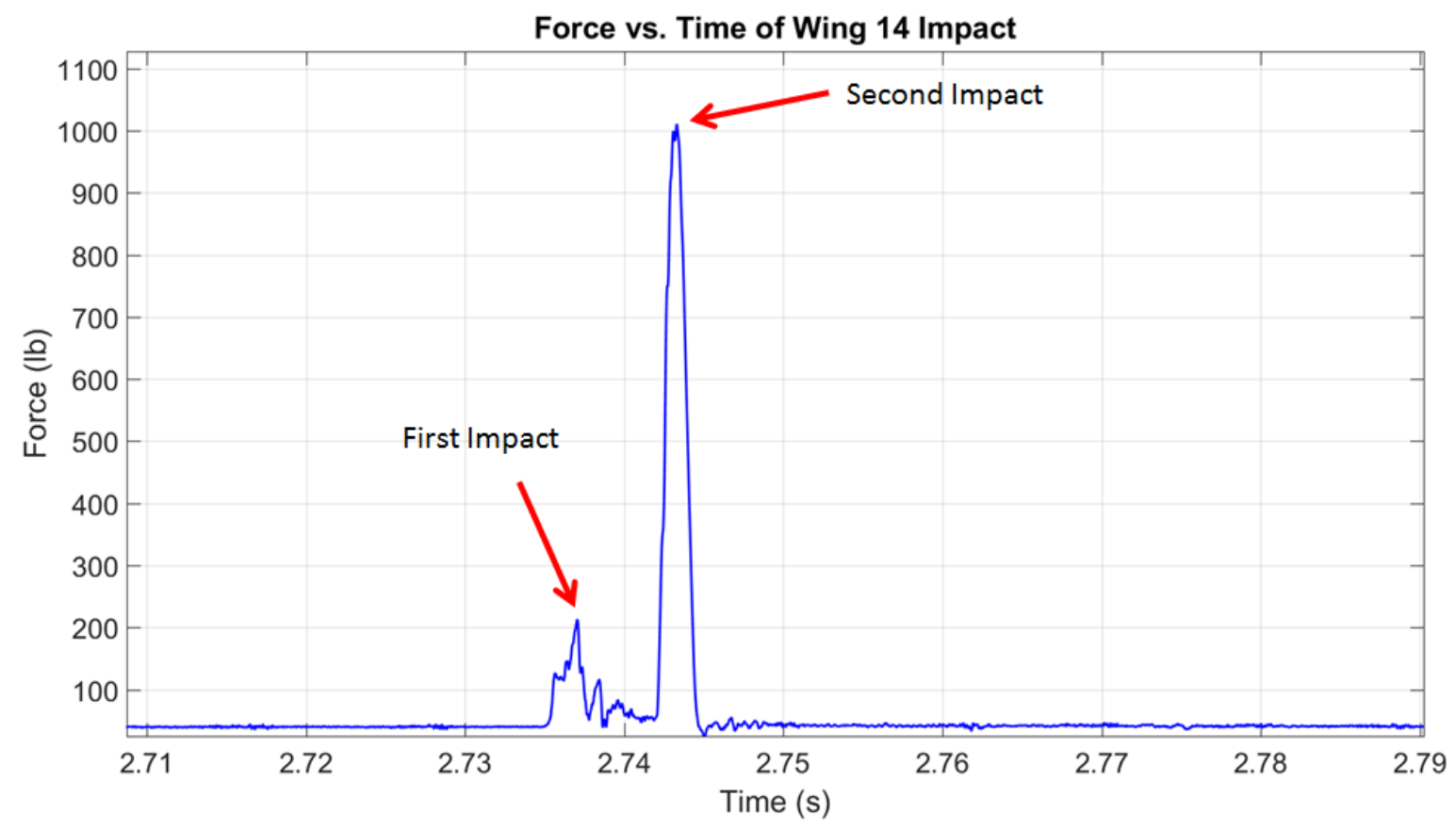

Figure 5.3.10: Force vs. time history of Wing 14 impact showing initial impact and secondary impact forces 
Force vs. Time of Wing 15 Impact

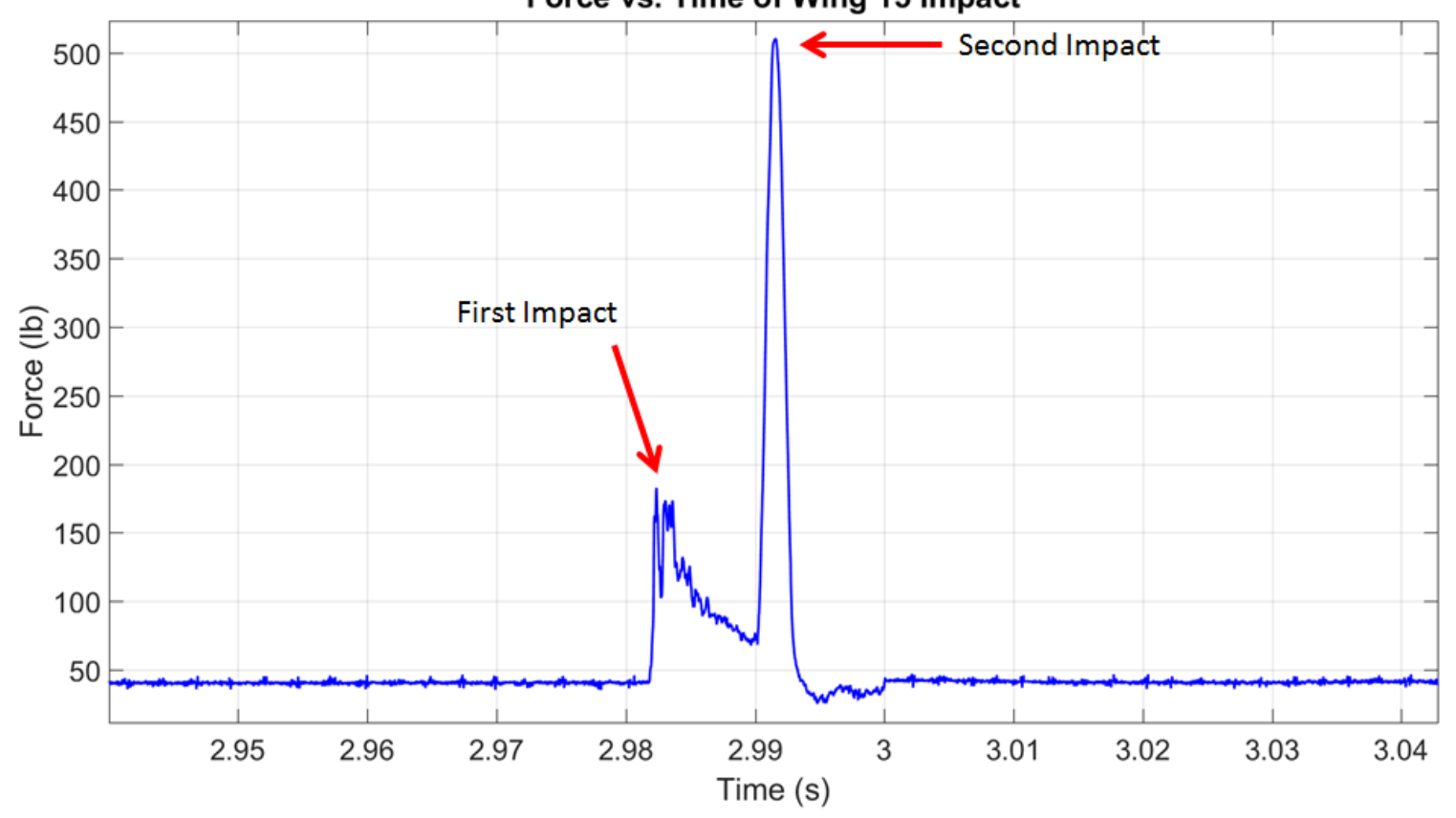

Figure 5.3.11: Force vs. time history of Wing 15 impact showing initial impact and secondary impact forces 


\subsection{Post-Impact Dynamic Testing}

After all the wings were impact tested, they were again tested dynamically to determine whether or not noticeable change existed in the dynamic characteristics of the wing. To determine the natural variation, Wings 1-3 were first analyzed to set the baseline for all of the other wings to be compared to. Table 5.4-1 displays the $1^{\text {st }}$ and $2^{\text {nd }}$ pre- and post-impact dynamic data for Wings 1,2 , and 3 . Based on the data below, the natural variation for the $1^{\text {st }}$ mode resonant frequency is $4 \mathrm{~Hz}$ while the natural variation of the average damping ratio is 0.0015 . Now the natural variation can be caused by many different factors. One factor that could have an effect is the stress from the multiple dynamic tests could cause some internal damage to the adhesive or various parts of the wing. Another aspect that could have affected the results is how the wing was mounted for each test. If the screws holding the wing in place or the top plate were tightened differently, it could have an effect on the results. One last possibility is the structure just has some natural variation from test to test due to the high complexity of the structure.

Table 5.4-1: Comparison of pre- and post-impact data for wings 1, 2 and 3

\begin{tabular}{|c|c|c|c|}
\hline & Wing 1 & Wing 2 & Wing 3 \\
\hline $\begin{array}{c}\text { Average Pre-Impact } 1^{\text {st }} \\
\text { Mode Natural } \\
\text { Frequency (Hz) }\end{array}$ & 198 & 193 & 193 \\
\hline $\begin{array}{c}\text { Average Post-Impact } \\
1^{\text {st }} \text { Mode Natural } \\
\text { Frequency (Hz) }\end{array}$ & 200 & 194 & 2.12 \\
\hline \% Change & 1.01 & 0.52 & 0.0164 \\
\hline $\begin{array}{c}\text { Average Pre-Impact 1 } \\
\text { Mode Damping Ratio }\end{array}$ & 0.0160 & 0.0149 & 0.0172 \\
\hline $\begin{array}{c}\text { Average Post-Impact } \\
1^{\text {st }} \text { Mode Damping } \\
\text { Ratio }\end{array}$ & 0.0143 & 0.0155 & 864 \\
\hline \% Change & -10.625 & & \\
\hline $\begin{array}{c}\text { Average Pre-Impact 2 } \\
\text { Mode Natural } \\
\text { Frequency (Hz) }\end{array}$ & 864 & 8.03 & 869 \\
\hline $\begin{array}{c}\text { Average Post-Impact } \\
2^{\text {nd }} \text { Mode Natural } \\
\text { Frequency (Hz) }\end{array}$ & 873 & & \\
\hline \% Change & -1.04 & 0.36 & 0.58 \\
\hline $\begin{array}{c}\text { Average Pre-Impact 2 } \\
\text { Mode Damping Ratio }\end{array}$ & 0.0215 & 0.0223 & \\
\hline
\end{tabular}




\begin{tabular}{|c|c|c|c|}
\hline $\begin{array}{c}\text { Average Post-Impact } \\
2^{\text {nd }} \begin{array}{c}\text { Mode Damping } \\
\text { Ratio }\end{array}\end{array}$ & 0.0194 & 0.0146 & 0.0224 \\
\hline$\%$ Change & -9.76 & -34.53 & 53.42 \\
\hline
\end{tabular}

The second mode variation was also fairly low with the highest frequency change being $9 \mathrm{~Hz}$. However, a large change occurred in the second mode damping ratio for Wings 2 and 3 with the change being a decrease 0.0077 for Wing 2 and an increase of 0.0077 for wing 3. Any change larger than this will be considered evidence of damage.

We will begin examining Wing 6. As mentioned earlier in Chapter 5.2; Wings 4 and 5 would only be used for determining the strain damage sustained by the wing. As for wing 6 , the pre- and postimpact data is listed in Table 5.4-2. Based upon the average damping ratio changes, there is no evidence this wing has sustained any damage even though it was impacted and damaged from testing. However, when looking at the damping ratio changes from point to point for Wing 6, a very large change occurred for the $2^{\text {nd }}$ mode damping ratio at point 3 , which is where this wing was impacted. The pre-impact $2^{\text {nd }}$ mode damping ratio for wing 6 at point 3 was 0.0260 and the post-impact $2^{\text {nd }}$ mode damping ratio was 0.0137 .

Table 5.4-2: Comparison of pre- and post-impact data for wing 6

\begin{tabular}{|c|c|}
\hline & Wing 6 \\
\hline $\begin{array}{l}\text { Average Pre-Impact } 1^{\text {st }} \text { Mode Natural Frequency } \\
\qquad(\mathrm{Hz})\end{array}$ & 195 \\
\hline $\begin{array}{c}\text { Average Post-Impact } 1^{\text {st }} \text { Mode Natural Frequency } \\
(\mathrm{Hz})\end{array}$ & 195 \\
\hline \% Change & 0.0 \\
\hline Average Pre-Impact $1^{\text {st }}$ Mode Damping Ratio & 0.0168 \\
\hline Average Post-Impact $1^{\text {st }}$ Mode Damping Ratio & 0.0170 \\
\hline$\%$ Change & 1.01 \\
\hline $\begin{array}{c}\text { Average Pre-Impact } 2^{\text {nd }} \text { Mode Natural Frequency } \\
(\mathrm{Hz})\end{array}$ & 884 \\
\hline $\begin{array}{c}\text { Average Post-Impact } 2^{\text {nd }} \text { Mode Natural } \\
\text { Frequency }(\mathrm{Hz})\end{array}$ & 873 \\
\hline$\%$ Change & -1.24 \\
\hline Average Pre-Impact $2^{\text {nd }}$ Mode Damping Ratio & 0.0207 \\
\hline Average Post-Impact $2^{\text {nd }}$ Mode Damping Ratio & 0.0172 \\
\hline$\%$ Change & -16.91 \\
\hline
\end{tabular}


This represented a decrease in the damping ratio by 0.0123 . What this means is this region of the wing became stiffer in the $2^{\text {nd }}$ mode after impact. This can be best illustrated by looking at the second mode time response of point 3 on Wing 6 seen in Figure 5.4.1. In the figure, the red line represents the time response of before the wing was impacted while the blue line represents the post-impact time response. As shown in the figure, it is clear that location 3 now dissipates less energy over time. This region of the wing was so robust due to the high concentration of adhesive and carbon in this region, the energy of the impact was not sufficient enough to cause damage and instead, compressed the region, increasing the stiffness at point 3. The impact for wing 6 was also the second highest of all of the impact forces (939 $\mathrm{lb}_{\mathrm{f}}$ ), being second to wing 14 where the impact tup struck directly into the bottom of the wing skin. The high measured impact force says that there was very little deformation of the wing in this region and the

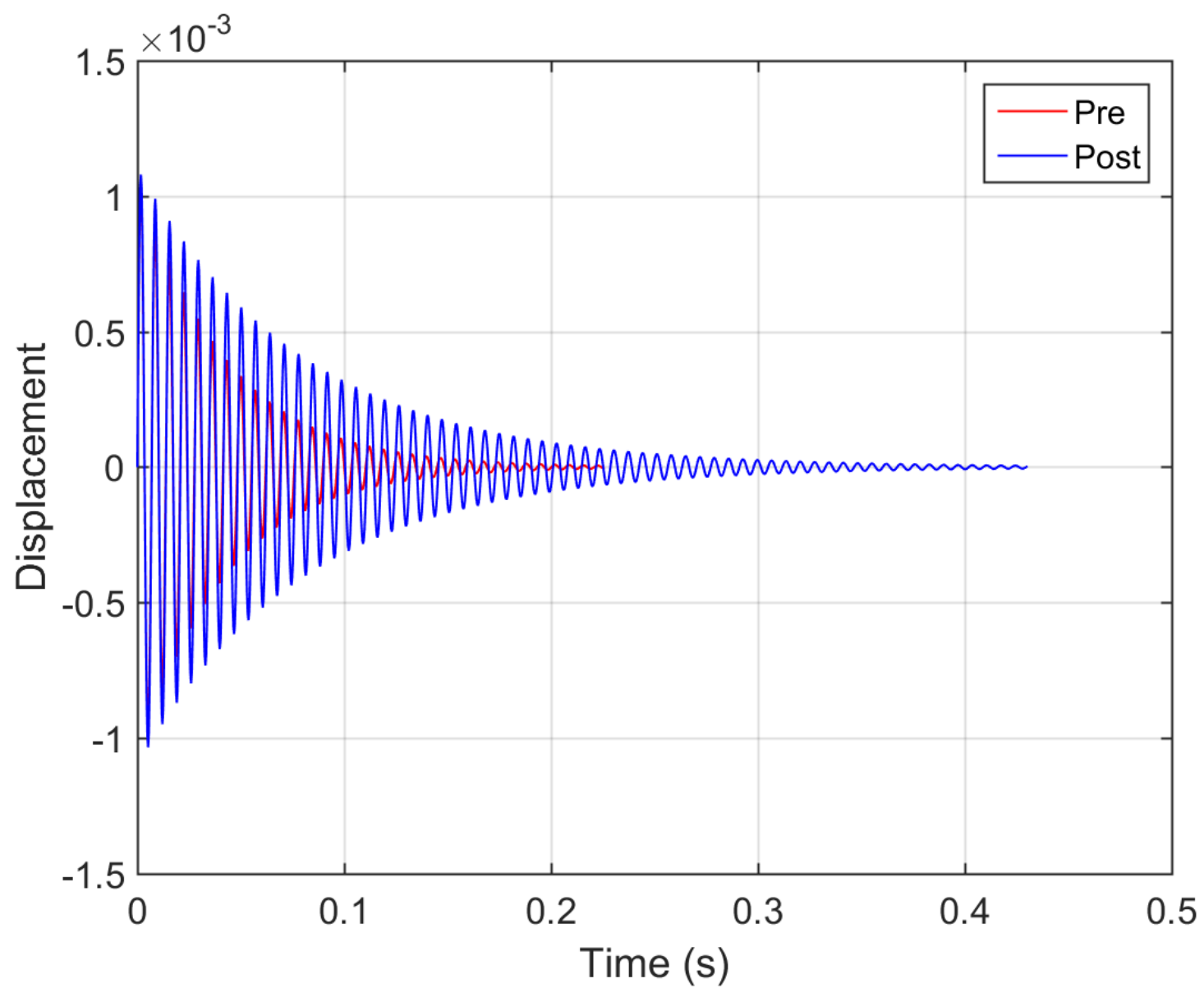

Figure 5.4.1: Second mode time response for Wing 6 at point 3 showing the effects of the impact damage on the time response 
decrease in the second mode damping ratio says that the adhesive did not dis-bond from the wing skin but was instead compressed and hardened. All of the other tested locations for wing 6 showed no sign of significant change after impact testing. So for Wing 6 it can be said that damage to the wing was localized to just the impact region and did not dissipate to areas around the rib/spar intersection.

The next set of wings that will be analyzed are Wings 7,8 , and 9 which were impacts directly over the leading edge spar. Table 5.4-3 lists the pre- and post-impact $1^{\text {st }}$ and $2^{\text {nd }}$ mode natural frequencies and damping ratios. Again, previewing the data and comparing the average changes to what was seen in the control samples, no value stands out. The largest change of any of the values is the second mode damping ratios of Wing 8 with a decrease in the damping ration of 0.0055 and wing 7 with an increase in the damping ratio by 0.0049 . However, these damping ratio changes are within the natural variation of the control samples (wings 1-3). The impact location for this set of wings was directly between points 1 and 3 and points 2 and 4 were also very close to this region.

Table 5.4-3: Comparison of pre- and post-impact data for Wings 7, 8 and 9

\begin{tabular}{|c|c|c|c|}
\hline & Wing 7 & Wing 8 & Wing 9 \\
\hline $\begin{array}{c}\text { Average Pre-Impact } 1^{\text {st }} \\
\text { Mode Natural } \\
\text { Frequency (Hz) }\end{array}$ & 195 & 189 & 187 \\
\hline $\begin{array}{c}\text { Average Post-Impact } \\
1^{\text {st }} \text { Mode Natural } \\
\text { Frequency (Hz) }\end{array}$ & 189 & 189 & -0.53 \\
\hline \% Change & -3.07 & 0.0 & 0.0162 \\
\hline $\begin{array}{c}\text { Average Pre-Impact 1 } \\
\text { Mode Damping Ratio }\end{array}$ & 0.0198 & 0.0158 & 0.0167 \\
\hline $\begin{array}{c}\text { Average Post-Impact } \\
1^{\text {st }} \text { Mode Damping } \\
\text { Ratio }\end{array}$ & 0.0191 & 0.0163 & 3.09 \\
\hline \% Change & -3.54 & & 795 \\
\hline $\begin{array}{c}\text { Average Pre-Impact 2 } \\
\text { Mode Natural } \\
\text { Frequency (Hz) }\end{array}$ & 874 & 868 & 788 \\
\hline $\begin{array}{c}\text { Average Post-Impact } \\
2^{\text {nd }} \text { Mode Natural } \\
\text { Frequency (Hz) }\end{array}$ & & & \\
\hline \% Change & 815 & 839 & -0.88 \\
\hline $\begin{array}{c}\text { Average Pre-Impact 2 } \\
\text { Mode Damping Ratio }\end{array}$ & 0.0190 & -3.34 & 0.0232 \\
\hline
\end{tabular}




\begin{tabular}{|c|c|c|c|}
\hline $\begin{array}{c}\text { Average Post-Impact } \\
2^{\text {nd }} \begin{array}{c}\text { Mode Damping } \\
\text { Ratio }\end{array}\end{array}$ & 0.0239 & 0.0193 & 0.0200 \\
\hline$\%$ Change & 25.79 & -22.17 & -13.79 \\
\hline
\end{tabular}

When comparing the damping ratio changes on a point by point basis, some trends do begin to

emerge. For the $2^{\text {nd }}$ mode of Wing 7 , there was a noticeable damping ratio increase at points 1,5 , and 9.

The value increase for each point was just above 0.0200 and the change to the time response of Location 1 is shown in Figure 5.4.2. From Figure 5.4.2, the damping ratio increased after impact suggesting damage was sustained to the wing. There were also observed decreases to the $2^{\text {nd }}$ mode damping ratio of Wing 7 at Locations 3, 7, and 8. The decrease in the damping ratio also suggests a change has occurred in the wing structure which was caused by the impact damaged sustained by the wing. So for Wing 7 , when analyzing the individual locations, it is very evident some damage was sustained by Wing 7 . Wing

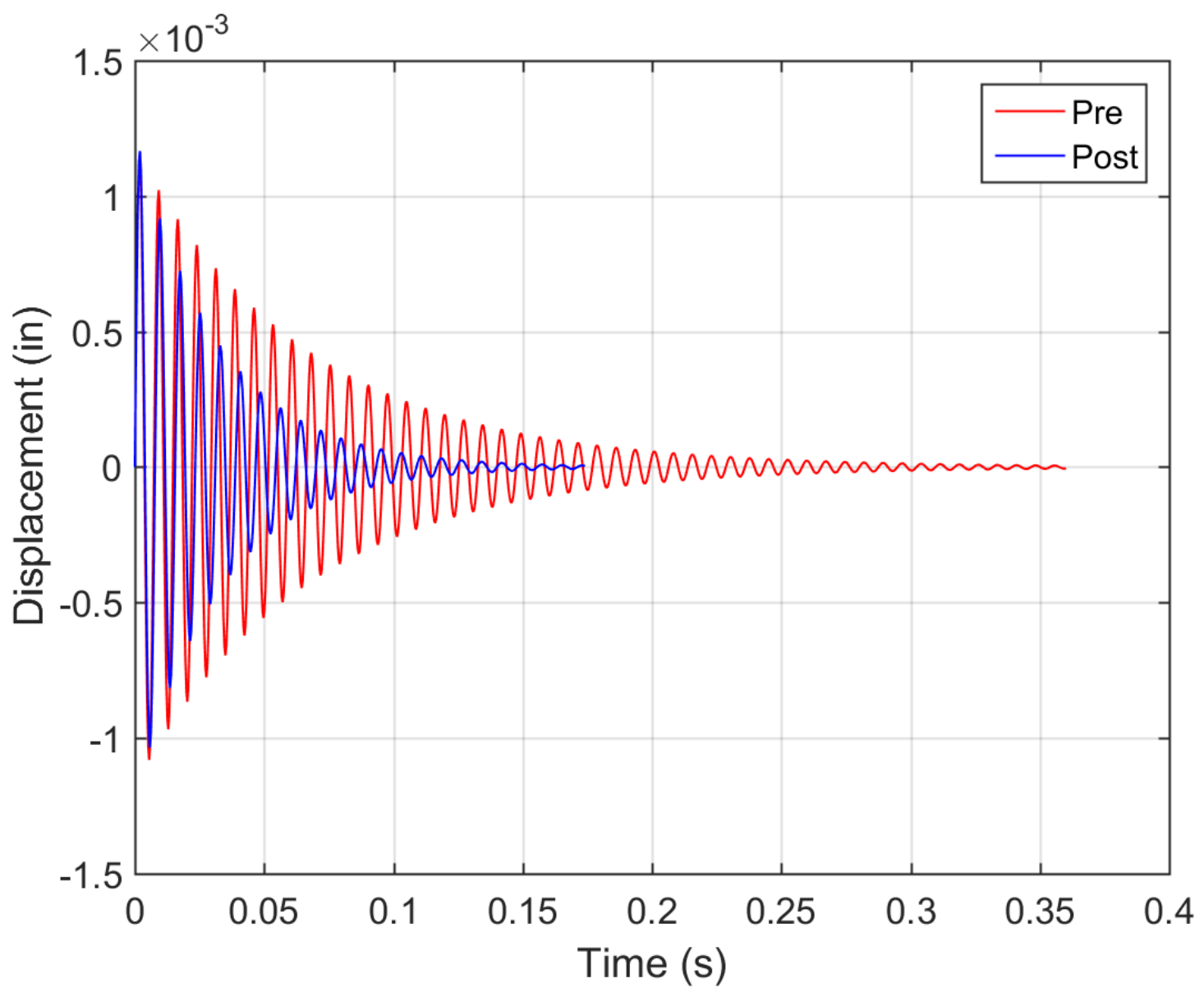

Figure 5.4.2: Second mode time response of Wing 7 at point 1 showing the effect of the impact damage in the time response 
8 also showed no noticeable change for the $1^{\text {st }}$ mode time response of the wing but did show a drastic change for some locations of the $2^{\text {nd }}$ mode. The largest change was at location 1 . With the damping ratio decreasing as can be seen from the time response at point 1 for Wing 8 shown in Figure 5.4.3. Wing 9 had the most variations with some ratios increasing while some others decreased. With the average damping ratio, no noticeable change was seen. The largest change for Wing 9 came at point 4 which is located just to the right of the impact sight.

Wings 10 and 11 had the same story where there was no large change to the damping ratios; however Wing 12 has a large change in the average $1^{\text {st }}$ mode damping ratio. Wing 12 is the only wing to have shown a large change of the $1^{\text {st }}$ mode damping ratio. Wing 12 showed an increase in damping ratio for all 9 locations measured with the minimum increase being 0.0051 , which is well outside the natural variation set by the control set of wings.

Table 5.4-4: Comparison of pre- and post-impact data for wings 10, 11 and 12

\begin{tabular}{|c|c|c|c|}
\hline & Wing 10 & Wing 11 & Wing 12 \\
\hline $\begin{array}{c}\text { Average Pre-Impact } 1^{\text {st }} \\
\text { Mode Natural } \\
\text { Frequency }(\mathrm{Hz})\end{array}$ & 194 & 189 & 196 \\
\hline $\begin{array}{c}\text { Average Post-Impact } \\
1^{\text {st }} \text { Mode Natural } \\
\text { Frequency }(\mathrm{Hz})\end{array}$ & 194 & 198 & 187 \\
\hline \% Change & 0.0 & 4.76 & -4.59 \\
\hline $\begin{array}{l}\text { Average Pre-Impact } 1^{\text {st }} \\
\text { Mode Damping Ratio }\end{array}$ & 0.0153 & 0.0160 & 0.0155 \\
\hline $\begin{array}{c}\text { Average Post-Impact } \\
1^{\text {st }} \text { Mode Damping } \\
\text { Ratio }\end{array}$ & 0.0150 & 0.0164 & 0.0224 \\
\hline \% Change & -1.96 & -2.50 & -44.51 \\
\hline $\begin{array}{c}\text { Average Pre-Impact } 2^{\text {nd }} \\
\text { Mode Natural } \\
\text { Frequency }(\mathrm{Hz})\end{array}$ & 870 & 805 & 861 \\
\hline $\begin{array}{l}\text { Average Post-Impact } \\
2^{\text {nd }} \text { Mode Natural } \\
\text { Frequency }(\mathrm{Hz})\end{array}$ & 869 & 903 & 857 \\
\hline$\%$ Change & -0.12 & 12.17 & -0.46 \\
\hline $\begin{array}{l}\text { Average Pre-Impact } 2^{\text {nd }} \\
\text { Mode Damping Ratio }\end{array}$ & 0.0151 & 0.0205 & 0.0170 \\
\hline
\end{tabular}




\begin{tabular}{|c|c|c|c|}
\hline $\begin{array}{c}\text { Average Post-Impact } \\
2^{\text {nd }} \begin{array}{c}\text { Mode Damping } \\
\text { Ratio }\end{array}\end{array}$ & 0.0147 & 0.0185 & 0.0147 \\
\hline$\%$ Change & -2.65 & -9.75 & -13.53 \\
\hline
\end{tabular}

The impact location for this batch of wings was directly over the middle rib and while Wings 10 and 12 sustained impacts that glanced off of the middle rib and punctured down into the skin, Wing 11 showed a direct impact onto the middle rib and the full force of the impact was felt at this location. The change to the first mode time response at Location 4, directly behind the impact site, is seen in Figure 5.4.4. One reason for the large change in the first mode damping ratios for Wing 12 was the location of the impact. Now it is very interesting that Wing 12 , with a low impact force of $235 \mathrm{lb}_{\mathrm{f}}$, is the only wing so far to show any distinct sign of a major change to the structure's dynamic characteristics when Wing 6, which

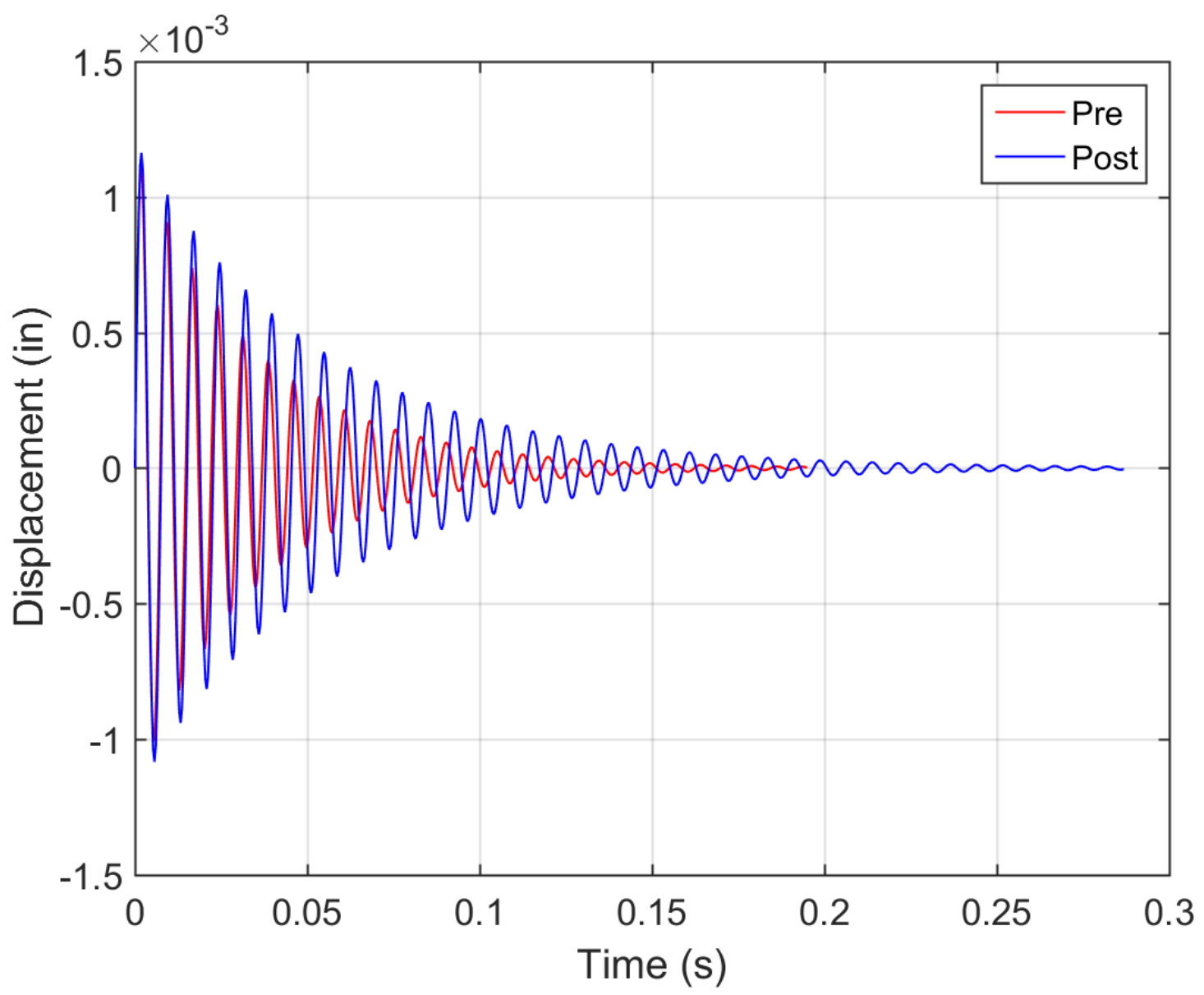

Figure 5.4.3: Second mode time response for Wing 8 at point 1 showing the effects of the impact damage on the time response 
had recorded the largest impact force, only showed signs of damage at a single measurement point.

When comparing the tests of Wing 6 and Wing 12, a clear contrast can be seen that fits with the work-energy principle. Wing 6 measured a very high impact force and showed very little visible damage whereas Wing 12 measured a very low impact force while there was a large visible crack in the skin. The reason Wing 12 showed a large change in the dynamic properties of the first bending mode is in part, due to the high amount of energy that was transferred into the structure at a key location. The middle rib is the only impacted location that is directly connected to both the leading and trailing edge spars. A strike at this location could allow the energy from the impact to effect the rest of the internal structure the most effectively. Wing 6 did not show a large change because the impact was at the most robust portion of the wing and the adhesive resisted the impact energy very well, reflecting most of the energy back into the impact tup. This is why the force measurement for this test was so high, while Wing 12 had very little adhesive near the impact region so the impact energy was transferred into the structure. Also, because the rib was thicker than the spars it did not compress to the degree the leading edge spar did which leads to another reason as to why this specific wing showed such a large change. With the leading edge spar impact, most of the energy was absorbed by the crushing of the leading edge spar and skin in this region. With the rib being thicker and stiffer, less of the energy from the impact went into deforming the composite and more was absorbed into the structure and bonds. As stated earlier, Wings 10 and 11 did not show this same result due to the impact tup not perfectly aligning with the rib at contact. No wings from this batch showed any large change for the second mode response as well. One reason this could be true is that the region of the impact was located at a node of the second mode. There is little to no deflection at the impact site, so during the second mode excitation, the impact damage has little effect to the modal response. 


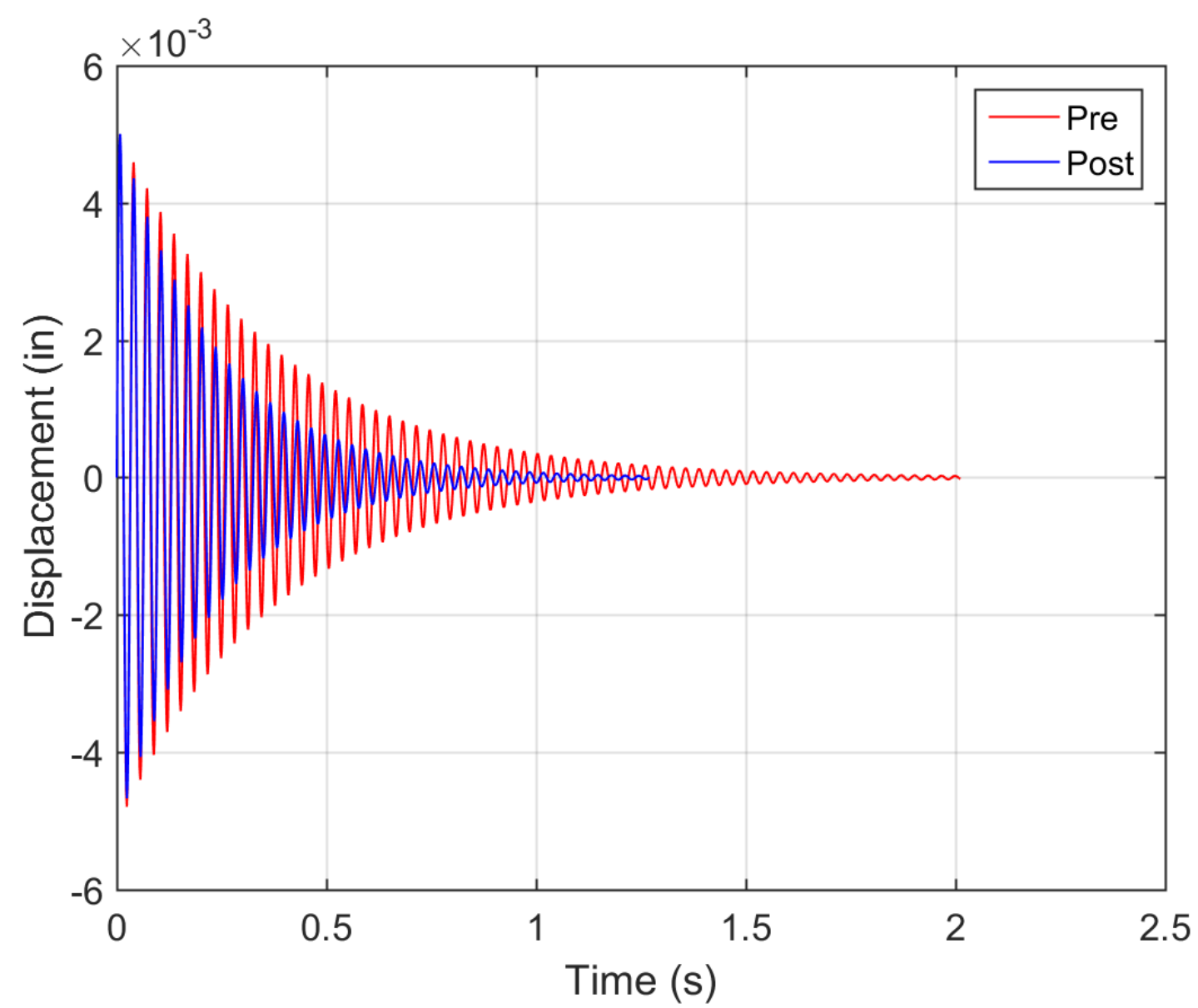

Figure 5.4.4 First mode time response for Wing 12 at point 4 showing the effects of the impact damage on the time response

The final group of Wings $(13,14$, and 15) consisted of impacts directly over the skin. The preand post-impact averages can be seen in Table 5.4-5. Wing 13 showed no significant change for either the first or second mode dynamic response. As a reminder, the Wing 13 impact measured a very low impact force of $170 \mathrm{lb}_{\mathrm{f}}$ while sustaining a large circular deformation of the skin. Since the impact was localized to the skin, and the skin is less stiff relative to the rest of the structure, it was not expected for damage to be visible for this impact location. The reason is because the skin will be able to absorb more of the impact energy due to the low stiffness of this region of the design. Wing 15 also showed little variation for the pre- and post-impact data. Wing 14, like Wing 12, showed a dramatic increase to the average damping ratio for the 1st bending mode which is interesting because a skin impact should not affect the rest of the structure so drastically. However recall that wing 14 recorded two different 
impacts, the second measured the highest impact force of $972 \mathrm{lb}_{\mathrm{f}}$, which could explain what occurred to Wing 14. What happened was initially the wing skin cracked (as shown in Figure 5.3.7) but did little to slow the speed of the impact tup causing the impact tup to smash into the bottom of the wing at full speed. Since a high force was measured, it is known little deformation occurred, but unlike the impact of Wing 6, which also measures a force close to this, no adhesive reinforcement existed in the impact site.

The lack of adhesive near the impact location caused the energy imparted into the structure to disperse outward along the wing, causing dis-bonding of the skin and the internal structure.

Table 5.4-5: Comparison of pre- and post-impact data for Wings 13, 14 and 15

\begin{tabular}{|c|c|c|c|}
\hline & Wing 13 & Wing 14 & Wing 15 \\
\hline $\begin{array}{c}\text { Average Pre-Impact 1 } \\
\text { Mode Natural } \\
\text { Frequency (Hz) }\end{array}$ & 196 & 189 & 194 \\
\hline $\begin{array}{c}\text { Average Post-Impact } \\
1^{\text {st }} \text { Mode Natural } \\
\text { Frequency (Hz) }\end{array}$ & 197 & 184 & \\
\hline \% Change & 0.51 & -2.64 & -0.51 \\
\hline $\begin{array}{c}\text { Average Pre-Impact 1 } \\
\text { Mode Damping Ratio }\end{array}$ & 0.0139 & 0.0155 & 0.0148 \\
\hline $\begin{array}{c}\text { Average Post-Impact } \\
1^{\text {st }} \text { Mode Damping } \\
\text { Ratio }\end{array}$ & 0.0136 & 0.0203 & 0.0144 \\
\hline \% Change & -2.16 & 30.96 & -2.70 \\
\hline $\begin{array}{c}\text { Average Pre-Impact 2 } \\
\text { Mode Natural } \\
\text { Frequency (Hz) }\end{array}$ & 887 & 858 & 871 \\
\hline $\begin{array}{c}\text { Average Post-Impact } \\
2^{\text {nd }} \text { Mode Natural } \\
\text { Frequency (Hz) }\end{array}$ & 872 & & \\
\hline \% Change & 10.81 & 844 & -1.60 \\
\hline $\begin{array}{c}\text { Average Pre-Impact 2 } \\
\text { Mode Damping Ratio }\end{array}$ & 0.0148 & -1.63 & 0.0167 \\
\hline $\begin{array}{c}\text { Average Post-Impact } \\
2^{\text {nd }} \text { Mode Damping } \\
\text { Ratio }\end{array}$ & 0.0164 & 0.0185 & 0.0134 \\
\hline \% Change & & 0.0174 & \\
\hline
\end{tabular}

The impact of Wing 6 occurred directly over the adhesive which stopped the energy if the impact from disbursing through the internal structure. The adhesive at the rib/spar intersection is what prevented the damage form the Wing 6 impact from spreading. 


\section{Finite Element Analysis (FEA)}

Chapter 6 discusses the methodology used to create the wing and analyze the finite element model of the wing design. Section 1 discusses the initial problems with using ANSYS [35] to perform the finite element analysis and why a switch to Abaqus [34] was made. Section 2 discusses the method used in creating the model of the wing beginning with the creation of each individual part as well as the assigning of the material properties. Also covered in this section is how the model was structured so all of the parts in the model interact properly and how the mesh was applied. Section 3 discusses how the frequency analysis was setup and performed on the model as well as comparing the numerical results to the experimental results. Section 4 begins by explaining the creation of the plate model to verify the impact step of the model by comparing experimental and numerical strain data. Finally in Section 4, the creation of the tup and the steps required for the explicit dynamic solver are discussed as well as a comparison of the experimental and numerical strain results for the wing structure.

\subsection{Selecting an FEA solver}

There are many different programs that can be used to perform FEA, each with its own specialty. Some solvers are better used for dynamic simulations whereas other solvers are superior for static or fluid simulations. The programs available for this research project were ANSYS and Abaqus.

At the start of this thesis, ANSYS was planned to be used as the modeling tool and solver because the software integrated with Solidworks so imported parts did not decrease in quality. This meant the curved surfaces of the ribs and skin would not become blocky after importing, which was a problem when importing parts into Abaqus. ANSYS was also very simple to use, as the setup for projects was very streamlined. However, problems using the meshing tools with ANSYS arose. ANSYS automatically meshes the parts of an assembly and had trouble making a quality mesh along the trailing edge of the skin. Another problem was meshes becoming distorted due to bonding conditions between the various parts in the assembly. When bonding the skin to the spars, nodes and elements would be distorted, causing the solution in those areas to lose resolution. Based on these problems, the FEA 
package was switched from ANSYS to Abaqus. Abaqus is not as user friendly as ANSYS and does not work well with imported parts, but the meshing tools of Abaqus were much easier to use and customize. For this reason, it was decided to use Abaqus for numerical validation.

\subsection{Building the Model}

The model was built in Abaqus by first creating a 2D sketch of the NACA 2412 airfoil and importing it into the model. The sketch was created using XFLR5 [36]. This program created a text file containing the $\mathrm{X}$ and $\mathrm{Y}$ coordinates based on percent chord. XLFR5 interface is displayed in Figure 6.2.1. In order to scale the $\mathrm{X}$ and $\mathrm{Y}$ coordinates to match the 3 inch chord length of the specimen, the data was read into MATLAB and then scaled to match the real world specimen, then exported to a new text file. Next the sketch was imported into Abaqus to begin the process of making the assembly of the model. The airfoil sketch was used as a basis to create all of the parts inside of Abaqus. To reduce the computation time of the model, every part was modeled as a shell. This was possible because the thickness of the various parts is smaller compared to the width and length of each part. The major consideration that needs to be taken when working with shells is the model needs to represent the midsurface of whatever part is being created. This is required because shells are modeled with no thickness; however that does not mean the thickness of each part is not important. The thickness of the part is used during the numerical solving of the model. The thickness of each shell is assigned in the second step of the FEA model assembly.

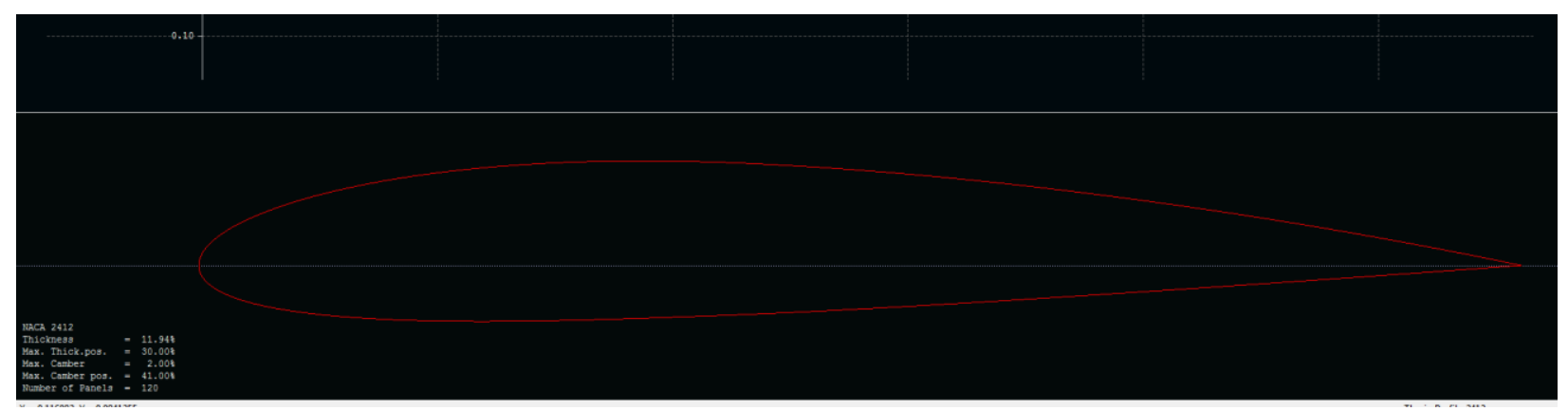

Figure 6.2.1: Creation of NACA 2412 airfoil $X$ and $Y$ coordinates in XFLR5 for use in Abaqus 
The first step done in Abaqus was to model each part of the wing. This was done in the part module by first creating a sketch of the part after selecting the base feature for the part. The base feature used for the skin and spars was a 3D deformable shell extrusion while the ribs were modeled as3D deformable planar shells. The ribs were the simplest parts to create because the sketch was already created using XFLR5. The imported sketch is displayed in Figure 6.2.2. In the figure are four vertical construction lines that were placed in the sketch to mark the locations of the spars. These lines expedited the creation of the spars. All that was needed to do for the ribs after importing the sketch was to save the part. However, the mounting rib required an extra step; the mounting holes needed to be added to the part. The holes were modeled as 0.635 inch diameter circles in the sketch and were located to mimic the specimen ribs. Figure 6.2.3 shows the sketch of the mounting rib with the holes. After the ribs were created the next part made was the skin. As mentioned earlier, the skin was modeled as a 3D deformable shell extrusion and was again, based off of the XFLR5 airfoil sketch. Recall the shells must be modeled as the mid-planes of the respective parts, which means that the imported sketch will require a slight modification in order to accurately model the wing skin. To correctly model the mid-plane of the wing skin, the airfoil sketch needed to have each point moved outward by 0.0075 inches, or half a ply thickness of LTM45EL. This was done easily as Abaqus has an "Offset Curves" which offset the skin outward from the center by 0.0075 inches. Once the offset was complete, the profile was extruded to match the same length of the wing specimens. The final two parts that needed to be created were the spars. Again, 3D deformable shell extrusions were created and the XFLR5 sketch was imported. The profile again needed to be offset, but only in certain areas which is where the construction lines (shown in Figure 6.2.2) come into play. Because the spars matched only a part of the airfoil profile, any section not a part of the spars is removed from the sketch. Before removal though, the points that make up the spar are selected and

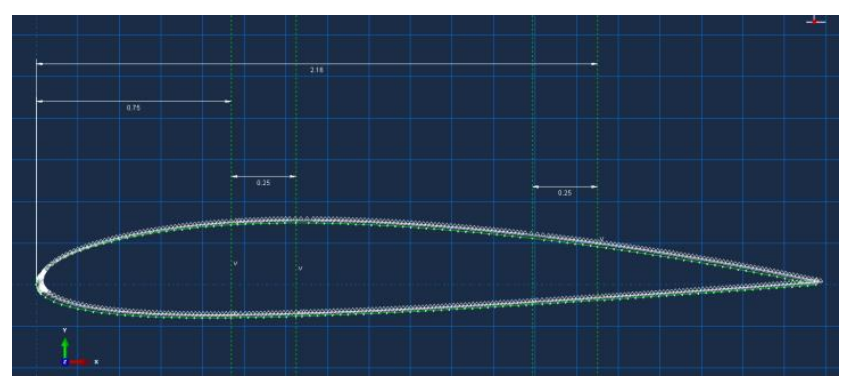

Figure 6.2.2: Base sketch of NACA 2412 airfoil used in creation of all model parts in Abaqus 
then offset inward by

0.0075 inches. A line

is drawn to connect the

upper and lower

flanges of the spar. In

Figure 6.2.4, the

yellow lines are what

will be extruded to

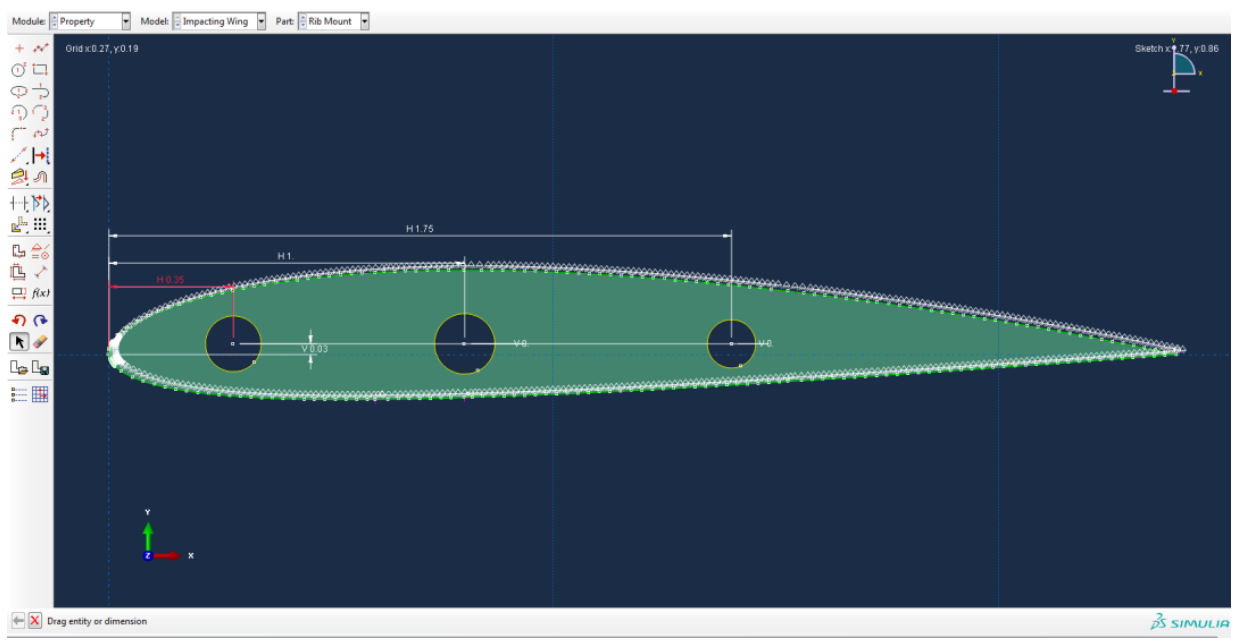

Figure 6.2.3: Sketch of mounting rib with locations of holes labeled

create the leading edge

spar while all of the green lines will be removed from the sketch. This method is used to create both the

leading and trailing edge spars. Both of the spars were extruded 4 inches to match the manufactured

parts of the wing specimens.

Now that each part of the assembly has been created, the material properties must be applied.

The material used for these parts was a carbon weave; the material properties were implemented as

engineering constants with the assumptions that the 1 and 2 directions are equal. The values used for the model are listed below in Table 6.2-1. Values with experimental data available were used and when experimental data was unavailable the values were taken from the data sheet and scaled according to the data sheet of the material. The values for $\mathrm{E}_{1}$ and $\mathrm{E}_{2}$ were taken from the experimental testing done on LTM45EL while all of the other values were used from Kodi Rider's Master's Thesis as he used the same type of material that was used in this thesis.

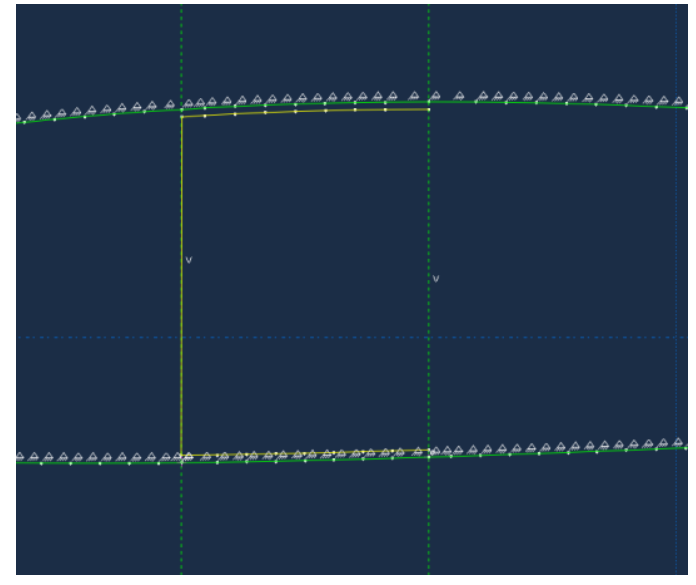

Figure 6.2.4: Showing the side profile of leading edge spar and how it will be positioned in model assembly 
Table 6.2-1: Material property variables used for wing model

\begin{tabular}{|l|l|}
\hline Material Property & Value \\
\hline Density & $0.0548 \mathrm{lb} / \mathrm{in}^{3}$ \\
\hline E1 = E2 & $6,540,000 \mathrm{psi}$ \\
\hline E3 & $2,900,754 \mathrm{psi}$ \\
\hline Nu12 = Nu13 & 0.096 \\
\hline Nu23 & 0 \\
\hline G12 = G13 & $725,000 \mathrm{psi}$ \\
\hline
\end{tabular}

After the material properties of LTM45EL were defined in Abaqus, sections needed to be created for each part. Sections are used to assign the material property to a part as well as the how thick the section will be. For solid sections, only a material property is assigned whereas with a shell, the thickness must be set as well. A section was created for the skin, spars, and both the mounting rib and outer ribs as each of these had different thicknesses. The thickness values used matched the experimental part thickness values.

The next stage for creating the model was to assemble the structure in the assembly module of Abaqus. The first part placed in the assembly was the mount rib. From there, the wing was pieced together, first by placing all of the ribs and spars and then placing the skin last. Since all of the parts are mid surface representations of the actual parts, this needed to be taken into account when assembling the model. For instance, between the ribs and spars, there is a gap $1 / 2$ the thickness of the rib. So between the mounting rib and first set of spars, there is a 0.032 inch gap while the other two ribs have a 0.016 inch gap. The gaps between the spars and middle rib are visible in Figure 6.2.5. As mentioned prior, the spar flanges were created to be offset below the airfoil profile so once the $\mathrm{X}$ and $\mathrm{Z}$ locations for the spars were set, they also had to be aligned vertically so that during the integration step on the analysis, the 
spars and skin come into contact. After placing all of the internal parts, the skin was added to the assembly (as seen in Figure 6.2.6). The skin is aligned so that when the thickness of the part is applied, it will come into contact, but not overlap, the ribs and spar flanges. To verify that all of the parts were correctly placed, the Abaqus query tool was used to measure the distances between each part.

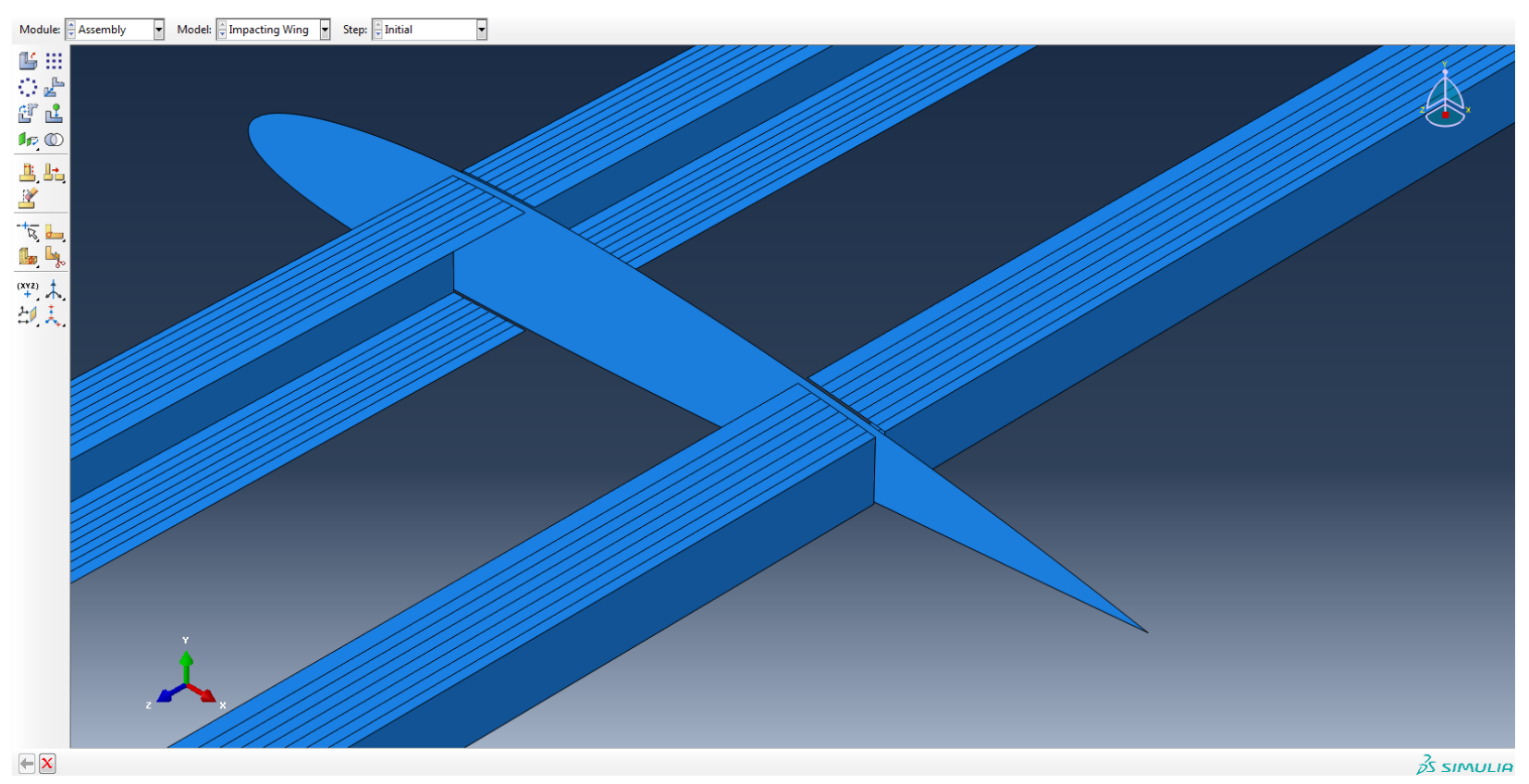

Figure 6.2.5: View of the gaps between the middle rib and spars

After assembling the wing design inside of Abaqus, all of the parts needed to be tied together using the Abaqus Tie Constraint. The tie constraint connects two nodes or surfaces so no relative displacement exists between the two nodes or surfaces during testing. This was done to simplify the bonding condition of the wing because attempting to model the adhesive properties of the structural adhesive would be excessive for what was being modeled. Tie constraints work by first selecting a master set of nodes or surface and then slaving a separate

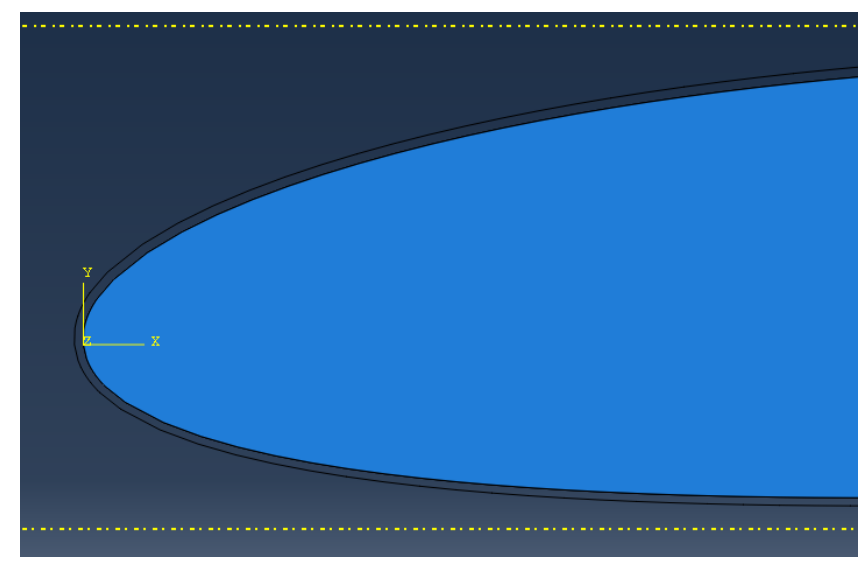

Figure 6.2.6: Visualization of gap between wing skin and internal structure in Abaqus model 
set of nodes or surface to this. The reason for the master-slave relationship between the sets is mainly used to make it easy for the Abaqus solver to determine how the structure will react. It does not have an effect on the final results. For the model, the skin was always set as master surfaces

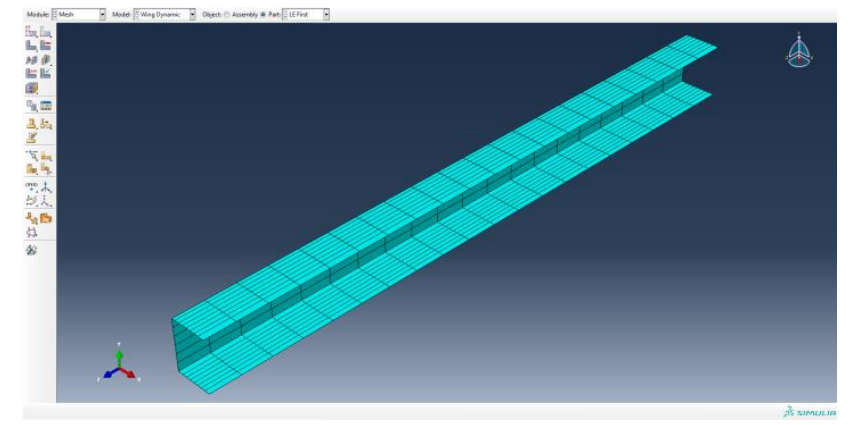

Figure 6.2.7: Mesh of leading edge spar while the ribs were always set as slaves. The spars were set as a slave to the spars, but as the master to the ribs. This hierarchy was chosen because element size does play a role in which surface should be set as the master. For Abaqus, the program suggests that the part with the larger element size is set as the master surface and because the spars had the largest elements, they were set as the master surfaces. Now as for the specific ties, the spars and ribs were modeled as node-to-node constraints because the surfaces of each part were perpendicular to each other, so a surface-to-surface contact would not work. A surface-to-surface contact was used when tying the spars and the skin together. To tie the skin to the ribs, a node-to-node contact was used. The next step done was to create the mesh for each part. The mesh for the spars was very simple with a seed size of 0.2 inches. The final mesh for the leading edge spar can be seen in Figure 6.2.7. The trailing edge spar mesh was made with the same parameters. The seed sizing for the skin was 0.4 inches and the seed sizing for the ribs was 0.1 inches. The element type were 4 node quad elements with reduced integration

After the meshing was complete, a test case for the wing was done to ensure that the mesh and tie constraints were operating correctly. The test case was done by applying a upward point load of 10 $\mathrm{lb}_{\mathrm{f}}$ while applying a fixed boundary condition at the wing root to simulate a cantilever loading of the wing. After the analysis was run, the wing was inspected to see how all parts in the assembly interacted. Figure 6.2.8 shows the resulting model response to the applied load. When examining the response of the assembly, it certainly does appear that all the ties are working correctly. This is evident because the skin, spars, and ribs are all moving together as a unified structure. Figure 6.2.9 shows the assembly, 
hiding the skin, so it is apparent that the internal structure is also working in unison. From the figure it is clear the load is being correctly transferred along the leading edge spar to the fixed mounting rib. Based

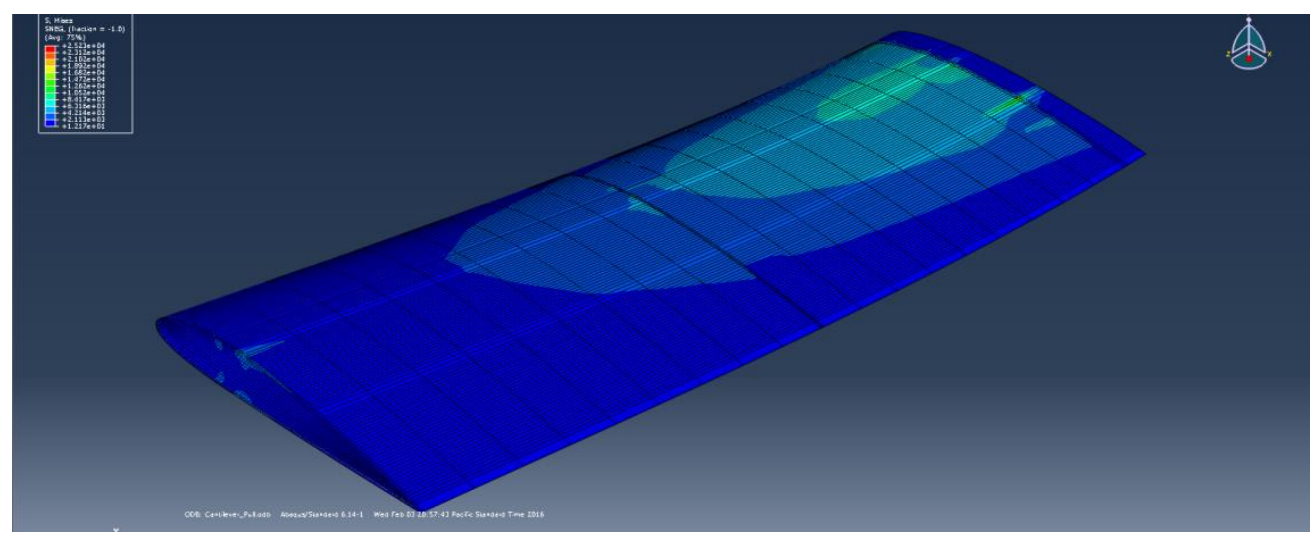

Figure 6.2.8: Results of cantilever analysis of wing model to verify all tie constraints are operating correctly

on this test case, the model was ready to proceed to frequency analysis.

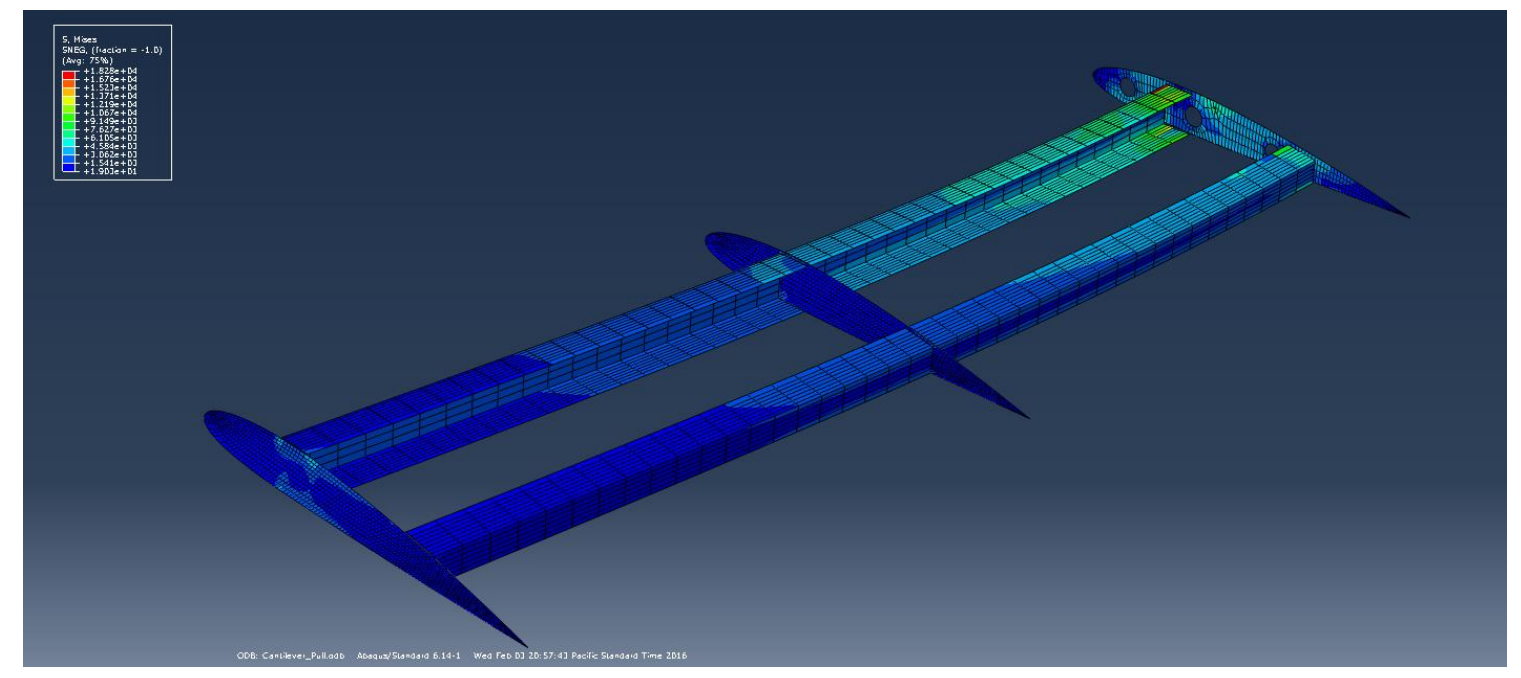

Figure 6.2.9: Visual confirmation that the tie constraints of the internal structure are operating correctly 


\subsection{Frequency Response Step}

In order to analyze the dynamic response of the wing, a frequency response step had to be created in the model tree. The step was defined to determine the natural frequencies from $0 \mathrm{~Hz}$ to $2000 \mathrm{~Hz}$. The boundary conditions of the wing for this step were a fixed boundary condition on the outer face of the mounting rib as well as the section of skin that hangs past the mounting rib. This was done to mimic as close as possible the clamping condition during the experimental testing. No load needed to be applied to the structure. The initial run of the model was not promising in the results. The first bending mode of the first run was solved to be at $12 \mathrm{~Hz}$, which is nowhere near what the first mode excitation was for the experimental testing which was between $190-200 \mathrm{~Hz}$. This means that there is something wrong with the model and the most likely suspect was the material properties. The material properties were identified as the problem. The frequency solver in Abaqus uses an eigenvalue extraction method to determine what the natural frequencies of the model are. The key variables in this solver are the mass and stiffness matrix which are both derived from the material properties. The equation used by the Abaqus eigenvalue extraction is shown in Equation 6.3.1.

$$
\left(-\omega^{2} M^{M N}+K^{M N}\right) \Phi^{N}=0
$$

$\mathrm{M}$ is the mass matrix, $\mathrm{K}$ is the stiffness matrix, $\Phi$ is the eigenvector matrix, and $\mathrm{M}$ and $\mathrm{N}$ are the degrees of freedom for the structure. So it is clear from Equation 6.3.1, the material properties are what the greatest effect of on the natural frequency. To prove this, a sensitivity analysis was done by changing the Young's Modulus and the material density to determine which value had the greatest effect on the structure. The Young's Modulus of the structure was varied from 1e6-5e8 psi and it was determined this equated to a first mode natural frequency range of $4-40 \mathrm{~Hz}$ which is would not move the natural frequency of the first mode to the same magnitude of the experimental testing. So the next property to be analyzed was the density. As a reminder, the density used to define LTM45EL was $0.0548 \mathrm{lb} / \mathrm{in}^{3}$ and so the density was varied from $1 \mathrm{lb} / \mathrm{in}^{3}$ down to $1 \mathrm{e}-5 \mathrm{lb} / \mathrm{in}^{3}$ and showed that the $1^{\text {st }}$ mode natural 
frequency varied from $3-946 \mathrm{~Hz}$. The result show the natural frequencies of the structure are most influenced by the density of the material. After looking at the densities and the corresponding frequencies, it was determined that the original density of $0.0548 \mathrm{lb} / \mathrm{in}^{3}$ was off by a factor of gravity meaning that the units needed to be in slugs instead of $\mathrm{lb}$. When converted to slugs/in ${ }^{3}$, the density of the model became $0.00017 \mathrm{slug} / \mathrm{in}^{3}$. After this change, the $1^{\text {st }}$ mode natural frequency was $214 \mathrm{~Hz}$ and the $2^{\text {nd }}$ mode natural frequency was $926 \mathrm{~Hz}$. The $1^{\text {st }}$ and $2^{\text {nd }}$ mode shapes are shown in Figure 6.3.1 and 6.3.2 respectfully. Displayed in Figure 6.3.1, the $1^{\text {st }}$ mode shape mimics what is expected from a cantilever beam with a large deflection at the tip and no deflection at the root. This also agrees with what was shown in Chapter 5 when analyzing the response amplitudes. When looking at the $2^{\text {nd }}$ mode shape, it is evident that the mode shape not only experiences bending, but also some torsional stress. This is because the cross section of the model is not symmetric and so the inertial force of the leading edge creates a lag, causing the torsional loading. This can be seen to a lesser extent in the $1^{\text {st }}$ mode shape.

After looking at the modal shapes and natural frequencies of the model it was time to compare them to the experimental test values. The results are listed in Table 6.3-1. From the results, the

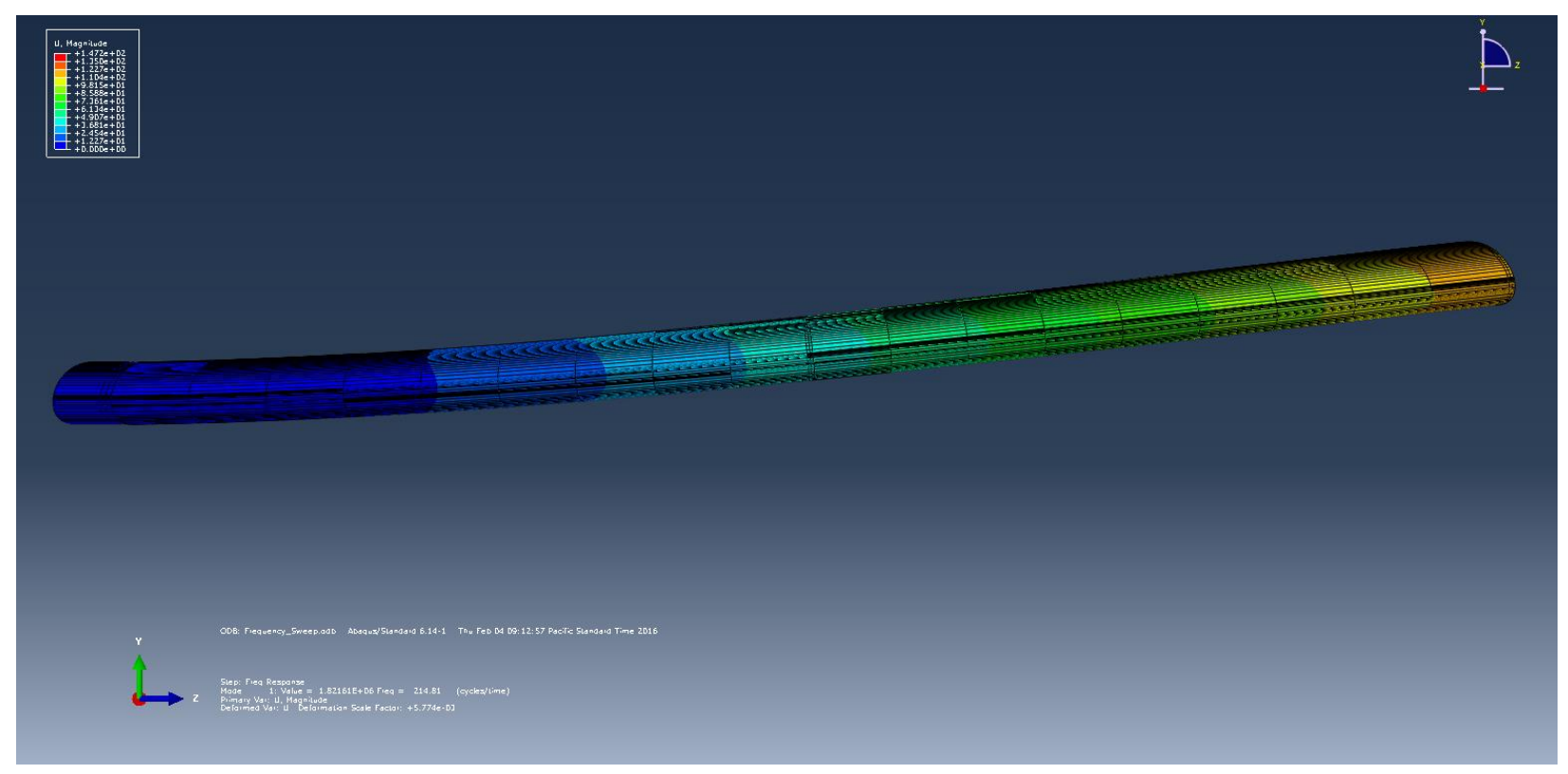

Figure 6.3.1: Mode shape of $1^{\text {st }}$ mode of wing model in Abaqus 


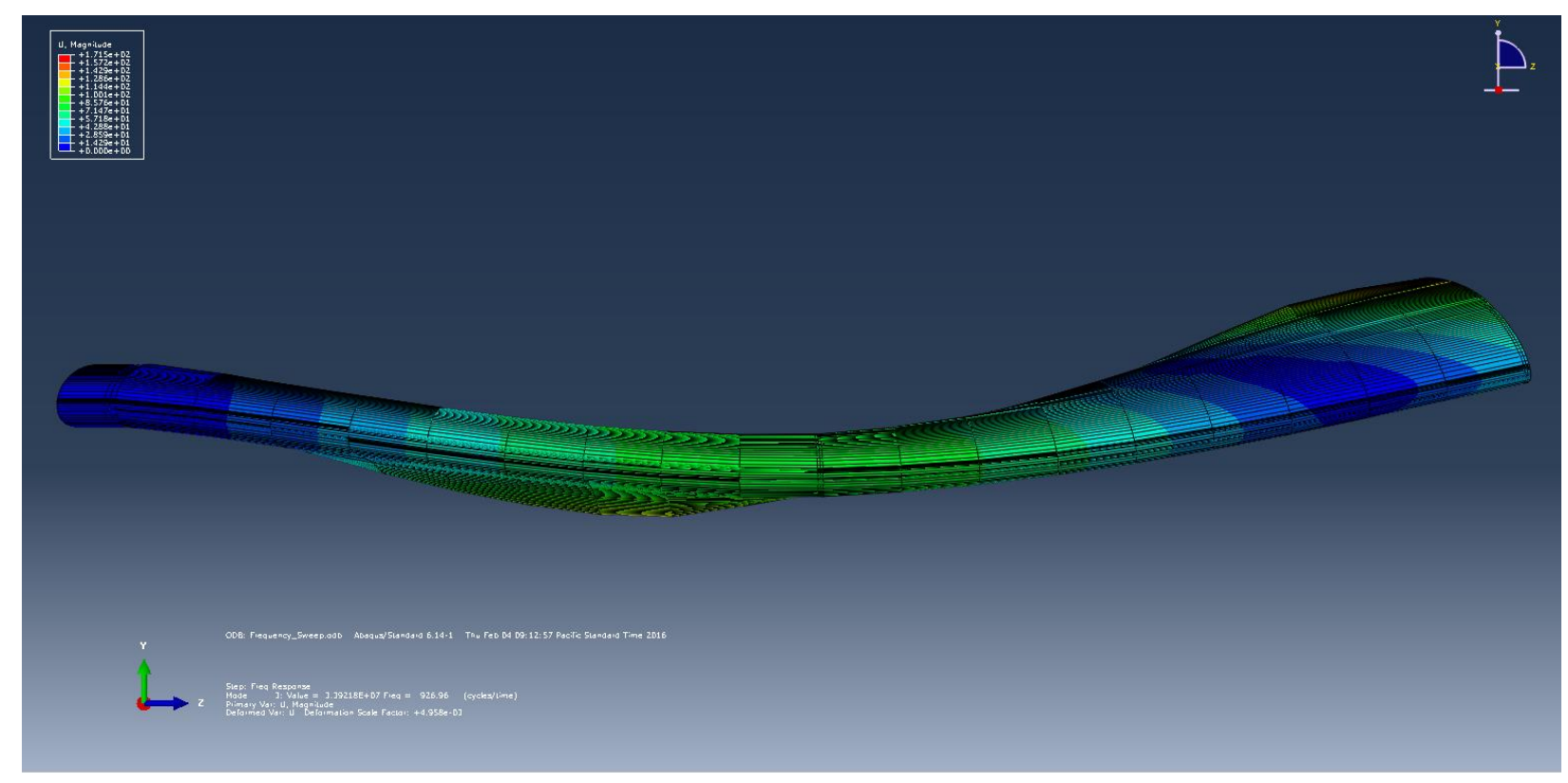

Figure 6.3.2: Mode shape of $2^{\text {nd }}$ mode of wing model in Abaqus

numerical model of the wing is very accurate as the largest percent difference was the $1^{\text {st }}$ mode natural frequency at $10.28 \%$ while the $2^{\text {nd }}$ mode percent difference was $7.95 \%$ which is very acceptable.

Table 6.3-1: Comparison of $1^{\text {st }}$ and $2^{\text {nd }}$ mode experimental and numerical results

\begin{tabular}{|c|c|c|c|}
\hline & Experimental & Numerical & Percent Difference \\
\hline $1^{\text {st }}$ Mode Natural & 192 & 214 & $10.28 \%$ \\
Frequency $(\mathrm{Hz})$ & & & \\
\hline $2^{\text {nd }}$ Mode Natural & 858 & 926 & $7.95 \%$ \\
Frequency (Hz) & & & \\
\hline
\end{tabular}

To verify the results of this model, a convergence study was done. The purpose of a convergence study is to ensure that the results from the numerical model are accurate. The results from the convergence study are shown in Table 6.3-2. From the table, it is clear that doubling number of seeds for each part has a small to insignificant effect on the $1^{\text {st }}$ and $2^{\text {nd }}$ mode natural frequency results. Based on this data, it can be said that the model results are accurate. 
Table 6.3-2: Results from convergence study of numerical wing model

\begin{tabular}{|c|c|c|c|}
\hline Part & \multicolumn{2}{|c|}{ Global Seed Size (nodes/inch) } \\
\hline Leading Edge Spar & 0.4 & 0.2 & 0.1 \\
\hline Middle and End Rib & 0.2 & 0.1 & 0.05 \\
\hline Mount Rib & 0.2 & 0.1 & 0.05 \\
\hline Trailing Edge Spar & 0.4 & 0.2 & 0.2 \\
\hline Skin & 0.8 & 0.4 & 214 \\
\hline $1^{\text {st }}$ Mode Freq (Hz) & 215 & 214 & 923 \\
\hline $2^{\text {nd }}$ Mode Freq (Hz) & 939 & 926 & \\
\hline
\end{tabular}

\subsection{Impact Analysis of Plate and Wing}

Before performing an impact step onto the wing model, an analysis was first conducted to compare the experimental strain results from the plate test to a numerical model. The plate model was created as 3D deformable solid with dimensions matching the experimental plate. The plate model is shown in Figure 6.4.1. There are partition lines around the outer edge that will be used during the load step of the model. The material was modeled as Al 6061-T6 to match the experimental plate. The Young's Modulus used was 10 Msi with a Poisson ratio of 0.33 and a density of $0.0975 \mathrm{lb} / \mathrm{in}^{3}$.

A new part that is required for this step is the creation of the impact tup. The tup was modeled as a $3 \mathrm{D}$ discrete rigid shell sphere with diameter of 0.625 inches and because it is a rigid part, also requires a reference point, which was placed at the center of the sphere. The purpose of the reference point is so there is a location to assign the tup a mass as well as where boundary conditions or velocities can be applied. The tup was assigned a weight of $10.1 \mathrm{lb}_{\mathrm{f}}$ in the inertia manager of the properties module.

After both parts were created, they were placed into the assembly stage with the sphere placed just above the plate. After the assembly is set up it was time to assign the necessary step required to run 


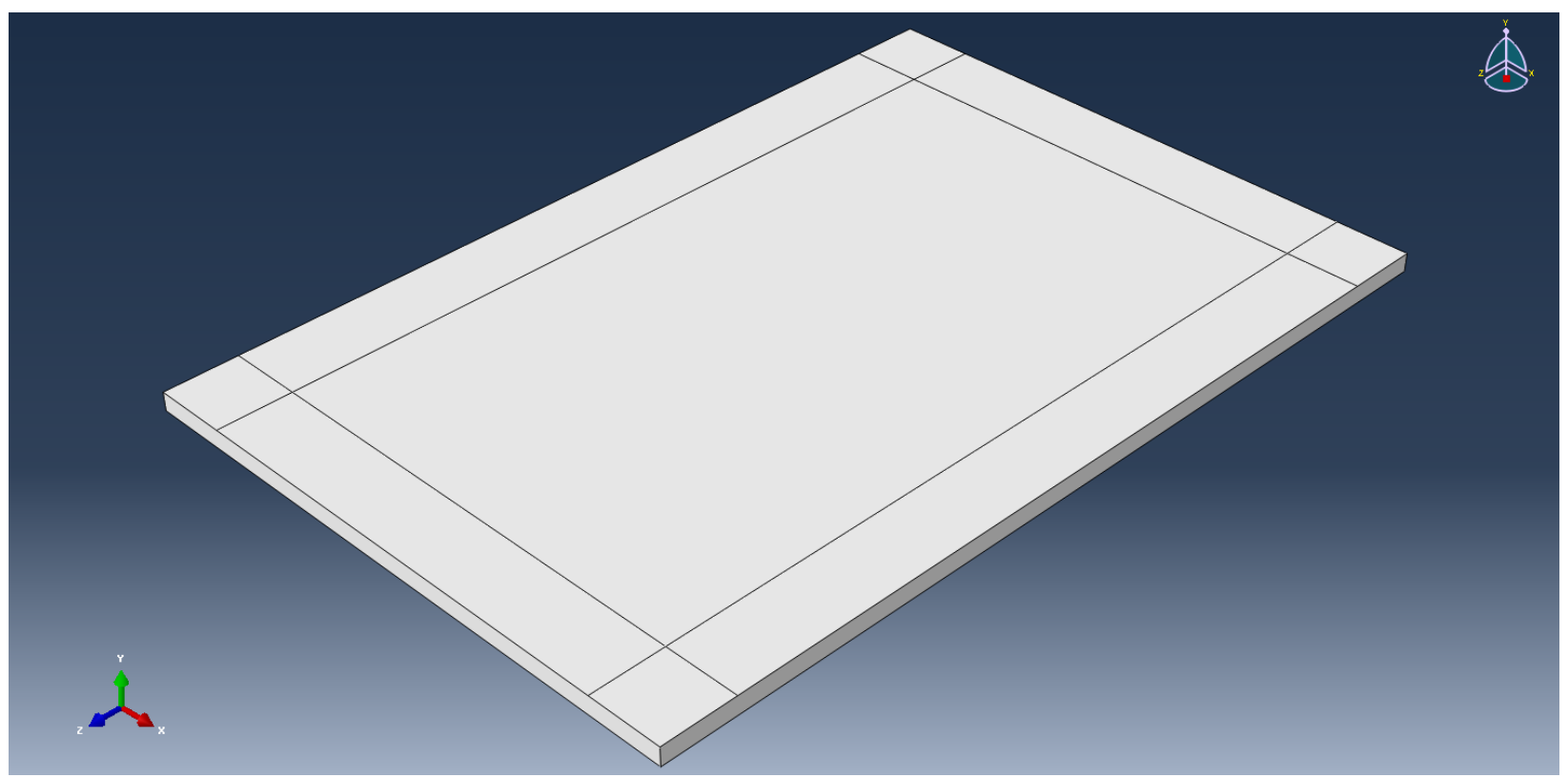

Figure 6.4.1: Isometric view of partitioned plate part to be used to verify experimental impact strain results for plate test

the impact analysis. To do this an explicit dynamic step was created with a total time of 0.025 seconds.

The time was set to 0.025 seconds to ensure that the ball bounces off of the plate and the maximum deflection of the plate is achieved. After the step was created, the interaction properties needed to be set. The purpose for the interaction properties is so that the numerical solver knows that objects are not allowed to pass through each other. If this property was not set, the tup would pass straight through the plate with no interaction. To set the appropriate contact property in the interaction step, the interaction property was selected and a new property was created. The property used was "Normal Behavior" located in the Mechanical tab and the default settings were used. After the property was created it was assigned to the model. The second to last step before running the analysis was to apply any boundary conditions as well as a predefined field to the tup to assign a velocity so that the impact can occur. A boundary condition was assigned to both the tup and the plate. The condition assigned to the plate was a pinned fixing of the outer half-inch of the plate to mimic the experimental testing conditions. A boundary condition was also assigned to the tup so during and after the impact there would be no lateral or rotational movement of the tup. This condition was assigned to the reference point of the tup. In order for the tup to move, a predefined field needed to be assigned to the tup at the reference point. The 


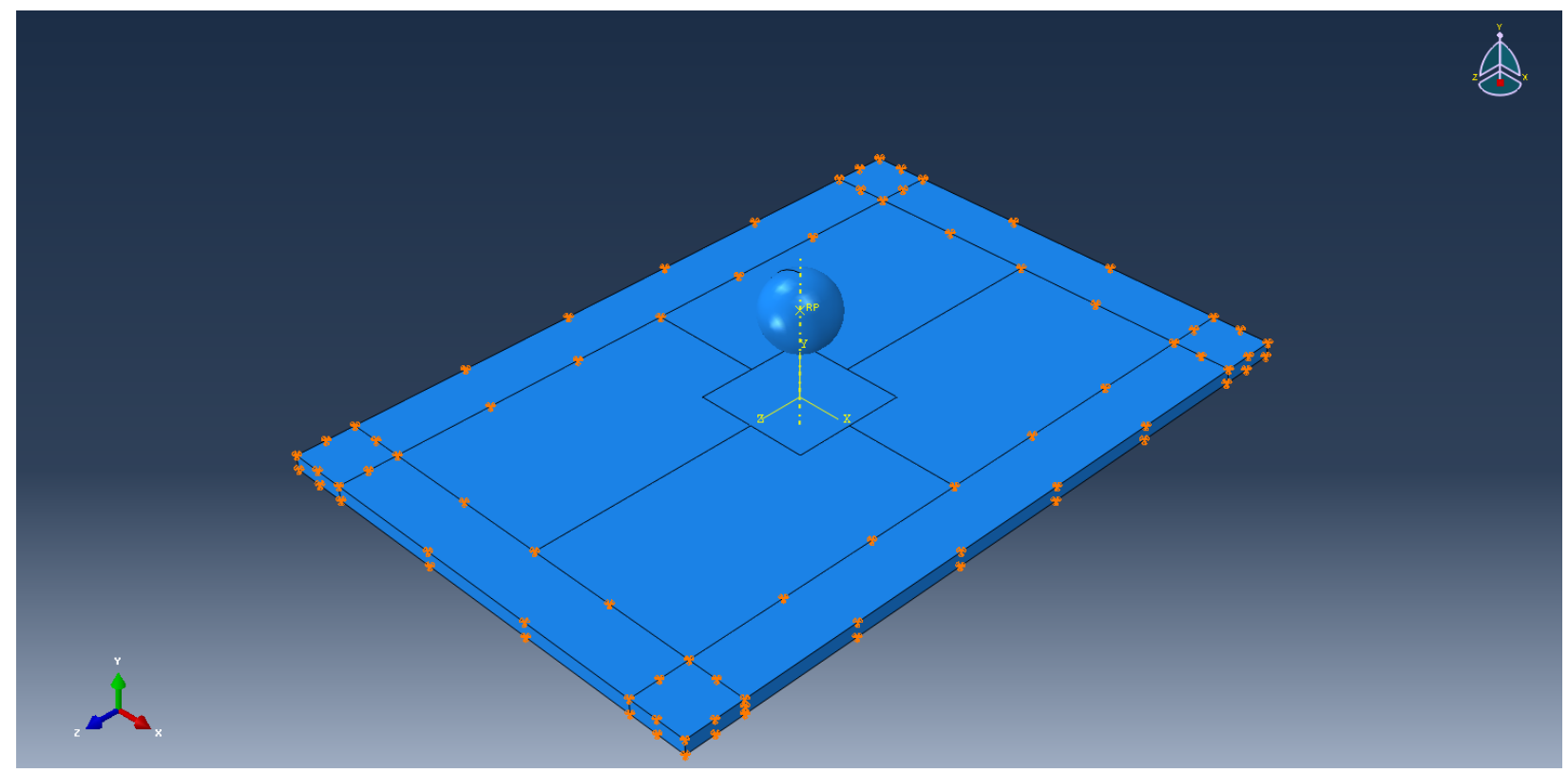

Figure 6.4.2: Isometric view of plate impact model assembly with sphere representing impact tup and showing boundary condition

velocity assigned was a downward velocity of 96 ips (inches per second). In Figure 6.4.2, the assembly of the plate and tup as well as the boundary condition assigned to the plate is shown. The final step is to assign a mesh to the ball and plate which were done using the global seed controls. A medial axis sweep with a seed sizing of 0.0625 inches was used for the plate. This size seed was chosen so that there would be at least 2 layers of elements that would make up the plate for a more accurate solution. After the mesh was assigned, the job was submitted and the results were analyzed and compared to the experimental results of the plate.

The analysis ran smoothly and the tup was able to impact the plate and rebound off. To determine the strain results of the plate, the query tool was used and the elements closet to the location of the strain gages was probed to determine the accuracy of the model. The locations for the strain gages are listed in Table 6.4-1 as well as the experimental and numerical strain values and the percent error. As a reminder, Gages 1 and 2 were located on the lengthwise on the plate while Gages 3 and 4 were located along the width of the plate. Refer back to Figure 5.3.1 for a top down picture of the impacted plate. As shown in Table 6.4-1, the percent error was fairly high for the model but there is a very close relation between the experimental and numerical results. Based on the data it can be said that the 
elements further from the impact location yield a less accurate result but the results are still within a close margin of the experimental results.

Table 6.4-1: Comparison of experimental and numerical results for impacted plate experiment

\begin{tabular}{|l|l|l|l|l|}
\hline & $\begin{array}{l}\text { Location (inches } \\
\text { from impact } \\
\text { location) }\end{array}$ & $\begin{array}{l}\text { Experimental } \\
\text { Strain }(\mu \mathrm{in} / \mathrm{in})\end{array}$ & $\begin{array}{l}\text { Numerical Strain } \\
(\mu \mathrm{in} / \mathrm{in})\end{array}$ & Percent Error (\%) \\
\hline Gage 1 & 0.710 & 1,600 & 1,900 & \\
\hline Gage 2 & 1.425 & 1,000 & 1,200 & 20.00 \\
\hline Gage 3 & 0.540 & 2,300 & 2,520 & 9.56 \\
\hline Gage 4 & 1.050 & 700 & 920 & 23.91 \\
\hline
\end{tabular}

Figure 6.4.3 shows how the max principal strains are distributed across the impacted plate. The largest strains are located near the impact site as well as the boundary condition closest to the impact location. This model verifies the experimental results of the plate.

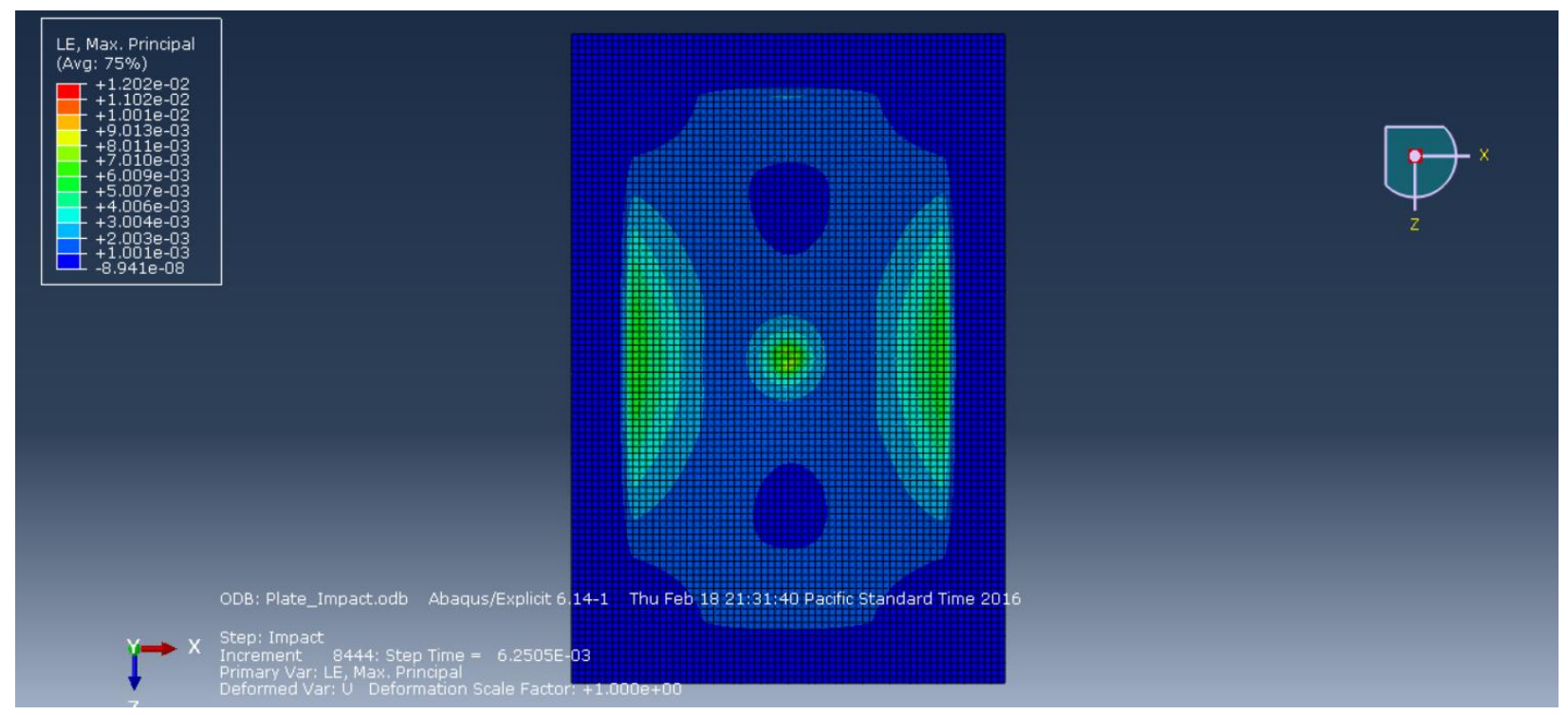

Figure 6.4.3: Contour view of logarithmic maximum principal strain of plate impact model 
After analyzing the impacted plate, it was time to apply this methodology to the wing model created in Chapter 6.2. The same steps were followed with a change to the boundary conditions of the wing and the initial velocity of the tup. The boundary condition that was applied to the wing was meant to closely mimic the experimental conditions of the test specimens. To do this, a fixed boundary condition was applied to the skin except for a 2 inch by 1.5 inch square directly over the impact location which mimics the constraints of the experimental testing. The predefined field for the tup was a downward velocity of 78 ips (inches per second) to match the experimental impact velocities. The comparison of the experimental and numerical results can be found in Table 6.4-2. The percent error from the experimental and numerical strain value is $15.39 \%$ which is well within the region that finite element models can be considered valid.

Table 6.4-2: Comparison of experimental and numerical results for impacted wing results of Wing 5

\begin{tabular}{|l|l|l|l|l|}
\hline & $\begin{array}{l}\text { Location (inches } \\
\text { from impact } \\
\text { location) }\end{array}$ & $\begin{array}{l}\text { Experimental } \\
\text { Strain }(\mu \mathrm{in} / \mathrm{in})\end{array}$ & $\begin{array}{l}\text { Numerical Strain } \\
(\mu \mathrm{in} / \mathrm{in})\end{array}$ & Percent Error $(\%)$ \\
\hline Gage 1 & 0.25 & 780 & 900 & 15.39 \\
\hline
\end{tabular}

A view of the impact damage of the wing is displayed in Figure 6.4.4. It is an isometric view of the skin at the apex of the impact showing the von-mises stress in the skin. From Figure 6.4.4, it can be seen that the stress of the damage is localized around the impact site and is not transferred very far from the impact site. This is because of the low-velocity of the impact only being able to generate a small amount of energy imparted into the wing.

It is also important to look at how the internal structure of the wing reacts to the impact as demonstrated in Figure 6.4.5 with a close up look at the rib/spar intersection of the model with the skin hidden from view. Based on the figure, it is clear that the middle rib absorbs the majority of the impact energy with very little energy being transferred into the spars. Sources of error for this model include 
the material properties of the carbon fiber used, the lack of adhesive modeling and the effect it has on reinforcing the joint of the wing in this region as well as experimental error with the measurement system or inaccurate modeling of the impact speed.

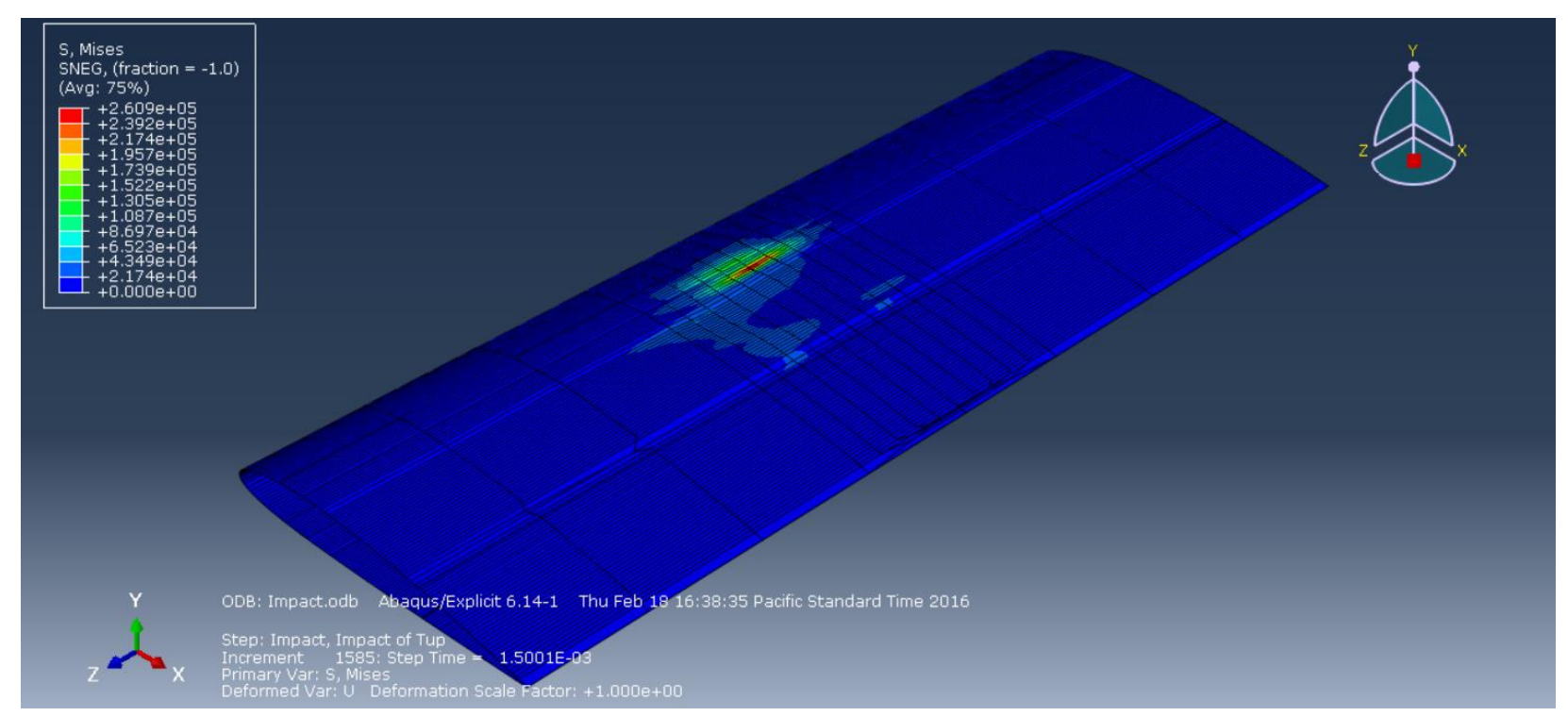

Figure 6.4.4: Isometric view of maximum mises stress for wing model impact

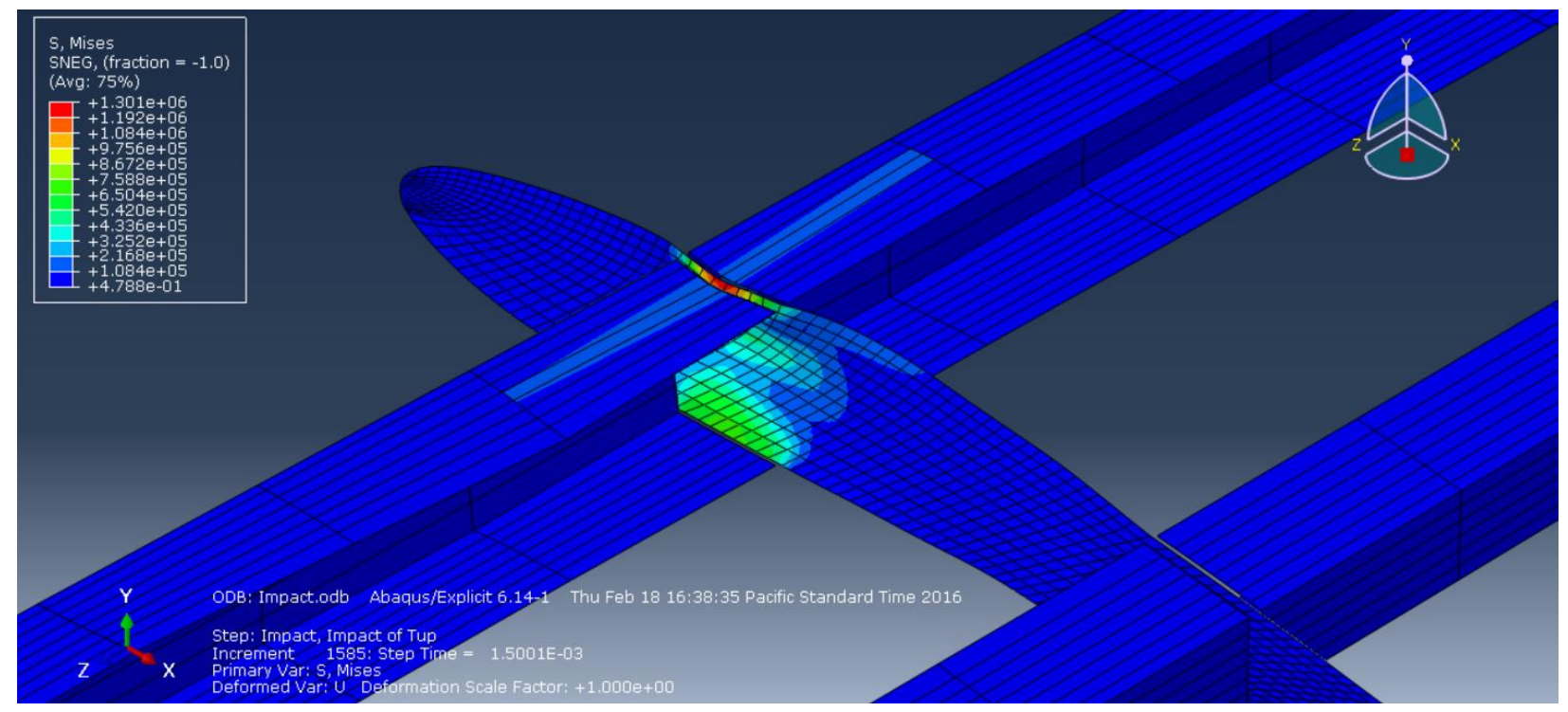

Figure 6.4.5: Isometric view of maximum mises stress for wing model impact without skin visible 


\subsection{Case Study on Spar Geometry}

To better understand the effect the spar geometry has on the frequency response of the wing a study was done changing the direction of the spar flanges. The four cases analyzed involved switching the direction that the flanges of the leading and trailing edge spars protruded. The first case was the original design with both flanges pointing inward to the center of the airfoil. The second case is the opposite of the first case with both flanges pointing outward to the edges of the airfoil. Case three has both flanges pointing towards the trailing edge and Case four has both flanges pointing towards the leading edge. A drawing of the four cases can be seen in Figure 6.5.1. All aspects of the model will be the same. The only change to the model is the direction of the spar flanges protrude. The reason for this study was to determine if the altering the spars can change either the torsional or bending strength of the wing design. The results of the study can be seen in Table $6.5-1$ with the $1^{\text {st }}, 2^{\text {nd }}$, and torsional mode frequencies listed. Clear trends can be seen after analyzing the table. The trend for the $1^{\text {st }}$ bending mode is a drop of $4 \mathrm{~Hz}$ when the trailing edge spar is facing the trailing edge of the airfoil. The leading edge spar does not seem to have an effect on the $1^{\text {st }}$ bending mode as Case 1 and 4, and Case 2 and 3, have opposite facing leading edge spars and no change to the $1^{\text {st }}$ bending mode frequency was observed. When analyzing the torsional mode, the same trend can be seen. However, there is a large change between each test case for the torsional mode. The original design shows a torsional mode frequency of $554 \mathrm{~Hz}$ and drops substantially to 523

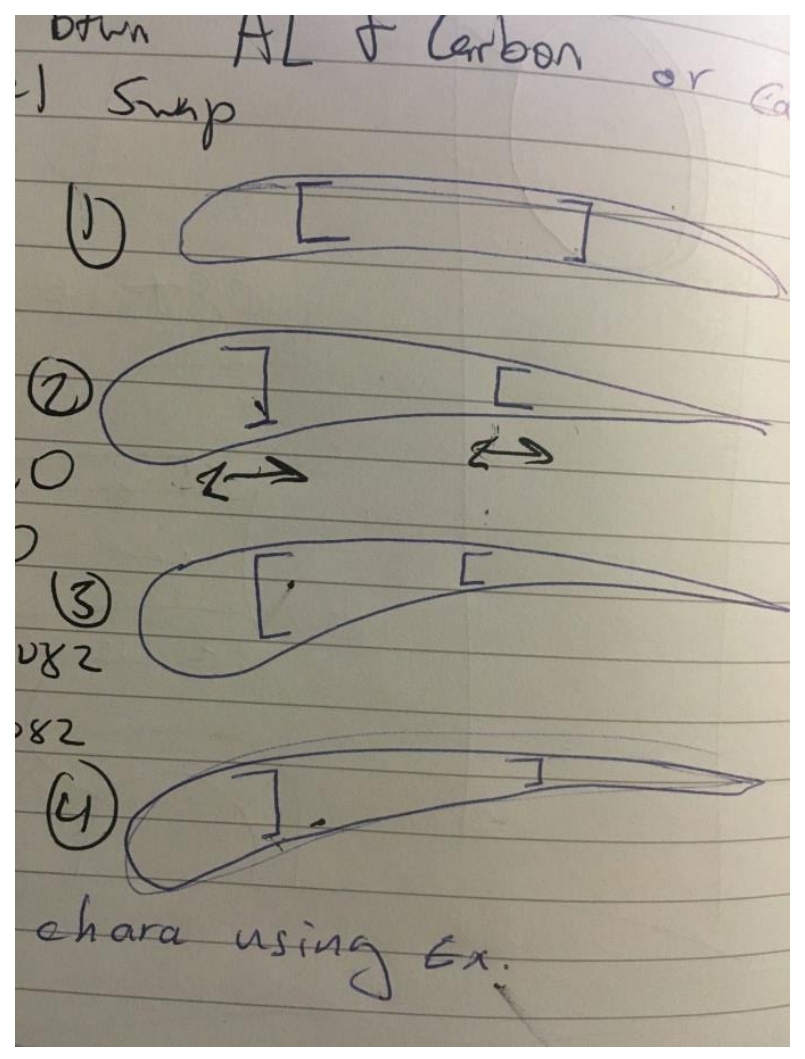

Figure 6.5.1: Four different scenarios analyzed for case study on the effect of the spar geometry on the natural frequencies of the wing 
$\mathrm{Hz}$ for Case 2. Case 3 and Case 4 have torsional modes between Case 1 and Case 2 .

Table 6.5-1: Frequency results for all four cases analyzed in study

\begin{tabular}{|l|l|l|l|}
\hline Cases & $\begin{array}{l}1^{\text {st }} \text { Bending Mode } \\
\text { Natural Frequency }(\mathrm{Hz})\end{array}$ & $\begin{array}{l}\text { Torsional Mode Natural } \\
\text { Frequency }(\mathrm{Hz})\end{array}$ & $\begin{array}{l}2^{\text {nd }} \text { Bending Mode } \\
\text { Natural Frequency }(\mathrm{Hz})\end{array}$ \\
\hline Case 1 & 214.81 & 554.32 & 926.96 \\
\hline Case 2 & 210.92 & 523.34 & 901.87 \\
\hline Case 3 & 210.94 & 536.44 & 907.21 \\
\hline Case 4 & 214.46 & 540.72 & 921.51 \\
\hline
\end{tabular}

The trend for the $2^{\text {nd }}$ bending mode is the same with Case 1 have the highest frequency and Case 2 at the lowest. Case 3 and Case 4 range between Case 1 and Case 2. When analyzing the mode shapes, there is no change from case to case. The $1^{\text {st }}, 2^{\text {nd }}$, and torsion modes are all similar. The torsional mode for Case 1 is shown in Figure 6.5.2. Based on the results from Table 6.5-1, it can be said that the trailing edge spar has the largest effect on the modal frequencies of the wing design. The reason for this is because the center of rotation for the torsional mode is closer to the trailing edge of the wing and changing the flanges of the trailing edge spar to face the trailing edge of the airfoil (e.g. Case 2 and 3) aligns the shear

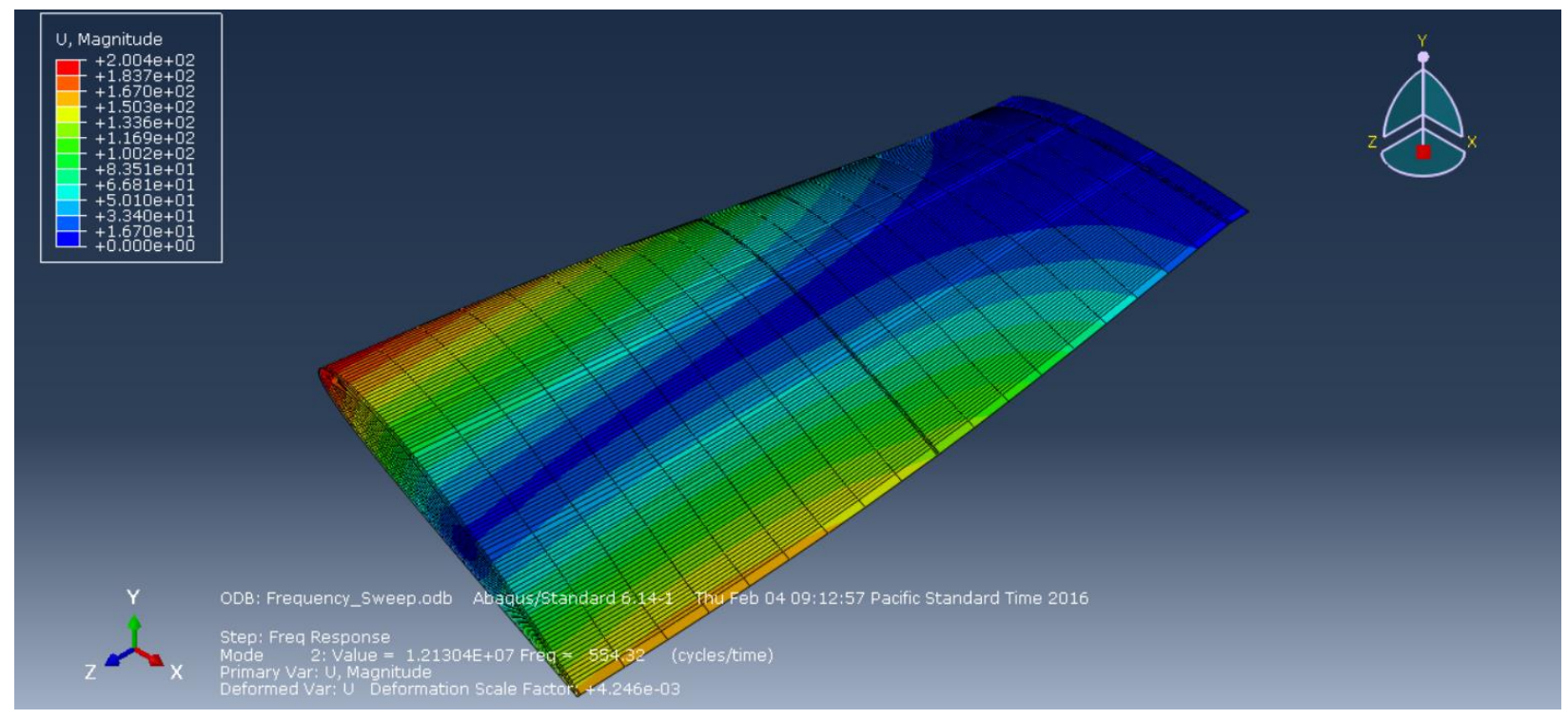

Figure 6.5.2: Isometric view of torsional mode for Case 1 study 
center of the spar with the center of rotation of the wing. Based upon Equation 6.3.1, a change to the natural frequency is either caused by the mass of the wing or the stiffness of the wing changing. Since a lowering of the natural frequencies occurred when the spars were turned away from the center of the airfoil and no mass has changed, it can be said that the stiffness of the model has decreased with the change in spar geometry. 


\section{Conclusion}

In this study a small scale wing was designed and built to determine the effectiveness of using dynamic characteristics to identify and structural damage after a low velocity impact. The conclusion remarks are presented in two different tasks.

The first task is the impact testing. The impact load was dependent of where on the wing structure the impact. Higher force measurements were recorded when an impact occurred over the middle rib. Smaller force measurements were recorded when only the skin was impacted. The amount of visible damage was inversely proportional to the force measurement of the load cell.

The second task is the vibrational testing. The $1^{\text {st }}$ bending mode of the wing design was around $190 \mathrm{~Hz}$ and the $2^{\text {nd }}$ bending mode close to $900 \mathrm{~Hz}$. The natural variation of the structure's dynamic characteristics due to the uniqueness and hand built aspect of each manufactured wing. Only 2 out of the 10 wings tested showed a dramatic shift for either the $1^{\text {st }}$ or $2^{\text {nd }}$ mode vibrational characteristics across the entire structure. There were also a few wings that showed localized changes near the impact locations. Impact locations over the middle rib of the wing tended to affect a larger region of the structure. 


\section{Future Works}

This study introduced too many variables across the design and manufacturing to be able to pinpoint any major flaws. Future work will need to consider an improved design to reduce natural variations of the wing and the manufacturing process. Another approach is to revert back to a simple geometry instead of a wing; for example a laminate or sandwich. As far as the testing goes, it is advised that the vibrational testing have the control acceleration lowered to below $1 \mathrm{~g}$ as this high acceleration could have caused damage in the structure affecting the results. 


\section{REFERENCES}

[1] Jones, Robert M. Mechanics of Composite Materials. 2nd ed., PA: Taylor \& Francis, 199. Print.

[2] Niu, Michael Chun-Yung. Composite Airframe Structures: Practical Design Information and Data. North Point: Hong Kong Conmilit, 1992. Print.

[3] Rider, Kodi. The Effect of Low Velocity Impact on the Flexural and Dynamic Response of Composite Sandwiches with Damage Arrestment Devices. Thesis. California Polytechnic State University, San Luis Obispo, August 2012. Print.

[4] Wood, Yvette Vanessa, Effects of Damage Arrestment Devices on the Fatigue Life of Impacted Composite Sandwich Beams. Thesis. California Polytechnic State University, San Luis Obispo, March 2013

[5] Carter, Jefferey S. Effects of Low Velocity Impact on the Flexural Strength of Composite Sandwich Structures. Thesis. California Polytechnic State University, San Luis Obispo, October 2014

[6] Perry, Dylan. Aerodynamic Design and Structural Analysis Procedure for Small Horizontal-axis Wind Turbine Rotor Blade. Thesis. California Polytechnic State University, San Luis Obispo, April 2015

[7] Hexcel. Prepreg Technology. March 2005

[8] Cytec Industrial Materials. LTM 45 Series Material Data Sheet. 2012

[9] Perez, Marco A. Gil, Lluis. Oller, Sergio. Impact Damage Identification in Composite Laminates Using Vibration Testing. Journal of Composite Materials (September 2013)

[10] Garcia, D., Palazzetti, R., Trendafilova, I., Fiorini, C., Zucchelli, A., Vibration-based Delamination Diagnosis and Modeling for Composite Laminate Plates, Composite Structures (2015), 
[11] Department of Defense. Composite Materials Handbook 17 Vol. 2 Polymer Matrix Composites Materials Properties. June 2002

[12] Hughes, Thomas J. R. The Finite Element Method. Englewood Cliffs, New Jersey, 1987

[13] Barbero, Ever J. Finite Element Analysis of Composite Materials, London, New York, 2008

[14] Logan, Daryl L. A First Course in the Finite Element Method. 2007

[15] Megson, T. H. G. Aircraft Structures for Engineering Students. Burlington, Massachusetts, 2007

[16] Thor Labs Si Biased Detector User Guide

[17] National Instruments SCC-SG Series Strain Gage Modules User Guide. PDF. National Instruments

[18] National Instruments NI USB-9162 User Guide. PDF. National Instruments

[19] National Instruments SC-2345 Signal Conditioning Carrier User Manual. PDF. National Instruments

[20] VIP Sensors Model 5004-10 Charge Converter Data sheet. PDF. VIP Sensors

[21] VIP Sensors Model 1011 a Accelerometer Data Sheet. PDF. VIP Sensors

[22] ASTM D3039 Standard Test Method for Tensile Properties of Polymer Matrix Composite Materials. ASTM

[23] ASTM D3410 Standard Test Method for Compressive Properties of Polymer Matrix Composite Materials with Unsupported Gage Section by Shear Loading. ASTM

[24] ASTM D7136 Standard Test Method for Measuring Damage Resistance of a Fiber-Reinforced Polymer Matrix Composite to a Drop-Weight Impact Event. ASTM

[25] URL: https://bcachemistry.wordpress.com/tag/composites/ 
[26] URL: http://www.tatasteelconstruction.com/en/reference/teaching-resources/architectural-teachingresource/elements/design-of-beams-structural-steel/support-conditions

[27] URL: http://www.iec-corp.com/nuts_brackets.html

[28] URL: http://www.acmeindustrial.com/heli-coil_comparison.html

[29] URL: http://abcnews.go.com/blogs/headlines/2012/07/united-airlines-flight-strikes-bird-on-descentto-denver/

[30] URL: http://www.mdpi.com/1996-1944/7/1/413/htm

[31] Barath, Daniel Alejandro. Design of a Specimen Fixture for Impact Resistance Testing in an Intron Dynatup 8250 Drop Weight Impact Tester. Senior Project. California Polytechnic State University, San Luis Obispo, March 2013

[32] URL: http://www.mar-bal.com/language/en/applications/history-of-composites/

[33] Chopra, Anil K. Dynamics of Structures: Theory and Applications to Earthquake Engineering. Upper Saddle River, NJ: Prentice Hall, 2012. Print.

[34] Abaqus User's Manual V 6.12, URL: https://things.maths.cam.ac.uk/computing/software/abaqus_docs/docs/v6.12/books/usb/default.ht $m$

[35]ANSYS User's Manual V 15.0, URL: http://148.204.81.206/Ansys/readme.html

[36] XFLR5. URL: http://www.xflr5.com/ReleaseNotes.htm

[37] Cytec Industrial Materials. Usage and Storage of LTM Series Material. 2012 


\section{APPENDICES}

\section{Appendix A}

$\%$ Thesis MATLAB Code analyzing Wing Data for Pre and Post Impact

clc

clearvars

close all

format compact

tic

$\%$ Description of Structures

All. -> Res g and zeta for all wings sorted by run before and after in single arrays

Specials. -> Inidivual arrays or res g zeta for each wing

Time. -> Time Responses sorted by Wing

Wings. -> Dynamic Run data for each Wing

data. -> Avgs and Stddevs for Wings

diff. -> Percent diffs for pre vs post of each data point

Load Data

load('WingRuns_Pre.mat')

load('WingRuns_Post.mat')

load('ImpactAnalysis.mat')

load('tension.mat')

load('compression.mat')

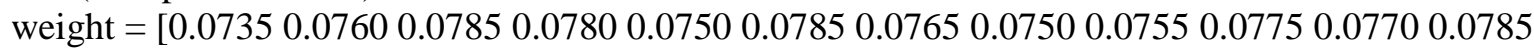

$0.07750 .07850 .0765]$;

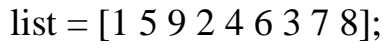

new $=\left[\begin{array}{llllllll}1 & 4 & 7 & 5 & 2 & 6 & 8 & 9\end{array}\right]$;

for $\mathrm{i}=1$ :length(Order_Pre)

Order_old $\{i, 1\}=$ Order_Pre $\{i\}$;

Order_old $\{i, 2\}=$ Order_post $\{i\}$;

end

for $\mathrm{i}=1: 15$

for $\mathrm{j}=1: 9$

$\operatorname{Order}\{9 *(\mathrm{i}-1)+\mathrm{j}, 1\}=$ Order_old $\{9 *(\mathrm{i}-1)+$ new $(\mathrm{j}), 1\}$;

$\operatorname{Order}\{9 *(\mathrm{i}-1)+\mathrm{j}, 2\}=$ Order_old $\{9 *(\mathrm{i}-1)+$ new $(\mathrm{j}), 2\}$;

end

end

for $\mathrm{i}=1: 9$

for $\mathrm{j}=1: 15$

eval(['Wings.W',num2str(j),'\{i,1\}= Order $\{\mathrm{i}+$ ',num2str(j-1),'*9,1\};']);

eval(['Wings.W',num2str(j), $\left.\left.\{i, 2\}=\operatorname{Order}\left\{i+', \operatorname{num} 2 \operatorname{str}(j-1),{ }^{\prime} * 9,2\right\} ; '\right]\right)$;

end

end

Freq $=\operatorname{Order}\{1,1\}(:, 2)$;

for $\mathrm{i}=1: 9$

for $\mathrm{j}=1: 15$ 


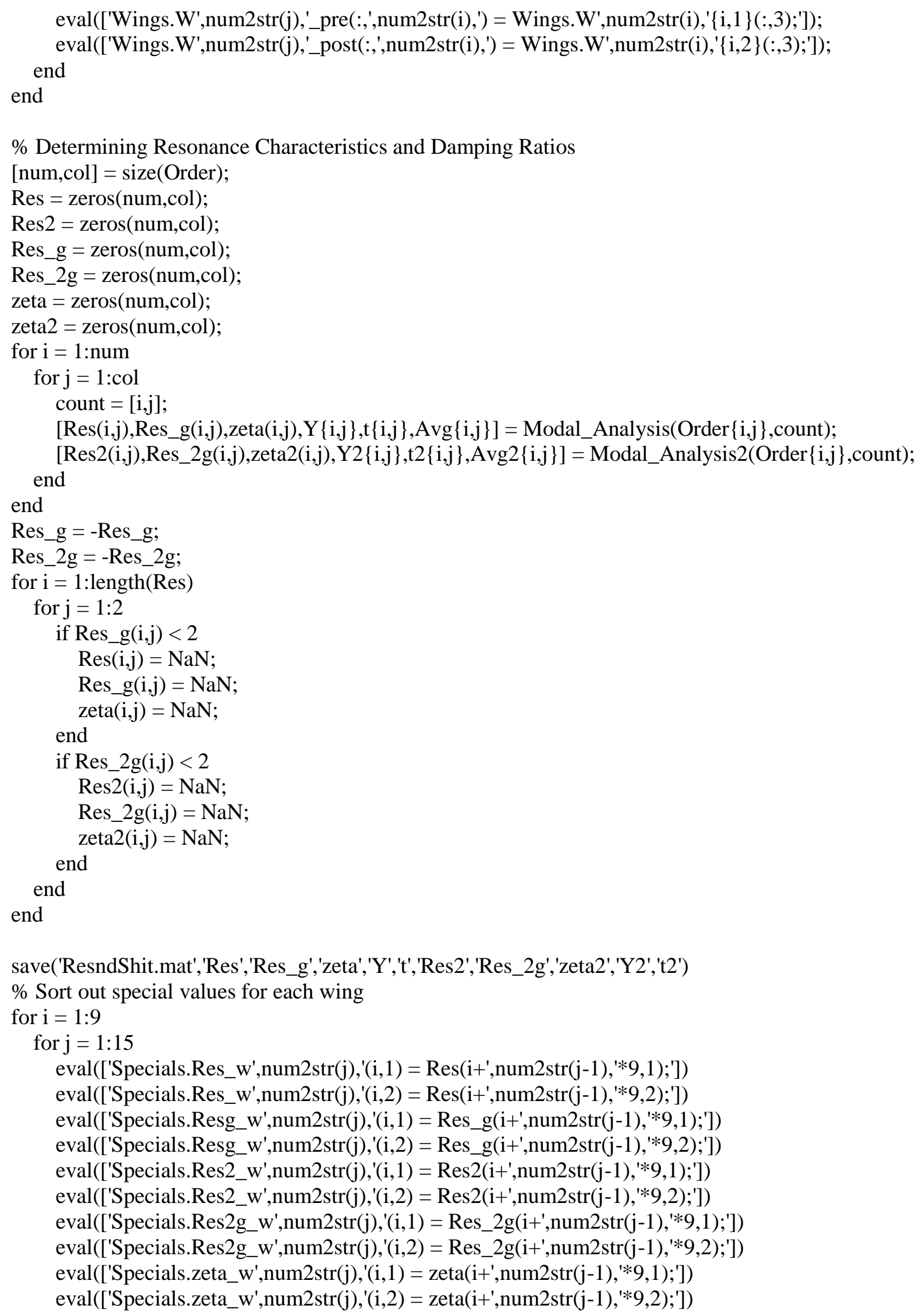


eval(['Specials.zeta2_w',num2str(j),'(i,1) = zeta2(i+',num2str(j-1),'*9,1);'])

eval(['Specials.zeta2_w',num2str(j),'(i,2) = zeta2(i+',num2str(j-1),'*9,2);'])

end

end

Place Responses for Wings into pre and post cells

for $\mathrm{i}=1: 9$

for $\mathrm{j}=1: 15$

eval(['Wings.W',num2str(j),'\{i,1\}= Order $\{\mathrm{i}+$ ',num2str(j-1),'*9,1\};']);

eval(['Wings.W',num2str(j),'\{i,2\} = Order $\{\mathrm{i}+$ ',num2str(j-1),'*9,2\};']);

eval(['Wings.W',num2str(j),',',num2str(i),'\{1,1\}= Wings.W',num2str(j),'\{i,1\};'])

eval(['Wings.W',num2str(j),',',num2str(i), $\{\{1,2\}=$ Wings.W',num2str(j),'\{i,2\};'])

end

end

Place Pre and Post into single array, sorted into each wing pre then post

for $\mathrm{i}=1: 15$

eval(['All.Res_all(:,',num2str(2*i-1),':',num2str(2*i),') = Specials.Res_w',num2str(i),'(:,1:2);'])

eval(['All.Res2_all(:,',num2str(2*i-1),':',num2str(2*i),') = Specials.Res2_w',num2str(i),'(:,1:2);'])

eval(['All.Resg_all(:,',num2str(2*i-1),':',num2str(2*i),') = Specials.Resg_w',num2str(i),'(:,1:2);'])

eval(['All.Res2g_all(:,',num2str(2*i-1),':',num2str(2*i),') = Specials.Res2g_w',num2str(i),'(:,1:2);'])

eval(['All.zeta_all(:,',num2str(2*i-1),':',num2str(2*i),') = Specials.zeta_w',num2str(i),'(:,1:2);'])

end

eval(['All.zeta2_all(:,',num2str(2*i-1),':',num2str(2*i),') = Specials.zeta2_w',num2str(i),'(:,1:2);'])

Sorting Time Response Vectors

for $\mathrm{i}=1: 15$

$$
\begin{aligned}
\text { for } j=1: 9 \\
\quad a=9 *(i-1)+j ;
\end{aligned}
$$

eval(['Time.W',num2str(i),'\{j,: $\}=\{\mathrm{t}\{\mathrm{a}, 1\}, \mathrm{Y}\{\mathrm{a}, 1\}, \mathrm{t}\{\mathrm{a}, 2\}, \mathrm{Y}\{\mathrm{a}, 2\}, \mathrm{t} 2\{\mathrm{a}, 1\}, \mathrm{Y} 2\{\mathrm{a}, 1\}, \mathrm{t} 2\{\mathrm{a}, 2\}, \mathrm{Y} 2\{\mathrm{a}, 2\}\} ; '])$ end

end

for $\mathrm{i}=1: 15$

for $\mathrm{j}=1: 9$

eval(['Time.p',num2str(j),'\{i,:; = Time.W',num2str(i),'\{j\};'])

$$
\text { end }
$$

end

$\%$ Data Analysis

data.pre_res $=\operatorname{sum}(\operatorname{Res}(:, 1)) /$ length $(\operatorname{Res}(:, 1))$;

data.post_res $=\operatorname{sum}(\operatorname{Res}(:, 2)) /$ length $(\operatorname{Res}(:, 2))$;

data.stdev_res_pre $=\operatorname{std}(\operatorname{Res}(:, 1))$;

data.stdev_res_post $=\operatorname{std}(\operatorname{Res}(:, 2))$;

data.pre_res2 $=\operatorname{sum}(\operatorname{Res} 2(:, 1)) /$ length $(\operatorname{Res} 2(:, 1))$;

data.post_res2 $=\operatorname{sum}(\operatorname{Res} 2(:, 2)) /$ length $(\operatorname{Res} 2(:, 2))$;

data.stdev_res2_pre $=\operatorname{std}(\operatorname{Res} 2(:, 1))$;

data.stdev_res2_post $=\operatorname{std}(\operatorname{Res} 2(:, 2))$;

data.pre_resg $=\operatorname{sum}\left(\operatorname{Res} \_g(:, 1)\right) /$ length $\left(\operatorname{Res} \_g(:, 1)\right)$;

data.post_resg $=\operatorname{sum}\left(\operatorname{Res} \_g(:, 2)\right) /$ length $\left(\operatorname{Res} \_g(:, 2)\right)$;

data.stdev_resg_pre $=\operatorname{std}\left(\operatorname{Res} \_g(:, 1)\right)$;

data.stdev_resg_post $=\operatorname{std}\left(\operatorname{Res} \_g(:, 2)\right)$;

data.pre_res2 $\mathrm{g}=\operatorname{sum}\left(\operatorname{Res} \_\mathrm{g}(:, 1)\right) /$ length(Res_2 $\left.\mathrm{g}(:, 1)\right)$;

data.post_res2 $\mathrm{g}=\operatorname{sum}\left(\operatorname{Res} \_2 \mathrm{~g}(:, 2)\right) /$ length(Res_2g(:,2)); 


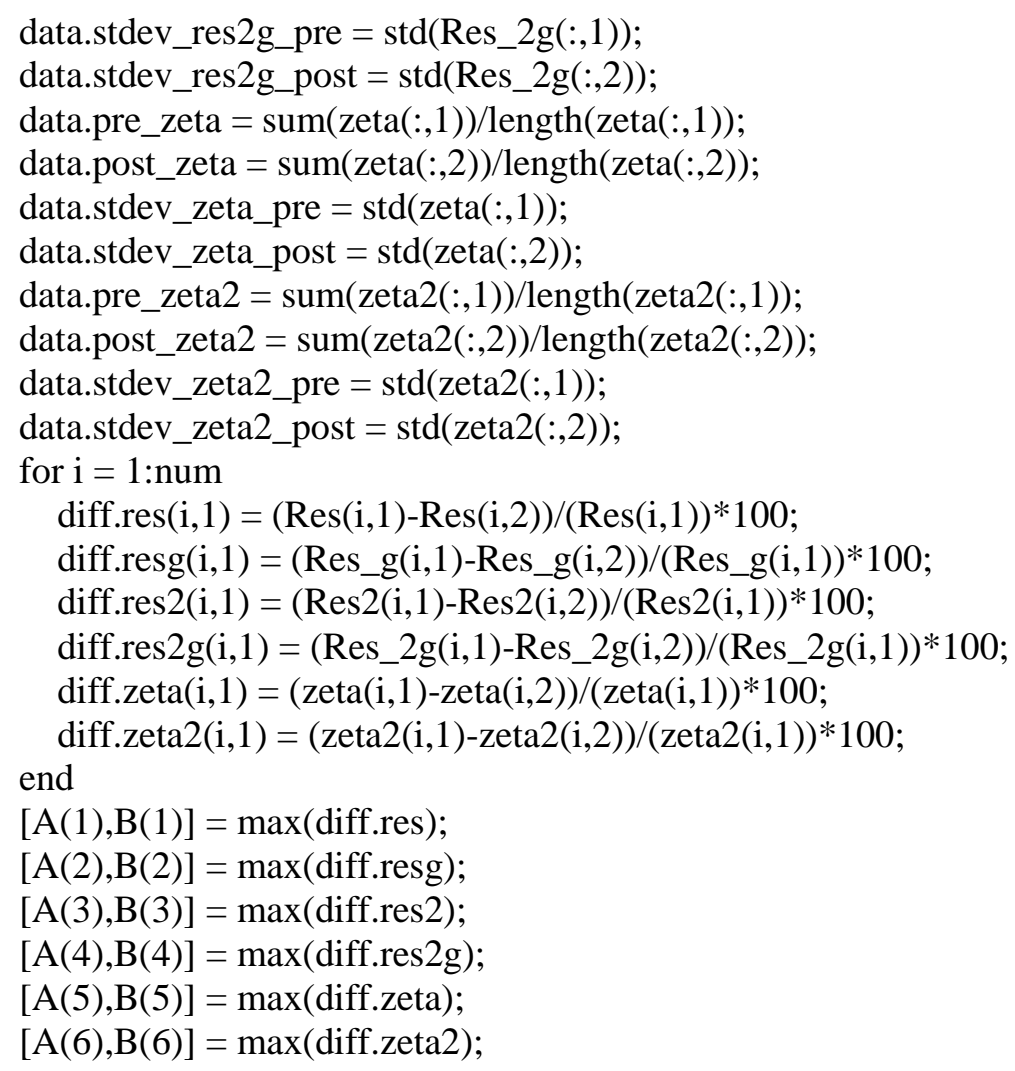

AVG per Wing

for $\mathrm{i}=1: 15$

eval(['mn.res(i,: $)=$ mean $($ Specials.Res_w',num2str(i),');'])

eval(['mn.resg(i,:) = mean (Specials.Resg_w',num2str(i),');'])

eval(['mn.res2(i,:) = mean (Specials.Res2_w',num2str(i),');'])

eval(['mn.res2g(i,:) = mean(Specials.Res2g_w',num2str(i),');'])

eval(['mn.zeta(i,:) = mean(Specials.zeta_w',num2str(i),');'])

$\operatorname{eval}([\operatorname{mn} . z e t a 2(i,:)=\operatorname{mean}($ Specials.zeta2_w',num2str(i),');'])

end

mn.res = resm;

mn.resg $=$ resgm;

$\mathrm{mn} . \mathrm{res} 2=\operatorname{res} 2 \mathrm{~m}$;

$\mathrm{mn}$. res $2 \mathrm{~g}=$ res $2 \mathrm{gm}$;

mn.zeta = zetam;

mn.zeta2 = zeta $2 \mathrm{~m}$;

str = \{'res';'resg';'res2';'res2g';'zeta';'zeta2' $\}$;

$\%$ Checking Data Removing wings $4 \& 5$

mn.resd $=$ mn.res;

$\operatorname{mn} \cdot \operatorname{resd}(4: 5,:)=[]$;

mn.resgd $=$ mn.resg;

$\operatorname{mn} \cdot \operatorname{resgd}(4: 5,:)=[]$;

mn.res $2 \mathrm{~d}=\mathrm{mn} . \mathrm{res} 2$;

mn.res $2 \mathrm{~d}(4: 5,:)=[]$;

$\mathrm{mn}$. res $2 \mathrm{gd}=\mathrm{mn} \cdot$ res2g;

mn.res $2 \operatorname{gd}(4: 5,:)=[]$; 


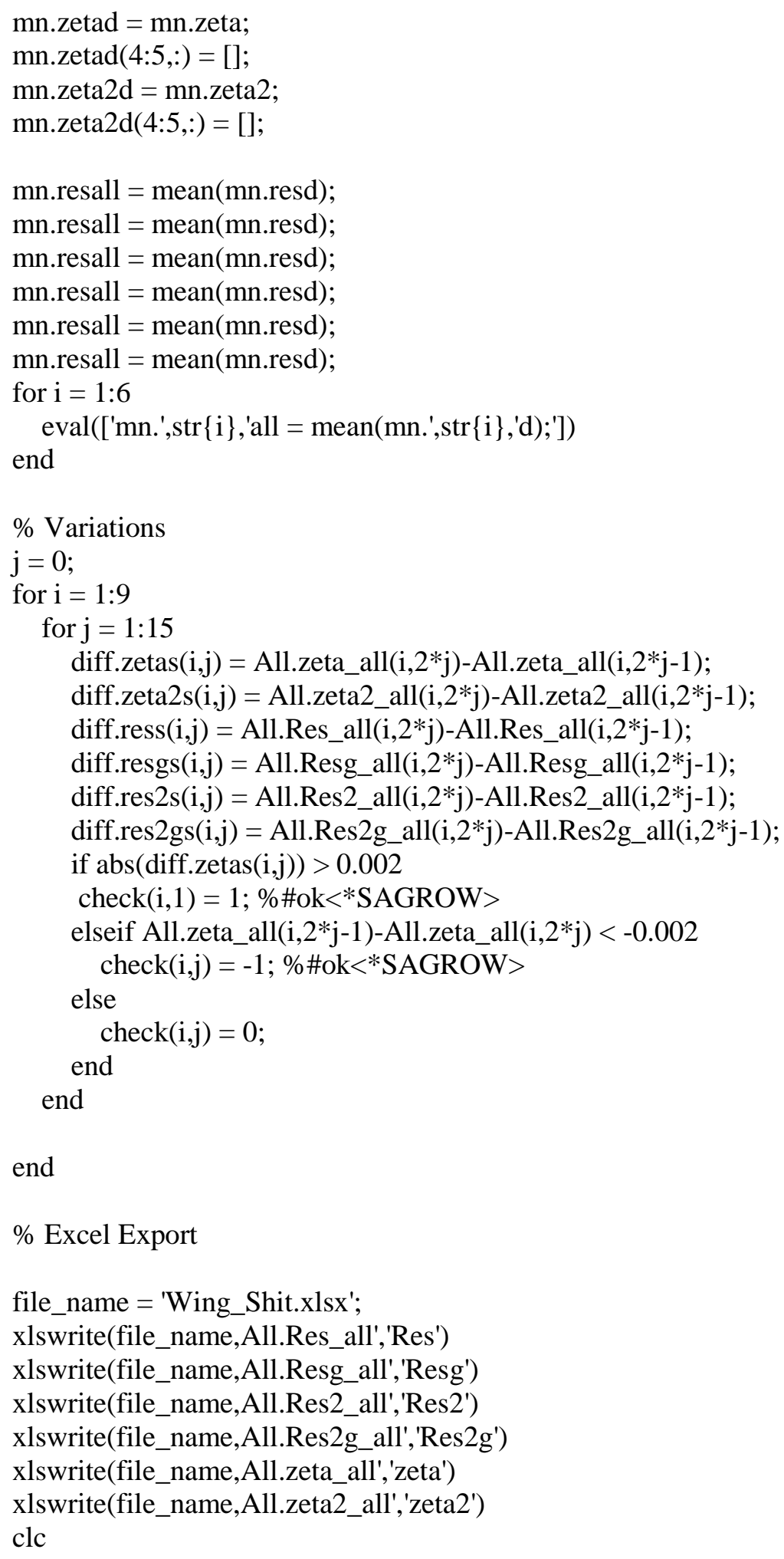




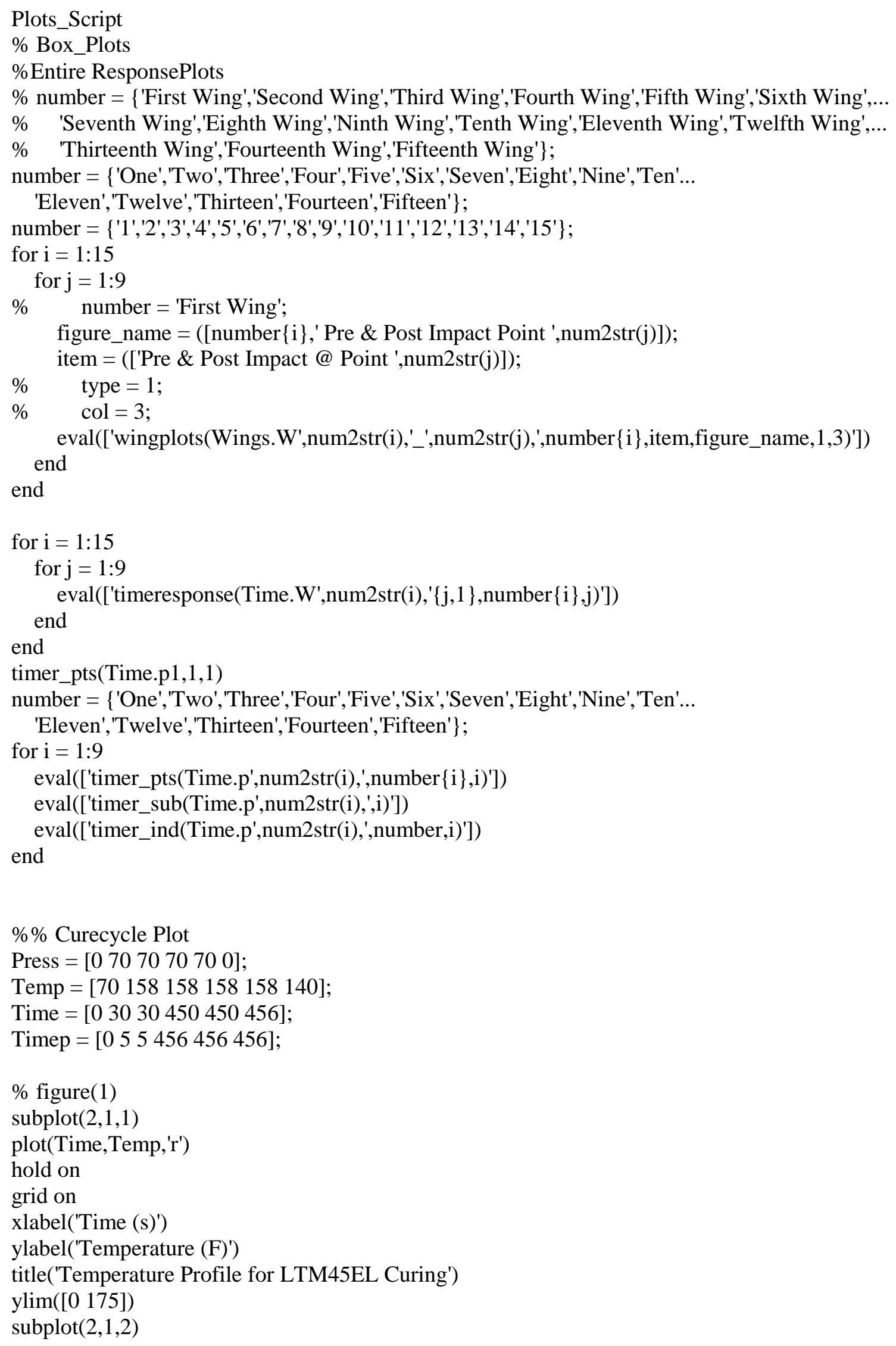




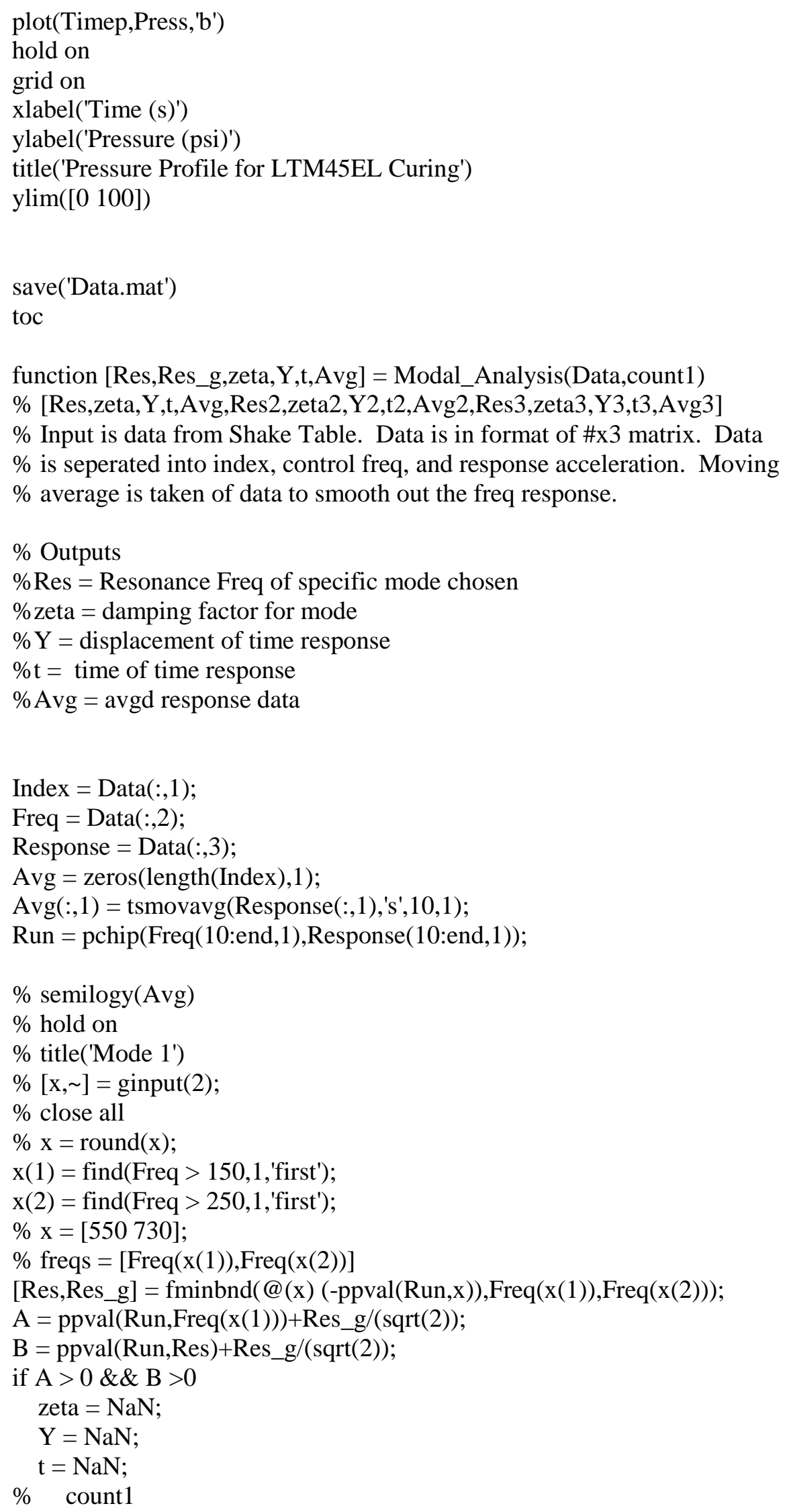




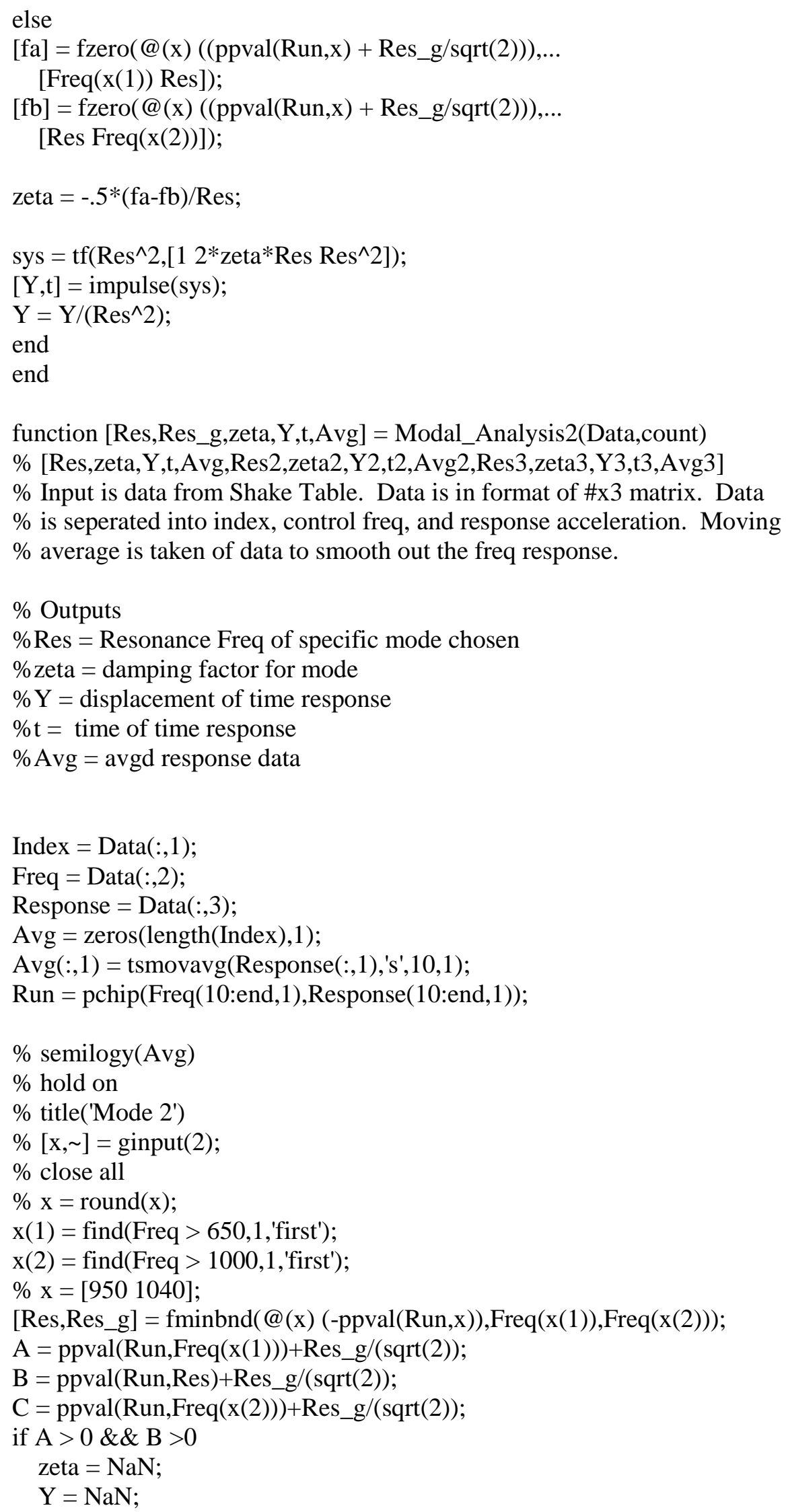




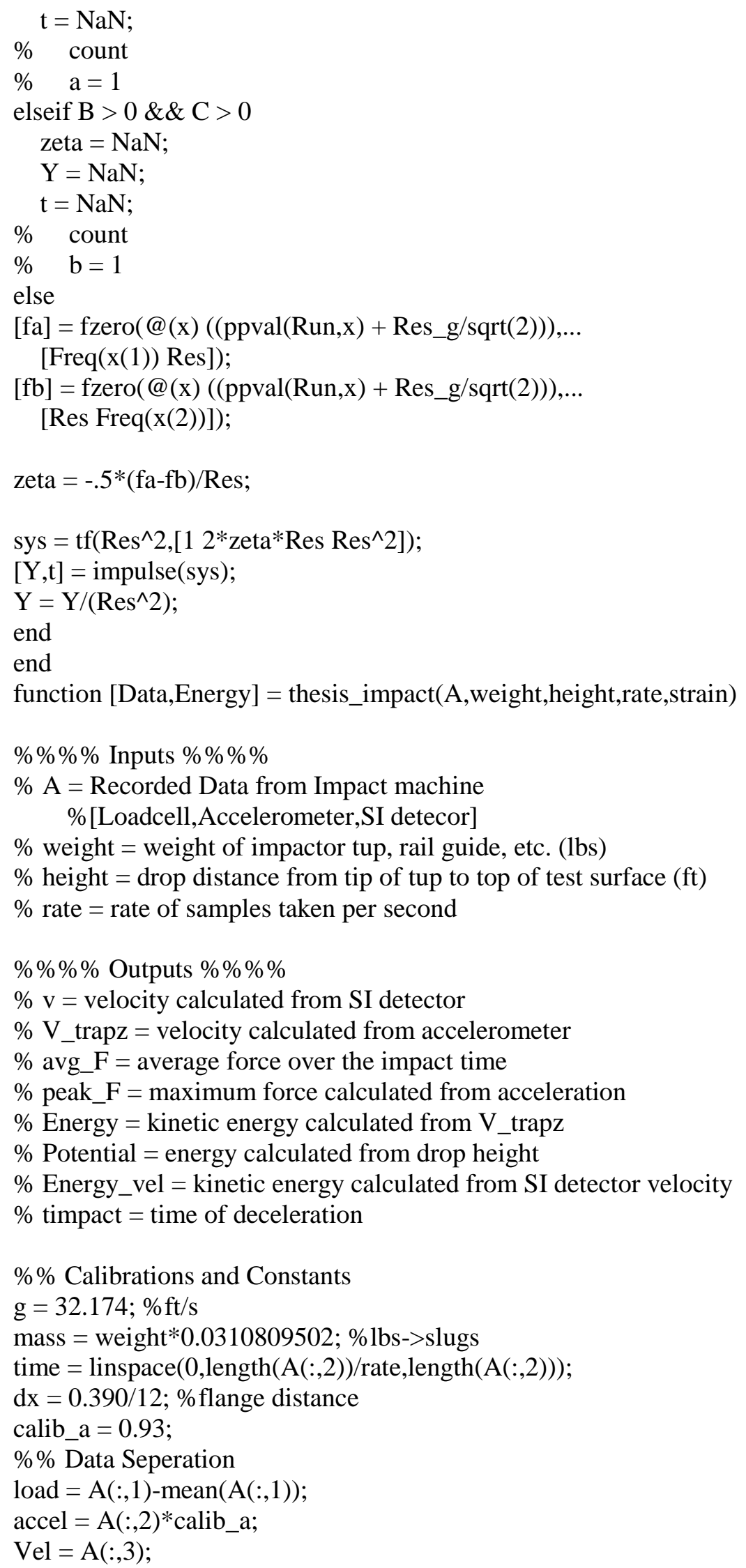




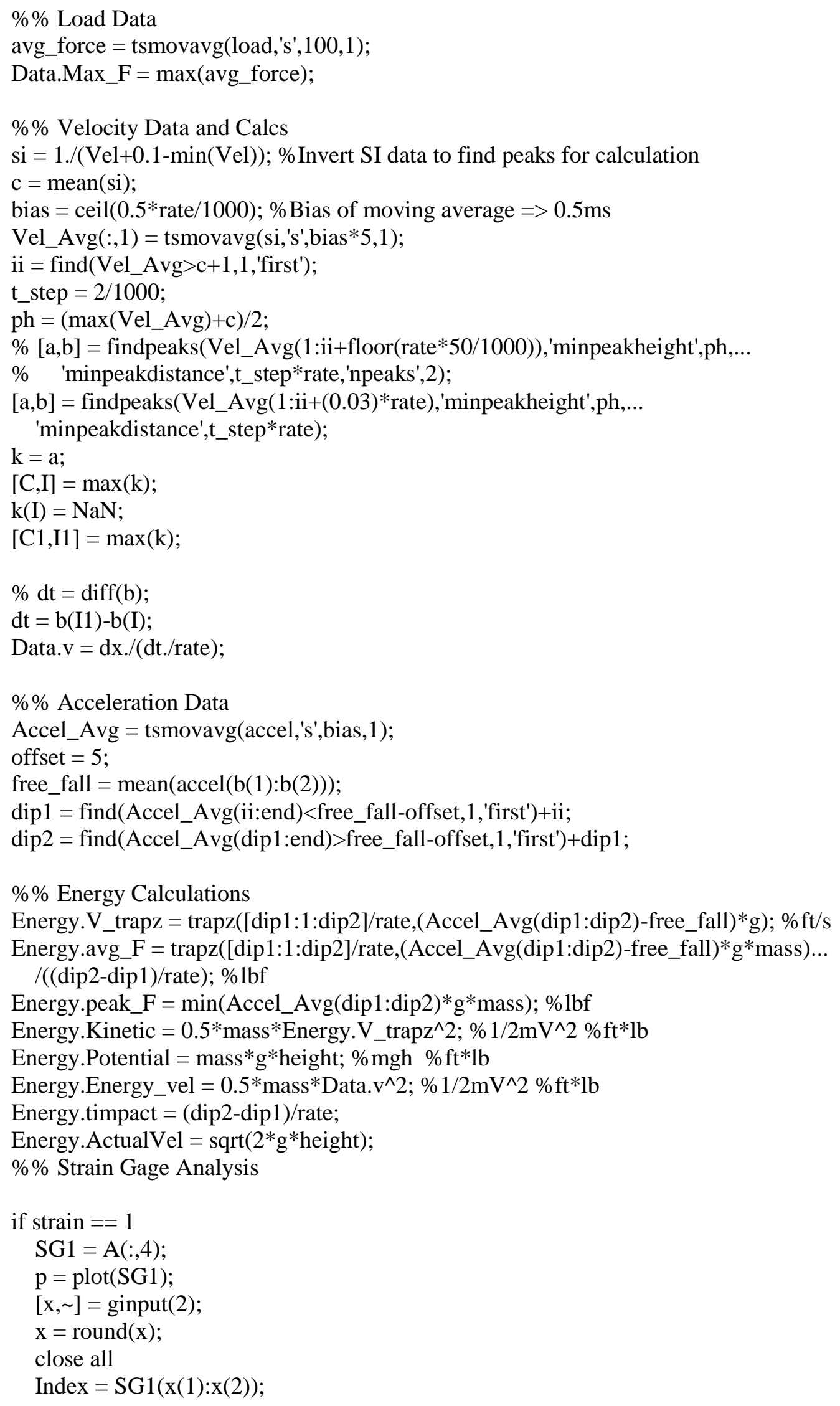




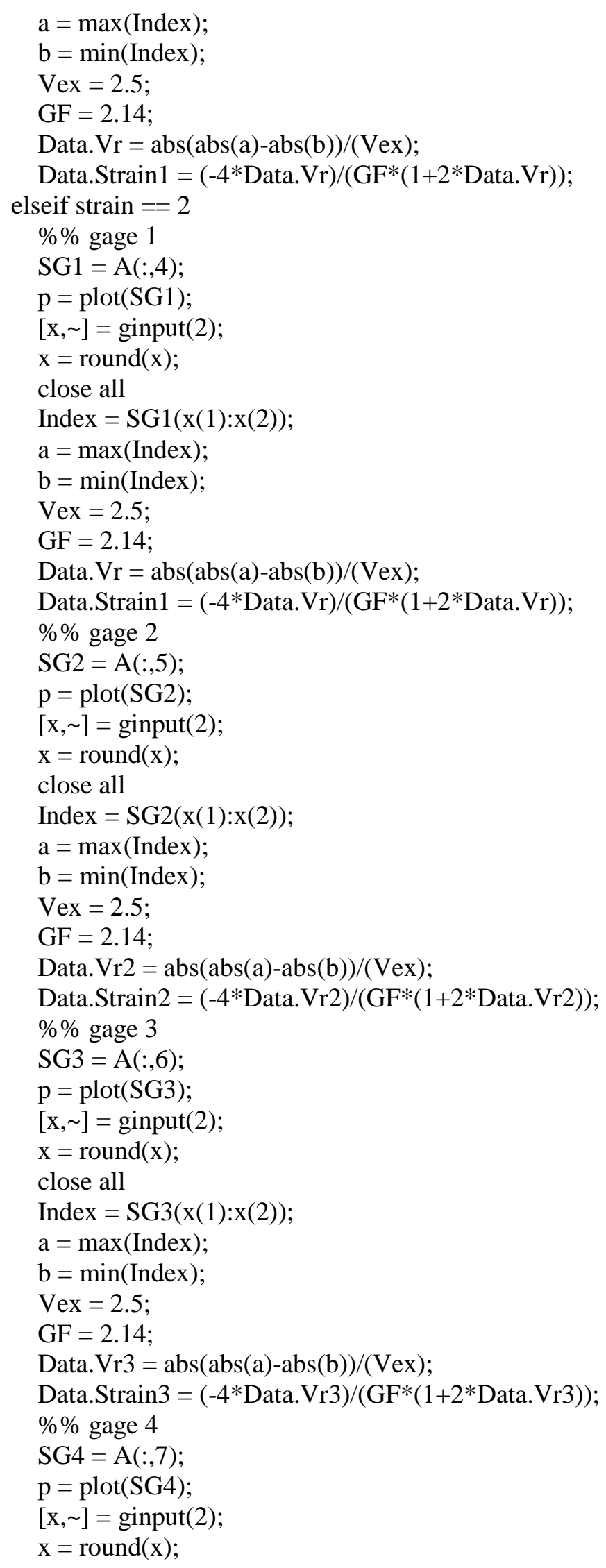




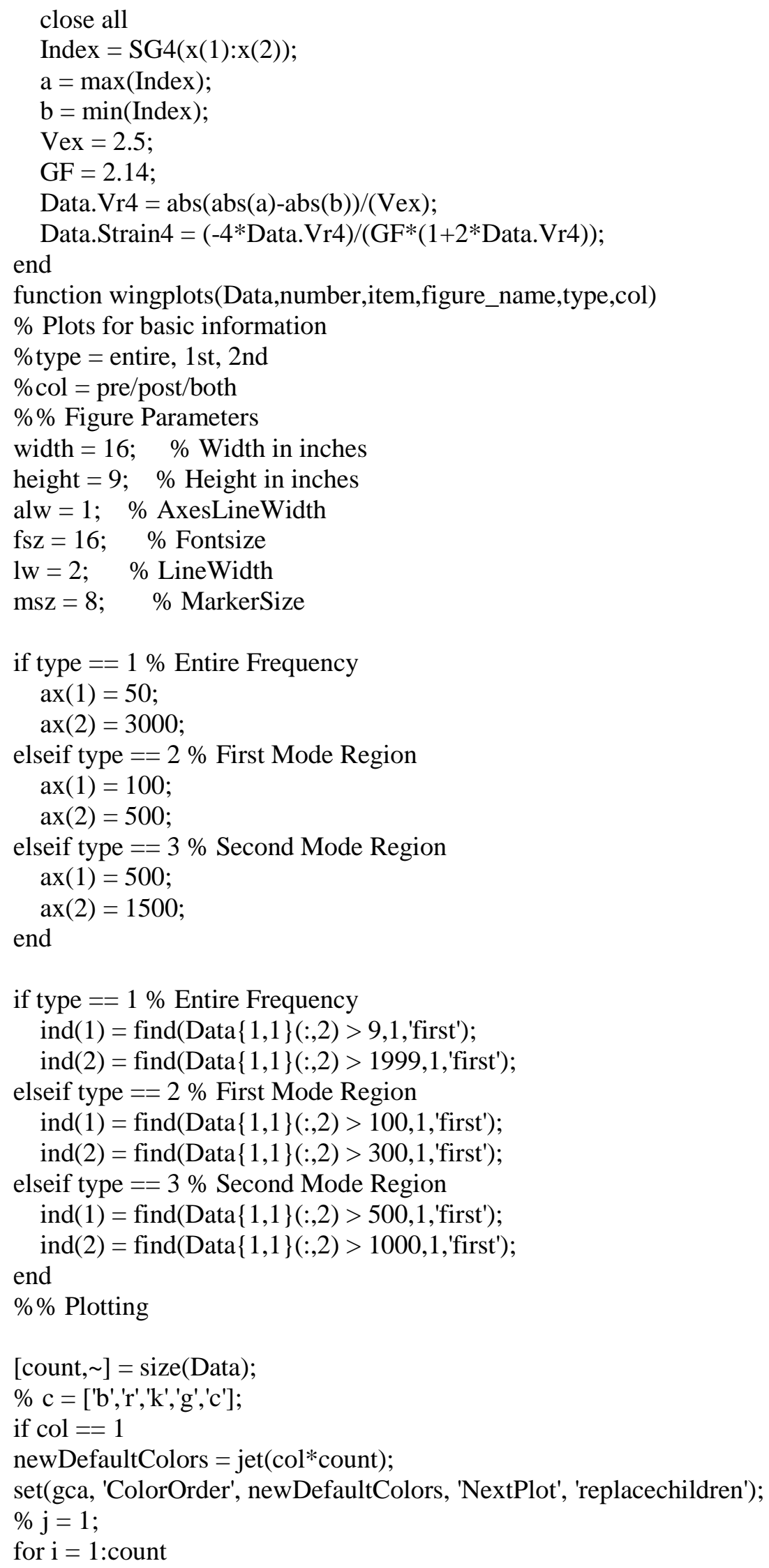




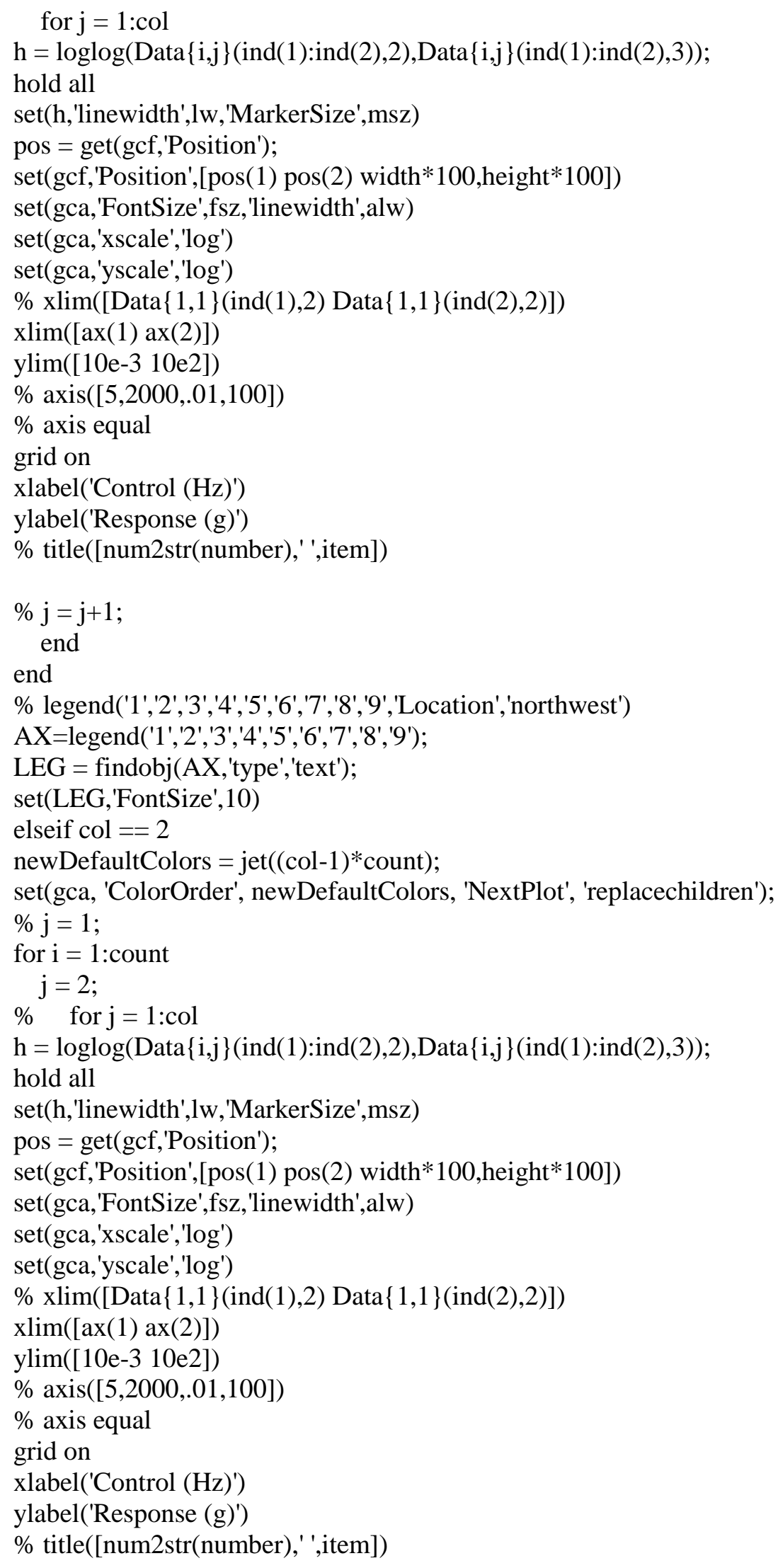




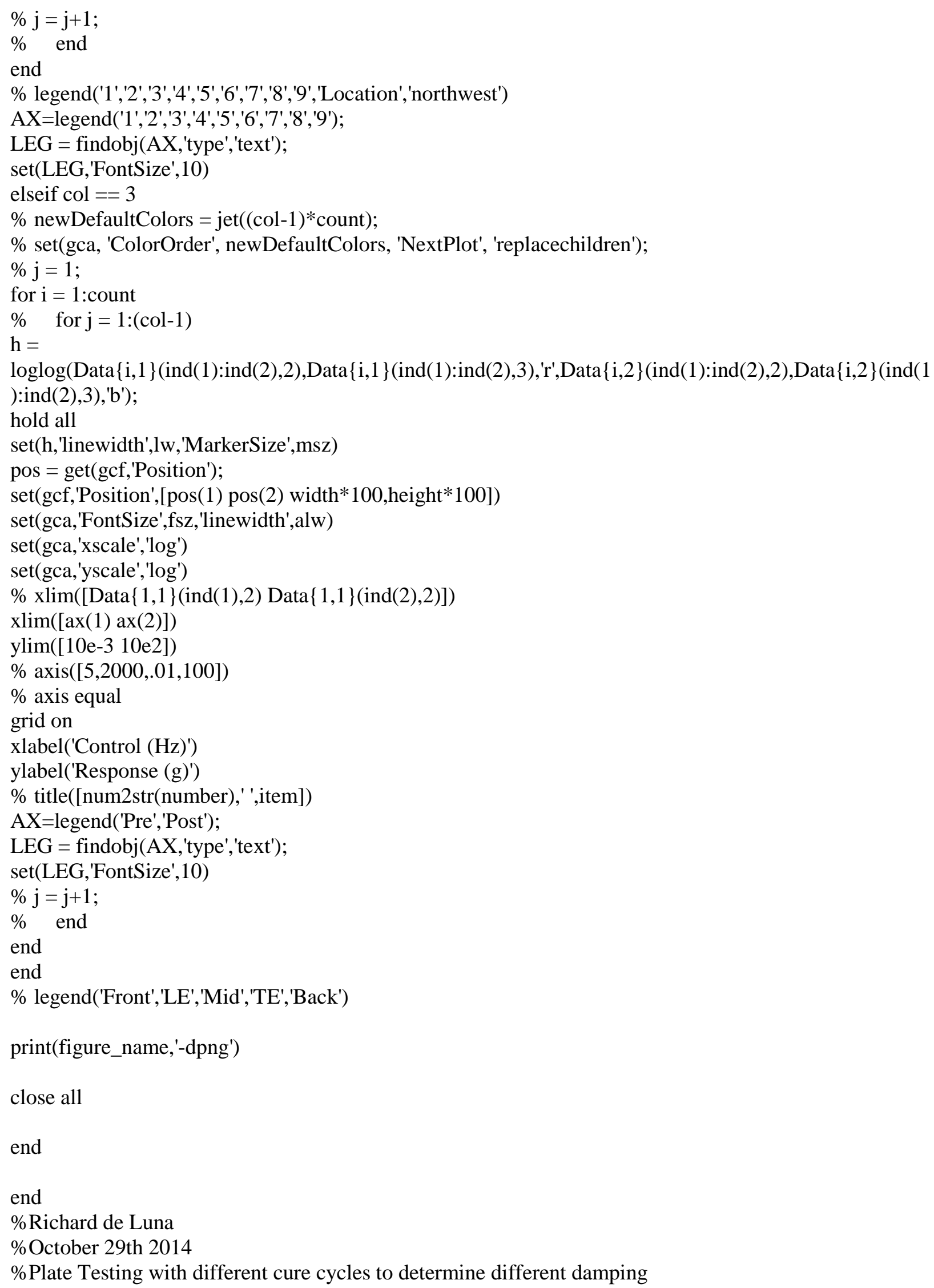


$\%$ characteristics for different cure cylces

clc,clear all,close all

format compact

addpath('ExcelFiles')

\%First Wing Data Read In

Run1 = xlsread('First Wing Run 1.csv','A29:N1228');

Run2 = xlsread('First Wing Run 2.csv','A29:N1228');

Run3 = xlsread('First Wing Run 3.csv','A29:N1228');

Run4 = xlsread('First Wing Run 4.csv','A29:N1228');

Run5 = xlsread('First Wing Run 5.csv','A29:N1228');

Run6 = xlsread('First Wing Run 6.csv','A29:N1228');

Run7 = xlsread('First Wing Run 7.csv','A29:N1228');

Run8 = xlsread('First Wing Run 8.csv','A29:N1228');

Run9 = xlsread('First Wing Run 9.csv','A29:N1228');

Run10 = xlsread('First Wing Run 10.csv','A29:N1228');

Run11 = xlsread('First Wing Run 11.csv','A29:N1228');

Run12 = xlsread('First Wing Run 12.csv','A29:N1228');

Run13 = xlsread('First Wing Run 13.csv','A29:N1228');

Run14 = xlsread('First Wing Run 14.csv','A29:N1228');

Run15 = xlsread('First Wing Run 15.csv','A29:N1228');

Run16 = xlsread('First Wing Run 16.csv','A29:N1228');

Run17 = xlsread('First Wing Run 17.csv','A29:N1228');

Run18 = xlsread('First Wing Run 18.csv','A29:N1228');

Run19 = xlsread('First Wing Run 19.csv','A29:N1228');

Run20 = xlsread('First Wing Run 20.csv','A29:N1228');

Run21 = xlsread('First Wing Run 21.csv','A29:N1228');

Run22 = xlsread('First Wing Run 22.csv','A29:N1228');

Run23 = xlsread('First Wing Run 23.csv','A29:N1228');

Run24 = xlsread('First Wing Run 22.csv','A29:N1228');

Run25 = xlsread('First Wing Run 2.csv','A29:N1228');

Run26 = xlsread('First Wing Run 26.csv','A29:N1228');

Run27 = xlsread('First Wing Run 27.csv','A29:N1228');

Run28 = xlsread('First Wing Run 28.csv','A29:N1228');

Run29 = xlsread('First Wing Run 29.csv','A29:N1228');

Runs $=\{$ Run1,Run2,Run3,Run4,Run5,Run6,Run7,Run8,Run9,Run10,Run11,Run12,Run13...

,Run14,Run15,Run16,Run17,Run18,Run19,Run20,Run21,Run22,Run23,Run24,Run25...

Run26,Run27,Run28,Run29\}';

$\% \%$ Locations for Each Test

$\% 1: 1,2,3 \quad$ Mid:0.5,3.5,6.5

$\% 2: 4,5,6 \quad$ Mid over Ribs:0,4ish,8ish

$\% 3: 7,8,9 \quad$ LE: $1,4,7$

$\% 4: 10,11,12 \quad$ TE: $1,4,7$

$\% 5: 13,14,15 \quad$ Front:0.5,3.5,6.5

$\% 6: 16,17,18 \quad$ LE: $0.5,3.5,6.5$

$\% 7: 19,20,21 \quad$ TE:0.5,3.5,6.5

$\% 8: 22,23,24 \quad$ Back:0.5,3.5,6.5

$\% 9: 25,26,27 \quad$ Back:1,4,7

$\% 10: 28,29,30$ TE: $1,4,7$

$\% 11: 31,32,33 \quad$ Mid:1,4,7 


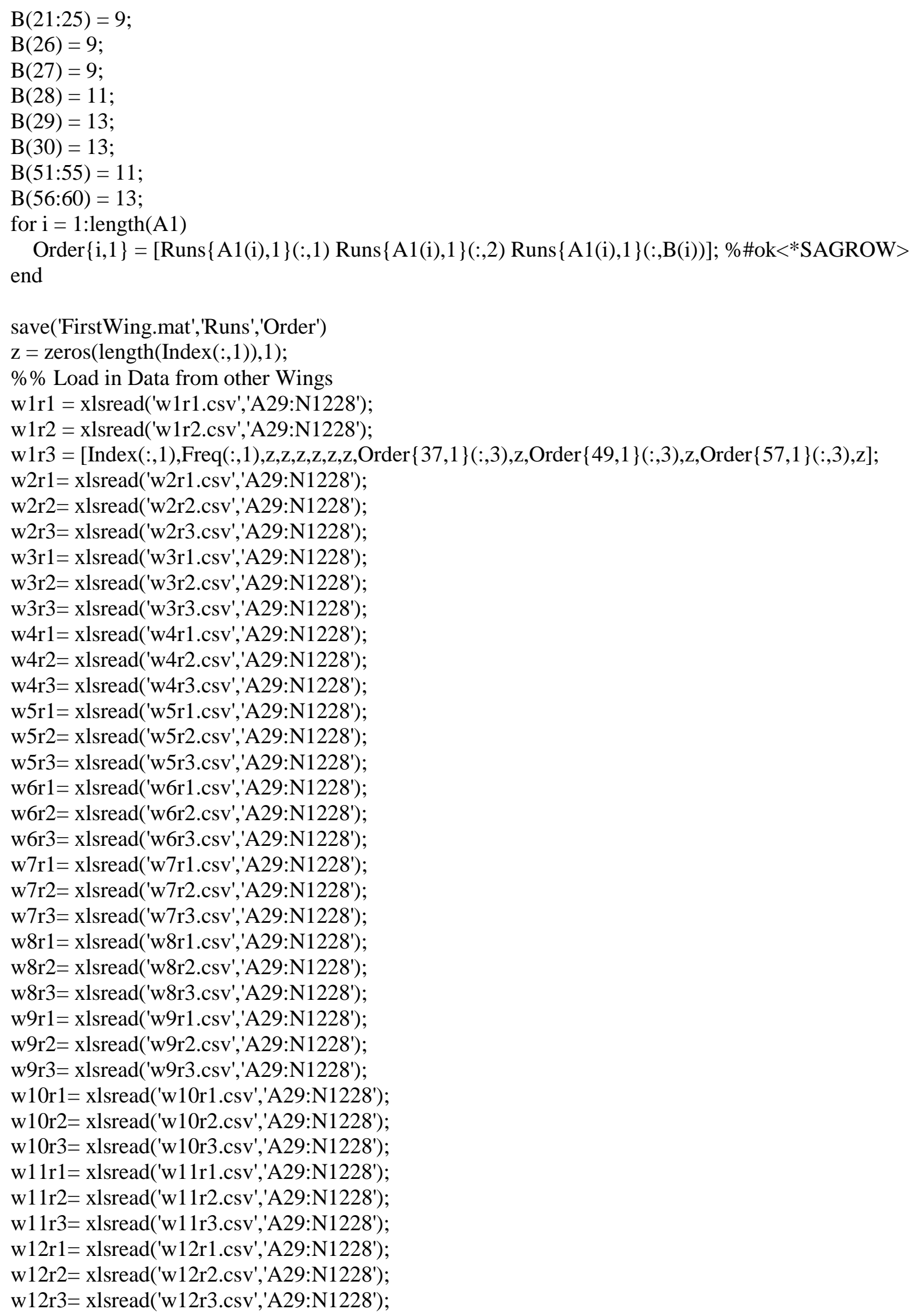




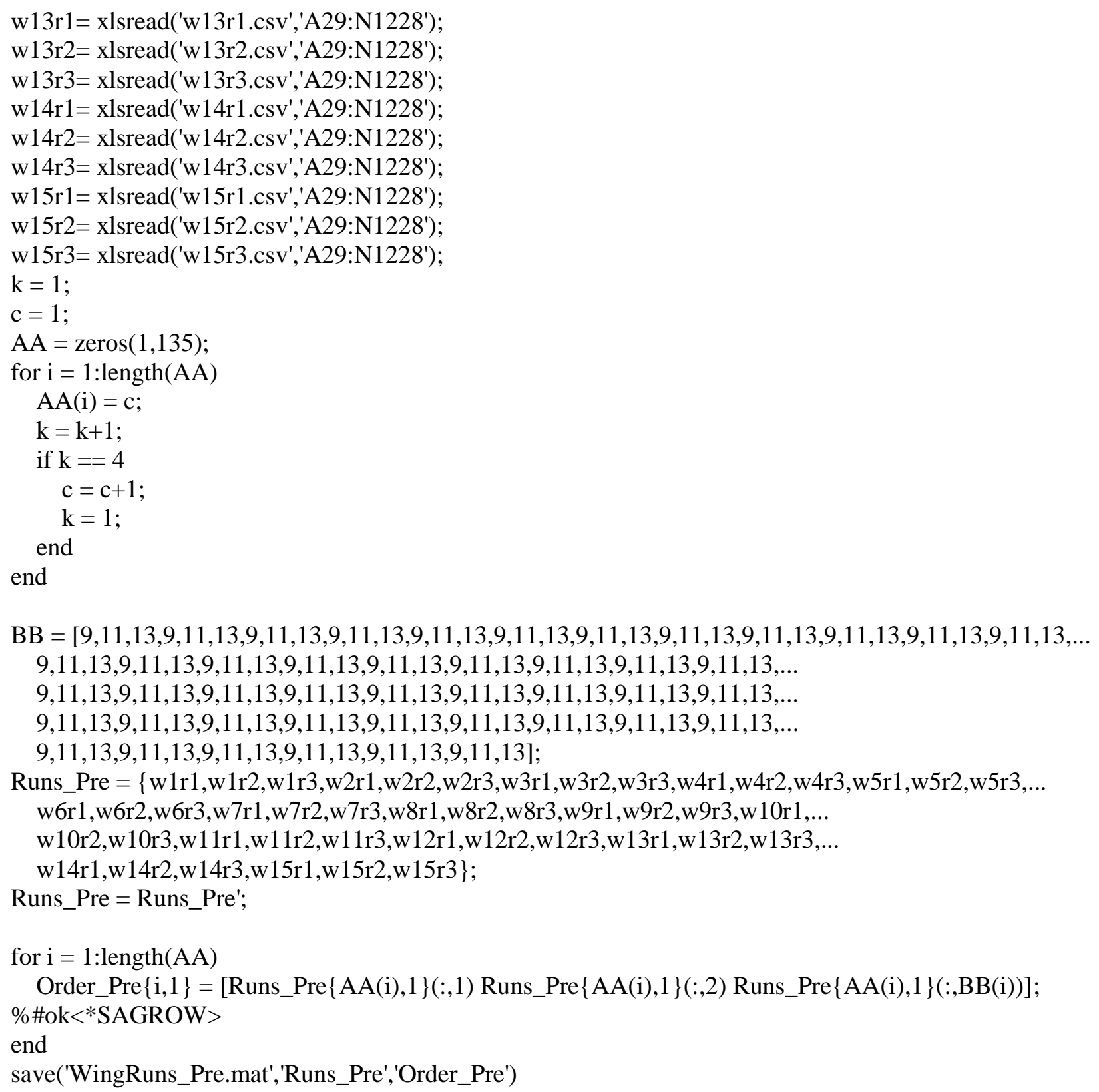




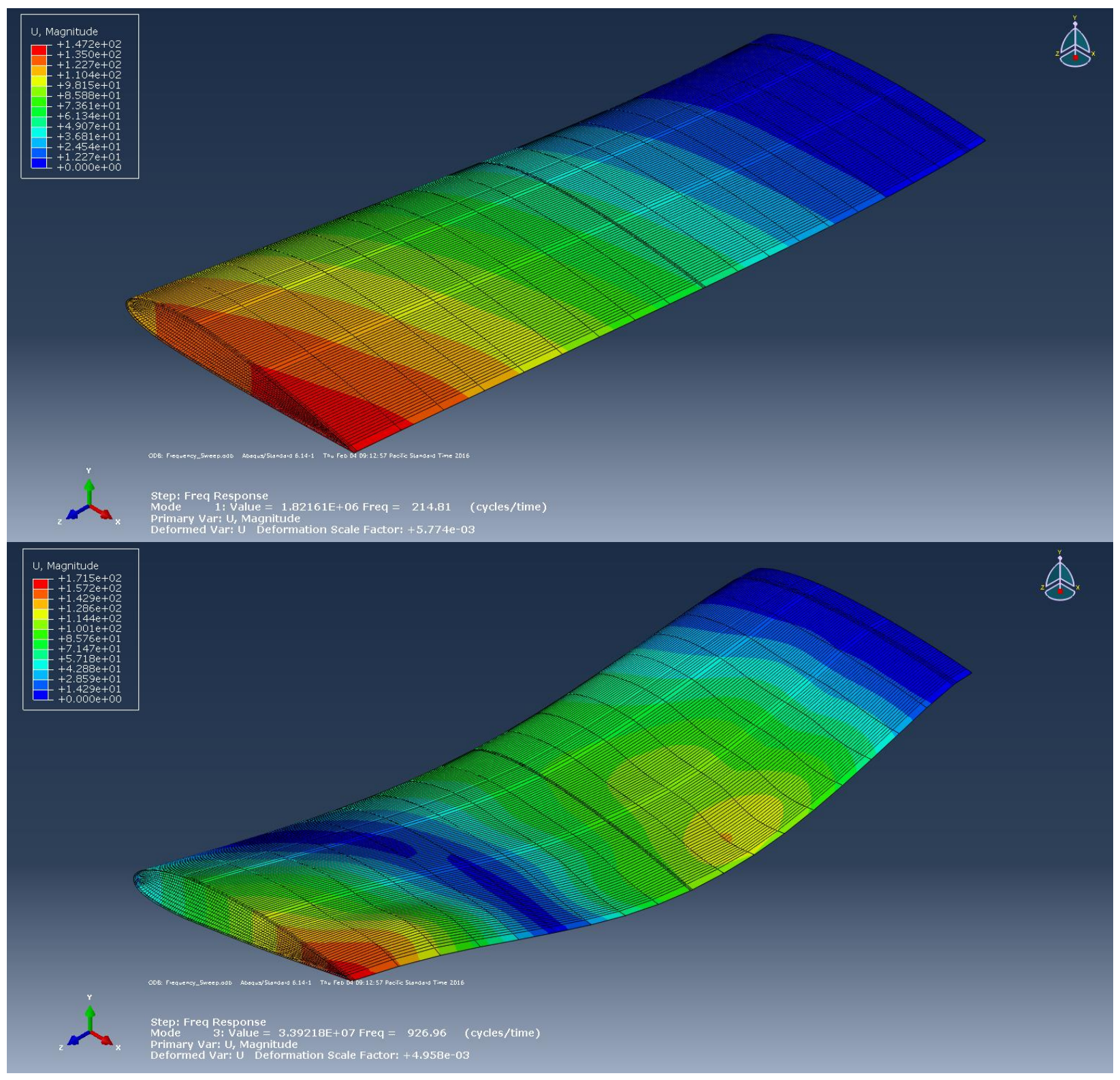




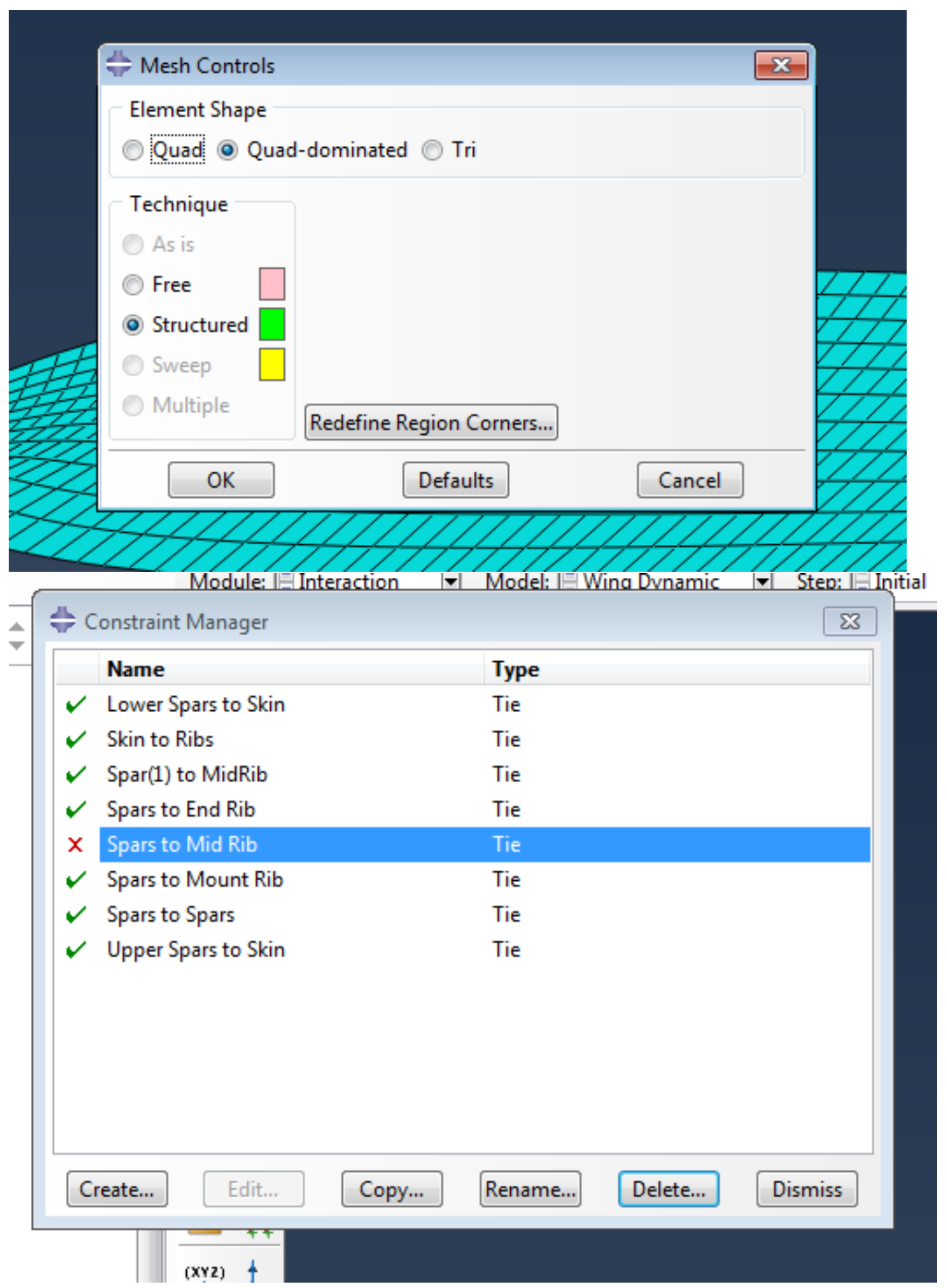




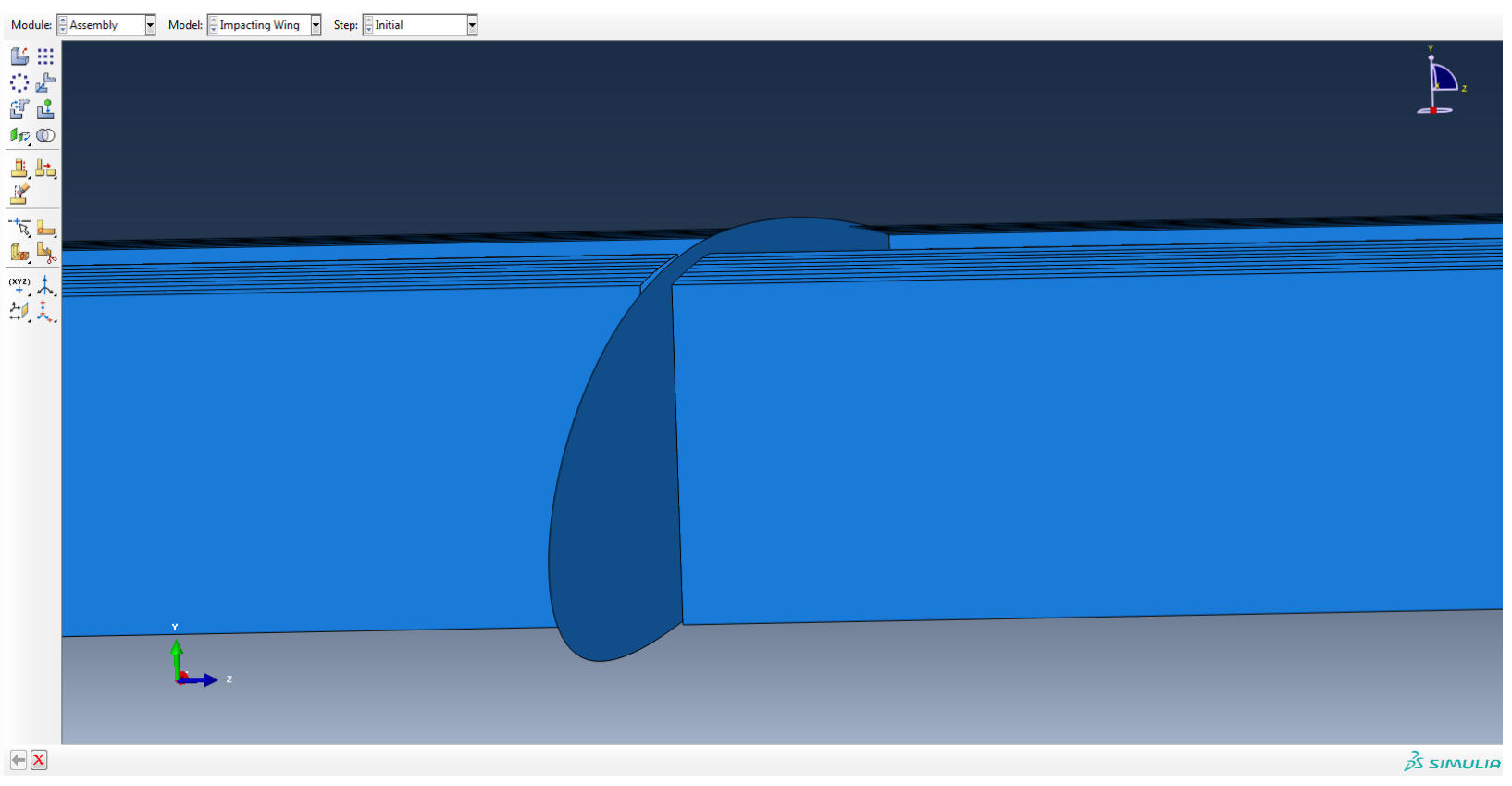

